STUDIES IN MIGRATION AND DIASPORA

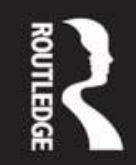

\title{
Belonging and Transnational \\ Refugee Settlement
} Unsettling the Everyday and the Extraordinary 


\section{Belonging and Transnational Refugee Settlement}

The image we have of refugees is one of displacement - from their homes, families and countries - and yet, refugee settlement is increasingly becoming an experience of living simultaneously in places both proximate and distant, as people navigate and transcend international borders in numerous and novel ways. At the same time, border regimes remain central in defining the possibilities and constraints of meaningful settlement. This book examines the implications of 'belonging' in numerous places as increased mobilities and digital access create new global connectedness in uneven and unexpected ways.

Belonging and Transnational Refugee Settlement positions refugee settlement as an ongoing transnational experience and identifies the importance of multiple belongings through several case studies based on original research in Australia and New Zealand, as well as at sites in the US, Canada and the UK. Demonstrating the interplay between everyday and extraordinary experiences and broadening the dominant refugee discourses, this book critiques the notion that meaningful settlement necessarily occurs in 'local' places. The author focuses on the extraordinary events of trauma and disasters alongside the everyday lives of refugees undertaking settlement, to provide a conceptual framework that embraces and honours the complexities of working with the 'trauma story' and identifies approaches to see beyond it.

This book will appeal to those with an interest in migration and diaspora studies, human geography and sociology.

Jay Marlowe is Associate Professor in the Department of Counselling, Human Services and Social Work at the University of Auckland, New Zealand. A former visiting fellow with the Refugee Studies Centre at the University of Oxford, UK, he has published more than 50 papers and is co-editor of South Sudanese Diaspora in Australia and New Zealand: Reconciling the Past with the Present. 


\section{Studies in Migration and Diaspora}

Series Editor:

Anne J. Kershen, Queen Mary University of London, UK

Studies in Migration and Diaspora is a series designed to showcase the interdisciplinary and multidisciplinary nature of research in this important field. Volumes in the series cover local, national and global issues and engage with both historical and contemporary events. The books will appeal to scholars, students and all those engaged in the study of migration and diaspora. Among the topics covered are minority ethnic relations, transnational movements and the cultural, social and political implications of moving from 'over there', to 'over here'.

www.routledge.com/sociology/series/ASHSER1049

Belonging and Transnational Refugee Settlement

Unsettling the Everyday and the Extraordinary

Jay Marlowe

The Cultures of Economic Migration

International Perspectives

Edited by Suman Gupta and Tope Omoniyi

Negotiating Boundaries in the City

Migration, Ethnicity, and Gender in Britain

Joanna Herbert

Migration and Domestic Work

A European Perspective on a Global Theme

Edited by Helma Lutz

Contemporary British Identity

English Language, Migrants and Public Discourse

Christina Julios

\section{Gendering Migration}

Masculinity, Femininity and Ethnicity in Post-War Britain

Edited by Louise Ryan and Wendy Webster 


\title{
Belonging and Transnational Refugee Settlement \\ Unsettling the Everyday and the \\ Extraordinary
}

\author{
Jay Marlowe
}

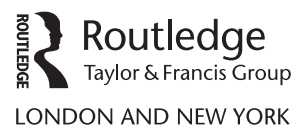


First published 2018

by Routledge

2 Park Square, Milton Park, Abingdon, Oxon OX14 4RN

and by Routledge

711 Third Avenue, New York, NY 10017

Routledge is an imprint of the Taylor \& Francis Group, an informa business

\section{(C) 2018 Jay Marlowe}

The right of Jay Marlowe to be identified as author of this work has been asserted by him in accordance with sections 77 and 78 of the Copyright, Designs and Patents Act 1988.

All rights reserved. No part of this book may be reprinted or reproduced or utilized in any form or by any electronic, mechanical, or other means, now known or hereafter invented, including photocopying and recording, or in any information storage or retrieval system, without permission in writing from the publishers.

Trademark notice: Product or corporate names may be trademarks or registered trademarks, and are used only for identification and explanation without intent to infringe.

\section{British Library Cataloguing in Publication Data}

A catalogue record for this book is available from the British Library

Library of Congress Cataloging in Publication Data

Names: Marlowe, Jay M., author.

Title: Belonging and transnational refugee settlement: unsettling the everyday and the extraordinary / Jay Marlowe.

Description: Abingdon, Oxon; New York, NY: Routledge, 2018.

Series: Studies in migration and diaspora | Includes bibliographical references and index.

Identifiers: LCCN 2017019010| ISBN 9781138285453 (hbk) |

ISBN 9781315268958 (ebk)

Subjects: LCSH: Refugees. | Transnationalism. | Group identity. |

Assimilation (Sociology) $\mid$ Emigration and immigration-Social aspects.

Classification: LCC HV640. M336 2018 | DDC 305.9/06914-dc23

LC record available at https://lccn.loc.gov/2017019010

ISBN: 978-1-138-28545-3 (hbk)

ISBN: 978-1-315-26895-8 (ebk)

Typeset in Times New Roman

by Cenveo Publisher Services 
To Pen 
$\because$ Taylor \& Francis Taylor \& Francis Group http://taylorandfrancis.com 


\section{Contents}

List of figures and tables viii

Series Editor's Preface ix

Foreword xi

Acknowledgements xiv

List of acronyms and abbreviations $\quad$ xvi

1 Transnational settlement 1

2 Belonging: everyday and extraordinary conceptualizations 33

3 Responding to trauma $\quad 64$

4 Responding to disasters 96

5 Professional practice 129

6 Conclusion 160

$\begin{array}{lr}\text { Index } & 172\end{array}$ 


\section{Figures and tables}

\section{Figures}

5.1 Conceptual practice framework 131

$\begin{array}{ll}5.2 \text { Vertical dimension one } & 132\end{array}$

5.3 Vertical dimension two 135

5.4 Scaffolding perspectives 138

5.5 Conceptual practice framework 146

\section{Table}

1.1 Per capita refugee resettlement for top countries in 2014 and 2015 


\section{Series Editor's Preface}

According to the Shorter Oxford English Dictionary, the word refugee, meaning a person seeking sanctuary from war, persecution or natural disaster, was first used in 1685, its roots lying in the French refugiér. It was the descriptive applied to the Huguenots - French Calvinists - escaping from religious persecution in France after the Revocation of the Edict of Nantes (1685). Following their arrival in England, the Huguenots began the processes of settlement and, in the terms of this book, belonging. They were met by both compassion and distrust; compassion for the abuse suffered as a result of their religious conviction and distrust allied with fear that the 'Frenchies' might be crypto-Catholics in a Protestant England and spies for the French government. Nearly three and a half centuries on, refugees remain recipients of both sympathy and suspicion.

In this insightful book, Jay Marlowe combines in-depth theoretical themes with intense fieldwork in order to highlight the plight of refugees undertaking the process of belonging in the twenty-first century. He describes how, in the life of the refugee, the everyday and the extraordinary sit side by side and, rather than one subsuming the other or remaining static, the positions can be mobilized in order that, when necessary, they can 'fit the moments'. Marlowe demonstrates how, in contrast to the experience of refugees in earlier centuries, modern technology has played a leading role in facilitating the parallel experiences of belonging in a new community - one that the author maintains remains a relatively under theorized and fuzzy concept - and of transnationalism, as migrants maintain their links with the people and places of 'home'. Skype has become a part of the refugee's everyday life: a meeting of the quotidian with the remarkable. As the author points out, 'the relationship between trauma, transnationalism and belonging' is an essential thread in the migrant resettlement programme.

This book explores the empirical and the socio-psychological aspects of the trauma experienced by refugees, not only in the context of escape and (re)settlement but additionally, and uniquely, in the circumstance of the experience of trauma during the process of establishing 'belonging' in a new environment. Marlowe explains how the process of belonging 'is structured across transnational, gendered, spatial and chronological dimensions'. He provides the reader with two separate empirical case studies. First, one that is the result of a two-year project interviewing South Sudanese male refugees who have (been) settled in 
Adelaide, Australia. For a number of those interviewed, the trauma of resettlement was as wounding as that of departure and arrival. Separation from the family and the familiar was in itself a traumatizing event, though not all refugee experiences result in the negative. The author points out that while for some the trauma of forced migration inhibits future advancement and success, for others it can be the spur to achievement, though we should bear in mind that this is as true of the pre-IT years as it is of the present day.

The second case study takes the process of establishing a state of belonging one step further. It explores the impact of a natural disaster - a further trauma - on those going through the process of settlement. The example is that of the earthquakes that devastated parts of the New Zealand city of Christchurch in 2010 and 2011. Christchurch had been a major refugee resettlement area prior to the earthquake. Marlowe describes how the refugees affected by the earthquake had been happy living in the city in spite of not experiencing a sense of belonging. Immediately subsequent to the earthquakes, the refugee population was shown compassion by local residents with whom previously they had had little contact. Yet this interaction proved transitory and relationships soon reverted back to those of pre-2010. In less than five years, many people from the refugee community had significantly dispersed, disillusioned with life in the city. By way of explanation, the author suggests that the refugees' sense of belonging played a powerful role in how they perceived, responded to and recovered from the earthquakes.

In a number of ways, Belonging and Transnational Refugee Settlement takes the reader on new routes through the migrant experience. Jay Marlowe highlights the way in which the need for refugees to connect with home is being facilitated by modern technology in the form of apps such as Skype, and other current aids to global connectivity. In spite of the author being an 'outsider' to the Australasian refugee communities under the microscope, he is able to provide us with the 'insider' experience and response to trauma, before, during and after the initial migration. He enables the reader to appreciate the way in which theory and practice are addressing the current refugee crisis, and how trauma is being put under the psychological and sociological microscopes in order that we may better understand how it impacts on those forced to leave their homelands. Although the empirical side of this volume focuses on Australia and New Zealand, it is structured in such a way that the recorded sentiments of the subjects in the book, its broad theoretical spread and the analysis by its author are applicable globally, and thus of value to all those working in the field of migration related studies. In addition, and equally importantly, a reading of this volume provides guidance for those seeking to assist the victims of forced migration who subsequently have to rebuild their lives and create a new sense of belonging.

Anne J. Kershen

Queen Mary University of London

Summer 2017 


\section{Foreword}

This book has been written during a time of great change and contestation as it relates to forced migration and global politics. The Syrian crisis has continued to deepen as global powers vie for influence. We are now witnessing unprecedented numbers of forced migrants since the Second World War. The tragedies that have occurred in the Mediterranean and Andaman Seas attest to the persecution that people are fleeing and the risks they are willing to take when stepping on to an overcrowded boat. Politicians and the wider society are asking questions about the implications of welcoming refugees and what this might mean for the protection of national values, identity and security. Written between the lines of such concerns are the implications of belonging - rarely defined but emotively experienced, particularly when these are perceived to be under threat.

As I began writing this book, it was first noting Donald Trump as Republican primary candidate. Then he was the Republican nominee all the way to writing the words that he is President Elect to President of the United States. Initially, I wrote about David Cameron as the prime minister, only to have to add the word 'former' after the unanticipated impacts of Brexit. The Australian election in July 2016 has seen the rise of the previously thought defunct right wing One Nation Party that now has several senators in parliament and holds powerful sway with the government's wafer-thin majority to pass legislation. Angela Merkel's position to secure a fourth term looks more tenuous than ever - many view this electoral reality as a consequence towards her open approach to refugees. Elections loom large in France, Austria, the Netherlands and many other countries where anti-immigrant platforms have secured greater populist support and political legitimacy. And the list continues.

We also seem to find ourselves in an uncomfortable moment (and let's hope that it is just that) of alternative facts and some have already labelled it a 'posttruth' era. This is where social media and fake news have made it difficult even to ascertain the facts and what is actually happening. There is a global moral panic that is evident where the discourse about asylum and refugee protection has shifted from seeing forced migrants as at risk to a risk. And as the Thomas Theorem powerfully warns, situations that are perceived as real are real in their consequences. 
For these reasons, writing a book that focuses on belonging and transnationalism as it relates to refugee settlement is incredibly pertinent. While there has been greater scholarly and policy-level focus on integration and social cohesion, the concept of belonging remains a relatively under-theorized and fuzzy concept. Transnational possibilities for policy, practice and research are often not imagined as refugee resettlement, and settlement is often considered an experience that occurs within national borders. This is why I have chosen the subtitle of this book as Unsettling the everyday and the extraordinary. By critiquing familiar and routine assumptions and understandings about refugees, trauma, disasters and the concept of belonging, this orientation can provide scaffolding to new ways of knowing and approaches to professional practice.

The driving idea behind this book arose from conducting research with refugee-background participants who had lived through the worst of the Canterbury earthquakes in New Zealand. Some of them left their social media video feeds on continuously with friends and family overseas as a form of constant presence that provided a sense of support. The levels of intimate connection that this provided led me to further reflect upon the ways that transnational relations are incorporated into everyday lives. While maintaining a cynicism about a digital utopia that connects family and friends living across the seas, I wanted to write a book that reflected my work alongside people from refugee backgrounds that often seemed to come back to the importance of belonging. Central to these experiences has been the importance of maintaining transnational networks and this is why I argue that refugee settlement needs to be conceptualized as an ongoing transnational experience.

I am very aware in writing this book that using the term refugee is a contested one. While I cover this issue to a greater extent in the first chapter and again throughout the book, I have chosen to predominantly to use the term. Although people who are resettled are arguably no longer refugees, it is also true for some that it is a label that they still hold on to to recognize the contexts that brought them to a new receiving society. I recognize in doing so that this might cause concern and there are places that I write the term refugee background to remind the reader of the dangers of particular labels.

In writing this book, I remain mindful that numerous authors caution that the power disparities and undisclosed associated research agendas can render refugee voices invisible in numerous contexts. This awareness highlights the importance that, as the author of this book and the researcher in the associated case studies, I reflexively consider the representations that follow to better ensure that I do not contribute to what several critical authors have cautioned as cultural imperialism or psychological colonization. As Kathy Charmaz (2006, p. 180) ${ }^{1}$ asserts in her book on the grounded theory that informs some of the case studies presented, 'We stand within the research process rather than above, before or outside it' (original emphasis). It is in this recognition that I locate myself as a non-refugee-background researcher who sits outside the associated communities I have worked alongside as a researcher and previously as a social worker. 
My professional training has been heavily influenced by the work of Michael White and others who have contributed to the understandings of narrative therapy and narrative approaches (discussed further in this book). While I have endeavoured to articulate accurately participant voices and make my involvement (and analysis) more explicit in the case studies presented, this process also highlights the politics of representation - something that I elaborate further in a possibility orientation towards thinking about various forms of health and social professional practice.

By positioning refugee resettlement as predominantly being about protection and refugee settlement primarily focused on the experience of belonging, it is my hope that the chapters that follow provide scaffolding to shift from what is known and familiar to what might be possible to know about understandings of refugees and professional practice. A possibility focus seems incredibly important as numerous countries are externalizing and securitizing their borders. Political parties have garnered huge populist support running on anti-immigrant and nationalist platforms. The politics of belonging highlights that there are huge issues at stake - the ways in which people remain connected to places both proximate and distant heralds both opportunities and cautions. It is within the grey spaces between constructed binaries of here/there; welcome/deterrence; everyday/extraordinary, and many others that the focus of this book resides.

\section{Note}

1 Charmaz, K. (2006) Constructing grounded theory: A practical guide through qualitative analysis. London; Thousand Oaks, CA: Sage Publications. 


\section{Acknowledgements}

Many people have gifted their wisdom, time, stories and passion in the creation of this book. I am grateful to Sue Elliott as a friend and mentor who has shared her deep knowledge and provided the critical questions to take the conceptualization of this book further. I would also like to recognize Jessica Steele and Katherine Haddock who assisted with updating global forced migration trends and settlement policies in a rapidly shifting environment. I would also like to recognize those who worked alongside me on the case studies that inform this book: Zibulnessa Zeba Alam, Mohamud Osman, Rachel Bogen, Lucy Lou and Anne-Marie Reynolds. Arvid Eriksson (the dude) at Untold Projects was central to crafting the conceptual practice framework diagram in an accessible form. Stephen May and Christa Fouche have been invaluable sounding boards and I have appreciated your thoughts about the broader questions of 'where to next'. The helpful comments and collegiality of Louise Humpage, Francis Collins, Allen Bartley and Liz Beddoe are hugely appreciated and represent a larger commitment to providing critical feedback not just for this book but across my academic career.

My greatest thanks go to my wife, Pen. She has been the mainstay during this entire writing project and has provided the family support to live through our experiences of the everyday and the extraordinary. To my boys Seb and Jasper, your ability to recentre and help me to regain perspective has been sustaining and enlightening. I am truly privileged to be your dad. To my mom and dad, thanks for hosting us in the United States and for looking after our boys so I could focus and write. Your years of unwavering support have been inspiring. Michelle and Sarah, thanks for creating a home for us away from home. And to Bob and Sandy, thanks for helping to create a new home and sense of belonging.

A number of people have provided invaluable insight, friendship and the scaffolding to work towards new ways of thinking: Abann Yor, Santino Atem Deng, Martine Udahemuka, Ahmed Tani, Alia Bloom, Aklilu Hibtit, James Lino Lejukole and Adel Salmanzadeh. The crew at Red Cross (previously Refugee Services) has been incredible, and I appreciate their ongoing willingness to collaborate and engage. I would like to give a big shout out to my colleagues within the School of Counselling, Human Services and Social Work and to the University of Auckland for giving me the opportunity to take a year's research 
and study leave to write this book. And I would like to thank Kathleen Tierney and colleagues from the Natural Hazards Center at the University of Colorado for hosting me during this time away.

I would like to give a big thanks to Neil Jordan at Routledge for positively receiving my book proposal and for your responsiveness whenever questions arose and to Sue Osborne for her eagle eye at the copy-editing stage. Most importantly, I would like to extend a heartfelt thanks to the numerous refugee background communities and individuals that have shared their stories and experiences over the last fifteen years. Their graciousness, support and willingness to engage have been a privilege, and I will continue to carry these conversations in my heart and mind.

Finally, I would like to thank Pen for reminding me of the importance of getting back to those mountain trails and the value of play. 


\section{Acronyms and abbreviations}

$\begin{array}{ll}\text { AfR } & \text { Alternative fuer Deutschland (Alternative for Germany) } \\ \text { APRN } & \text { Asian Pacific Rights Network } \\ \text { AU } & \text { African Union } \\ \text { CDU } & \text { Christian Democratic Union (Germany) } \\ \text { CERD } & \text { Centre for Research on the Epidemiology of Disaster } \\ \text { DIBP } & \text { Department of Immigration and Border Protection (Australia) } \\ \text { DRC } & \text { Democratic Republic of Congo } \\ \text { DRR } & \text { Disaster Risk Reduction } \\ \text { EBCG } & \text { European Border and Coast Guard } \\ \text { ECRE } & \text { The European Council for Refugees and Exiles } \\ \text { EU } & \text { European Union } \\ \text { FARC } & \text { Fuerzas Armadas Revolucionarias de Colombia } \\ \text { FRONTEX } & \text { Frontières extérieures ('external borders') } \\ \text { GAR } & \text { Government Assisted Refugees (Canada) } \\ \text { GDP } & \text { Gross Domestic Product } \\ \text { GPP } & \text { Gateway Protection Programme (United Kingdom) } \\ \text { IFRC } & \text { International Federation of the Red Cross } \\ \text { IOM } & \text { International Organization for Migration } \\ \text { IRC } & \text { International Rescue Committee } \\ \text { ISIL } & \text { Islamic State of Iraq and the Levant } \\ \text { MRS } & \text { Mandate Refugee Scheme (United Kingdom) } \\ \text { MSF } & \text { Médecins Sans Frontières (Doctors without Borders) } \\ \text { NATO } & \text { North Atlantic Treaty Organization } \\ \text { NIMBY } & \text { Not In My Back Yard } \\ \text { NGO } & \text { Non Government Organization } \\ \text { NZ } & \text { New Zealand } \\ \text { ORR } & \text { Office of Refugee Resettlement (United States) } \\ \text { PEGIDA } & \text { Patriotic Europeans Against the Islamisation of the West } \\ \text { PSR } & \text { (Germany) } \\ \text { PTSD } & \text { Private Sponsorship of Refugees (Canada) } \\ \text { SCEP } & \text { Post Traumatic Stress Disorder } \\ \text { SHP } & \end{array}$


Acronyms and abbreviations xvii

TFPE Trauma Focused Psychiatric Epidemiology

UK

United Kingdom

UKIP

United Kingdom Independence Party

$\mathrm{UN}$

United Nations

UNHCR

United Nations High Commissioner for Refugees

UNISDR

United Nations Integrated Strategy for Disaster Reduction

US

United States

VPR

Vulnerable Persons Relocation Scheme 
$\because$ Taylor \& Francis Taylor \& Francis Group http://taylorandfrancis.com 


\section{Transnational settlement}

\section{Introduction}

An Afghan woman resettled in Christchurch, New Zealand, leaves her Skype video continuously connected with family based in Afghanistan, effectively creating a constant social presence where family members can participate in her daily life. Two Burmese parents work full-time jobs in London to send money to family still living along the Thailand-Burma border. A Vietnamese man who came to the United States as an unaccompanied minor now runs his own company in California and frequently conducts business in Vietnam. Members of the South Sudanese community resettled in Atlanta use Facebook to simultaneously engage with their diaspora across three continents about local elections and tensions in South Sudan as a way of enacting their citizenship from overseas. When disasters strike, whether these arise from natural hazards such as earthquakes or from human-induced crises, refugees will look for sources of information and support from local to transnational locations. What becomes clear in these daily lives is that refugee settlement is increasingly about settling 'in place' where international borders are, at times, unsettled, and at others, powerfully reinforced.

This book examines the above experiences of refugee settlement and uses a theoretical lens of belonging to understand the multiple aspirations associated with integration, social cohesion and participation in a new host society. The descriptors, new and host, can be misleading. Many people from refugee backgrounds might have lived in a given locality for decades. For the children born in these new countries, the refugee label may still accompany them, although they were never refugees themselves. And the notion of host suggests that those who arrive are only visitors who will eventually leave. Some refugees might never return home and will live in their country of resettlement for the rest of their lives. People from refugee backgrounds might have quite significant connections to the wider society around them or they may still feel a lack of a common narrative that ties them across different groups. As this book will show, belonging provides a helpful theoretical lens to examine people's commitments to particular places alongside the contextual everyday and extraordinary events that shape forced migration experiences and the wider society's receptiveness to refugees. 


\section{Transnational settlement}

The book's focus is to inform the theory and practice of belonging to transnational refugee settlement. I employ the terms everyday and extraordinary to consider the contested debates of settlement for those working alongside refugees, whether this is related to service provision, policy or research. One of the book's key arguments is that media-based representations, political commentary and professional practice discourses often generate dominant understandings of refugee communities through extraordinary stories of adversity. The associated stories of the refugee experience which become powerful, even singular, descriptors of people's experiences can construct these communities as traumatized and their actions as the outcomes of war trauma. While there can be few arguments against the fact that refugees experience very difficult and traumatic events, it does not necessarily follow that they are indelibly damaged people.

As this book will demonstrate, it is necessary to identify who has a predominant say in characterizing particular experiences as everyday or extraordinary. In many respects, the forced migration narratives of oppression, trauma and significant adversity represent a powerful currency that helps refugees lay their claims for recognition. This recognition, while granting some benefits and resources in settlement and forced migration circumstances, also limits opportunities for wider civic participation due to the othering dynamics of such narratives. The book uses the concept of belonging to understand the interplay between the everyday and the extraordinary to broaden dominant discourses about refugees and to challenge the notion that meaningful settlement necessarily occurs in local places.

I refer to understandings of the everyday in a non-pejorative sense to conceptualize the routine and commonplace experiences of settlement (education, employment, housing, community relations, and many others). These everyday aspects generally escape critical examination because such activities and commitments are routinely seen as mundane and represent shared experiences with a wider society. This explicit, everyday focus responds to the politics of representation that often portray people from refugee backgrounds on the most sensational aspects of their lives (for instance, living in a refugee camp, being child soldiers, experiencing flight from persecution, and so on). It is all too easy for these narratives to then become dominant descriptors and achieve master status for an individual, family or community - one that impacts upon their opportunities to participate as peers in settlement contexts.

I refer to the extraordinary to outline experiences that sit beyond the everyday and are not necessarily shared by the wider society. These perspectives inform sensationalist (even voyeuristic) media presentations and, at times, the moral panic of political and populist discourse that essentialize wider society's perspectives of them (Bogen \& Marlowe, 2015; Gale, 2004; Klocker \& Dunn, 2003). At the same time, I will emphasize the importance of the extraordinary. For some people, extraordinary experiences represent important aspects of who they are, aspects of themselves that they hold on to and embrace. Such experiences help people to gain entry into refugee camps, acquire refugee status, cross sovereign borders and access services in resettlement contexts. In some instances, these 
stories and understandings are what grab the attention of the world stage and generate international humanitarian responses. Recent examples of the Syrian boy, Aylan Kurdi, drowned on a Turkish beach and the terror attacks in Paris and Brussels have galvanized and shaped both local and international responses (albeit in very different ways) to the tens of thousands of people making their way to Europe to escape conflict, persecution and the loss of livelihoods. As I will present in a later chapter, it was the story of the 'Lost boys of South Sudan' (drawing on the reference to Barrie's novel Peter Pan) that provided an initially warm welcome for thousands of South Sudanese refugees to resettle in the United States. The warmth of the welcome changed, however, after the terrorist event of 9/11, demonstrating how multiple stories and histories come together in dynamic and unexpected ways.

The term refugee is one that is contested and not easily bounded. In relation to several etymologies, its origins come from the French noun réfugié, meaning to take shelter or to protect. The term was originally used to mean one seeking asylum until 1914, by which time it had evolved to mean one fleeing home (Boutruche et al., 2008). This general definition, however, does not capture the varied situational contexts and the intersections of particular social, cultural, historical, political histories that refugees emerge from and indeed, are still emerging. For instance, Betts (2013) highlights how the international instruments established to protect refugees after the Second World War have failed to keep pace with the multiple ways that people are displaced, ranging from climate change, globalization, loss of livelihoods and generalized violence. Some refugee situations may arise very quickly such as that in Syria where the country had been stable for many years. Others, such as Sudan and Colombia, show evidence of protracted armed conflicts that extend into decades. Some conflicts between groups have histories that extend into centuries or even millennia. Recent history demonstrates how forced displacement includes a vast array of circumstances: Asians fleeing Uganda under Idi Amin's racist policies in the 1970s; the Salvadorians and Guatemalans displaced by civil war in the 1980s; Afghan refugees trying to escape persecution from Soviet occupation, US invasion and Taliban insurgencies over a forty-year period; Muslim Rohingyas living under the oppressive rule of the Burmese junta since the 1990s; the longstanding conflict in Sri Lanka, which created thousands of internally displaced Tamils; and the harrowing accounts of Jewish refugees during and after the Second World War. And the list continues to grow - these conflicts are just a few of the many examples across the varied situational geographic, demographic, political and historical contexts that forced migration occurs.

Obtaining refugee status can be critical for people living in protracted and tenuous situations where their safety and security is seriously compromised. This status affords access to support and resources from the 148 states signatory to the 1951 Convention and/or the associated 1967 Protocol as the United Nations High Commissioner for Refugees acknowledges (UNHCR, 2015d). The 1951 United Nations Convention Relating to the Status of Refugees formally defines a refugee as: 
A person who is outside his or her country of nationality or habitual residence; has a well-founded fear of persecution because of his or her race, religion, nationality, membership of a particular social group or political opinion; and is unable to avail himself or herself of the protection of that country, or to return there, for fear of persecution.

(UNHCR, 2015d)

Critical to the Convention is that signatory countries are to provide protection to refugees and ensure a commitment to non-refoulement (no forced repatriation). The 1967 Protocol Relating to the Status of Refugees removed the temporal and geographic restrictions outlined in the 1951 Convention. ${ }^{1}$ A key strength of the Convention is that it enshrines particular rights and human rights protection to those who have well-founded fears of persecution.

Different regions across the world have also revised the definition of a refugee or a refugee-like situation that responds to how displacement occurs. In 1969 a convention of the Organization of African Unity (now the African Union or AU) extended this definition to include as legitimate reasons for refugee status, 'external aggression, occupation, foreign domination or events seriously disturbing public order in either part or whole' of a country. Fifty of the 53 African countries have signed it. The Cartagena Declaration of 1984 broadened the scope of the refugee declaration in a similar manner for countries in Latin America. Debates now extend to the relevance of the Convention for climate change where people are forcibly displaced by rising sea levels, desertification and other events that have constrained or destroyed particular livelihoods (Docherty \& Giannini, 2009). While the ongoing importance of the 1951 Convention is clear, the new contexts in which forced migration occurs highlights the need to also consider the contemporary ways in which displacement and persecution transpire.

Those people with refugee status who have permanently and safely resettled in another country, are arguably not refugees any more as they have a 'durable solution' that addresses their well-founded fear of persecution. Other terms have emerged, such as 'refugee background' or 'former refugee' to respond to those complexities that attest to a person's identity beyond the master status of being a refugee. This book will explore these dynamics and will use the term 'refugee' while acknowledging that it remains contested and contestable in the academic literature and through people's narratives and identities. As Arendt (1943, p. 55) famously stated: 'In the first place, we don't like to be called "refugees." Although it may be that some refugees no longer identify with this term, it is also true that others still do and some may even embrace it. The plenitude of autobiographical accounts that document people's experiences as forced migrants demonstrates how they relate to such histories as aspects of who they are and as an ongoing testimony to the past.

As one South Sudanese man who was resettled in Australia for more than 15 years once stated in response to my question as to whether he still identified as a refugee: "I will always be a refugee ... And if I forget my past, then I won't know where I am going.' Similar sentiments are expressed in Cienfuegos and 
Monelli's (1983) work on testimonio and the importance of Chileans being able to give public testimony to the experiences of oppression under Pinochet's rule. Primo Levy's (1996) and Viktor Frankl's (1964) accounts of survival in concentration camps during the Holocaust also provide such testimony that gives voice to and acknowledges experiences that are, at times, unspeakable. Margalit's (2002) book, entitled The Ethics of Memory, explores the complexities of memory and the associated tensions (even obligations) to remember and at times, to forget. It is not my intent to set up binaries of refugee/migrant, everyday/extraordinary, remembering/forgetting, insider/outsider, past/present, agency/structure, here/there or forced/voluntary, but rather to explore the interplay and spaces between such positions. While such constructions can be helpful in understanding a particular social phenomenon, these positions are best utilized as starting points to further engage with the complexity of people's lives, relationships and aspirations. It is on the grey spaces or, as Bhaba (1994) has it, the 'in between spaces', that this book focuses and where belonging is often situated.

My aim throughout this book is twofold. First, I outline the key theoretical debates and discourses that relate to understanding refugee settlement as a transnational experience through the lens of belonging. Second, I contextually apply this framework to previous research studies to examine what is possible through an analysis of the everyday and the extraordinary for professional practice (broadly conceptualized first and then applied to specific fields in later chapters). With reference to the international literature and the case studies of my own research, I examine and illustrate the role of belonging in forced migration and settlement contexts. And, while highlighting that resettled refugee communities have many tools and knowledges to respond to profound difficulties, I will reinforce how the exclusionary experiences of poverty and racism limit their abilities, opportunities and the social affordances to access such resources (Valenti \& Gold, 1991; Wellman et al., 2003). ${ }^{2}$ The moral panic of forced migration and the antiimmigrant platforms that have taken root and even assumed power clearly signal that belonging is an experience and opportunity informed by multiple actors with serious consequences.

This book provides a critical engagement with refugee narratives and representations alongside a structural analysis to develop a conceptual and practicebased framework to understand the possibilities of transnational settlement and belonging through the sociology of the everyday and the extraordinary. To achieve this aim, the book presents three principal questions that build, one upon another:

1 In what ways can refugee settlement be conceptualized as a transnational experience?

2 How does an understanding of belonging in relation to the sociology of the everyday and the extraordinary provide insight to the experience of meaningful transnational settlement?

3 What are the associated implications of belonging and an orientation to transnational settlement for professional practice situated in local places? 
The notion of unsettling the everyday and the extraordinary within the book's title is used as a reminder to engage critically with familiar concepts and discourses. It is all too easy to present terms such as belonging, the refugee experience, trauma or natural disasters without critiquing the ways in which such concepts are understood, represented and legitimate professional practices. Looking to deconstruct such understandings, I examine everyday and extraordinary experiences to unsettle the familiar constructions and representations of such concepts.

The terms, settlement and resettlement, are often used interchangeably in the forced migration literature. These have contested histories with respect to informing and justifying policy and people's lived experiences. For instance, the ways in which settlement has been used to describe the Israeli-Palestinian context, European settlers in North America, settler societies in Europe and the many references to colonization highlight its multiple and politically charged meanings. This book uses 'resettlement' as it relates to the specific way that the UNHCR discusses it as the third durable solution for refugees whereby they are offered permanent protection in a third country (discussed further in the next section). From this understanding, I argue that refugee resettlement is about protection and that refugee settlement (after a person has arrived in a country of resettlement) is about belonging.

While remaining mindful of the different ways in which such terms have been used, this book maintains that, if resettlement is about protection (addressing the well-founded fear of persecution) and settlement is about belonging, then a focus on the latter needs to address how refugees meaningfully integrate and participate in a receiving society. An argument I will develop is that an aspect, and often a significant one, of people's experience of belonging relates to their transnational networks. Thus, to address the book's first question, this introductory chapter presents an overview of refugee settlement to orient the ways that it can be viewed as an ongoing transnational experience.

\section{Global trends: in search of durable solutions}

The world is now witnessing unprecedented movements and numbers of forced migrants, since the Second World War, totalling more than 65 million people. The global refugee population has increased significantly and consistently in recent years from 10.5 million in 2012, 11.7 million in 2013, 14.4 million in 2014, to 15.1 million by mid-2015 - the highest number since its peak in the 1990 s and an increase of 45 per cent over the last few years. The UNHCR notes that, in 2015 , one in every 113 people worldwide were refugees, internally displaced or seeking asylum, and in 2016, approximately 34,000 people were displaced each day. There are now over 2.7 million Syrians under temporary protection in Turkey as well as 236,000 others mainly from Iraq and Afghanistan (UNHCR, 2016b). Over one million people crossed the Mediterranean to Europe in 2015. Of these people, it is estimated that 850,000 braved the Aegean Sea on poorly equipped vessels from Turkey to Greece (Crawley et al., 2016). Over 218,000 forced migrants 
crossed the Mediterranean to Europe in the month of October 2015 alone, eclipsing the estimated total for all of 2014. Although the number of Mediterranean crossings in 2016 has not kept pace with the exceptional volume of 2015, the journey has become more perilous. ${ }^{3}$ As of late 2016, the total number of those on these journeys reported dead or missing is close to 4,700. The UNHCR reports that this will make 2016 the deadliest year on record in the Mediterranean Sea. As of 31 December 2016, the International Organization for Migration (IOM) estimates, on its Missing Migrants Project website, there were 4,913 migrant deaths in the Mediterranean and 7,274 migrant deaths recorded worldwide. ${ }^{4}$

Numerous countries are now laying out hundreds of kilometers of razor wire trying to stem the flow. Right-wing parties espousing anti-immigration platforms are on the political ascendancy across Europe, the United States and elsewhere. Various countries are actively securitizing borders and legislating new policies that determine and limit who is able to cross its borders and decide the opportunities afforded to those who do. Some countries such as Australia are externalizing their borders through having offshore processing centres to consider people's claims for asylum.

What these vast statistics and state-level responses do not illustrate are people's actual experiences of forced migration that may include experiences of trauma, various forms of persecution, economic deprivation, conflict and complete loss of livelihoods. Responding to how these situations can create ongoing instability and insecurity, the UNHCR (2015a) identifies three durable solutions for refugees:

1 Voluntary repatriation;

2 local integration in the country of first asylum; or

3 resettlement to a third country in situations where it is impossible for a person to return home or remain in the host country.

The UNHCR notes that each of these solutions requires legal, economic, cultural, political and civil considerations to be comprehensive, highlighting the unique context in which each solution occurs. Here the word durable connotes something that is long lasting and characterized by a state of permanence and stability.

The first durable solution, voluntary repatriation, represents the largest option people have taken in statistical terms, but the number of refugees able to return home has declined in recent years due to the increasingly protracted nature of conflicts. In 2015, 201,400 refugees returned to their countries of origin, a significant increase compared to 2014, which saw the lowest number of returning refugees since 1983 with 126,000 returnees, down from 415,000 in 2013 (UNHCR, 2015a). Although repatriation may be the aim of many refugees, it does not usually occur until conditions allow them to return safely and with dignity, and is more common among those seeking asylum in close proximity to their country of origin. Most recently, voluntary repatriation is expected in places such as Afghanistan, Ivory Coast, Mali, Mauritania, Somalia, Sri Lanka and within the Balkan region where sustainable livelihoods represent genuine possibilities 
(UNHCR, 2015d). These opportunities, however, are not always available as other countries do not have such favourable conditions. Examples include those such as Iraq, Syria, South Sudan and the Democratic Republic of Congo where many people remain in neighbouring countries of asylum.

The second durable solution, local integration, represents the gradual inclusion of refugees into a neighbouring country of asylum. This is an inherently complex process that is both context-specific and subjective as to whether integration has been achieved because it is difficult to both quantify and qualify. In addition to being difficult to define, naturalization data are limited as most states do not distinguish between those with or without refugee backgrounds in their population statistics (UNHCR, 2015d). And those who have integrated into a new society can be very reluctant to identify as refugees. For instance, Burmese people of mostly Kayin and Kayah origin have fled armed conflict and targeted persecution to seek refuge over the northern Thailand border in significant numbers since 1984. Many of these people have been housed in the nine official refugee camps along the border; others live illegally outside the camps. Thailand is not a signatory to the 1951 Refugee Convention or its 1967 Protocol and does not have a formal national asylum framework or an effective mechanism for refugee-status determination that meets international standards (Human Rights Watch, 2012; UNHCR, 2015c). Burmese asylum seekers are allowed to seek refuge in Thailand temporarily as long as they stay within the confines of the camps. Those who leave the camps without permission forfeit their claim to asylum and become illegal immigrants subject to arrest, detention and deportation (Human Rights Watch, 2012). Despite these risks, the Center for Excellence in Disaster Management and Humanitarian Assistance (2015) estimates that 2 million Burmese migrants reside in Thailand, predominantly in Bangkok. ${ }^{5}$ Other examples of local integration include Syrians living in Lebanon, Afghans based in Pakistan and Colombians residing in Ecuador. Numerous refugees across Africa have settled in places such as Zambia, Kenya and Uganda. While not all of these people would be technically refugees and recognizing that this solution is not without precarity and uncertainty, it highlights how people can integrate and adapt to life in another country of asylum.

The third durable solution, resettlement, is defined by the UNHCR (2015d, p. 51) as the 'transfer of refugees from the country in which they have sought asylum to another State that has agreed to admit them as refugees, granting them permanent settlement and the opportunity for eventual citizenship'. In many cases, the UNHCR nominates particular priority situations for resettlement to states providing such programmes. ${ }^{6}$ And although the people who are resettled represent the minority of populations of concern worldwide, resettlement offers a durable solution whereby people can begin a new life with (relative) human rights protections. Fewer than 100,000 refugees on average are resettled each year. There are 33 countries that currently deliver resettlement programmes (compared to 27 countries in 2014). Most of these countries have relatively few forced migrants arriving at their borders and therefore can afford more easily to have resettlement programmes. ${ }^{7}$ 
The UNHCR notes that 86 per cent of the world's refugees are settled in neighbouring countries and the top ten countries hosting refugees are classed as developing (UNHCR, 2015b). Lebanon, for instance, hosts one refugee for nearly every five people per capita and Turkey now hosts more refugees than any other country due to the Syrian civil war, whereas the United States takes approximately two-thirds of the global resettlement total but can claim to host only one refugee for every 6,384 people. The opportunity for resettlement represents a pathway for less than 1 per cent of all refugees globally, thereby highlighting the challenges of physical reunion with country-of-origin family and friends and the wider diasporic community.

Of these durable solutions, this book focuses predominantly on resettlement pathways. A concurrent focus on transnationalism and belonging provides a lens to understand the ways that these people are able (at times) to remain connected across time and distance to the remaining 99 per cent. And it is also necessary to recognize that resettlement, as the third durable solution, involves interactions with those who have found the other two durable pathways. In this sense, transnationalism provides an enduring solution through a migration and mobility approach (Long, 2014; Van Hear, 2003) and is presented in this book as something that is powerfully coupled with settlement in places both proximate and distant. This orientation provides a justification for examining the ways in which refugees can experience multiple forms of belonging as it relates to forced migration and settlement trajectories. The next section introduces transnationalism and its relationship to local places, people's mobilities and the experience of settling in a new country by further considering the book's first question: in what ways can settlement be conceptualized as an ongoing and enduring transnational experience?

\section{Transnational refugee settlement}

As established in the last section, the concept of durable solutions in refugee resettlement is based on the idea of refugees regaining or acquiring permanent residence wherein refugee status comes to an end because a well-founded fear of persecution has been addressed. These solutions are linked to distinct physical locations. In reality, an individual may experience different kinds of movement as part of a sequence or cycle and, within a family, it is possible that members are located across many countries, either simultaneously or over time that can have elements of all three durable solutions. What this literature demonstrates is that transnational practices are becoming increasingly common and even expected among particular social networks. Such linkages of people, proximal and distant, herald new ways of understanding socialities that have positive and negative implications for refugees and the societies that host them.

While transnationalism itself remains a contested concept, there is broad consensus that transnational processes and relationships traverse one or more nation-states and that the analytical focus is on everyday lives and social relationships (Baldassar et al., 2007; Castles et al., 2014; Faist, 2010; Levitt \& Jaworsky, 
2007; Vertovec, 2009). The term transnationalism became prominent in the 1990s with reference to the transnational turn that endeavoured to address the false dichotomy between emigrants and immigrants, and to capture people's attachments to multiple places that extend beyond national borders (Schiller et al., 1995).

The prefix trans suggests the notion of going across or through, which, when combined with nationalism, provides a sense of traversing beyond borders and the nation itself. Thus, transnational networks extend across nations, yet collectively constitute a site of belonging or home through which social affinities are created and sustained (Blunt, 2007; Perkins \& Thorns, 2011; Wilding, 2006). As such, the intersections of family life, geographic place and digital/non-digital ways of communicating are becoming increasingly complex, creating new forms of transnational families, communities and other social relationships (Beck \& Beck-Gernsheim, 2014).

By critiquing what has often been a dominant focus on methodological nationalism that positions refugee resettlement as a generally static phenomenon existing within national borders (Wimmer \& Schiller, 2003), this book examines the experience of refugee settlement as an ongoing transnational experience that extends beyond the receiving country. Responding to the tendency to treat people as immigrants or emigrants in reference to the nation-state, Basch et al. (1994, p. 6) suggest an alternative focus that considers 'the processes by which immigrants forge and sustain multi-stranded social relations that link together their societies of origin and settlement'. Similarly, Levitt and Schiller (2004) argue that people's social relationships and the associated exchange of ideas, practices and resources are not necessarily bound by national borders. These exchanges represent interlocking networks through which resources and relationships are organized, distributed and potentially transformed. Thus, a more deliberate orientation to transnational settlement can help open new ways of thinking about refugee settlement in relation to practice, research and policy.

One of the most common examples of how such relationships transcend national borders is through the practice of transnational family. While there is a limited (but growing) literature in relation to refugee families, there is a wellestablished body of transnational research relating to migrants. For instance, parents are choosing to transnationalize their family for the sake of their children's education and to give their children an edge in a competitive education and labour market, particularly from Asia to English-speaking countries such as Canada, the United States, the United Kingdom, Australia and New Zealand. These commitments emphasize the family as the basic unit of society, where different family members work together for the success of the family unit (Landale et al., 2006). For some, transnational families may be translocal, meaning they have rooted and rerooted forms of transnationalism that connect them to more than one locality - or what is sometimes referred as local-local connections (Brickell \& Datta, 2011). In fact, Schiller et al. (1995) use the term transmigrant to describe the experience of living simultaneously between nation borders of here and there. This orientation highlights new configurations and ways that people remain connected to particular places and relationships. 
Transnational families will experience settlement in different ways over time that involve negotiating new situations, pressures, relationships and expectations (Goulbourne et al., 2010). One of the most evident ways of achieving this is through the practices of sending remittances (Akuei, 2005; Lindley, 2007; World Bank, 2016). Transnational remittances represent an exchange of capital, either to or from a migrant. The associated flows may be economic or social and help to maintain relational, cultural and political links with their families and country of origin. These can be a decisive agent for economic and social change in which global breadwinners remain important actors in their countries of origin. These forms of support are crucial to numerous countries and represent a large proportion of global financial flows that substantially exceed official development assistance. The World Bank (2016) estimates that remittances to developing countries are worth US\$441 billion - nearly three times the amount of development assistance that these countries receive usually through state-sponsored means. ${ }^{8}$ And Levitt's (2001) work highlights that financial support comprises only a portion of the picture as social remittances provide additional cultural, political and relational forms of support that sustain and create communities across significant distance. While such remittances may provide connection and reaffirmation to overseas networks, these commitments also represent a potential strain as people maintain responsibilities across multiple localities. These interactions alongside rapid technological advances and physical mobilities herald how people create, sustain and negotiate everyday practices of family and friendship across national borders.

Advances in communication and travel, particularly the mobile phone, the internet, affordable flights and digital cameras facilitate the transnational lives of contemporary migrants creating a network society that reduces the importance of physical distance and proximity. Separated families now have the opportunity to practice co-presence to the point of connected presence in which boundaries between absence and presence are blurred (Licoppe, 2004). For instance, the transnational literature increasingly acknowledges that digital technologies and internet access transform the ways that people can interact in more than one locality simultaneously (Collins, 2009; Esnard \& Sapat, 2016; Kissau \& Junger, 2010; Madianou \& Miller, 2013).

Digital technologies offer the potential for new social configurations and connections for transnational and diasporic communities as the increasing accessibility and affordability of communication devices and web-based connectivity radically transform the structure and role of social networks (Castells, 2013; Wilding, 2012). The recent proliferation and associated integration of a wide range of digital communication technologies and social media platforms such as Facebook, Skype, Viber and others are central to this transformation (Madianou $\&$ Miller, 2013). This is particularly the case for refugees, where these technologies generate the opportunity to practise friendship and family differently and beyond the accepted social and spatial boundaries of local places (Elliott \& Urry, 2010; Urry, 2007). The speed of technological development and increasing connectivity means that people are able to connect across distance instantaneously 


\section{Transnational settlement}

and continuously. These contexts raise new questions about the integrity of sovereign national borders and people's commitments to local places. Such technologies also highlight the innovative ways in which new mobilities and mass population movements work across and within them that further bolster the possibilities of transnational forms of family and friendship.

These examples suggest that there is a reasonable amount of choice in relation to whether families transnationalize or not. However, the opportunities for transnationalism and translocality can be far from voluntary decisions where economic, social and other pressures may drive people from places they traditionally associate with home. In conflict zones, countries of asylum and refugee camps, transnational contact with family members and friends also remains a significant challenge as basic communications infrastructure is missing and communication technologies are too expensive/complex to coordinate and risky to use (Leung, 2011). For some, the experience or threat of persecution highlights that transnational interactions are limited for safety and surveillance reasons.

Transnational interactions and mobilities are often limited by forces beyond people's immediate control. Domestic policies and legislation have not kept pace with increasingly mobile and multi-local lives that constrain the possibilities for ongoing transnational interactions. This reality is perhaps most evident in relation to the challenges of achieving family reunification in resettlement contexts. Although refugees have always struggled to reunite with their families, recent changes to immigration policies in many countries receiving refugees and asylum seekers have actively reduced opportunities for family reunion (Baldassar \& Wilding, 2013; Schweitzer, 2015). These families have ongoing concerns about relatives still living in perilous circumstances in transit countries, conflict zones and refugee camps that represent a significant ongoing stressor while settling in a new receiving country. The associated challenges sit alongside restrictive immigration policies with narrow views of eligible kinship selection criteria, which also contribute to an ongoing disruption of family relationships and barriers to reunion (Robertson et al., 2016). As a result, resettled refugees may struggle with both the realities of their new settlement existence and the knowledge of the precarious situation of those left behind. Family and friends still living in unsafe circumstances may perceive resettlement countries as opportunities to accrue significant wealth and resources, generating situations ripe for misinterpretation and frustration on both sides (Robertson et al., 2016).

These contexts signal the possibilities of digital-unification to link people across multiple places. The promise of digital technologies can be Janus-faced, however, as Collins (2009) highlights that these digital platforms provide both pathways to inclusion and exclusion, and thereby cautions against a digital utopian view of increased connectivity. Many fear that their communications are being monitored by the government from which they have fled, making them cautious about what is said and to whom.

While transnational settlement remains an important concept for many who maintain ongoing commitments to people in distant places, there are also many examples where a person, family or community may develop stronger ties to 
local networks and livelihoods. It is not my intent to create a further bifurcation between the transnational and the local, as both are often intertwined. For many refugees, successful and meaningful settlement remains an ongoing transnational commitment. Although people resettle within a particular border, their daily presence and forms of support may come from many places where borders hold less relevance. People's associated mobilities for transnational interactions can be significantly constrained, however. In particular, the power of borders and the conceptualization of the nation have profound implications for people's everyday transnational interactions. The heated debates that continue across Europe, North America and elsewhere about refugee integration and belonging powerfully shape the possibilities and constraints of people's commitments to both local and distant places.

\section{Countries of resettlement}

Each resettlement country provides different forms of protection and rights. For most countries, refugees who are resettled as part of its annual settlement programme are usually provided permanent residency (or a pathway to it) and opportunities to eventually gain citizenship. This means, for refugees, that they would have similar (if not the same) rights and entitlements as other permanent residents living in that host country. Refugee resettlement also provides an avenue for the sponsoring countries to share international responsibility for the most vulnerable refugees as a contribution to international human rights obligations. The ways in which these obligations are met through domestic and international legislation and particular social policies, however, represent a key consideration in how well people from refugee backgrounds are able to integrate into, and participate within, a new host country (Mahony et al., 2017).

Successful integration represents a growing and contested global social issue that includes not only refugees and other migrants separated from their friends and families, but also the nations that accept them. Although the forced migration literature has extensive reference to integration, the role of belonging as it intersects with resettlement is much less developed, particularly within a transnational frame and across multiple aspects of experience relating to family, work, education and civic participation. There is a plenitude of papers that discuss the implications of integration and how refugees craft a new existence in a country of resettlement (Ager \& Strang, 2008; Lundborg, 2013; Polzer, 2008; Valtonen, 2008; Zetter et al., 2006). While others have also presented alternative integration models/perspectives, it is clear within these that the interplay between refugees, the wider society and the institutions that surround them is critical.

It is within this level of awareness that it is important to distinguish between an invitation and a welcome, and the differences of presence and participation. Although refugees may be invited by another country to resettle, it does not necessarily follow that they are entirely welcomed. Second, just because a refugee is then resettled (i.e. they are present), it does not mean that they are necessarily afforded the opportunity to meaningfully participate (Colic-Peisker \& 


\section{Transnational settlement}

Tilbury, 2003, 2006; Harris \& Marlowe, 2011; Pupavac, 2008). These distinctions are important for considering what constitutes integration where I will maintain that a sense of belonging is inculcated within the welcome and participation distinctions.

There are now 33 countries that have formal refugee resettlement programmes and the vast majority of these people go to the United States, accounting for about 60 per cent of the overall intake. The table below presents 2014 and 2015 data for several of the main refugee resettlement countries in relation to per capita resettlement and associated rank. Several of the main refugee resettlement countries are listed below in alphabetical order.

What this table highlights is that there are many ways that countries can present their associated commitments to global displacement and durable solutions. Although Germany would have a ratio of 1 refugee to 116,667 people for 2015 if included within this table, it is worth noting the significant number of asylum seekers it does accept. In 2015, the country registered more than 440,000 asylum seekers, constituting the largest recipient of claims globally according to the International Organization for Migration (IOM, 2016). Although New Zealand ranks 8 th in the world for refugee resettlement per capita, these numbers can be misleading. When compared to the total number of refugees that a country accepts per capita, Amnesty International (2016) notes that New Zealand drops to 90 th in the world and 116th when examined in relation to gross domestic product. In relation to total inhabitants, the country only hosts 0.3 refugees per 1,000 people (compared to the United States at 0.83 per 1,000 and Sweden at 14.77 per 1,000$)$.

The next section briefly introduces some of the main refugee resettlement countries to help situate the specific national contexts in which settlement occurs. ${ }^{9}$

Table 1.1 Per capita refugee resettlement for top countries in 2014 and 2015

\begin{tabular}{lllllll}
\hline Country & $\begin{array}{l}\text { Refugees } \\
\text { per capita } \\
\text { (2014) }\end{array}$ & $\begin{array}{l}\text { Country } \\
\text { rank per } \\
\text { capita } \\
(2014)\end{array}$ & $\begin{array}{l}\text { Total } \\
\text { refugees } \\
\text { resettled } \\
(2014) *\end{array}$ & $\begin{array}{l}\text { Refugees } \\
\text { per capita } \\
(2015)\end{array}$ & $\begin{array}{l}\text { Country } \\
\text { rank per } \\
\text { capita } \\
(2015)\end{array}$ & $\begin{array}{l}\text { Total } \\
\text { refugees } \\
\text { resettled } \\
(2015)^{*}\end{array}$ \\
\hline Australia & $1: 3,636$ & 1 & 6,162 & $1: 2,551$ & 4 & 9,399 \\
Canada & $1: 4,718$ & 3 & 7,233 & $1: 1,795$ & 1 & 20,010 \\
Denmark & $1: 16,720$ & 9 & 332 & $1: 9,615$ & 9 & 592 \\
Finland & $1: 5,310$ & 5 & 1,011 & $1: 5,464$ & 7 & 1,007 \\
New & $1: 6,911$ & 7 & 632 & $1: 5,525$ & 8 & 808 \\
$\quad$ Zealand & $1: 4,117$ & 2 & 1,188 & $1: 2,188$ & 2 & 2,383 \\
$\begin{array}{l}\text { Norway } \\
\text { Sweden }\end{array}$ & $1: 5,177$ & 4 & 1,812 & $1: 5,155$ & 6 & 1,902 \\
United & $1: 98,831$ & 18 & 628 & $1: 34,483$ & 15 & 1,864 \\
$\quad$ Kingdom & $1: 6,384$ & 6 & 48,911 & $1: 4,831$ & 5 & 66,517 \\
USA & 18 & & & & & \\
\hline
\end{tabular}

Note: *These numbers do not include asylum seekers. Data sourced from UNHCR (2015e, 2016a). 
The future of many current resettlement programmes is understood to be unpredictable following both the Brexit vote (the United Kingdom's referendum in June 2016 in favour of leaving the European Union (EU)) and the November 2016 American presidential election of Republican Party nominee, Donald Trump, as the 45th President of the United States of America. How these developments will impact on refugee resettlement agreements and policies is still unclear. While it is important to remain mindful that resettlement is by far the smallest of the three durable solutions and the associated politics of reporting particular statistics, it still represents a vital pathway for those living in situations where other options are not possible and safety remains a serious ongoing concern.

\section{The United States}

The United States of America (US) accepts the largest number of resettled refugees globally and has resettled over 3 million refugees since 1975 (United States Department of State, 2015). It set its 2015 annual target at 70,000 people and announced an increased target of 85,000 people for the 2016 financial year with an additional intake of 10,000 Syrians. ${ }^{10}$ The President sets the number of refugees who will be accepted each year, and those who arrive are provided with financial and medical support for up to eight months along with a range of other social services funded through the Office of Refugee Resettlement (ORR) (Martin, 2014). Selection is on a priority basis for those fleeing persecution, groups of special concern to the US (this has included persons from the former Soviet Union, Cuba, the Democratic Republic of Congo (DRC), Iraq, Iran, Burma and Bhutan), and then family members of refugees already settled in the US. Refugees are placed all over the country, mainly in medium-sized cities, and are expected to find jobs within six months and to apply for permanent residence after one year. Currently, a third of refugees resettled in the US come from Iraq, Syria and Iran, a third from Africa and the final third from East Asian countries such as Myanmar and Bhutan. Data from Pew Research Center and Refugee Processing Center show that, from October 2015 to May 2016, 34,405 refugees were resettled. Of these, 12,130 came from the DRC or Somalia, 11,036 came from Myanmar or Bhutan, and the final 10,239 came from Iraq, Syria and Iran. ${ }^{11}$ The United States is signatory solely to the 1967 Protocol.

\section{Australia}

Australia's refugee intake of 2015-2016 was 13,500 humanitarian entrants, which is inclusive of asylum seekers. Since the end of the Second World War, the country has resettled approximately 850,000 refugees and others on humanitarian bases (McNevin, 2014). Australia makes a distinction between offshore and onshore refugee entrants in their humanitarian programme (UNHCR, 2014b). This distinction is critical, as those who are processed offshore (as state-sponsored refugees who already have this status determination) have a much different pathway for resettlement from those who arrive onshore or as asylum seekers looking 
for refugee status (McNevin, 2014). The offshore component provides resettlement for people outside Australia who cannot be repatriated or locally integrated, and who are in need of humanitarian assistance. Also in this category is the Special Humanitarian Programme (SHP) whereby citizens or permanent residents of Australia may sponsor the resettlement to Australia of family members or other persons abroad who have humanitarian needs or are in refugee-like situations. ${ }^{12}$ Both refugees and SHP entrants are granted a permanent residence visa on arrival in Australia. Asylum seekers, largely from Afghanistan, Sri Lanka, Iraq, Iran and Burma arriving on boats from Indonesia have recently been sent for offshore processing in Nauru and Papua New Guinea, ${ }^{13}$ a move widely criticized for associated human rights abuses and violations (Fiske \& Briskman, 2016). The Australian Government announced in September 2015 an emergency intake of an additional 12,000 Syrians to resettle those fleeing the conflicts there; as of mid-2016, 3,790 of these visas have been granted (Australian Government, 2016). Australia is signatory to both the 1951 Convention and the 1967 Protocol.

\section{Canada}

Canada has maintained a resettlement programme since 1977 and now resettles the second-highest number of refugees, behind the United States (Martin, 2014). Over the last several years, the country has resettled between 11,000 and 14,000 refugees annually. Prime Minister Justin Trudeau promised an intake of 25,000 Syrian refugees, over and beyond this commitment, which was achieved in early 2016. Canada's resettlement programme is funded by a mixture of governmentassisted and private sponsorship, with the intention of increasing the governmentassisted figure to its intended target by the end of 2016. The Private Sponsorship of Refugees (PSR) programme allows sponsors such as community organizations, church groups or private individuals to identify the refugees they wish to sponsor and support up to a year post-settlement. There is a strong family link component to this approach and, since its inception; the programme has resettled 235,000 refugees from over 140 countries. Government Assisted Refugees (GAR) are provided with income support and other essential services for up to one year or until the person becomes self-sufficient, whichever comes first (Martin, 2014). Canada is signatory to both the 1951 Convention and the 1967 Protocol.

\section{The United Kingdom}

The United Kingdom has delivered a formal resettlement programme since 2004 and has an annual target of resettling 750 refugees within the Gateway Protection Programme (GPP), although they met this quota for the first time only in 20112012 (UNHCR, 2013). In addition to this, the Mandate Refugee Scheme (MRS) allows refugees with close family ties with the UK to be resettled, although not with the support of the GPP. Refugees resettled under the GPP are fully funded by the Home Office/European Refugee Fund (EU) for the first year and then costs 
fall to the relevant Local Authority (UNHCR, 2014a). Refugees are placed in Greater Manchester, Sheffield, Hull or Bradford, and support is contracted to nine local authorities, two NGOs and one specialist housing and support organization. GPP-resettled refugees may apply for family reunification (spouse and minor children) for their dependants once they have been granted resettlement and they reside in the UK. There is no provision for emergency or urgent cases within the resettlement programme (as of 2014). The UK has supported refugee resettlement from Liberia, Burma, Congo, Iraq, Somalia, Ethiopia, Sudan and Bhutan since 2004 and, in times of crisis, has operated specific resettlement programmes to help offer protection to people on a larger scale such as those from Vietnam and Uganda, and refugees fleeing the Balkan wars (UNHCR, 2014a). In response to the recent conflicts in Syria and considerable public pressure, the former Prime Minister David Cameron announced in September 2015 that the UK would accept up to 20,000 refugees from camps bordering Syria by 2020 under the Vulnerable Persons Relocations Scheme (VPR). The United Kingdom is signatory to both the 1951 Convention and the 1967 Protocol.

\section{New Zealand}

New Zealand has resettled refugees since the Second World War and has maintained a formal resettlement programme since 1987. Since this time, the country has settled more than 50,000 refugees through its quota refugee programme with the seven top-source countries being Burma, Bhutan, Iraq, Afghanistan, Columbia, Sri Lanka and Iran, with an increasing commitment to resettling people from the Asia-Pacific region (Marlowe \& Elliott, 2014; Mortensen et al., 2012). Within its annual quota, there are dedicated places for women at risk, a category for medical or disabled cases, and for those requiring priority protection and family reunification. Under this quota, refugees are granted permanent residence on arrival, with the opportunity to apply for citizenship after five years. Each intake completes a six-week orientation programme before being placed in the community. In addition to these, a small number of asylum claims are received each year. A boat has never arrived on New Zealand shores with people seeking asylum. The recent political and public pressure to increase the annual refugee intake resulted in a government announcement to increase the quota from 750 to 1,000 people in 2018. New Zealand is signatory to the 1951 Convention and the 1967 Protocol.

\section{Scandinavia}

Denmark, Sweden and Norway have current refugee resettlement programmes and all have ratified and implemented the 1951 Convention and the 1967 Protocol. These countries resettle some of the highest numbers of refugees per capita in Europe. The majority of refugee resettlement in Scandinavia comes from those identified via country missions or dossier referrals, with a smaller percentage accepted on medical or emergency grounds. There is limited access to family reunification within the Danish resettlement programme and only close 
family members such as a spouse or dependent children are included (UNHCR, 2014c). Resettled refugees in Denmark and Norway are granted temporary residence and work permits, and priority is given to those most able to integrate into society. Cultural orientation training is provided aimed at gaining employment and self-sufficiency. In addition, Scandinavian countries have accepted large numbers of asylum seekers, particularly Sweden which has hosted the most refugees per capita in Europe through granting 32,631 of the nearly 163,000 asylum claims received in 2015 (Swedish Migration Agency, 2016). ${ }^{14}$ Since 2013, Sweden has granted permanent residency to Syrian refugees in response to the worsening crisis, but has since tightened these rules to provide only temporary residence. Overall, heated debates about Scandinavia's societies and the ability of foreigners to assimilate sit alongside the role of the welfare state, leaving questions as to how current and future resettlement policies will be shaped.

\section{Refugee resettlement and the refugee 'crisis'}

A particular contemporary issue arises from the mass migrations of displaced people in Europe as the notion of national borders is, in many ways, imagined (even though thousands of kilometres of razor wire provide a worrying and stark physical presence). Numerous analysts posit that the recent mass migrations into Europe represent significant problems for the European Union's Schengen Zone and the 1990 Dublin Convention (Casella Colombeau, 2015; Kasparek, 2016). ${ }^{15}$ Examples of populist uprisings across Europe signal fundamental changes to its governance, identity and ability to coordinate multinational solutions in relation to the so-called migrant crisis where strident forms of nationalism and protectionism are taking root. Right-wing parties have capitalized on the perception that the EU cannot cope with the flow of refugees and this, coupled with hostilities towards Islam and concerns about traumatized populations, is fanning fears of terrorism in the wake of recent terrorist attacks in Manchester, London, France, Germany and Belgium.

These parties across Europe have campaigned on ethnic, nationalistic, antiimmigration platforms based on the rhetoric of protecting heritage and borders, particularly among voters disillusioned amid a time of economic uncertainty. In some countries, these parties are topping the polls and have even assumed government. Recent examples include the right-wing populist United Kingdom Independence Party's (UKIP) successful campaign for the UK's removal from the EU during the Brexit vote. Famously and controversially, the UKIP leader, Nigel Farage, used a photograph of refugees queued at the Slovenian border in the Leave campaign promotional materials. The photograph was branded with the slogan 'Breaking Point: The EU has failed us all: We must break free of the EU and take back control of our borders'. Although these posters were denounced as xenophobic and Islamophobic by supporters of both the Leave and Remain campaigns, a majority of British voters (just under 52 per cent) decided to leave the EU as part of the Brexit referendum. 
Europe is not the only region to reconsider its welcoming of refugees. Across the Atlantic, the heated debates on illegal migrants crossing the partially and virtually fenced border between Mexico and the United States (through a series of physical walls and operating sensors and monitors) highlight how sovereign borders are being tested. A central plank of Donald Trump's bid for presidency was built upon the fear of undocumented migrants and refugees. The Republican Party has control of Congress allowing for the legislation of associated responses that will likely have far-reaching ramifications for those living within and outside the United States. The campaign slogans, 'build the wall' and 'Muslim ban' are now beginning to take shape within domestic and foreign policy.

New Zealand has recently amended legislation allowing for the detention of a mass arrival of people by boat, defined as more than ten people, even though a boat has never arrived on its shores to seek asylum (see Bogen \& Marlowe, 2015). Australia has been condemned for its recent policies related to asylum seekers for its approaches to offshore processing and mandatory detention (Briskman et al., 2008; Gale, 2005). In late 2016, the current government under Prime Minister Malcolm Turnbull introduced legislation to ban asylum seekers who arrive by boat from ever being allowed entry to Australia through any type of visa, including tourist, spousal or business. The government has stated its plans to amend the 1958 Migration Act to reflect this ban should their bid prove successful in parliament, and asserts that the law is necessary to deter peoplesmuggling activities and to enhance border protection. ${ }^{16}$ These developments help justify the increased securitization of asylum that makes it more difficult to cross borders and receive particular protections from countries signatory to the 1951 Convention and the 1967 Protocol.

\section{Borders, diaspora and the nation}

What informs, and often justifies, such policy directions are understandings of the nation and its associated values, identity and histories. When these emotive identifiers are perceived to be under threat, nationalism becomes a powerful electoral force that influences election outcomes and legitimizes migration and settlement policy decisions. These political developments can, at times, challenge, and even legislate against, the possibilities for particular people's mobilities across national borders.

As Diener and Hagen (2012) acknowledge, borders differentiate places and define geographical meanings as defined along cultural, political, social and/or economic axes. In this sense, borders are symbolic, geographic, cultural and political demarcations. Further, the United Nations definition of a refugee explicitly incorporates the concept of national borders as a central criterion. Until a person crosses the border of their home country or place of habitual residence, they are not eligible for refugee status determination. And, if citing a wellfounded fear that they are unable or unwilling to return back to this country, they are able to make a case for refugee status. 
National borders remain a powerful and decisive factor that inform migration regimes and associated policies, and determine the physical (and at times, digital) mobilities of particular people. The ways in which borders are externalized through security checks at airports exemplify these trends. The externalization of borders through offshore processing centres for asylum seekers in places like Australia and the outsourcing of border controls to groups such as the European Border and Coast Guard (EBCG, formerly known as FRONTEX; Frontières extérieures translated from the French meaning 'external borders') in the EU highlights how resourced countries shift the 'problem' of forced migration beyond its borders.

Different citizenships give people access to other countries more easily than others and highlight how mobilities are influenced by the ways in which they might be profiled (as refugees, as foreign nationals and other identifiers that a state apparatus deems as a risky or desirable quality) and their eligibilities for particular visa schemes relating to the passport they carry. International agreements such as the Schengen define who can freely cross sovereign borders and those who cannot. Thus, for some, transnationalism is an integral component of a refugee's settlement experience and for others, less so.

Many writers have contested what the nation means and note that it lacks conceptual clarity (Bhabha, 1990; Malkki, 1992; Ong, 2006; Winter, 2007). Smith (2013) acknowledges that the nation has multiple interpretations, but it generally refers to or assumes a large body of people who are united by a common history and inhabit a particular territory defined by the notion of a sovereign border composed of both objective (language, religion, institutions) and subjective (attitudes, perceptions, sentiments) factors. He formally defines the term as 'a named human community residing in a perceived homeland, and having common myths and a shared history, a distinct public culture, and common laws and customs for all members' (Smith, 2013, p. 13). In particular, the idea of a common history is one that is becoming increasingly problematic as languages, cultures and ethnic identities are not universally shared or embraced within such neat territorial boundaries. The impacts of globalization, urban spaces characterized by superdiversity, the economic implications of free trade and mass movements of forced migrants significantly inform the construction of such societal narratives. However, there is also an element of an imagined community where the assumption of shared values and identities occur, often assumed at the national level (Anderson, 2006). These imaginaries manifest in a number of ways, as Smith (2013) maintains that nation and nationalism are distinct concepts where it is entirely possible to have nationalism without the nation (citing the USSR as just one example). This is where diaspora studies provide a compelling understanding of the ways in which people belong and how they are connected to places both proximal and distant.

The focus on diaspora studies in the forced migration literature highlights the important relationships that people maintain, reinforce and augment across geographic distance (Lindley, 2007; Wahlbeck, 2002). ${ }^{17}$ According to Van Hear (2014, p. 176), diasporas involve three main components: dispersal from a 
homeland to two or more other territories; an enduring presence abroad (though not necessarily permanent); and an exchange of social, economic, political and/ or cultural resources/capital. These three components show the potential, and even the necessity, of transnational networks that overlap across several domains, and at times, inseparably.

Faist (2010, pp. 21-2) argues that the terms diaspora and transnationalism have been used interchangeably and in problematic ways. While recognizing commonalities, he positions these terms as dance partners that are analytically distinct but are related in three principal aspects. First, he notes that diasporas relate to specific religious, ethnic and/or national groups, whereas transnational groups include other sorts of social formations. Second, diasporas focus on aspects of collective identity and the latter more on particular mobilities that cross and transcend borders. Finally, diaspora usually has a multigenerational component, whereas transnational groups focus on more recent migrant flows.

This book focuses on the term transnational instead of diaspora as it provides for a broader engagement with the different facets of belonging and the intersectional forms of identification that avoid the reification of identity politics (discussed in the next chapter). While diasporas are often positioned as ties between 'here' and 'there', transnationalism provides a more flexible relationship that recognizes the possibilities and constraints of transcending borders. I maintain that envisaging settlement as an ongoing transnational experience helps to understand people's commitments to integration and participation in a receiving society and in other places. In particular, the multiple ways that people might belong in relation to social groupings, shared societal narratives and forms of civic participations across time and space are central to this analysis. To achieve this focus, a summary of the following chapters is provided below.

\section{Orientation of the chapters}

This chapter sets the basis and justification to consider settlement that remains inclusive of its transnational opportunities. Central to this orientation of transnational settlement is simultaneously recognizing the ways that people continue to their local lives and livelihoods. As Levitt and Schiller (2004) argue, enduring ties can inform multiple ways of being across different geographic spaces. The chapters that follow maintain this emphasis to consider the possibilities of local and distant relationships and networks that characterize the lives of many resettled refugees.

Chapter 2: Belonging: everyday and extraordinary conceptualizations addresses the second major question of this book: how does an understanding of belonging in relation to the sociology of the everyday and extraordinary provide insight into the experience of meaningful transnational settlement? The notions of the everyday and the extraordinary arise from Bourdieu's critique on how the examinations of difference (frequently defined on cultural or ethnic axes) have a tendency to reify and essentialize particular groups. By following his suggestions to challenge such understandings, this chapter elevates the status of the everyday to sit 
alongside (rather than subsume) extraordinary experiences. In particular, I position this orientation within Yuval Davis's work on intersectionality and the three facets of belonging. Throughout the chapter, belonging is the theoretical anchor point, with the following chapters presenting distinct case studies concerning everyday and extraordinary experiences related to forced migration and transnational settlement.

Chapter 3: Responding to trauma discusses the experience of, and responses to, trauma by examining the political and social theories of recognition and redistribution. Drawing on the international literature that focuses on trauma arising from forced migration and settlement experiences, this chapter establishes a relationship between trauma, transnational relations and belonging. This approach forwards the rationale for distinguishing between the effects of trauma and people's responses to associated events. This critical examination of the literature illustrates the debates related to mental health and well-being, providing a historical account of trauma within forced migration studies. I present a case study of the South Sudanese community settling in Australia to demonstrate how they define and respond to trauma, and to theorize how they negotiate life in settlement contexts. These implications are then examined in relation to the policy directions and contestations of what is currently referred as the refugee 'crisis'. The chapter considers what it means to understand the trauma story but, importantly, to also look beyond it.

Chapter 4: Responding to disasters examines the role of belonging during times of disasters and how transnationalism can help inform disaster risk reduction. First, I position the concepts of capacities and vulnerabilities within the context of disasters that are both human-induced crises and catastrophes arising from natural hazards (earthquakes, tsunami, etc.). These predominantly extraordinary phenomena are then linked to the international literature related to belonging and disaster recovery. To illustrate the associated links, I present a three-phase study with multiple refugee-background communities living in Christchurch, New Zealand, on their perspectives and responses to the Canterbury earthquakes of 2010-11. Although the Canterbury earthquakes caused significant devastation and fatalities, refugee background communities found multiple ways to respond effectively to such adversity where belonging represented a critical element for recovery. This discussion includes an intersectional analysis that highlights how belonging has gendered, contextual, transnational and chronological dimensions that impact on people's perspectives on, and responses to, a disaster. The chapter concludes by making wider global links of disaster risk reduction with forcibly displaced populations.

Chapter 5: Professional practice presents a conceptual practice framework that critically accounts for possibilities of belonging and transnational settlement for resettled refugees. Following from the previous two case study chapters, it addresses the third question of this book: what are the associated implications of belonging for professional practice located in local places? This analysis is buttressed by a return to, and critique of, dominant discourses in the study of refugees and forced migration. It concurrently examines the everyday and the 
extraordinary through the narrative ideas of Michael White's work on dominant and subordinate storyline development that offer ways to honour everyday and extraordinary experiences. Using a human rights lens, it focuses on the 'profession' as enacted through health and social practices related to interpersonal service delivery, policy development and research in relation to refugee settlement. The chapter concludes with discussion of how professionals can work alongside refugee communities in realizing improved pathways to meaningful forms of settlement to move from what is known and familiar to what it might be possible to know.

Chapter 6: Conclusion draws together the threads of the previous chapters to revisit the idea of unsettling the everyday and the extraordinary when understanding the multiple ways that people belong. It provides concluding remarks related to practice and addresses the necessary interplay between the everyday and extraordinary by validating and dignifying the impact of adverse experiences in people's lives while recognizing their pathways to healing and agency. Such a focus necessitates acknowledging past, present and future realities that consider the possibilities and constraints of belonging within an increasingly transnational world.

\section{Author's comment}

This book represents a compilation of previous work I have conducted with the South Sudanese community in Australia, numerous groups resettled in New Zealand and analyses of refugee-based settlement policies across Europe, the United Kingdom, Canada and the United States. As such, I present some previously published material from journal articles to illustrate the possibilities of belonging and what this might mean from a transnational standpoint. While some of this work has been published, everything presented has been updated and reworked to align with the specific and original focus of this book. I provide reference to where this material is incorporated in the respective chapters.

The case studies provide a basis to compare and contrast local research with some of the most pressing issues related to forced migration globally through considering the possibilities of transnational settlement and belonging. Thus, I position the discussion that follows from the New Zealand and Australia-based case studies in a wider international context. The massive influx of asylum seekers to Germany, for instance, has created a renewed interest on the impacts of trauma and how traumatized populations can integrate into a new society. Alongside these populist and political concerns, there is a trauma industry waiting to treat the symptoms and psychiatric presentations that arise from conflict and persecution. ${ }^{18}$ Similar debates about social cohesion and finding ways to integrate the Other rage across Europe, the United States, Canada and other receiving countries. Numerous political parties have successfully used this politics of fear as a primary platform for populist legitimacy. Having a conceptual framework to engage with the complexities of honouring the trauma story and its impact while also having ways to work and see beyond it have never been so pressing in resettlement contexts. 


\section{Transnational settlement}

The book's focus on transnational settlement and belonging provides a basis to critically consider, rather than prescribe, how a concurrent everyday and extraordinary analysis relates to research, policy and direct practice. The fact that disaster losses in terms of deaths, financial losses and damage to infrastructure are increasing also highlight the need to consider what disaster risk reduction represents with culturally and linguistically diverse populations in places such as North America, Europe and neighbouring countries of asylum. The limited knowledge of who has crossed borders and how many people live in precarious circumstances illustrates the heightened vulnerabilities of particular populations generally and in disaster contexts specifically. In some instances, these populations have decided to remain hidden for good reasons (see the previous discussion on Burmese people living in Thailand) and means that they will often be missed, unintentionally or deliberately, in the associated response.

Although refugee communities may have certain vulnerabilities that arise from their associated flight from their country, their previous experiences also provide adaptive capacities because they have had to find ways to cope with trauma, limited resources and other forms of hardship. Several authors have noted that significant adversity can represent opportunities for post-traumatic growth (Calhoun \& Tedeschi, 2014; Rosseau \& Measham, 2007) and has a 'steeling effect' that creates resilience to future challenges (Rutter, 2012). An effective analysis of refugee communities, therefore, is to assess both the vulnerabilities and capacities that exist within specific groups - a focus I will maintain over the coming chapters.

Finally, what these chapters demonstrate is a pressing need to further consider how the 'profession' is enacted - whether in clinical, community-based settings or for those working in research or policy development. My critique of the focus on the extraordinary is that it all too often positions trauma and other forms of adversity as occurring within individual, biomedical and/or microsystem-level analyses that limit the ways in which transnationalism and belonging can be understood alongside the associated politics. It is not my intent, however, to discredit such understandings but to broaden the conceptual scope in which settlement occurs from local to transnational levels.

\section{Conclusion}

This chapter addresses the book's first of three primary questions: in what ways can refugee settlement be conceptualized as a transnational experience? Through defining several key concepts of transnationalism, the nation, mobilities and outlining global refugee resettlement trends, I have problematized the assumption of settlement as occurring solely in local places. While transnationalism remains a contested concept, the focus on processes and relationships that go beyond one or more nation-states increasingly highlights the importance of everyday lives and social relationships.

The unprecedented forced migration flows since the Second World War as millions of people cross national borders highlights the need to consider the ways 
in which people live their lives transnationally and how this impacts on their commitments to local places. For durable solutions to be comprehensive, these require a progressive realization of the associated economic, political, civil, cultural and social dimensions that occur within particular localities. As I argued earlier, refugee resettlement is about protection and refugee settlement is predominantly about belonging. This orientation sets the basis to further consider the theoretical and applied utilities of belonging for meaningful settlement.

New forms of mobility herald the possibilities of transnational settlement whereby people remain connected across time and distance. The national border regime, however, remains a powerful force that still influences and at times determines how people maintain transnational linkages and define their belonging. These opportunities are shaped by numerous actors, often in deliberate and uneven ways that reinforce the importance of a multi-local and multi-scalar analysis alongside people's lived experiences and narratives. By focusing on the everyday and the extraordinary, the next chapter examines how the concept of belonging influences the experience of meaningful refugee settlement in places both proximate and distant.

\section{Notes}

1 Most countries that are signatory to the 1951 Convention have also signed the 1967 Protocol. The temporal dimension noted earlier relates to the 1951 statement that had restricted refugee status to events occurring before 1 January 1951 and the geographic one related to events occurring in Europe.

2 The term social affordances has been used in numerous ways over time and within different disciplines. Valenti and Gold (1991), for instance, stress the interplay between social knowing and social interaction that thereby impacts on people's engagement in civic spaces. Wellman et al. (2003) provide a comprehensive account of how the digital environment through online interactions has also influenced people's social affordances - for better and for worse - to ask the question over how the internet decreases, transforms and supplements community. The term focuses upon a person's interplay with their social environment whether this is defined by physical, cultural, digital or other intersectional bases.

3 The UNHCR notes that the number of refugees and migrants arriving in Greece has dropped dramatically, from over 67,000 in January 2016 to 3,437 in August 2016. The UNHCR says this is due to the closure of the so-called Balkan route and the implementation of the European Union-Turkey Statement. Italy's arrivals have remained constant, with some 115,000 refugees and migrants landing in Italy as of the end of August 2016, compared to 116,000 during the same period in 2015.

4 See the IOM's Missing Migrant Report website that details total migrant deaths for people trying to find asylum in another country: http://missingmigrants.iom.int/

5 Two organisations work to support and measure the displaced Burmese population. Both The Border Consortium (TBC) and the United Nations Commissioner for Refugees (UNHCR) include in their reported figures both those who are registered and those who are unregistered as refugees or 'people living in refugee like situations' (Human Rights Watch, 2012). Since November 2005, most new Burmese arrivals are unregistered. How people self-identify can complicate matters, as many Burmese living outside of the camps do not self-identify as refugees, but often express reasons for leaving Burma that relate to conflict or the consequences of fighting - the informal Thai refugee determination criteria (Human Rights Watch, 2012). They may present 
themselves as migrant workers rather than as refugees in order to work and move freely. In the wake of the May 2014 military coup, immigration measures in the country were tightened and the policy restricting the movement of undocumented people in border areas was implemented more strictly (UNHCR, 2015c).

6 Currently, the strategic use of resettlement focuses on seven key situations/places identified by the UNHCR (2015d): 1) Kenya; 2) the Islamic Republic of Iran; 3) Pakistan; 4) Turkey; 5) Syria, Jordan and Lebanon; 6) the Colombian refugee situation; and 7) the Congolese (DRC) refugee situation.

7 The countries currently offering resettlement programmes include, in alphabetical order: Argentina, Australia, Austria, Belarus, Belgium, Brazil, Bulgaria, Canada, Chile, Czech Republic, Denmark, Finland, France, Germany, Hungary, Iceland, Italy, Ireland, Japan, Republic of Korea, Liechtenstein, Luxembourg, Netherlands, New Zealand, Norway, Paraguay, Portugal, Romania, Spain, Sweden, Switzerland, the United Kingdom, Uruguay and the USA. As of December 2016, the UNHCR has noted that there are now 37 countries that offer resettlement programmes.

8 The World Bank (2016) projected that worldwide remittances would reach $\$ 601$ billion in 2016 (\$635 billion in 2017) and that remittances to developing countries would surpass $\$ 453$ billion in 2016, up from $\$ 441$ billion in 2015.

9 Many resettlement programmes are in a state of flux due to national and international developments relating to elections, referendums and populist pressures. The associated brief summaries of the countries that follow are correct up to the end of 2016.

10 The number of refugees that the US intends to resettle is unclear under the Trump administration, which has issued an executive order to temporarily halt the intake of refugees and more than halve its current annual commitment.

11 See Pew Research website: www.pewresearch.org/fact-tank/2016/06/17/where-refugeesto-the-u-s-come-from/\#

12 A sponsor who arrived as an 'illegal maritime arrival' after 13 August 2012 is not eligible to sponsor a person. Note the alternative language the government uses to describe an asylum seeker.

13 Papua New Guinea's Supreme Court ruled on 26 April 2016 that the agreement between the Australian and PNG governments to detain asylum seekers on Manus Island was illegal.

14 In Sweden, there has been a backlash fuelled by changing sentiments over the influx of migration, reflected in the rise of right-wing parties and anti-immigration policies. The Swedish government declared in December 2015 that the large number of migrants claiming asylum was a 'serious threat to public order and domestic security', implementing new legislation in a reversal of its open border policy in the form of identity checks at the border with Denmark and turning back anyone without valid identification. Denmark has recently stepped up border controls, including temporarily stopping rail travel, along their border with Germany in an attempt to slow migration. The Denmark Liberal Party formed a minority government in June 2015 and has actively been dissuading asylum seekers by cutting benefits and it recently announced a bill to enable the searching of luggage and seizing of money and valuables to fund welfare. When asylum seekers started entering Norway by crossing the Russian-Norwegian border, the Norwegian government threatened to charge anyone who helped them with human trafficking and has started deporting any who have had their claim rejected.

15 The Schengen Zone is composed of 26 countries, most of which are part of the European Union, that allow people to cross borders without a passport and between which there is no formal border control. Some of these controls, however, have been reinstated with the recent mass migrations into Europe predominantly from Syria, Afghanistan and Eritrea. Recent examples in 2016 include Denmark, which stepped up border controls with Germany in response to an influx of people seeking protection. Sweden and Norway have also followed suit. Austria, Germany and France have also reintroduced some border controls since November 2015 in response to the terrorist attacks in Paris. 
Fences along the central and southern borders of the Schengen Zone have also been erected. The Dublin Regulation is a European Union law that basically establishes that the country in which an asylum seeker first applies for refugee status/protection is the country responsible for either accepting or rejecting asylum. Also referred to as the Dublin Convention, this law is increasingly being questioned regarding its fairness because it places disproportionate pressure and obligation on those states closest to the migratory movements of mass populations (for instance, countries such as Greece and Italy).

16 Detractors have noted that the proposed lifetime ban on refugees in offshore detention centres from entering Australia runs contrary to international law and refugee conventions. As of November 2016, the federal opposition (Labour Party) has voted unanimously to reject the legislation.

17 The term diaspora was originally used to refer to forced dislocation associated with the Jewish, Armenian and Palestinian experiences of persecution. Contemporary and historical examples of such diasporas developing out of forced migration circumstances are now numerous and some even claim that the usage around diaspora is so loosely employed that it has lost much of its analytic power (Faist, 2010). These multiple understandings are due, in part, to the various forced and voluntary experiences of many groups. It also relates to the awareness that people now migrate and situate themselves 'in place' differently from how diasporas might have occurred historically. These differences have largely arisen due to new forms of mobility (physical and digital) and more circular forms of exchange where new migrant categories have emerged, as previously discussed.

18 The new stories emerging of the promise of particular therapies (almost exclusively Western-informed) are thriving in Europe and provide feel-good stories of traumatized refugees being released from their pain and able to contribute to society. This book will emphasize (while not discounting the potential of such approaches to heal some) is that the lived experiences of discrimination and exclusion inhibit particular groups' indigenous knowledges and pathways to healing. Thus, I will present a structural critique that informs both community-based and clinical work with refugees that broadens the scope in the ways that people can work towards meaning-making and recovery.

\section{References}

Ager, A. \& Strang, A. (2008) Understanding integration: A conceptual framework. Journal of Refugee Studies, 21(2): 166-91. doi:10.1093/jrs/fen016

Akuei, S. (2005) Remittances as unforeseen burdens: The livelihoods and social obligations of Sudanese refugees. Retrieved from: www.refworld.org/docid/42ce4d354.html

Amnesty International (2016) Facts about refugee resettlement in New Zealand. Retrieved from: www.amnesty.org.nz/sites/.../family_reunification_fact_sheet.pdf

Anderson, B. (2006) Imagined communities: Reflections on the origin and spread of nationalism. London: Verso Books.

Arendt, H. (1943) We refugees. Menorah Journal, 31(1): 69-77.

Australian Government (2016) Annual report 2015-16. Retrieved from: www.border.gov. $\mathrm{au} /$ about/reports-publications/reports/annual/annual-report-2015-16

Baldassar, L., Baldock, C. \& Wilding, R. (2007) Families caring across borders: Migration, ageing and transnational caregiving. New York: Palgrave.

Baldassar, L. \& Wilding, R. (2013) Middle-class transnational caregiving: The circulation of care between family and extended kin networks in the global north. In L. Baldassar \& L. Merla (eds), Transnational families, migration and the circulation of care: Understanding mobility (pp. 235-52). London: Routledge. 


\section{Transnational settlement}

Basch, L., Schiller, N. G. \& Blanc, C. S. (1994) Nations unbound: Transnational projects, postcolonial predicaments and deterritorialized nation-states. Amsterdam: Gordon \& Breach Science Publishers.

Beck, U. \& Beck-Gernsheim, E. (2014) Distant love. Cambridge: Polity Press.

Betts, A. (2013) Survival migration: Failed governance and the crisis of displacement. Ithaca, NY: Cornell University Press.

Bhabha, H. (1990) Nation and narration. London: Routledge.

Bhabha, H. (1994) The location of culture. London: Routledge.

Blunt, A. (2007) Cultural geographies of migration: Mobility, transnationality and diaspora. Progress in Human Geography. doi:10.1177/0309132507078945

Bogen, R. \& Marlowe, J. (2015) Asylum discourse in New Zealand: Moral panic and a culture of indifference. Australian Social Work, 1-12. doi:10.1080/0312407X.2015.1076869

Boutruche, S., Lyamouri-Bajja, N. \& Bourgeois, S. (2008) Raising young refugees'voices in Europe and beyond. Retrieved from: https://book.coe.int/eur/en/youth-otherpublications/3996-raising-young-refugees-voices-in-europe-and-beyond.html

Brickell, K. \& Datta, A. (2011) Translocal geographies. London: Ashgate Publishing.

Briskman, L., Latham, S. \& Goddard, C. (2008) Human rights overboard. Melbourne, VIC: Scribe Publications.

Calhoun, L. G. \& Tedeschi, R. G. (2014) Handbook of posttraumatic growth: Research and practice. London: Routledge.

Casella Colombeau, S. (2015). Policing the internal Schengen borders - Managing the double bind between free movement and migration control. Policing and Society, 1-14. doi:10.1080/10439463.2015.1072531

Castells, M. (2013) Networks of outrage and hope: Social movements in the Internet age. New York: John Wiley \& Sons.

Castles, S., de Haas, H. \& Miller, M. J. (2014) The age of migration: International population movements in the modern world (5th edn). New York: Guilford Press.

Center for Excellence in Disaster Management \& Humanitarian Assistance (2015) Retrieved from: http://reliefweb.int/sites/reliefweb.int/files/resources/disaster-mgmt-refhdbk-2015-thailand.pdf

Cienfuegos, A. \& Monelli, C. (1983) The testimony of political repression as a therapeutic instrument. American Journal of Orthopsychiatry, 53(1): 43-51.

Colic-Peisker, V. \& Tilbury, F. (2003). 'Active' and 'passive' resettlement: The influence of support services and refugees' own resources on resettlement style. International Migration, 41(5): 61-91.

Colic-Peisker, V. \& Tilbury, F. (2006) Employment niches for recent refugees: Segmented labour market in twenty-first century Australia. Journal of Refugee Studies, 19(2): 203-29. doi:10.1093/jrs/fej016

Collins, F. L. (2009) Connecting 'home' with 'here': Personal homepages in everyday transnational lives. Journal of Ethnic and Migration Studies, 35(6): 839-59. doi:10.1080/13691830902957668

Crawley, H., Duvell, F., Sigona, N., McMahon, S. \& Jones, K. (2016) Unpacking a rapidly changing scenario: Migration flows, routes and trajectories across the Mediterranean. Retrieved from: www.medmig.info/research-brief-01-unpacking-a-rapidly-changingscenario/

Diener, A. C. \& Hagen, J. (2012) Borders: A very short introduction (Vol. 328). Oxford: Oxford University Press.

Docherty, B. \& Giannini, T. (2009) Confronting a rising tide: A proposal for a convention on climate change refugees. Harvard Environmental Law Review, 33: 349-403. 
Elliott, A. \& Urry, J. (2010). Mobile lives. Abingdon: Routledge.

Esnard, A.-M. \& Sapat, A. (2016) Transnationality and diaspora advocacy: Lessons from disaster. Journal of Civil Society, 12(1): 1-16. doi:10.1080/17448689.2015.1114737

Faist, T. (2010) Diaspora and transnationalism: What kind of dance partners? In R. Baubock \& T. Faist (eds) Diaspora and transnationalism: Concepts, theories and methods (pp. 9-34). Amsterdam: Amsterdam University Press.

Fiske, L. \& Briskman, L. (2016) Creating criminals: Australia's response to asylum seekers and refugees. In R. Furman, G. Lamhear \& D. Epps (eds) The Immigrant Other: Lived experiences in a transnational world (pp. 225-39). New York: Columbia University Press.

Frankl, V. (1964) Man's search for meaning: An introduction to logotherapy. London: Hodder \& Stoughton.

Gale, P. (2004) The refugee crisis and fear: Populist politics and media discourse. Journal of Sociology, 40(4): 321-40. doi:10.1177/1440783304048378

Gale, P. (2005) The politics of fear: Lighting the Wik. Frenchs Forest, NSW: Pearson Education Australia.

Goulbourne, H., Reynolds, T., Solomos, J. \& Zontini, E. (2010) Transnational families: Ethnicities, identities and social capital. London: Routledge.

Harris, V. \& Marlowe, J. (2011) Hard yards high hopes: The educational challenges of African refugee students in Australia. International Journal of Teaching Learning and Higher Education, 23(2): 186-96.

Human Rights Watch (2012) Ad hoc and inadequate: Thailand's treatment of refugees and asylum seekers. Retrieved from: www.hrw.org/sites/default/files/reports/thailand0912.pdf

IOM (2016) 2015 Global migration trends: Factsheet. Retrieved from: http://iomgmdac. org/global-trends-2015-factsheet/

Kasparek, B. (2016) Complementing Schengen: The Dublin System and the European border and migration regime. In H. Bauder \& C. Matheis (eds) Migration policy and practice: Interventions and solutions (pp. 59-78). New York: Palgrave Macmillan.

Kissau, K. \& Junger, U. (2010) The internet as a means of studying transnationalism and disapora. In R. Baubock \& T. Faist (eds) Diaspora and transnationalism: Concepts, theories and methods (pp. 245-65). Amsterdam: Amsterdam University Press.

Klocker, N. \& Dunn, K. (2003) Who's driving the asylum debate? Newspaper and government representations of asylum seekers. Media International Australia, 109: 71-92.

Landale, N. S., Oropesa, R. S. \& Bradatan, C. (2006) Hispanic families in the United States: Family structure and process in an era of family change. In M. Tienda \& F. Mitchell (eds) Hispanics and the future of America (pp. 138-78). Washington, DC: National Academies Press.

Leung, L. (2011) Taking refuge in technology: Communication practices in refugee camps and immigration detention. Retrieved from: www.refworld.org/docid/4d88757f2.html

Levitt, P. (2001) The transnational villagers. Los Angeles, CA: University of California Press.

Levitt, P. \& Jaworsky, B. N. (2007) Transnational migration studies: Past developments and future trends. Annual Review of Sociology, 33(1): 129-56. doi:doi:10.1146/annurev. soc. 33.040406 .131816

Levitt, P. \& Schiller, N. G. (2004) Conceptualizing simultaneity: A transnational social field perspective on society. The International Migration Review, 38(3): 1002-39.

Levy, P. (1996) If this is a man. London: Vintage.

Licoppe, C. (2004) 'Connected' presence: The emergence of a new repertoire for managing social relationships in a changing communication technoscape. Environment and Planning D: Society and Space, 22(1): 135-56. doi:10.1068/d323t 
Lindley, A. (2007) The early morning phonecall: Remittances from a refugee diaspora perspective. Oxford: Centre on Migration, Policy and Society, University of Oxford.

Long, K. (2014) Rethinking 'durable' solutions. In E. Fiddian-Qasmiyeh, G. Loescher, K. Long, \& N. Sigona (eds) The Oxford handbook of refugee and forced migration studies (pp. 475-87). Oxford: Oxford University Press.

Lundborg, P. (2013) Refugees' employment integration in Sweden: Cultural distance and labor market performance. Review of International Economics, 21(2): 219-32. doi:10.1111/roie.12032

McNevin, A. (2014) Forced migration in Australia, New Zealand, and the Pacific. In E. Fiddian-Qasmiyeh, G. Loescher, K. Long \& N. Sigona (eds) The Oxford handbook of refugee and forced migration studies (pp. 639-49). Oxford: Oxford University Press.

Madianou, M. \& Miller, D. (2013) Migration and new media: Transnational families and polymedia. London: Routledge.

Mahony, C., Marlowe, J., Humpage, L. \& Baird, N. (2017) Aspirational yet precarious: Compliance of New Zealand refugee settlement policy with international obligations. International Journal of Border and Migration Studies, 3(1): 5-23. doi:10.1504/ IJMBS.2017.081176

Malkki, L. (1992) National geographic: The rooting of peoples and the territorialization of national identity among scholars and refugees. Cultural Anthropology, 7(1): 24-44.

Margalit, A. (2002) The ethics of memory. New York: Harvard University Press.

Marlowe, J. \& Elliott, S. (2014) Global trends and refugee settlement in New Zealand. Kōtuitui: New Zealand Journal of Social Sciences Online, 9(2): 43-49. doi:10.1080 /1177083x.2014.953186

Martin, S. (2014) Forced migration in North America. In E. Fiddian-Qasmiyeh, G. Loescher, K. Long \& N. Sigona (eds) The Oxford handbook of refugee and forced migration studies (pp. 677-89). Oxford: Oxford University Press.

Mortensen, A., Rainger, W. \& Hughes, S. (2012) Refugee health care: A handbook for professionals. Retrieved from: www.health.govt.nz/publication/refugeehealth-care-handbook-health-professionals

Ong, A. (2006) Mutations in citizenship. Theory, Culture and Society, 23(2-3): 499-505.

Perkins, H. \& Thorns, D. C. (2011) Place, identity and everyday life in a globalizing world. New York: Palgrave Macmillan.

Polzer, T. (2008) Invisible integration: How bureaucratic, academic and social categories obscure integrated refugees. Journal of Refugee Studies, 21(4), 476-97. doi:10.1093/jrs/ fen038

Pupavac, V. (2008) Refugee advocacy, traumatic representations and political disenchantment. Government and Opposition, 43(2): 270-92.

Robertson, Z., Wilding, R. \& Gifford, S. (2016) Mediating the family imaginary: Young people negotiating absence in transnational refugee families. Global Networks, 16(2), 219-36. doi:10.1111/glob.12111

Rosseau, C. \& Measham, T. (2007) Posttraumatic suffering as a source of transformation: A clinical perspective. In L. Kirmayer, R. Lemelson \& M. Barad (eds) Understanding trauma: Integrating biological, clinical, and cultural perspectives (pp. 275-93). New York: Cambridge University Press.

Rutter, M. (2012) Resilience as a dynamic concept. Development and Psychopathology, 24(02): 335-44. doi:doi:10.1017/S0954579412000028

Schiller, N. G., Basch, L. \& Blanc, C. S. (1995) From immigrant to transmigrant: Theorizing transnational migration. Anthropological Quarterly, 68(1): 48-63. doi: $10.2307 / 3317464$ 
Schweitzer, R. (2015) A stratified right to family life? On the logic(s) and legitimacy of granting differential access to family reunification for third-country nationals living within the EU. Journal of Ethnic and Migration Studies, 1-19. doi:10.1080/13691 $83 X .2015 .1037256$

Smith, A. D. (2013). Nationalism. Cambridge: Polity Press.

Swedish Migration Agency (2016) Statistics for 2015. Retrieved from: www.migrationsverket. se/English/About-the-Migration-Agency/Facts-and-statistics-/Statistics/2015.html

UNHCR (2013) United Kingdom Country Chapter. UNHCR Resettlement Handbook, June 2013 revision. Geneva: United Nations High Commissioner for Refugees.

UNHCR (2014a) Country chapter: United Kingdom of Great Britain and Northern Ireland. Retrieved from: www.unhcr.org/40ee6fc04.html

UNHCR (2014b) Country chapter: Australia Resettlement Handbook. Geneva: United Nations High Commissioner for Refugees. Retrieved from: www.unhcr.org/protection/ resettlement/4a2ccf4c6/unhcr-resettlement-handbook-country-chapters.html

UNHCR (2014c) Country chapter: Denmark. Retrieved from: www.unhcr.org/3c5e57b07.html

UNHCR (2015a) Chapter 3: Durable solutions and new displacement. Retrieved from: Geneva: www.unhcr.org/566584fc9.html

UNHCR (2015b) Mid year trends. Retrieved from: www.unhcr.org/56701b969.html

UNHCR (2015c) Thailand global appeal 2015. Retrieved from: www.unhcr.org/5461e60b17. html

UNHCR (2015d) UNHCR Global appeal 2014-2015: Finding durable solutions. Retrieved from: Geneva: www.unhcr.org/pages/49c3646cf8.html

UNHCR (2015e) UNHCR global resettlement statistical report 2014. Retrieved from: www.unhcr.org/pages/4a16b1676.html

UNHCR (2016a) Global trends: Forced displacement in 2015. Retrieved from: www.unhcr.org/globaltrends/

UNHCR (2016b) Regional refugee and migrant response plan for Europe. Eastern Mediterranean and Western Balkans Route. January-December 2016. Retrieved from: www.refworld.org/docid/56a9e5134.html

United States Department of State (2015) Refugee resettlement in the United States. Retrieved from: www.state.gov/r/pa/pl/249076.htm

Urry, J. (2007) Mobilities. Cambridge: Polity Press.

Valenti, S. S. \& Gold, J. M. M. (1991) Social affordances and interaction I: Introduction. Ecological Psychology, 3(2), 77-98. doi:10.1207/s15326969eco0302_2

Valtonen, K. (2008) Social work and migration: Immigrant and refugee settlement and integration. Farnham: Ashgate Publishing.

Van Hear, N. (2003) From durable solutions to transnational relations: Home and exile among refugee diasporas (Working Paper No. 83). Retrieved from: www.unhcr.org/ 3e71f8984.pdf

Van Hear, N. (2014) Refugees, diasporas, and transnationalism. In E. Fiddian-Qasmiyeh, G. Loescher, K. Long \& N. Sigona (eds) The Oxford handbook of refugee and forced migration studies (pp. 176-87). Oxford: Oxford University Press.

Vertovec, S. (2009) Transnationalism. London: Routledge.

Wahlbeck, Ö. (2002) The concept of diaspora as an analytical tool in the study of refugee communities. Journal of Ethnic and Migration Studies, 28(2): 221-38. doi:10.1080/ 13691830220124305

Wellman, B., Quan-Haase, A., Boase, J., Chen, W., Hampton, K., Díaz, I. \& Miyata, K. (2003) The social affordances of the internet for networked individualism. Journal of Computer-Mediated Communication, 8(3). doi:10.1111/j.1083-6101.2003.tb00216.x 


\section{Transnational settlement}

Wilding, R. (2006) Virtual intimacies? Families communicating across transnational contexts. Global Networks: A Journal of Transnational Affairs, 6(2): 125-42.

Wilding, R. (2012) Mediating culture in transnational spaces: An example of young people from refugee backgrounds. Continuum, 26(3): 501-11. doi:10.1080/10304312.2012.665843

Wimmer, A. \& Schiller, N. G. (2003) Methodological nationalism, the social sciences, and the study of migration: An essay in historical epistemology. International Migration Review, 37(3): 576-610. doi:10.2307/30037750

Winter, E. (2007) How does the nation become pluralist? Ethnicities, 7(4): 483-515. doi:10.1177/1468796807084014

World Bank (2016) Migrations and remittances factbook 2016. Retrieved from: www.worldbank.org/en/topic/migrationremittancesdiasporaissues

Zetter, R., Griffiths, D. \& Sigona, N. (2006) Immigration, social cohesion and social capital: What are the links? Oxford: Joseph Roundtree Foundation. 


\section{Belonging \\ Everyday and extraordinary \\ conceptualizations}

\section{Introduction}

A Somali woman who migrated to the United States as a refugee flies into New York where she has lived for more than twenty years. Upon seeing the Statue of Liberty, the city's skyline and harbour, she immediately feels a sense of belonging and of home. Thirty minutes later, an immigration official singles her out of the arriving passengers to enquire about her activities and whereabouts because her profile matches one of constructed risk. After thirty minutes of questions and knowing that thousands of other people have effortlessly walked through these security checks, she doubts if she ever belonged and that any other sentiment was based on falsehoods. Once she arrives home and interacts with the people living around her, a sense of belonging is restored. Several days later, her eldest child sends a text message stating 'hello and what's up?' for the first time in English, a language in which she still lacks full confidence to communicate. She is suddenly overwhelmed with concern about keeping her children connected to the Somali language and its related customs and traditions - an association to which she has always felt a strong bond and spiritual connection. She then questions if her belonging in New York is in some ways a betrayal of her past and she emails several relatives who are based in Nairobi asking if they can Skype some time soon. The next day, her neighbours of five years invite the family for dinner and such concerns seem to dissipate as the evening progresses.

What is clear in this example is that it is possible to belong and not belong at similar times and such sentiments can be relatively stable or ephemeral. Belonging has gendered, spatial, relational, technological, age-related and cultural dimensions (among others). It is a term that people can easily relate, and yet find difficult to define on conceptual and affective levels.

This chapter frames the second major question of this book: how does an understanding of belonging in relation to the sociology of the everyday and the extraordinary provide insight to the experience of meaningful transnational settlement? The notions of the everyday and extraordinary arise from Bourdieu's (1988) critique that the examination of difference has a tendency to present sensationalist accounts of people's experiences or practices that reify particular understandings and discourses. By following his suggestion of exoticizing the 


\section{Belonging}

domestic (discussed in the next section), this chapter elevates the status of the everyday alongside, rather than subsuming, the extraordinary. I approach this task first by unpacking what is understood by belonging in the migration literature and position this concept as a personal experience that simultaneously occurs within socio-spatial forms of inclusion and exclusion. This examination requires an analysis of the intersectionality of people's social locations, identities and the domains of power that define the ways in which belonging is supported, created and constrained. The focus on power relations is important and introduces the political projects that inform belonging through both recognition and misrecognition. The interplay between belonging and its associated politics thereby provides the basis to consider the ways in which everyday and extraordinary representations influence the lived experiences of refugee settlement. ${ }^{1}$

\section{Rendering concepts 'newly strange': the everyday and extraordinary}

There is clearly value in knowing about the hardships encountered through forced migration as it gives voice to and, at times, justifies interventions into the lived experiences of oppression and injustice. Written between the lines of such adverse and traumatic events, however, are refugees' responses and stories of supporting one another, remembering and living by their culture and parents' teachings, maintaining hope and following particular histories and traditions that provide opportunities for survival, growth and meaning-making. These understandings are often less well known or privileged when placed against experiences of profound suffering.

Within this book, I maintain that people's responses to extraordinary events are often grounded within the everyday understandings of one's history, spirituality, culture, background, folklore, etc. This distinction is inspired by Bourdieu's (1988, p. xii) discussion of rendering familiar perspectives newly strange. He suggested that this approach could be achieved through 'exoticizing the domestic' that reconsiders preconceived concepts and ideas outside what is routinely thought and imagined:

The sociologist who chooses to study his own world in its nearest and most familiar aspects should not ... domesticate the exotic, but, if I may venture the expression, exoticize the domestic, through a break with his initial relation of intimacy with modes of life and thought which remain opaque to him because they are too familiar. In fact the movement towards the originary, and the ordinary, world should be the culmination of a movement towards alien and extraordinary worlds.

(Bourdieu, 1988, p. xii, italics added)

Bourdieu used this term to address the concern of taking the exotic or most sensational and engaging aspects about a group of people and rendering these 
observations as 'domestic' or everyday understandings of them - a process that he referred as 'domesticating the exotic'. The ways in which the media refer to asylum seekers as 'boat people' or the ways that Syrians are predominantly understood being through the lens of war trauma are just two current examples. The politics of fear that ties Islam to terrorism is another that then creates unfounded archetypes of people, religions and cultures in numerous resettlement localities.

To counteract this tendency of domesticating or reifying the exotic, Bourdieu suggests that taking the domestic elements of people's lives and making them exotic was a way to transform the familiar as strange and hence make it possible to critically engage previously unquestioned assumptions or concepts anew. This perspective can be more easily understood within forced migration contexts as placing greater emphasis upon understanding a person's life beyond their ascribed refugee status and the associated traumatic experiences resulting from forced migration. In this book, the exotic and domestic terminologies are not used, recognizing the associated multiple and contested meanings particularly from an anti-oppressive lens and its gendered usage. Rather, I emphasize the terms extraordinary and everyday to delineate different aspects that characterize representations of refugees' lives.

I refer to understandings of the everyday in a non-pejorative sense to conceptualize the commonplace experiences of refugee settlement that include education, employment, housing, community relations and other routine practices. These everyday aspects often escape critical examination because such activities and commitments are viewed as mundane and are generally shared with the wider society. This is not to say that I am equating everyday with good and extraordinary with bad. While often referenced in a negative light, extraordinary experiences also relate to events of a more empowering and positive nature that increase people's sense of well-being - possibly through spiritual, social, cultural and/or other pathways. And illustrating the relationship between the two, extraordinary practices and experiences that were once deemed mentionable and memorable may now be incorporated into the everyday. In many ways, the Vietnamese communities that were resettled from the mid-1970s to the United States, across Europe, Australia and elsewhere are no longer predominantly viewed as refugees by the wider society. Similar things could be said of Cambodians who resettled from 1975 to the 1990s as refugees after fleeing the Khmer Rouge and Cambodia's associated later instability. For other groups, however, the refugee label as an extraordinary descriptor is one more difficult to disassociate, either by choice or as an ascribed master status. Over the course of this book, I will look to examine the subtleties of these terms and importantly, who gets to define a particular experience, practice or history as everyday or extraordinary.

It is not my intent, therefore, to bifurcate everyday and extraordinary experiences as both are interrelated with positive and negative dimensions. In fact, the impacts of everyday racism can be so powerful and ingrained into the practices of a particular society and its institutions that such experiences also go unnoticed 
(Hällgren, 2005; Van Dijk, 2015). Berger and Luckman (1966) acknowledged this trend as the 'taken-for-grantedness of everyday life'.

When engaging with these terms, it is necessary to critique what comprises the everyday or the extraordinary for refugees - whether this focus relates to forced migration and/or settlement. The academic and popular literature is awash with evidence of living situations in unsafe and insecure environments that include refugee camps, urban places of displacement and other precarious circumstances. Some people may have lived in these camps and urban centres for decades, creating questions over what actually comprises the everyday or the extraordinary. The UNHCR (2016) states that a 'protracted situation' is one where more than 25,000 people from the same nationality are forcibly living in a given asylum country for five years or more. In 2015, there were more than 6.7 million in this situation representing an increase of 300,000 from the previous year. In total, the UNHCR (2016) notes that there are 32 protracted situations around the world in sites across 27 countries. Eleven of these situations extend beyond 30 years.

For instance, there are Afghan refugees who have lived in Pakistan and Iran for more than three decades (UNHCR, 2016). In 1991, the UNHCR established the Dadaab refugee camp intending to accommodate 90,000 people in Northeast Kenya in response to the Somali civil war. Today, it is the largest camp in the world and hosts more than 300,000 people. The Colombian conflict, which has lasted more than five decades, represents the longest running war in the Western hemisphere with estimated displacements of 7 million people internally and 360,000 across the country's borders (Gottwald \& Rodríguez Serna, 2016). ${ }^{2}$ These protracted situations, among many others, highlight the ways in which others can thrust meaning and associated labels on such experiences (i.e. it is extraordinary, traumatic, sensational, etc.).

Thus, there is a need to position who is classifying a particular situation, routine or experience as the everyday or extraordinary. Obviously, this awareness requires a reflexivity and responsiveness to my own assumptions that inform such terms in writing this book and the case studies that inform it. It might very well be that the circumstances of life in a refugee camp or the insecurity of living illegally in another country could be seen as extraordinary to someone who has not shared similar circumstances. For the person or community whose narrative arises from such experiences, however, they may not necessarily see it as so.

\section{A concurrent everyday and extraordinary analysis}

The book's explicit, everyday focus is a response to the politics of representation that generally portray people from refugee backgrounds on the most sensational aspects of a person's life that emphasizes the extraordinary often in relation to significant trauma arising from the 'refugee journey'. Thus, I refer to the extraordinary to outline experiences that often sit beyond the everyday and which are not necessarily shared by the wider society. A predominant focus upon the extraordinary privileges stories of forced migration over the everyday considerations that arguably speak more to who people are over time and what they inherently value. 
In many respects, such narratives of oppression, trauma and significant adversity represent a powerful currency that helps refugees lay their claims for recognition. This recognition, while granting some benefits and resources to refugees, can also impede their integration and participation within a wider society through extraordinary representations of them. As I will further argue in Chapter 3, where trauma represents a powerful extraordinary frame that defines wider societal understandings of refugees, why would employers want to hire traumatized populations?

This critique of the extraordinary also relates to the ways that researchers develop particular study designs and how they choose to represent refugee issues. For instance, one could conclude from the edited book entitled Broken Spirits (Wilson \& Drozdek, 2004), that there is some inherent form of disability or damage in having acquired the refugee or asylum-seeker status - namely, that one is broken. In this book's Preface, Wilson and Drozdek (2004, p. xxvii) state: '[b]roken spirits is a metaphor for 40 million people worldwide who are victims of war, political oppression, and torture in all their insidious forms and humanly devised demonic variations'. While experiencing hardship, it is arguable that many of these 'victims' would directly challenge the accuracy of this sensationalized metaphor intended to describe them. The assumptions surrounding what is commonly referred to as the refugee journey, associated negative mental health outcomes arising from trauma and fears about resettling communities can become the grounds for myopically rendering them visible only as refugees, traumatized and the Other: a potent combination that often fosters unfounded stereotypes and discriminatory practices (Marlowe, 2013). Harrell-Bond (1999, p. 143) notes: '[r]ather than viewing themselves as heroes who have stood up to and escape[d] oppressive regimes, today many refugees are reluctant to admit their status. This reluctance speaks to the awareness of pervasive refugee discourses on traumatized individuals, social welfare dependence and undue burdens on an 'overly generous' society.

As noted in Chapter 1, this critique is not intended to marginalize and trivialize extraordinary experiences. In many respects, these understandings need to be honoured and dignified. It is also necessary to recognize that the extraordinary can relate to more positive experiences that help people respond to everyday events - this may include forms of spirituality, cultural practices, meaning systems, important histories and indigenous knowledges. This reality reflects the need to consider who is labelling any particular experiences as everyday or extraordinary and the associated politics that inform this. Throughout this book I maintain this concurrent analysis to critique who has a say in representing refugee-based experience and what is at stake through such representations. To achieve this, however, it is necessary to go beyond extraordinary experiences to consider the ways that the everyday is interrelated with the journeys associated with forced migration and settlement.

\section{Elevating the everyday alongside the extraordinary}

The interest in examining the everyday aspects of people's lives, which have also been referred to as the mundane, ordinary, routine, unremarkable or even banal, 
is now fairly established and growing. The literature suggests a general consensus that an everyday focus has to do with the less sensational and often uncritical aspects of people's lives, and which provide insight and authenticity to sensory, mobile, embodied and mediated experiences (Pink, 2012). These everyday aspects often escape conscious examination or critique when placed next to sensationalized accounts. When elevated from pejorative understandings, everyday stories can help appreciate people outside the refugee label and realize where they have drawn strength during their resettlement and forced migration journeys. As Neal and Murji (2015) highlight, there is a value in raising the status of the everyday as it is 'dynamic, surprising and even enchanting; characterized by ambivalences, perils, puzzles, contradictions, accommodations and transformative possibilities ... everyday life can be thought of as providing the sites and moments of translation and adaption' (p. 811). While recognizing the importance of the extraordinary, this book addresses the significance of elevating the everyday alongside the sensational stories of forced migration often represented through a trauma-focused narrative.

Others have written about the importance of avoiding the further bifurcation and separation between the everyday and extraordinary (Hall, 2015; Neal \& Murji, 2015; Robinson, 2015). Robinson (2015), for instance, notes the transformative capacities of the everyday in people's lives in relation to navigating adverse circumstances. I have previously argued how ordinary stories inform people's responses to extraordinary experiences of trauma, a focus for the next chapter (Marlowe, 2010). What is clear is that there is a need to juxtapose and consider the 'everyday life micropublics' or the ways in which difference and diversity come together in shared public spaces (Valentine et al., 2008).

This focus relates to Amin's (2002) writing about how the negotiation of difference is often situated and best understood through local everyday encounters where identities are seen as agonistic and fluid. Billig's (1995) seminal work on banal nationalism highlights how migration makes events and practices that were once interwoven into the fabric of previous, everyday, lived experience worth actively remembering in a new host society. The embodiment of particular cultural markers such as clothing, enactment of rituals, childhood games and food production are examples whereby these commonplace symbols reinforce (and construct) national identities in largely unnoticed ways because they are embedded in everyday life. However, the notions of the everyday and extraordinary (or the domestic and the exotic) must consider the relationships between narrator and audience as it is possible that what outsiders may define as extraordinary can be perceived as the everyday for those with such lived experiences, and vice versa. While initially I position understandings of trauma and significant adversity within an extraordinary frame, I do so only to obtain a starting position to engage with the complexities between these designations. It is often in the grey spaces between such binaries (migrant/refugee, insider/outsider, everyday/extraordinary) that the most interesting social science questions and understandings arise.

It is also important to recognize that extraordinary practices can eventually become inculcated into the everyday. The initial experience of forced migration, 
for instance, may be seen initially as an extraordinary event but protracted refugee situations clearly illustrate how these situations translate into everyday lives. The speed at which the 'internet of things' (devices embedded with network connectivity that collect and exchange data) has pervaded the everyday is another powerful example of this shift. From mobile phones, wearable technologies such as smart watches, health-related applications and countless social media platforms, the various ways that technology is integrated into social lives heralds new ways that people practice social relationships.

The ways in which superdiversity (Vertovec, 2007) has become prevalent in urban societies also highlights how difference can be integrated into everyday spaces and interactions. Cities such as New York, London, Toronto, Sydney and Auckland are just a few examples whereby the intersections of multiple ethnic groups, religious affiliations, various civil society attachments and high levels of migration and labour market experiences represent a 'diversification of diversity'. These trends, of course, are not without problems and contestations - this is nowhere more apparent than in the contexts of the current refugee 'crisis' where millions of people have crossed international borders.

Rather than placing the everyday and extraordinary at opposite ends of a spectrum, I use these terms as tools to problematize and conceptually orient uncritical approaches and understandings of refugee settlement. As this book will demonstrate, it is necessary to identify who has a predominant say in characterizing particular experiences as everyday or extraordinary as these perceptions influence the opportunities that refugees have to participate as peers in civil society. The construction of the wider narratives around forced migration and refugee resettlement through everyday and extraordinary understandings powerfully inform such possibilities. These dynamics highlight the interplay between various actors and institutions whereby some stories and discourses are privileged over others. These interactions and relationships influence the ways in which people belong, form identities and participate in civic life.

\section{Belonging and intersectionality}

Becoming a refugee, by definition involves geographic displacement, but refugees undergo social displacement as well ... even when refugee households remain intact, changes in human relationships almost always accompany the movement of people from one geographic location to another.

(Bascom, 1998, p. 130)

Returning to the Somali woman introduced at the start of this chapter, her experience of belonging was, at times, seemingly stable and fixed. Alternatively, it was fleeting, changeable and contradictory. Belonging has contested conceptualizations across different fields of study and often escapes critical examination because it is something people intimately identify but rarely need to define. In fact, Yuval-Davis (2011) argues that belonging is often only consciously 
articulated when it is under threat in some way. This means that, when belonging becomes an explicit concept, people can already be defensive about protecting it - at whatever levels it may be understood and embraced. It illustrates how migration can make deliberations on belonging visible and why the politics of fear can hold such powerful sway. One only has to look at the rise of right-wing, anti-immigration parties across Europe, statements about protecting the United States from refugees and undocumented migrants, and Australia's sordid history with asylum seekers to consider how representations of the Other can leverage significant populist support.

Within the refugee literature, the concept of belonging has become increasingly prominent although it still remains a relatively under-theorized concept (Bird et al., 2016; Correa-Velez et al., 2010; Fozdar \& Hartley, 2014; Wille, 2011). Yuval-Davis (2011) argues that belonging has powerful associations with notions of home, which requires an analysis of people's identities alongside various socio-political contexts. Antonsich (2010, p. 652) draws attention to the interaction between 'place-belongingness' and the 'politics of belonging' which include the interplay of people's subjective lived experiences, the opportunities for agency and an awareness of structural power (see also Chow, 2007; Sampson $\&$ Gifford, 2009). Antonsich's concern with some of the recent literature is that it has focused predominantly on the politics of belonging and power relations that has, at times, been conflated with belonging itself.

Focusing on place-belongingness, Antonsich (2010) relates it to the understandings of home and aligns it with a sense of familiarity and safety that may be defined on multiple levels and forms of identification. Belonging, in this sense, is embodied by particular foods, cultural traditions, religious practices, national borders and flags, familiar sounds, landscapes, shared creation myths and narratives that establish common forms of solidarity and purpose. These aspects may be represented within homes, neighbourhoods, communities or nations. Thus, belonging is a multi-scalar concept that occurs within a number of relational and situational contexts, which might seem relatively stable or might change over time (Morley, 2001). Antonsich (2010, pp. 647-8) provides six factors that contribute to a feeling of home:

- $\quad$ auto-biographical (past experiences and histories that attach person to place);

- $\quad$ relational (personal and social ties within given places);

- cultural (ways in language, traditions and practices connect to a sense of home);

- $\quad$ economic (importance of work to sustaining livelihood in place);

- legal (citizenship and other mechanisms through which people's opportunities to participate in society are defined);

- length of residence.

These factors are important in how refugees develop a sense of belonging that provides points of contact between various social groupings and institutions through the powers of memory, shared narratives and collective identification. In 
particular, I will illustrate the importance of belonging and the associated factors that embody it in Chapters 3 and 4 when presenting the ways that refugees define and respond to trauma and disaster-based events. Studies within various refugee resettlement countries provide examples of the above - in both a positive and negative sense (Capps et al., 2015; Correa-Velez et al., 2013; Steel et al., 2002). Thus, it is necessary to recognize the dynamic and transitional realities of people living in culture which impact on refugees and the receiving countries as well. These group identities are neither static nor monolithic and rather represent dynamic processes that connect people and institutions - some of which transcend national borders (Bird et al., 2016). Within this frame, it is possible to consider how people and groups may envisage home from local to transnational domains.

Numerous studies within the migration literature establish how notions of home are meaningfully created and sustained transnationally (Baldassar et al., 2007; Bhimji, 2008; Gifford \& Wilding, 2013; Robertson et al., 2016; Unger, 2012). The transnational and diaspora literature demonstrates that people are able to maintain meaningful contact and connection with important elements that constitute home and the homeland. For instance, there are numerous studies that illustrate how the Somali diaspora maintains transnational linkages through political, cultural and financial forms of exchange (Horst, 2006; Kleist, 2008). Other studies detail similar experiences for communities from South Sudan (Lim, 2009), Vietnam (Chamberlain \& Leydesdorff, 2004), Burma (Brees, 2010), Colombia (Bermudez, 2010), Bosnia (Al-Ali et al., 2001), and many others. These linkages and connections are supported through various communication technologies, social media, remittance flows, travel and access to web-based information.

As noted in the previous chapter, Gifford and Wilding (2013) suggest that increased mobilities and growing opportunities for digital interaction represent how refugees form community and belonging in new and innovative ways. Several authors have used the term ethno-portals to describe this phenomenon that allows for meaningful belonging across distance and the reinforcement of particular narratives (Stevens et al., 2005; Unger, 2012). While a window provides a certain insight or glimpse through to another perspective or place, portals suggest far more of a relational interaction and mobility between locations even if there is no physical crossing of borders or movement. For some, these portals represent preferred forms of interaction over daily face-to-face encounters.

Several studies have now documented the importance of these technologies for connecting refugees and asylum seekers in Europe with those back home (Allison, 2012; Rutkin, 2016). These digital platforms herald the multiple ways that technology is intimately tied (at times inseparably) to particular forms of belonging. Some refugees might rely on digital technologies as an escape from everyday experiences of racism. For others, ongoing transnational interactions might mean that they have limited commitment to local host society interactions. As Carruthers (2013) powerfully shows, there can be tensions between national 


\section{Belonging}

belonging, transnational commitments and hybrid identities as migrants craft a new existence that tries to simultaneously straddle both 'here' and 'there'.

What becomes clear within these interactions is that developing a sense of belonging is sourced from diverse experiences, histories, relationships, situations and localities. And these interactions occur within local, regional, national and transnational spaces. This is why Yuval-Davis (2006) emphasizes the need to consider belonging as the place where the sociology of emotion and the sociology of power meet. Belonging, in these respects, is intersectional. With strong roots in feminist-based literature, Yuval-Davis (2011, p. 6) metaphorically describes intersectionality as numerous road intersections 'with an indeterminate or contested number of intersecting roads, depending on the various users of the terms and how many social divisions are considered in the particular intersectional analysis'. This metaphor can easily be enriched to consider different road users, models of vehicles and roads that converge and diverge. The drivers on the road assume that others also understand the rules of the game such as stopping at red lights and knowing what particular signage represents. The roads are also regulated by particular laws and actively patrolled to ensure (at varying levels) that drivers follow these. There are rules that establish what is required to have a license and what constitutes a road-worthy vehicle. This system involves numerous actors and institutions that establish what is safe, acceptable and possible in a given situation. And, while many people might share the road, the interactions between users may be negligible except at particular points or destinations that connect people through common interests and relationships.

This intersectional perspective of belonging requires the recognition of the complex ecologies that inform it, which include intrapersonal and interpersonal interactions, cultural perspectives, economic conditions, legal underpinnings and shared societal understandings. Within this book, I utilize Yuval-Davis's (2006, 2011) three facets that construct belonging to examine how it impacts on transnational refugee settlement:

- $\quad$ social locations;

- $\quad$ people's identifications and emotional attachments; and

- $\quad$ ethical and political value systems that people judge their own and other's belonging.

These facets have close relationships with one another, but are not subsumable. Each facet has associated specific political projects whereby people's opportunities to belong are determined - at times in empowering and inclusive ways and exclusionary forms at others. An intersectional analysis between these three facets provides as Yuval-Davis (2011, p. 4) suggests, a basis that 'accounts for the social positioning of the social agent ... [whereby] situated gaze, situated knowledge and situated imagination construct how we see the world in different ways'. I expand upon the three facets of belonging as each relates to forced migration and settlement below to consider the important interplay of people's positions and relationships that exist within and beyond borders. Following Yuval-Davis, 
I discuss these three considerations separately while recognizing that these facets do not operate independently of each other. In the chapters that follow, the interaction between these facets (often situated in relation to particular political projects of belonging) provides a basis to recognize the possibilities and constraints of belonging for transnational settlement in multi-scalar ways.

\section{Social locations}

The social locations that people identify and associate (whether voluntary, achieved or ascribed) highlight that particular categories of identification intersect along numerous axes. Some of these locations might be stable and seemingly fixed, and others rapidly shifting, temporal and context-dependent. For instance, Yuval-Davis (2006) notes that some social locations are rigidly ascribed that allow for very little movement and freedom of association that include ethnicity, age, national affiliation and (at times) religion. Other locations have greater permeability that relate to linguistic capacities/identifications, class, sexuality and culture. And then there are broader categories of affiliation that allow greater movement (though not for all). These are associated with human rights, education, employment and other civic engagements afforded within a particular society (see also Antonsich, 2010; Benhabib, 2002). It is clear, however, that not all social locations are created equal.

Social locations are powerfully determined by various forms of difference. The associated relationships, which might be defined within religious, ethnic, gender or other categories, can easily be invisible to the outsider but powerfully dictate people's opportunities in participating in public and private life. These dynamics illustrate the important interplay between the everyday and the extraordinary that often define difference in relation to hegemonic forms of identification and privilege. Thus, the rigidity and ability of voluntary association with any particular social location is contextual as there are power relations within and across these particular identifications that may be defined across gender, age, religion and ethnicity among others.

While the exercise of power across particular social locations is a critical element to remain aware of, it is also necessary to recognize that hegemony also exists within communities and other forms of identification. In relation to this, Yuval-Davis cites McCall's (2005, p. 1777) critique of taking an intercategorical approach that considers the relationships across categories (gender, class, religion, etc.) without a strong enough emphasis on the intracategorical that examines the relationships within a category. For instance, refugees can be seen solely through an ethnic or gender-based lens that fails to appreciate the diversity and contestations that may occur within these categories. Intracategorical analyses can help unpack 'master categories' that often reify and label particular groups.

At the same time, taking either the generalized social location identifier of refugee or perhaps ethnicity can provide a helpful basis to examine other intercategorical relationships such as gender, age, class, education, rural/urban, religion, etc. This broader analysis can often achieve more powerful macro-structural 


\section{Belonging}

understandings in relation to wider levels/categories of difference. As I will show in Chapter 4, the ways in which the Afghan community responded to the 2011 Canterbury earthquakes in New Zealand were, in some ways, dependent on whether they identified as Hazara, Pastho or Tajik. Other identifications and affiliations were also relevant and include gender, age, educational background and people's transnational links - all of which informed the ways in which refugees experienced the earthquake as a disaster or not.

The awareness of multiple social locations is particularly important when thinking about refugee settlement, considering the fact that most refugees and other populations of concern are created by intra-country conflicts rather than external ones that are often defined across ethnic, cultural and/or religious identities (see UNHCR, 2013). To an outsider, they may assume that the terms Afghan, Burmese or Syrian suggest a cohesive community when, in fact, there may be some ethnic groups within a particular country that see another as being responsible for their forced migration experiences. The next section examines how particular social locations intersect with people's identities and social attachments as another key facet of belonging.

\section{Identifications and emotional attachments}

The Somali woman returning home to New York presented at the beginning of this chapter experienced affirmations and threats to her forms of belonging in a range of both predictable and unpredictable ways. When her sense of belonging through a particular identity (as a Somali, as an American, as a neighbour, as a mother) was either destabilized or reconstituted, she felt the powerful emotions and commitments of such attachments. As Deleuze (1995, p. 157) states: 'There's nothing more unsettling than the continual movement of something that seems fixed.' This brief vignette illustrates that these movements occur through lifecourse development, in relationships with family and friends, and the larger socio-political contexts in which settlement occurs. These identities and attachments are forged from local to international levels, sometimes in ways that are not of one's making or control.

The second facet of belonging that Yuval-Davis (2011) puts forward relates to the narratives people tell and associate that convey particular identifications and emotional attachments. The individual and collective identity narratives that arise function to explain and justify people's past, present and future trajectories. Numerous novels written by exiles capture this dynamic well (Deng et al., 2005; Levy, 1996; Reid \& Schofield, 2011). While these attachments may occur at individual-, family- and community-level interactions, they also play out powerfully at state and international levels. The previous Prime Minister of Australia, Tony Abbott, tried to suggest that everyone needed to join 'Team Australia' as a counter-terrorism narrative. This sporting metaphor was used to suggest that the Muslim community needed to get on board to help fight the threat of a terror attack. This highly criticized approach largely fed into the growing Islamophobia that is occurring in numerous Western countries that defines who is on the team, 
who is not and the invisible cultural capital that determines who is privileged to play (Briskman, 2015). Looking at a more international example, one only needs to consider Russia's annexation of Crimea and the debated discourses of belonging in the Ukraine to see how belonging can have deadly consequences. The role of NATO and other international players also highlights how politics can dangerously enter the fray that attempts to determine the ways in which particular discourses on belonging are sanctioned.

Linked with the first facet discussed above, the intersections of different social locations influence the various contexts in which people identify and feel they belong. As these narratives are contextualized between narrator and audience, people can develop strong emotional attachments to these stories, particularly if these are threatened in some way. In fact, Yuval-Davis (2011) argues that people's identity constructions and their associated emotional attachments become stronger and more consciously experienced as these are increasingly challenged.

People's emotional attachments and identifications are also not necessarily rigid. While some aspects and constructions of people's identities and affiliations are seemingly stable, these can also be subject to change and are determined by relational and contextual circumstances. Bhaba (1994, p. 309) defines this dynamic as a 'third space' or an 'in-between-ness' of culture that resides in the 'nervous temporality of the transitional'. Papastergiadis (2000, pp. 192-3) interprets this space as a constant movement between the foreign and familiar, but also emphasizes that this process does not create a boundless horizon or some type of infinity where limitless identities and associated narratives reside. Rather, he acknowledges that diasporic communities are often caught in a bind:

[The] experience of displacement is a testimony of loss and reconfiguration. To summon an identity of wholeness and continuity would be a denial of the violations and transformations that have led them to their present position, and yet to express the absences and contradictions of their identity would also undermine their claim to be recognized in the present.

(2002, p. 194)

The challenge of this bind can require a new engagement with one's social world that may include the performance of culture and roles defined through gender, age and other social positioning. This is where the recognition of multiple social locations in relation to identity narratives is so important. Having an awareness of the discursive meanings associated with culture, Benhabib's (2002) focus on the public manifestation of cultural identities within civic spaces provides a perspective to traverse beyond the dangers of reifying culture and developing a normative theory of cultural taxonomy and identity politics. Remaining mindful of the polysemic nature and usage of this word, she states: 
Any view of cultures as clearly delineable wholes is a view from the outside that generates coherence for the purposes of understanding and control. Participants in the culture, by contrast, experience their traditions through shared, albeit contested and contestable, narrative accounts. From within, a culture need not appear as a whole; rather, it forms a horizon that recedes each time one approaches it.

(2002, p. 5, emphasis added)

The perspective of horizons eschews developing essentialized notions of culture or other forms of identification. This focus again provides a justification for the further recognition of the everyday alongside the extraordinary to understand the ways that people's identity narratives and emotional attachments can shift depending on relational, spatial and situational contexts.

\section{Ethical and political value systems}

Multiple social locations and the different identity narratives also relate to the third facet whereby particular political and ethical value systems powerfully judge and determine people's opportunities to belong. As noted in Chapter 1, there is a difference between an invitation/welcome and presence/participation for resettled refugees. The lived experience of whether a refugee experiences the former or the latter is powerfully influenced by the opportunities to practise family, ways they experience community, host society receptiveness and those who inform the social policies and organizational practices directed towards them. The associated value systems occur on multi-scalar levels, some of which refugees are able to substantially shape and others that they are powerless to influence.

The commonly spoken term, crisis, to describe Europe's situation with forced migrants crossing its borders represents a clear example. Several authors have noted how political parties have employed this term alongside the lexicon of terror to justify particular state interventions that include the turning back of boats and strewing borders with razor wire (Holmes \& Castañeda, 2016; Kallius et al., 2016). The people on the move are often mentioned as migrants as a careful construction to limit particular international obligations and responsibilities of hosting them if they were seen as refugees or forced migrants. And the use of such terms can sanitize and obfuscate the horrors that are happening in Syria and elsewhere. The securitization of asylum and externalization of borders signal how particular value systems create forms of belonging that establish and judge who is able to belong and those who are not. The current and heated debates about forced migrants crossing European borders demonstrate the intransigence of numerous nation-states to develop effective coordinated international responses to the many associated issues. As the Thomas Theorem suggests, situations that are defined as real can be very real in their associated consequences. 
There is little argument that those fleeing persecution from Syria, Afghanistan, Eritrea and other places are experiencing a crisis. And so, too, are these people's families and communities. It is also clear that some localities that are receiving high numbers of them are struggling to cope with the sheer numbers of people seeking asylum; it is debatable whether Europe as a whole or particular countries are really coping with such a crisis. Although the notion of crisis needs critique, it is also necessary to recognize that societies receiving significant numbers of migrants can also be affected, in both positive and negative ways. Numerous countries are now hosting the millions of Syrians who have fled a protracted conflict that continues to defy attempts at resolution. Berlin, as one city of many, has resettled tens of thousands over the last two years. The Greek island of Lesbos has been a destination for hundreds of thousands of people fleeing persecution. The International Rescue Committee (IRC) estimates that over 366,000 Syrian refugees are now living in urban Istanbul; the single largest population of Syrians outside of Syria (although it has been estimated that over a third of urban refugees are undocumented in Turkey). ${ }^{3}$ How the receiving society receives such demographic shifts and associated interactions can strongly influence those who are judged to belong and those who are not.

These developments are not unique to Europe. In Australia, New Zealand and the United States, governments have used terms such as maritime arrivals, illegals, undocumented migrants, irregular migrants and economic migrants to shift the debate on protecting the vulnerable to protecting national values and the securitization of borders (Bogen \& Marlowe, 2015). The Australian government refers to asylum seekers who arrive by boat as 'unlawful noncitizens' even though they have committed no crime (Tazreiter, 2013). Donald Trump won the US election partly on the campaign promise to 'build the wall and make Mexico pay for it' referring to the perceived problem of undocumented and illegal migrants damaging the fabric of American society. His fiery rhetoric to ban Muslim immigration has generated an up-swell of populist support despite widespread condemnation within and beyond the US. Reports of increasing discrimination and outright hate crimes against visible minorities followed both the Brexit and the US presidential election results. According to numerous media sources, the British Home Office found that the number of hate crimes soared by 41 per cent in the month after the vote to leave the European Union; this represents tens of thousands of reported individual incidents of racialized or religiously aggravated offences. ${ }^{4}$ A survey delivered to educators across the country in the immediacy of the election detailed intensified anxieties among marginalized students. Educators reported witnessing a proliferation of verbal and physical harassment, as well as incidents involving swastikas and other Nazi symbolism. The associated choice of words and terms, and the associated policy directives that sit behind these highlight the power of identity politics. It is clear that refugees are not the only people who determine what constitutes their opportunities to belong.

Bhabha (1990) critiques colonial and essentialized understandings of culture and other forms of identity by arguing that discourses of primitive and civilized peoples reinforce the West's subordination of what is termed the Global South. 
He then argues an imperative to think beyond binary oppositions such as centre/ periphery, modern/undeveloped, first/third world, etc., which construct overly simplified and inaccurate perspectives of complex concepts (Bhabha, 1994). Rendering the power dynamic of binaries and its associated construction more visible, Hall (1996, p. 5) speaks to the contested notions of identity, defining it as:

discourses and practices which attempt to 'interpellate', speak to us or hail us into place as social subjects ... [and] the processes which produce subjectivities, which construct us as subjects which can be 'spoken'. Identities are thus points of temporary attachment to the subject positions which discursive practices construct.

Refugee communities constructed as subjects by the media and political representations highlight how they have already been 'spoken' by others, sometimes in empowering and accepting ways and others much less so (Esses et al., 2013; Gale, 2004; Sulaiman-Hill et al., 2011; Windle, 2008). Such communities find themselves in passionate community debates about keeping one's culture and what it means to successfully integrate in a host society. The contested discourses on resettlement, identity and integration mean that reconciling one's past with the present is not just a nostalgic exercise but part of the necessity of everyday lives and livelihoods. This negotiation highlights the meeting places of stories, where narrator and audience come into focus and the ways in which particular accounts of identities and belongings are forged, understood and embraced. While a focus on the extraordinary related to forced migration can make the wider society aware of associated atrocities and generate responses to such situations on multiple levels, such understandings can also dangerously label people in ways or roles that inhibit agency and equity of access to resources in settlement contexts.

If the wider society's understanding of a person's world is limited to the refugee camp, forced migration and negative mental health outcomes, then these descriptors can adversely influence the opportunities and roles that refugees can assume in a particular host society. These comments echo Pupavac's (2006) cynical sentiments that the fear of refugees informs policy rather than consideration of its possibilities. Similar analyses have noted the shift of refugees being positioned from at risk to a risk (Bogen \& Marlowe, 2015; Stanford, 2008). It is then an easy step for policy makers to express the issues related to refugee settlement and integration through unemployability, poor mental health outcomes and incompatibility with national values. Examples of such concerns are evident in Australia (Gale, 2005; Hage, 2003), across Europe (Fekete, 2009; Holmes \& Castañeda, 2016; Pupavac, 2008), New Zealand (Beaglehole, 2013) and the United States (Hollifield et al., 2014). This is why, throughout the book, I maintain the importance of a concurrent everyday and extraordinary analysis. Chapter 5 presents a conceptual professional practice framework that helps to orient this approach.

As noted in the beginning of this chapter, the notion of belonging is something that largely escapes critical examination because it is so familiar. It is only when 
it seems threatened does it really need to be clearly articulated. This dynamic helps explain why it is such a powerful political platform that creates an $u s$ and a them, and alters the focus of refugees being at risk and deserving of human rights protections, to a risk that suggests that our belonging and way of life is under attack. The shift to viewing people as a risk, whether deliberate or not, fails to acknowledge the very real and powerful structural and historical processes that influence people's daily lives. It realigns the focus of refugee resettlement (protection) and settlement (belonging) to more narrowly defined and demarcated projects of economic contribution, assimilating with host society values and ensuring border security. And more cynically, these representations are used to leverage populist support and justify anti-immigration platforms as previously noted. The intersection of these facets between different groups is often where belonging intersects with the politics of belonging. This dynamic highlights how multiple actors and various interests compete in having a say as to who belongs and who does not.

\section{The politics of belonging}

Each facet of belonging has its own associated political projects. At times, these projects may endeavour to define particular social locations or construct, and reinforce certain narratives that inform identities and practices of belonging. There are powerful politics that actively look to determine particular emotional identifications and influence people's affective attachments. Specific groups and institutions may actively construct political and ethical value systems that attempt to decide and legitimize people's opportunities to belong, which influence access to resources and forms of recognition. Such politics might involve all three facets or focus on a particular aspect of one. Yuval-Davis (2011) argues that the word politics in relation to belonging refers to the ways in which a sense of belonging is destabilized or threatened in some way. This threat necessitates an explicit understanding of how multiple forms of belonging are formally structured and understood, and importantly, by whom.

The term political for the purposes of this book speaks to far more than politics occurring within local, state or national government assemblages. As Edkins (1999, p. 2) acknowledges, '[t]he political has to do with the establishment of that very social order which sets out a particular, historically specific account of what counts as politics and defines other areas of social life as not politics'. Most simply stated, politics is about having a say in something that counts.

Taken at this level, it is possible to see that politics occur on multiple planes that include the intrapersonal, interpersonal, family, community, workplace and many structural/institutional levels. Different family members, for instance, will have a say as to household rules, roles and accepted cultural practices that may be defined and enacted along age and gender-based axes. Community politics can define gender relations, remedies for local disputes and the distribution of finite resources. Universities can choose to recognize refugee background students as an equity group and offer scholarships to them or not. Philanthropists can do the 
same or direct their interests and resources elsewhere. And local, state and federal/national governments can influence and legislate social policies that powerfully dictate people's lived experiences, sometimes with little to no input from refugees themselves. Transnational groups can wield power and influence through sending remittances, travel and engaging in local politics through social media. Politics is thus the business of having a say, which can be leveraged and influenced for varying purposes that can be well-intentioned and also as a form of oppression that legitimizes the interests of one group over another.

What is important to emphasize is that different groups have varying powers to establish what counts regarding any particular decision, idea or perspective. And there are politics that occur across social, cultural and political dimensions. This reality is perhaps best captured by Crowley's (1999, p. 30) often cited definition of the politics of belonging, suggesting it involves 'the dirty work of boundary maintenance'. In relation to this, Yuval-Davis (2011, p. 13) acknowledges that social locations are rarely constructed across one axis of difference and that power is sourced, sustained and reinforced across multiple points of difference, even if identity politics tries to construct social issues in a simplified and reified manner. This tendency is why she argues that understanding the politics of belonging requires an analysis of how the sociology of emotions intersects with the sociology of power.

The powerful discourses around integration, trauma and refugees in general are predicated on a location and relationship with numerous players, and hence, the resettlement experience is far from an apolitical process. This focus highlights that the facets of belonging and its associated politics bring a number of people and institutions together. This is where recognition theory can help achieve an analysis that identifies who stands to benefit from having a say in who belongs and who does not.

\section{Recognition theory}

Following the 19th-century German philosopher Hegel's famous phrase, 'the struggle for recognition', refugees can find themselves in contested landscapes whereby particular identifications coincide, and at times collide with political, economic, social, cultural and media-driven forces. Drawing upon Nancy Fraser's political theory on recognition and redistribution, it is possible to envision what is at stake and whose interests are at play for refugee background communities in settlement contexts. There are a plenitude of debates within the social theory, moral philosophy and political analysis associated with recognition theory, but even a partial explication of these is beyond the scope of this book.

While this book aligns with Nancy Fraser's conceptualizations, there is a rich literature on recognition theory. Further reading includes a contemporary and critic of Fraser, Axel Honneth (Honneth, 1995, 2001, 2007; Honneth \& Margalit, 2001) along with others who have written about the topic (Benhabib, 2002; Kymlicka, 2015; Ricoeur, 2005; Taylor, 1992). Fraser's contributions are particularly important as she places redistribution alongside recognition dynamics, 
which sits distinct from the ways that Honneth and Taylor conceptualize this theory. Honneth's work has been critiqued that it has a tendency to focus too strongly on the psychologization of misrecognition, thereby placing too much emphasis on what it means to experience misrecognition rather than what it might mean for the misrecognizers to commit it (see Bauman, 2001; Garrett, 2009; Markell, 2003; McNay, 2008). Fraser (2008) engages misrecognition from the standpoint of status insubordination rather than harm to personal identity and provides a better fit to engage with associated discourses about refugees on broader levels.

Fraser's dual focus on recognition and redistribution provide an important justification to move beyond the extraordinary underpinnings frequently associated with the master status of refugee and opens new possibilities to examine belonging through the everyday and transnational ways that people participate in public life. She argues (2001, p. 24) that recognition is a question of social status that allows group members to engage as 'full partners in social interactions' through what she terms the parity of participation. However, the ideal of parity is often not achieved, particularly with minority groups and those not enjoying privileged positions of power.

This dynamic highlights how the different facets of belonging and its associated politics interact. Fraser (2003, p. 24) maintains that recognition through misrecognition can cause social subordination as institutionalized patterns of cultural value constitute actors as inferior, excluded, wholly other, or simply invisible, hence as less than full partners in social interaction'. Malkki (1995) writes how dominant discourses on refugees tend to narrowly focus on the person as a passive victim and further ensconce refugees within the purviews of deviant and deficit focused understandings - political commentary, media reporting and academic research has contributed to these understandings through extraordinary representations that become accepted societal everyday understandings. Likewise, Ingleby (2005, p. 23) states: '[t]hough the status of 'victim' may help in obtaining political asylum, it can create an extra handicap when it comes to social integration'. Fraser (2003) warns that such victimized discourses can directly impede people's standing in society and the parity of participation. Again, such impediments are often informed exclusively through the extraordinary fact that position refugees as the Other in relation to the host society.

While Fraser acknowledges the importance of recognition, she cautions that an exclusive focus upon this can be at the expense of an equally important consideration: redistribution. When people experience injustices related to socioeconomic inequalities that lead to marginalization and exploitation, Fraser (2000) maintains that this issue involves concerns about both recognition and redistribution. Placed together, Fraser (2003) introduces her perspectival dualism that situates recognition and redistribution as two conceptual domains that are co-fundamental to achieving justice. And although redistribution achieves the objective condition of parity, recognition helps to protect the more intersubjective conditions associated with it (Fraser, 2003, p. 36). For instance, forms of cultural disrespect (recognition) often relate to economic exclusion and exploitation 


\section{Belonging}

(redistribution). As such, both domains are not reducible or subsumable to the Other but interact together in complex ways.

Most theories of recognition assume that a person's sense of identity is fundamentally tied to the perspectives and actions of others (from friends, family, community, wider society, institutions, etc.). Recent studies have shown the presence of a segmented labour market whereby refugees are allocated low-status jobs, if allocated one at all, regardless of their prior skills and training, in numerous countries such as Australia (Fozdar, 2012), New Zealand (O'Donovan \& Sheikh, 2014), Canada (Simich, 2004), Sweden (Lundborg, 2013), the United States (Fassin, 2012) and numerous other countries. Other studies document how social disadvantage characterizes the daily experience of resettled/resettling refugee communities that relate to:

- health (Bäärnhielm, 2016; Nicolai et al., 2015);

- $\quad$ education (Anselme \& Hands, 2010; Marlowe \& Humpage, 2016);

- housing (Fozdar \& Hartley, 2013; Francis \& Hiebert, 2014);

- family reunification (Choummanivong et al., 2014; Schweitzer, 2015);

- access to welfare and other support services (O'Donovan \& Sheikh, 2014).

The ways in which refugees are represented/misrepresented can have significant implications - positive and negative - as to people's participation in civic society even if supportive policies and legislative frameworks are in place. Again, the facets of belonging powerfully influence these important aspects of settlement and highlights how politics can have a say as to who is included or not, whether this is in relation to social policy, organizational approaches, employer hiring practices, access to education or the numerous other forms of civic participation that characterize the experience of meaningful settlement.

It is also possible to consider how recognition and redistribution dynamics occur in a transnational sense. The migration literature establishes how refugees send significant remittances back to their respective homelands and to other countries where family and friends reside. A common assumption within these countries of origin is that the settlement location is loaded with riches where acquiring wealth and status is relatively easy (Lindley, 2007; Marlowe, 2012; Wilding, 2006). This perception is complicated by evidence of refugees often struggling to find meaningful work even if they are qualified to do the job, and evidence of higher rates of underemployment and unemployment relative to the general population. The lack of opportunity versus perceived opportunities from transnational relations can be a source of stress where family and community expectations of support can be difficult to maintain. ${ }^{5}$ It demonstrates that the parity of participation (often in relation to employment) not only impacts the lives of individuals or families in local places but those in the wider diasporic and transnational realms. Examples of transnational remittances to Somalia, South Sudan and Vietnam represent just a few situations where people's ongoing commitments to those back home and the wider diaspora represents potential strain, but also a necessary and important ongoing commitment (Horst, 2004; Johnson \& Stoll, 
2013). It highlights how belonging has transnational and translocal dimensions as people negotiate relational and place-based responsibilities in multiple places.

\section{Misrecognition: everyday and extraordinary representations}

Fraser (2003) argues that most forms of injustice involve a combination of disrespect (often targeted in relation to a particular social location) and forms of economic exploitation. The wider host society can accept and legitimize these forms of injustice as these practices are weaved into everyday understandings about refugees. For example, Chapter 1 illustrated how political parties have successfully and opportunistically leveraged populist support using the recent migratory flows into Europe and the associated integration debates, to elevate concerns about protecting national values and safety. Heated debates about religious expression, cultural compatibility and social cohesion are occurring across Europe and the Americas that draw powerful lines of demarcation, entrench forms of difference and justify forms of injustice. Therefore, the consideration of wider social and political powers is important and, as Zetter $(1988$, p. 1) critically acknowledges, "The label "refugee" both stereotypes and institutionalizes a status.' Thus, a predominant focus on the extraordinary gives further credence to perceptions where someone who is linguistically and/or visibly different by virtue of accent, skin tone, dress or other aspects of one's appearance is (mis)recognized as a dangerous person. The associated descriptors of poverty, conflict, chronic exposure to violence and the stereotypic image of the terrorist often become the public's explicit and tacit understandings of particular groups. Such perspectives are reinforced in media reporting and political commentary that clearly have overtones of racial profiling and opportunistic sensationalism that serve to justify particular group interests (see Bolt, 2007; Gale, 2004; Lueck et al., 2015). These representations are often made and communicated through particular political projects of belonging that construct an us and a them.

An example of the ways that political values construct people's belonging (or not) has recently been presented by numerous governments and right-wing parties that note the economic implications of hosting refugees as a way to justify limited resettlement commitments and particular social policies. These political projects and resulting discourses potentially obscure the wider historical analysis of where refugees originate to the negative social and economic implications of hosting them. These understandings are then reinforced with figures and statistics, usually expressed as increased annual costs to a refugee settlement budget which are very short-sighted and take a narrow view of what constitutes meaningful contribution.

Such developments are often positioned as political projects that define the facets of belonging. For instance, political projects can reify particular social locations (e.g. refugee, Muslim, Syrian, economic migrant, illegals) to convince others, who often enjoy privileged positions of power, that some groups belong and others do not. There are also projects that shape people's identifications and emotional attachments, which are constructed and constrained within wider 


\section{Belonging}

nationalist frames that effectively position the Other as undesirable, deviant or different and at odds with local values. And finally, political and ethical values are shaped through discourses such as the charitable nation that 'saves' the refugee or 'empowers' the oppressed and powerless woman to enjoy human rights. These are often constructed problematically (and politically) in binaries as developed/undeveloped, north/south, Christianity/Islam, etc. Others may espouse how specific cultural groups are compatible with constructed national values. The recent referendum in the UK to leave the EU partly reflects such politics.

Iser (2013) maintains that recognition theory provides a useful approach to understanding alternative discourses that inform social and political resistance to misrecognition. One way of achieving and recognizing such acts of resistance is to consider alternative understandings beyond the dominant discourses that construct refugees and the facets of belonging in particular ways. Legrain (2016) however, provides a counter-narrative to these conclusions suggesting that investing one euro welcoming refugees can yield two euros in economic benefits in five years. He presents seven dividends that refugees can return to developed economies, summarized briefly here:

1 4D dividend - many refugees do dirty, difficult, dangerous and dull jobs that are not readily taken by the host society.

2 Deftness dividend - highly skilled refugees and their children can fill gaps in the labour market.

3 Debt dividend - several studies show that over time, refugees can become net contributors to public finances (though not in the short term).

4 Development dividend - through meaningful settlement opportunities, refugees can contribute to their own development, their families and countries of origin through remittances and other forms of engagement.

5 Dynamism dividend - there are numerous examples of enterprising refugees who have started new businesses that make an economy more dynamic and adaptable.

6 Diversity dividend - refugees can bring new ideas and forms of innovation outside what is routinely thought and imagined within a receiving society.

7 Demographic dividend - refugees tend to be younger than the general population and can help build a younger and adaptable workforce.

And yet, acknowledging these dividends and the possibilities are difficult when a politics of fear and a lexicon of terror are maintained. For instance, the International Monetary Fund released a report suggesting a modest increase in GDP growth in the main European asylum countries of Germany, Sweden and Austria (Aiyar et al., 2016). This report, however, maintains that the long-term outlook is then largely dependent on how committed these countries are to integrating refugees into the labour market. The Business Review Weekly (BRW) names the wealthiest Australians and highlights that several billionaires are either former refugees or children of parents who were (see Hugo, 2014; McAdam, 2013). These perspectives do not necessarily contradict studies that acknowledge 
increased rates of unemployment, underemployment and welfare assistance. This awareness illustrates that different political projects of belonging (for better and for worse) will seek studies, discourses and alliances that support particular endorsed or preferred narratives.

Though not a panacea for misrecognition, distinguishing between extraordinary and everyday stories can be helpful. These perspectives, when brought together, do not diminish or invalidate adverse experiences associated with the refugee experience and recognize people as agents capable of responding to difficulties, recovery and importantly, contributing to society. In fact, Fraser (2000) cautions that recognition politics can quickly descend into identity politics that reify particular groups within a master status and create further bifurcations between us and them. Turton (2004) likewise argues that when society views refugees more as ordinary people beyond the category of passive victim, there is greater potential to see them more like us and consequently a member of the new community. This is why a dual focus on recognition and redistribution is important to ensure a parity of participation. If the focus is solely on the redistribution then it is easy for the wider society to possibly view the recipients of targeted support as 'social parasites'. At the other end, recognition without redistribution runs the risk of reifying identity politics that can limit people's wider engagement in civil society (Iser, 2013). While it is more difficult to make a direct link to distribution dynamics from dominated perspectives that focus on the extraordinary, the Othering process associated with refugee discourses can lead to exclusionary practices related to education, employment and other types of civic participation.

Bryceson and Vuorela (2002) see families, ethnicities, nations and other social groupings as imagined communities; although a person can be born into a family or nation, a sense of membership develops by choice and by negotiation. The ways in which people choose to associate and the categories that they are ascribed highlight how the politics of belonging represents specific projects that can largely determine the parity of participation in settlement contexts. Thus, it is about the interplay between refugees, the receiving society and its institutions. In many ways, refugees themselves shape the directions and paths they take, such as whether they choose to engage with the wider society or remain relatively close to their own community. This decision, however, is also powerfully influenced by the receiving society and the institutions that surround them.

If refugees are welcomed, have meaningful opportunities for work and other forms of civic participation and are integrated into the everyday social fabrics of a host society, then this will also strongly feature in a person's calculus regarding their acculturation trajectories and commitments to particular places and relationships. As Yuval-Davis (2011) notes, when relating citizenship to belonging, that citizenship is not just a legal status or concept, but one that is performative, relational and defined at levels not necessarily linked to country. These layers of citizenship highlight the multiple ways and contexts that people can belong. And when people do not feel that they belong (even if they are citizens), it creates alienation where other forms of belonging can fill the void, sometimes with 
significant human costs as the multiple terror attacks across Belgium, France, UK and Germany from 2015-2017 testify. ${ }^{6}$

\section{Conclusion}

Belonging is a term that often only requires conscious definition when it is under threat in some way. It means that the principal time that people engage with what belonging possibly means and represents, they are already defensive about it. What makes anti-immigrant and xenophobic platforms so powerful is that they seize upon the politics of fear to convince the electorate that they protect the national values, border security, local jobs or whatever component that might relate to belonging within a particular group. The facets of belonging, however, provide a way to unpack what is understood by this familiar yet rarely defined term. And the political projects associated with these facets (as having a say in something that counts) can significantly impact the opportunities for, and people's commitments to, belonging and meaningful settlement. As the vignette at the start of this chapter illustrates, belonging exists in, and is sourced from, multiple and transnational places. These sentiments of, and commitments to, belonging might range from relatively ephemeral to seemingly fixed.

Bourdieu's call to consider exoticizing the domestic relates to the critique and tendency to represent and define the most sensational aspects of a particular group's experience (often understood through culture, ethnicity, nationality or some other identifier). The resulting ways in which the refugee label can then become the dominant and master status of particular individuals highlights this call for a concurrent everyday analysis. The conclusion is not to deny extraordinary stories, but to be open to alternative understandings through the recognition that there are multiple ways of understanding the forced migration experience and people's broader lives. The notion of rendering the familiar strange provides the basis to engage with taken-for-granted terms and perspectives in a more reflexive manner and opens spaces to unpack assumptions about what is understood by the words refugees, settlement and belonging. This approach can help consider the possibilities and implications for the parity of participation and ongoing transnational relationships.

A sense of belonging is sourced and sustained through various actors and institutions that highlight that the concept has transnational, gendered, relational and situational dimensions. The following chapters focus upon belonging and its associated politics in relation to understandings of trauma, disasters and various forms of professional practices. I present the contexts of South Sudanese settlement and trauma in the next chapter to demonstrate how recognition theory intersects with extraordinary understandings of refugees and their associated opportunities to participate as peers in civic life. What will remain clear is that people's transnational relations and commitments alongside multiple forms of belonging represent an important part of their everyday lives that inform how they both define and respond to trauma. 


\section{Notes}

1 This chapter uses some material from previously published articles in the Journal of Refugee Studies and Ethnicities. The references are as follows:

Marlowe, J. (2010) Beyond the discourse of trauma: Shifting the focus on Sudanese refugees. Journal of Refugee Studies, 23(2), 183-98.

Marlowe, J. (2012) 'Walking the line': Southern Sudanese masculinities and reconciling one's past with the present. Ethnicities, 12(1), 50-66.

2 The Colombian government and left wing guerrilla group FARC (Fuerzas Armadas Revolucionarias de Colombia) agreed to a peace deal in July 2016. If this agreement is honoured, it could bring the country closer to ending the protracted conflict that has raged for decades.

3 See: International Rescue Committee's website that regularly updates details about the Syrian refugee crisis: www.rescue.org/country/syria

4 See: www.independent.co.uk/news/uk/crime/brexit-hate-crimes-racism-eu-referendumvote-attacks-increase-police-figures-official-a 7358866.html

5 There are clear exceptions to this claim, of course. However, the evidence of discriminatory labour market practices/structures highlights how particular forms of recognition (through the politicization of particular facets of belonging) exacerbate such situations.

6 Independent security intelligence agencies have attested to the powerful recruitment opportunities present for terrorist organizations within France's current climate where immigrant communities report feelings of isolation and marginalization. Thus, the propaganda of the Islamic state offers a striking alternative of belonging, determination and respect sought within the host country. This can result in attacks like the events of 14 July 2016 when Tunisian-born, French resident Mohamed Lahouaiej-Bouhlel killed 84 people and injured 434 using a truck to deliberately drive into pedestrian crowds.

\section{References}

Aiyar, S., Barkbu, B., Batini, N., Berger, H., Detragiache, E., Dizioli, A., ... Sosa, S. (2016) The refugee surge in Europe (1513552597). Retrieved from: www.imf.org/external/ pubs/ft/sdn/2016/sdn1602.pdf

Al-Ali, N., Black, R. \& Koser, K. (2001) The limits to 'transnationalism': Bosnian and Eritrean refugees in Europe as emerging transnational communities. Ethnic and Racial Studies, 24(4): 578-600. doi:10.1080/01419870120049798

Allison, A. (2012) Ordinary refugees: Social precarity and soul in 21st century Japan. Anthropological Quarterly, 85(2): 345-70.

Amin, A. (2002) Ethnicity and the multicultural city: Living with diversity. Environment and Planning A, 34(6): 959-80. doi:10.1068/a3537

Anselme, M. L. \& Hands, C. (2010) Access to secondary and tertiary education for all refugees: Steps and challenges to overcome. Refuge, 27(2): 89-96.

Antonsich, M. (2010) Searching for belonging - An analytical framework. Geography Compass, 4(6): 644-59. doi:10.1111/j.1749-8198.2009.00317.x

Bäärnhielm, S. (2016). Refugees' mental health-A call for a public health approach with focus on resilience and cultural sensitivity. The European Journal of Public Health. doi:10.1093/eurpub/ckw055

Baldassar, L., Baldock, C. \& Wilding, R. (2007) Families caring across borders: Migration, ageing and transnational caregiving. New York: Palgrave Macmillan.

Bascom, J. (1998) Losing place: Refugee populations and rural transformations in East Africa. New York: Berghahn. 
Bauman, Z. (2001) The great war of recognition. Theory Culture Society, 18(2-3): 137-50. doi:10.1177/02632760122051823

Beaglehole, A. (2013) Refuge New Zealand: A nation's response to refugees and asylum seekers. Wellington, New Zealand: Otago University Press.

Benhabib, S. (2002) The claims of culture. Princeton, NJ: Princeton University Press.

Berger, P. \& Luckman, T. (1966) The social construction of reality: A treatise in the sociology of knowledge. New York: Anchor Books.

Bermudez, A. (2010) The transnational political practices of Colombians in Spain and the United Kingdom: Politics 'here' and 'there'. Ethnic and Racial Studies, 33(1): 75-91. doi:10.1080/01419870903125838

Bhaba, J. (1990) Nation and narration. London: Routledge.

Bhabha, H. (1994) The location of culture. London: Routledge.

Bhimji, F. (2008) Cosmopolitan belonging and diaspora: Second-generation British Muslim women travelling to South Asia. Citizenship Studies, 12(4): 413-27. doi:10.1080/13621020802184259

Billig, M. (1995) Banal nationalism. London: Sage.

Bird, J. N., Brough, M. \& Cox, L. (2016) Transnationalism and the Karen wrist-tying ceremony: An ethnographic account of Karen settlement practice in Brisbane. The Australian Journal of Anthropology, 27(1): 104-20. doi:10.1111/taja.12176

Bird, J. N., Cox, L. \& Brough, M. (2016) Doing belonging: Meanings of home and settlement among the Karen Community in Brisbane, Australia. Journal of Social Inclusion, 7(1): 72-84.

Bogen, R. \& Marlowe, J. (2015) Asylum discourse in New Zealand: Moral panic and a culture of indifference. Australian Social Work, 1-12. doi:10.1080/0312407X. 2015.1076869

Bolt, A. (2007) It's time we got a grip. Herald-Sun, Melbourne. Retrieved from: http:// blogs.news.com.au/heraldsun/andrewbolt/index.php/heraldsun/comments/column_its_ time_we_got_a_grip/

Bourdieu, P. (1988) Homo academicus (P. Collier, trans.) Cambridge: Polity Press.

Brees, I. (2010) Refugees and transnationalism on the Thai-Burmese border. Global Networks, 10(2): 282-99. doi:10.1111/j.1471-0374.2010.00286.x

Briskman, L. (2015) The creeping blight of Islamophobia in Australia. International Journal for Crime, Justice and Social Democracy, 4(3): 112-21.

Bryceson, D. \& Vuorela, U. (2002) Transnational families in the 21st century. In D. Bryceson \& U. Vuorela (eds) The transnational family: New European frontiers and global networks (pp. 3-30). Oxford: Berg Publishers.

Capps, R., Newland, K., Fratzke, S., Groves, S., Auclair, G., Fix, M. \& McHugh, M. (2015) Integrating refugees in the United States: The successes and challenges of resettlement in a global context. Statistical Journal of the IAOS, 31(3): 341-67.

Carruthers, A. (2013) National multiculturalism, transnational identities. Journal of Intercultural Studies, 34(2): 214-28. doi:10.1080/07256868.2013.781984

Chamberlain, M. \& Leydesdorff, S. (2004) Transnational families: Memories and narratives. Global Networks, 4(3): 227-41. doi:10.1111/j.1471-0374.2004.00090.x

Choummanivong, C., Poole, G. E. \& Cooper, A. (2014) Refugee family reunification and mental health in resettlement. Kötuitui: New Zealand Journal of Social Sciences Online, 9(2): 89-100. doi:10.1080/1177083x.2014.944917

Chow, H. P. H. (2007) Sense of belonging and life satisfaction among Hong Kong adolescent immigrants in Canada. Journal of Ethnic and Migration Studies, 33(3): 511-20. doi:10.1080/13691830701234830 
Correa-Velez, I., Barnett, A. G. \& Gifford, S. (2013) Working for a better life: Longitudinal evidence on the predictors of employment among recently arrived refugee migrant men living in Australia. International Migration. doi:10.1111/imig.12099

Correa-Velez, I., Gifford, S. M. \& Barnett, A. G. (2010) Longing to belong: Social inclusion and wellbeing among youth with refugee backgrounds in the first three years in Melbourne, Australia. Social Science \& Medicine, 71(8): 1399-408. doi:http:// dx.doi.org/10.1016/j.socscimed.2010.07.018

Crowley, J. (1999) The politics of belonging: Some theoretical considerations. In A. Geddes \& A. Favell (eds) The politics of belonging: Migrants and minorities in contemporary Europe (pp. 15-41). Aldershot: Ashgate.

Deleuze, G. (1995) Negotiations. New York: Columbia University Press.

Deng, A., Deng, B., Ajak, B. \& Bernstein, J. (2005) They poured fire on us from the sky: The true story of three lost boys from Sudan. New York: Public Affairs.

Edkins, J. (1999) Poststructuralism and international relations: Bringing the political back in. Cambridge, MA: MIT Press.

Esses, V. M., Medianu, S. \& Lawson, A. S. (2013) Uncertainty, threat, and the role of the media in promoting the dehumanization of immigrants and refugees. Journal of Social Issues, 69(3): 518-36. doi:10.1111/josi.12027

Fassin, D. (2012) Humanitarian reason: A moral history of the present. Berkeley, CA: University of California Press.

Fekete, L. (2009) A suitable enemy: Racism migration and Islamophobia in Europe. London: Pluto Press.

Fozdar, F. (2012) Social cohesion and skilled Muslim refugees in Australia: Employment, social capital and discrimination. Journal of Sociology, 48(2): 167-86. doi: $10.1177 / 1440783311413482$

Fozdar, F. \& Hartley, L. (2013) Housing and the creation of home for refugees in Western Australia. Housing, Theory and Society, 1-26. doi:10.1080/14036096.2013.830985

Fozdar, F. \& Hartley, L. (2014) Civic and ethno belonging among recent refugees to Australia. Journal of Refugee Studies, 27(1): 126-44. doi:10.1093/jrs/fet018

Francis, J. \& Hiebert, D. (2014) Shaky foundations: Refugees in Vancouver's housing market. The Canadian Geographer / Le Géographe Canadien, 58(1): 63-78. doi:10.1111/j.1541-0064.2013.12056.x

Fraser, N. (2000) Rethinking recognition. New Left Review, 3: 107-20.

Fraser, N. (2001) Recognition without ethics? Theory Culture Society, 18(2-3): 21-42. doi: $10.1177 / 02632760122051760$

Fraser, N. (2003) Social justice in the age of identity politics: Redistribution, recognition and participation. In N. Fraser \& A. Honneth (eds) Redistribution or recognition (pp. 7-109). London: Verso.

Fraser, N. (2008) Rethinking recognition: Overcoming displacement and reification in cultural politics. In K. Olson (ed.) Adding insult to injury: Nancy Fraser debates her critics (pp. 129-41). London: Verso.

Gale, P. (2004) The refugee crisis and fear: Populist politics and media discourse. Journal of Sociology, 40(4): 321-40. doi:10.1177/1440783304048378

Gale, P. (2005) The politics of fear: Lighting the Wik. Frenchs Forest, NSW: Pearson Education Australia.

Garrett, P. M. (2009) Recognizing the limitations of the political theory of recognition: Axel Honneth, Nancy Fraser and social work. British Journal of Social Work, 1-17. doi:10.1093/bjsw/bcp044 
Gifford, S. M. \& Wilding, R. (2013) Digital escapes? ICTs, settlement and belonging among Karen youth in Melbourne, Australia. Journal of Refugee Studies, 26(4): 55875. doi: $10.1093 / \mathrm{jrs} /$ fet020

Gottwald, M. \& Rodríguez Serna, N. (2016) Comprehensive solutions for Colombian refugees in Latin America. Retrieved from: www.unhcr.org/research/working/57580f9f7/ comprehensive-solutions-colombian-refugees-latin-america.html

Hage, G. (2003) Against paranoid nationalism: Searching for hope in a shrinking society. Annandale, NSW: Pluto Press Australia.

Hall, S. (1996) Who needs 'identity’? In S. Hall \& P. Du Gay (eds) Questions of cultural identity (pp. 1-9). London: Sage Publications.

Hall, S. M. (2015) Migrant urbanisms: Ordinary cities and everyday resistance. Sociology, 49(5): 853-69. doi:10.1177/0038038515586680

Hällgren, C. (2005) 'Working harder to be the same': Everyday racism among young men and women in Sweden. Race, Ethnicity and Education, 8(3): 319-42. doi:10.1080/13613320500174499

Harrell-Bond, B. (1999) The experience of refugees as recipients of aid. In A. Ager (ed.), Refugees: Perspectives on the experience of forced migration (pp. 136-68). New York: Continuum.

Hollifield, J., Martin, P. \& Orrenius, P. (2014) Controlling immigration: A global perspective. Redwood City, CA: Stanford University Press.

Holmes, S. M. \& Castañeda, H. (2016) Representing the 'European refugee crisis' in Germany and beyond. American Ethnologist, 43(1): 12-24. doi:10.1111/amet.12259

Honneth, A. (1995) The struggle for recognition (J. Anderson, trans.). Cambridge, MA: The MIT Press.

Honneth, A. (2001) Recognition or redistribution?: Changing perspectives on the moral orderof society. Theory CultureSociety, 18(2-3):43-55.doi:10.1177/02632760122051779

Honneth, A. (2007) Disrespect: The normative foundations of critical theory. Cambridge: Polity Press.

Honneth, A. \& Margalit, A. (2001) Recognition: Proceedings of the Aristotelian Society, Supplementary Volumes, 75: 111-39.

Horst, C. (2004) Money and mobility: Transnational livelihood strategies of the Somali diaspora. Global Commission on International Migration, Retrieved from: www. refworld.org/docid/42ce49684.html

Horst, C. (2006) Buufis amongst Somalis in Dadaab: The transnational and historical logics behind resettlement dreams. Journal of Refugee Studies, 19(2): 143-57. doi: $10.1093 / \mathrm{jrs} / \mathrm{fej} 017$

Hugo, G. (2014) The economic contribution of humanitarian settlers in Australia. International Migration, 52(2): 31-52. doi:10.1111/imig.12092

Ingleby, D. (2005) Editor's introduction. In D. Ingleby (ed.) Forced migration and mental health: Rethinking the care of refugees and displaced persons (pp. 1-28). New York: Springer.

Iser, M. (2013). Recognition. In E. N. Zalta (ed.) The Stanford Encyclopedia of Philosophy. Retrieved from: https://plato.stanford.edu/cgi-bin/encyclopedia/archinfo.cgi? entry=recognition

Johnson, P. \& Stoll, K. (2013) Impact of remittances on refugees' lives in Canada: Views of Sudanese and Vietnamese leaders and settlement counsellors. Refuge: Canada's Journal on Refugees, 29(1): 53-64.

Kallius, A., Monterescu, D. \& Rajaram, P. K. (2016) Immobilizing mobility: Border ethnography, illiberal democracy, and the politics of the 'refugee crisis' in Hungary. American Ethnologist, 43(1): 25-37. doi:10.1111/amet.12260 
Kleist, N. (2008) Mobilising 'the diaspora': Somali transnational political engagement. JournalofEthnicandMigrationStudies, 34(2):307-23.doi:10.1080/13691830701823855

Kymlicka, W. (2015) Solidarity in diverse societies: Beyond neoliberal multiculturalism and welfare chauvinism. Comparative Migration Studies, 3(1): 1-19. doi:10.1186/ s40878-015-0017-4

Legrain, P. (2016) Refugees work: A humanitarian investment that yields economic dividends. Retrieved from: www.tent.org/refugees-work/

Levy, P. (1996) If this is a man. London: Vintage.

Lim, S.-L. (2009) 'Loss of connections is death': Transnational family ties among Sudanese refugee families resettling in the United States. Journal of Cross-Cultural Psychology, 40(6): 1028-40. doi:10.1177/0022022109346955

Lindley, A. (2007) The early morning phonecall: Remittances from a refugee diaspora perspective. Oxford: Centre on Migration, Policy and Society, University of Oxford.

Lueck, K., Due, C. \& Augoustinos, M. (2015) Neoliberalism and nationalism: Representations of asylum seekers in the Australian mainstream news media. Discourse \& Society. doi:10.1177/0957926515581159

Lundborg, P. (2013) Refugees' employment integration in Sweden: Cultural distance and labor market performance. Review of International Economics, 21(2): 219-32. doi:10.1111/roie.12032

McAdam, J. (2013) Australia and asylum seekers. International Journal of Refugee Law, 25(3): 435-48. doi:10.1093/ijrl/eet044

McCall, L. (2005) The complexity of intersectionality. Signs, 30(3), 1771-800. doi:10.1086/426800

McNay, L. (2008) Against recognition. Cambridge: Polity.

Malkki, L. (1995) Refugees and exile: From 'refugee studies' to the national order of things. Annual Review of Anthropology, 24(1): 495-523. doi:10.1146/annurev.an. 24.100195.002431

Markell, P. (2003) Bound by recognition. Princeton, NJ: Princeton University Press.

Marlowe, J. (2010) Beyond the discourse of trauma: Shifting the focus on Sudanese refugees. Journal of Refugee Studies, 23(2): 183-98. doi:10.1093/jrs/feq013

Marlowe, J. (2012) 'Walking the line': Southern Sudanese masculinities and reconciling one's past with the present. Ethnicities, 12(1): 50-66. doi:10.1177/1468796811419605

Marlowe, J. (2013) Going slowly slowly: An ethnographic engagement with the South Sudanese. Studies in Symbolic Interaction, 40(1): 153-73.

Marlowe, J. \& Humpage, L. (2016) Policy responses to refugees in New Zealand: A rightsbased analysis. In J. Maidment \& E. Beddoe (eds) New Zealand Social Policy for Social Work and Human Services: Diverse Perspectives (pp. 150-63). Christchurch: Canterbury University Press.

Morley, D. (2001) Belongings: Place, space and identity in a mediated world. European Journal of Cultural Studies, 4(4): 425-48. doi:10.1177/136754940100400404

Neal, S. \& Murji, K. (2015) Sociologies of everyday life: Editors' introduction to the special issue. Sociology, 49(5): 811-19. doi:10.1177/0038038515602160

Nicolai, T., Fuchs, O. \& von Mutius, E. (2015) Caring for the wave of refugees in Munich. New England Journal of Medicine, 373(17): 1593-95.

O'Donovan, T. \& Sheikh, M. (2014) Welfare reforms and the refugee resettlement strategy: An opportunity to achieve meaningful employment outcomes for New Zealanders from refugee backgrounds? Kōtuitui: New Zealand Journal of Social Sciences Online, 9(2): doi:10.1080/1177083X.2014.944193 


\section{Belonging}

Papastergiadis, N. (2000) The turbulence of migration: Globalizaton, deterritorialization and hybridity. Cambridge: Polity Press.

Pink, S. (2012) Situating everyday life: Practices and places. Thousand Oaks, CA: Sage Publications.

Pupavac, V. (2006) Refugees in the 'sick role': Stereotyping refugees and eroding refugee rights. Retrieved from: www.unhcr.org/research/working/44e198712/refugees-sickrole-stereotyping-refugees-eroding-refugee-rights-vanessa.html

Pupavac, V. (2008) Refugee advocacy, traumatic representations and political disenchantment. Government and Opposition, 43(2): 270-92.

Reid, A. \& Schofield, H. (2011) Goodbye Sarajevo: A true story of courage, love and survival: London: Bloomsbury.

Ricoeur, P. (2005) The course of recognition (D. Pellauer, trans.). Cambridge, MA: Harvard University Press.

Robertson, Z., Wilding, R. \& Gifford, S. (2016) Mediating the family imaginary: Young people negotiating absence in transnational refugee families. Global Networks, 16(2): 219-36. doi:10.1111/glob.12111

Robinson, V. (2015) Reconceptualising the mundane and the extraordinary: A lens through which to explore transformation within women's everyday footwear practices. Sociology, 49(5): 903-18. doi:10.1177/0038038515591942

Rutkin, A. (2016) Phoning in refugee aid. New Scientist, 230(3069): 22-3.

Sampson, R. \& Gifford, S. (2009) Place-making, settlement and well-being: The therapeutic landscapes of recently arrived youth with refugee backgrounds. Health \& Place, 16(1): 116-31.

Schweitzer, R. (2015) A stratified right to family life? On the logic(s) and legitimacy of granting differential access to family reunification for third-country nationals living within the EU. Journal of Ethnic and Migration Studies, 1-19. doi:10.1080/13691 83X.2015.1037256

Simich, L. (2004) The study of Sudanese settlement in Ontario: Final report. Toronto, ONT: Culture, Community and Health Studies Program, Centre for Addiction and Mental Health, University of Toronto.

Stanford, S. (2008) Taking a stand or playing it safe?: Resisting the moral conservatism of risk in social work practice. European Journal of Social Work, 11(3): 209-20. doi:10.1080/13691450802075063

Steel, Z., Silove, D., Phan, T. \& Bauman, A. (2002) Long-term effect of psychological trauma on the mental health of Vietnamese refugees resettled in Australia: A populationbased study. Lancet, 360(9339): 1056-62.

Stevens, G., Veith, M. \& Wulf, V. (2005) Bridging among ethnic communities by crosscultural communities of practice. Communities and Technologies 2005 (pp. 377-96). New York: Springer.

Sulaiman-Hill, C. M. R., Thompson, S. C., Afsar, R. \& Hodliffe, T. L. (2011) Changing images of refugees: A comparative analysis of Australian and New Zealand print media 1998-2008. Journal of Immigrant \& Refugee Studies, 9(4): 345-66. doi:10.1080/1556 2948.2011.616794

Taylor, C. (1992) Multiculturalism and the politics of recognition. Princeton, NJ: Princeton University Press.

Tazreiter, C. (2013) Asylum, refugee, and immigration movements in Australia, The WileyBlackwell Encyclopedia of Social and Political Movements. Oxford: Blackwell Publishing. 
Turton, D. (2004) The meaning of place in a world of movement: Lessons from long-term field research in Southern Ethiopia. Retrieved from: www.rsc.ox.ac.uk/publications/ the-meaning-of-place-in-a-world-of-movement-lessons-from-long-term-field-researchin-southern-ethiopia

Unger, A. (2012) Transnational spaces, hybrid identities and new media. Transnational Spaces and Regional Localization: Social Networks, Border Regions and Local-Global Relations, 43.

UNHCR (2013) United Kingdom Country Chapter. UNHCR Resettlement Handbook, June 2013 revision. Geneva: United Nations High Commissioner for Refugees.

UNHCR (2016) Global trends: Forced displacement in 2015. Retrieved from: www.unhcr. org/globaltrends/

Valentine, G., Sporton, D. \& Bang Nielsen, K. (2008) Language use on the move: Sites of encounter, identities and belonging. Transactions of the Institute of British Geographers, 33(3): 376-87. doi:10.1111/j.1475-5661.2008.00308.x

Van Dijk, T. A. (2015) Racism and the press. New York: Routledge.

Vertovec, S. (2007) Super-diversity and its implications. Ethnic and Racial Studies, 30(6): $1024-54$.

Wilding, R. (2006) Virtual intimacies? Families communicating across transnational contexts. Global Networks: A Journal of Transnational Affairs, 6(2): 125-42.

Wille, J. (2011) Agency and belonging: Southern Sudanese former refugees' reflections on life in Australia. The Australasian Review of African Studies, 32(2): 80-100.

Wilson, J. \& Drozdek, B. (eds) (2004) Broken spirits. New York: Brunner-Routledge.

Windle, J. (2008) Racialisation of African youth in Australia. Social Identities, 14(5): 553-66.

Yuval-Davis, N. (2006) Belonging and the politics of belonging. Patterns of Prejudice, 40(3): 197-214. doi:10.1080/00313220600769331

Yuval-Davis, N. (2011) The politics of belonging: Intersectional contestations, London: Sage.

Zetter, R. (1988) Refugees and refugee studies: A label and an agenda. Journal of Refugee Studies, 1(1): 1-6. 


\section{Responding to trauma}

\section{Introduction}

Much of the forced migration literature acknowledges the plight of refugees who find themselves entangled in conflicts or untenable situations that are beyond their immediate control. There is little doubt that experiences of war, life in refugee camps and other situations of displacement can expose people to highly traumatic experiences. However, debate continues as to whether those who experience acts of political violence and threats to their sense of safety are left with indelible marks on their mental health and well-being. After all, not all refugees who survive harrowing experiences develop psychological problems in the wake of traumatic events.

Now that more than a million people have crossed Europe's borders since the start of Syria's civil war, countries are grappling with the questions over how to meaningfully integrate them and the possible ramifications of hosting 'traumatized' populations. There is an existing trauma industry ready to respond to some of these issues - at times with very good intentions and at others, more opportunistic. In many cases, assumptions about what trauma is, and how to recover from it, are often determined within (Western) professional realms.

The associated stories relating to forced migration speak of atrocities and living conditions almost beyond imagination; accounts of forced marches, dislocation, death and despair. In relation to these events, the academic literature places a strong emphasis on the extraordinary experiences of trauma and its associated negative impacts for refugees, particularly in relation to mental health and settlement outcomes. There is inherent value in knowing about such events, as recognizing the stories of oppression can inform interpersonal, community, regional, national and international responses. A less explored path, however, has been that of understanding how those with refugee status respond to traumatic events. What might be their own sources of strength, hope and survival that establish forms of healing and resistance distinct from the trauma story itself?

This chapter focuses upon the theoretical utility of belonging to address this question and emphasizes how trauma has become a powerful, dominant and extraordinary descriptor that impacts upon people's experiences of the everyday. After defining trauma and noting its professional, political and academic 
intersections, this chapter illustrates how medicalized perspectives significantly influence people's opportunities to participate as peers in civil society.

As established in the last chapter, belonging can be understood through its facets: 1) social locations (migration status, race, class, nation, etc.); 2) identifications and emotional attachments; and 3) political/ethical value systems. Focusing on the interplay of these facets with the everyday and extraordinary experiences, this chapter broadens the way that trauma is potentially perceived, experienced and transcended. I introduce a case study of the South Sudanese people who have resettled in Australia to highlight how trauma informs refugees' claims for recognition and the ways in which belonging and transnational ties provide important responses to adverse circumstances - whether these are past, present or future oriented. ${ }^{1}$ These implications are then considered in the light of the current refugee 'crisis.'

\section{Trauma: rendering the familiar strange}

The concept of trauma has powerful discursive understandings within psychiatry, medical terminology and, more generally, in the popular media. Its etymology refers to the Greek word for 'wound', which has now developed and expanded into many usages across popular and professional domains. Similar to how familiar terms can easily go unexamined (as presented earlier in Chapter 2), Fassin and Rechtman (2009) caution that the concept of trauma is often taken as a priori and thereby escapes the need for formal definition. They argue that trauma has become a moral category that is difficult for individuals, and at times communities, to transcend. In this sense, the focus on trauma occurs only after it has supposedly happened - often defined, diagnosed and prescribed by the professional rather than the particular person or group that experienced the event themselves (Marlowe, 2013).

Within Herman's (1997) flagship book, Trauma and Recovery, the definition of trauma seems to rest primarily within the domains of psychological trauma. Her chapter on 'terror' is perhaps where the term is most comprehensively conceptualized:

At the moment of trauma, the victim is rendered helpless by overwhelming force. When the force is that of nature, we speak of disasters. When the force is that of humans we speak of atrocities. Traumatic events overwhelm the ordinary systems of care that give people a sense of control, connection and meaning.

(Herman, 1997, p. 33)

This chapter deconstructs the first part of this definition by critiquing and challenging the helpless victim model. However, the fact that adversities arising from forced migration have the potential to disrupt a person's sense of control, connections with others and meaning structures is important to note. After all, significant 
trauma can alter the social, cultural, historical and psychological fabrics of individuals and larger collective groupings. This discussion locates trauma provisionally within these disruptions and then presents a case study of resettled South Sudanese men living in Adelaide to examine how they define and respond to it where belonging and transnational ties broaden such understandings.

Furedi (2004) argues that the concept of trauma has become a hopelessly tangled term that has infiltrated and colonized the everyday (e.g. 'it was traumatic trying to find a car park'). Ingleby (2005) illustrates that while there were few mentions of 'trauma or post-traumatic stress disorder (PTSD)' and 'refugee' within the bibliographic literature in the early 1980s, the growth of articles published since have increased, at times exponentially, whereby various forms of mental distress have gained worldwide currency as common outcomes for warrelated trauma. Even in academic books with a trauma focus, its conceptual clarity often eludes the reader. Kirmayer (2007, p. 4) engages with this term historically, stating:

Like any generative trope, the metaphor of trauma shapes our thinking in ways that are both explicit and hidden. The history of trauma, then, is not simply a story of the march of scientific, medical, and psychiatric progress toward greater clarity about a concept with fixed meaning, but a matter of changing social constructions of experience, in the context of particular clinical, cultural and political ideologies.

Such changing constructions and contestable discourses highlight that trauma is located within multiple professional domains and theoretical positions. This context is particularly the case with refugees whereby the extraordinary stories of adversity impact on how receiving societies and professions perceive them.

Returning to the facets of belonging, Yuval-Davis (2011) cautions that the reification of specific categories creates unfounded archetypes and limits opportunities for intersectional analyses. For instance, in the recognition of multiple social locations as a facet of belonging, it is important to ensure that one category does not slip into identity politics that define and essentialize particular groups. And this awareness is important for understanding trauma as its conceptualizations and associated responses can vary within intercategorical and intracategorical analyses that require examinations across and within gender, ethnicity, culture, religion, class and many others. These different social locations offer situated histories and perspectives that inform how trauma is understood and negotiated.

Trauma also has clear links to the second facet of belonging: identifications and emotional attachments. While trauma can silence individuals and destabilize collective groupings, it is also important to consider the ways in which such experiences can create a sense of solidarity and collective consciousness against the face of oppression. Cienfuegos and Monelli's (1983) work on testimonio, for instance, highlighted how the account of traumatic experiences and giving testimony was a way of responding to transgressions of the past. At the same time, 
many people are reluctant to even identify as a refugee partly because biomedical perspectives can depoliticize forced migration narratives and label communities as traumatized and damaged - a concern I return to later in this chapter.

Different forms of trauma can be socially accepted by people's community or these can be taboo and sanctioned, thereby highlighting the role of political and ethical value systems. The associated discourses (medical, moral, human rights, etc.) can thereby label people as diseased, deviant, destitute or deserving. These different labels judge people's opportunities to belong or not. Whether the trauma is in relation to forcible displacement, torture, acts of violence or resettlement issues, the ways in which the associated stories are spoken, received and heard will vary due to relational and contextual factors. These dynamics demonstrate that the facets of belonging and the associated political projects each occur on multiple levels and with numerous social groupings and institutions.

A central tenet of this wider engagement is that the initial impact of trauma (often presented individually with physical and/or psychological consequences) plays out through the transmutation into social and community-level effects over space and time. Thus, intersectional points of identification and affiliation inform the lived experience of trauma that relate to how it might be defined, experienced and, at times, transcended. Such responses can establish pathways to resolution, recovery and even growth. This emphasis does not discount the impacts of trauma and opens new possibilities for the ways that belonging and transnational relations can inform recovery. Before I address this orientation it is, first, important to recognize the powerful biomedical discourses that dominate understandings of trauma. After all, intersectional positions and competing discourses linked to the extraordinary and traumatic experience are not created equal.

\section{The medicalization of trauma}

A substantial body of literature documents the negative impacts on those who bore witness to and experienced the atrocities of civil war, conflict and oppressive regimes (Cook et al., 2015; Crosby, 2013; Fazel et al., 2005; Heeren et al., 2012; Silove et al., 2007; Slobodin \& de Jong, 2015; Willard et al., 2014). Acknowledged in these associated accounts are common expressions of guilt, sadness, despair, fear, shame and psychological distress. With the formal recognition of PTSD in 1980, the refugee-related literature maintains a strong focus towards understandings of trauma and associated forms of Western psychopathology (Bracken et al., 1997; Fassin \& Rechtman, 2009; Summerfield, 1999).

The first mention of trauma in the Diagnostic and Statistical Manual for Mental Disorders (DSM) came with the third edition in 1980. In this updated manual, the PTSD diagnosis was the first classification to explicitly acknowledge external causation (a stressor) of the symptoms of distress. The diagnoses of PTSD and, to a lesser extent, depression, anxiety and schizophrenia, are now widely acknowledged mental health outcomes stemming from traumatic experiences related to war, conflict and political violence (see Marlowe \& Adamson, 2011). Now into its fifth rendition, the DSM-5 relies on traumatic experiences to 
help inform the diagnoses of disorders related to adjustment, acute stress, dissociation and PTSD.

Sociologist Vanessa Pupavac and anthropologist Lisa Malkki have written insightful responses to the discourses of refugeedom and note the historic shift of viewing refugees from a political perspective to a medicalized one. Malkki (1995, p. 510) critically reflects upon this tendency, stating:

The quest for the refugee experience (whether as an analytical model, normative standard, or diagnostic tool) reflects a wider tendency, in many disciplines, to seize upon political or historical processes and then to inscribe aspects of those processes in the bodies and psyches of the people who are undergoing them.

The practice of inscribing trauma into the body and psyche reflects a tendency towards medicalization and limits opportunities to consider wider notions of belonging and people's cultural, social and political histories. To outline this critique, Pupavac (2006) employs Talcott Parson's concept of the sick role where refugees are potentially seconded. Parsons (1965) presented the sick role as a form of sanctioned deviance. This role goes beyond simply being sick to having assigned rights and obligations based on the norms surrounding it. Pupavac argues that the sick role, as an ascribed status, moves refugee discourses from those with a political focus towards a narrowly medicalized lens of trauma that situates refugees as victims and burdens on society. This discourse is often informed through medicalized and individualized discourses of trauma, and expressed through assumptions about unemployability, adverse mental health outcomes, lawlessness and incompatibility in resettlement contexts - essentially the consequences of war trauma. As victims, the wider society is more open to accepting refugees as a form of charity, but this affordance also relegates them to be viewed as damaged. This extraordinary positioning of trauma and refugee lives thereby limits their opportunities for belonging and equal standing in the broader society.

Fassin and D'Halluin (2005) argue that the primary social currency in the terrain of truth for refugees rests predominantly with their physical and psychological injuries associated with the trauma that narrowly defines them. The evidence of trauma therefore provides a form of currency (and recognition) that facilitates admission into camps, obtaining refugee status and access to humanitarian pathways for resettlement. However, as Silove and Ekbald (2002) maintain, if refugees are presented to host countries as psychologically damaged, then the debates of asylum and resettlement can easily move from humanitarian responsibilities to the economic implications and associated fears of accepting them. One only needs to consider the heated debates and, at times, moral panic of resettling refugees across Europe, the United States, Australia and elsewhere to see how these arguments are constructed and justified.

The question that arises, then, is how does this critique relate to the book's focus? The extraordinary stories of trauma and how it has negatively influenced 
a person's life can easily overpower other considerations that might underscore something very different about what a person values or aspires to achieve - a focus that effectively 'domesticates the exotic' as Bourdieu cautioned in Chapter 2. ${ }^{2}$ This predominant emphasis obscures the political and social realities of everyday lives and reinforces a 'therapeutic culture' that neglects the wider acknowledgement of how unjust social policies, government agendas and powerful institutions place structural barriers to people's well-being and forms of belonging (Furedi, 2004; Kleinman, 1995; Marlowe, 2010a). These considerations require a macrolevel analysis to ensure that structural forms of oppression are not rendered invisible. A focus on the facets of belonging (particularly upon political/ethical value systems) and the associated political projects that are tied to each can help make this wider analysis visible.

\section{Labels: politics and diverging perspectives}

Related to this medicalizing critique, Zetter (2007, p. 188) demonstrates how bureaucratic powers deconstruct and reinvent interpretations of the refugee label to legitimize state interests, and argues: 'Labels reveal the political in the apolitical.' The supposed neutrality of biomedical perspectives masks the fact that labels create significant ramifications for people's wider participation in civil society and for their sense of belonging. And herein lies an area of major contention: Aroche and Coello (2004) identify two primary, and diverging, viewpoints within the literature that relates to people experiencing forced migration and trauma. The first perspective places a strong emphasis upon focusing on, and treating, psychological traumatization as a key element in post-conflict recovery. The second view critiques privileged Western concepts of psychopathology such as PTSD and depression as a form of medicalization that colonizes and silences indigenous knowledges, narratives and pathways to healing.

There is little question that experiencing significant trauma can result in negative mental health outcomes; much of the academic literature cites psychological distress and most notably PTSD as relatively common outcomes for refugees. For example, Silove (2004) establishes, in a systematic review of studies from wartorn countries, that the prevalence of psychological disorders surpasses those from non-war-affected Western countries. Fazel et al.'s (2005) meta-analysis of large PTSD studies also found that prevalence rates for resettled refugees could be ten times higher than that of the age-matched general population. Another meta-analysis of 59 studies found that refugees had poorer mental health outcomes than those of the general population (Porter \& Haslam, 2005). Most recently, a major study in Sweden found the incidence rate of schizophrenia between the Swedish-born, non-refugee migrants and refugees to be 38.5, 80.4 and 126.4 per 100,000 people respectively (Hollander et al., 2016). At the extreme end of the spectrum, another study reported that the prevalence of PTSD of conflict survivors in Sierra Leone was 99 per cent (K. De Jong et al., 2000). This last study is frequently cited as an example of how trauma-focused enquiry deduced from a Western perspective has limited use in other contexts. While this 
particular study could be a 'straw man' against the biomedical model, it does highlight the need to critically engage all forms of research-based enquiry with culturally and linguistically diverse populations and to render familiar constructs as strange.

The increased prevalence of psychiatric disorders is also supported by epidemiological studies where PTSD is higher in those who have experienced torture in relation to comparison groups (Jaranson et al., 2004). A study of more than 3,000 people from four post-conflict countries found that conflict-related trauma was a risk factor for the development of PTSD in Algerians, Cambodians, Ethiopians and Palestinians (J. de Jong et al., 2001). Several longitudinal studies also report similar conclusions. Mollica et al. (2001) found that Bosnian refugees who remained living in the region after the war still displayed psychiatric problems three years after assessment, suggesting a sustained psychiatric symptomatology over time and highlighting the importance of coordinated mental health intervention. These findings are supported by another longitudinal study of 240 refugees who reported ongoing severity and chronic post-traumatic stress and psychological symptoms over a three-year period (Lie, 2002). Overall, this literature generally evidences that trauma with respect to the specific type of exposure (i.e. rape, torture, extended stays in refugee camps) and dose effect (relating to frequency or number of experiences) and are risk factors for adverse mental health outcomes (Davidson et al., 2008; Ellis et al., 2014).

While these studies provide an important backdrop to understand the risk factors associated with meaningful settlement experiences, it is imperative to recognize that the forced migration literature generally demonstrates that the vast majority of refugees do not develop long-term psychiatric problems (Murray et al., 2008; Summerfield, 2005). The focus, therefore, can extend beyond trauma (without discounting it) to consider how is it that so many people are able to maintain their well-being and reduce the impacts of trauma despite what they endured (White, 2006). Others acknowledge how people can experience posttraumatic growth (Rosseau \& Measham, 2007; Simich et al., 2010). These salutogenic perspectives make it possible to honour the experiences of trauma while also considering people's pathways to healing. ${ }^{3}$

Miller et al. (2006) introduce a term, trauma-focused psychiatric epidemiology (TFPE) and criticize the unnecessarily narrow research focus on refugees that employs the biomedical model of psychiatry and the field of traumatology. While they recognize the importance of such studies, they also question the dominance that this emphasis has had upon other important perspectives, stating:

Reflecting its strongly positivist underpinnings, the TFPE framework has prioritized the identification of universal patterns of distress, emphasizing findings that can be generalized ... while minimizing the exploration of local variations in the ways that people understand, react to, and are affected by their experiences of violence and displacement.

(2006, p. 410) 
TFPE presents an important consideration among a number of other perspectives that more deeply acknowledge a person's social, cultural, historic, economic and current resettlement backgrounds. When juxtaposed, these understandings add depth and sophistication to people's forms of healing and pathways to responding to trauma, both past and present. As McFarlane (2004, p. 81) argues, the challenge in ascertaining psychological disorders across cultural, geographic and social localities is in establishing whether a person's reported distress and suffering is a normal and expected response to situations associated with forced migration or is actually indicative of a psychopathological condition. Although the symptoms of PTSD have been noted worldwide, Kleinman (1987) cautions that it is a categoric fallacy to assume, because the features or symptomatology of a particular psychological disorder are observed in one locality, that they necessarily mean the same thing in a different place.

Kirmayer (2007) writes about the 'failures of the imagination' whereby narrow, medicalized understandings of trauma obscure opportunities for a structural analysis and limit what might be possible for people's pathways to recovery. One of the principal issues with trauma studies is that it focuses on past experiences, often stemming from the forced migration journey with a dominant emphasis on the extraordinary. There is recognition, however, that trauma can be ongoing (challenging the notion of post trauma) and the settlement experience can sometimes be as traumatizing, if not more so, than the forced migration experience itself.

As Ryan et al. (2008, p. 2) importantly state: 'Trauma discourse focuses on high-impact events that occurred in the pre-migration environment. One of the dangers of this focus is that it overshadows basic needs in the present lives of resettled refugees.' Indeed, Miller et al. (2006) maintain that displaced survivors of political violence are often more concerned with the daily stressors related to adjusting within a new environment, social isolation and lacking access to basic resources. These concerns are not always directly related to past extraordinary experiences associated with war trauma/ political violence and rather, present challenges related to the everyday daily practicalities of living and social inequalities in resettlement contexts. This awareness requires an analysis that extends beyond medicalized understandings. I will illustrate this necessity and the potential of belonging and transnational relations in the case study that follows by examining the intersections between everyday and extraordinary lives, trauma and recovery for the South Sudanese community that has resettled in Adelaide, Australia.

\section{South Sudan case study: conceptualizing and responding to trauma}

On 9 July 2011, the world witnessed the birth of the 193rd country - the Republic of South Sudan. This country emerged as an independent state from Sudan after enduring more than four decades of conflict. Characterized by two civil wars since 1956, these protracted situations created one of the world's largest 
populations of displaced people. According to the UNCHR Global Appeal (2015) on the current situation in South Sudan, there are more than 2.1 million people internally displaced (UNHCR, 2017). These displacements from fertile agricultural lands have led to severe food shortages placing close to 6 million people at risk of starvation. As fighting intensified following violent conflicts in July 2016, the number of South Sudanese refugees increased to 1.26 million, making it Africa's largest scale refugee crisis. Jok (2015) maintains that the associated historical and contemporary conflicts have resulted in the deaths of more than 3 million people, with an additional 4 million displaced. While many understand these wars as a conflict between northern Islamic Arabs and southern black Christians, South Sudan is one of the most ethnically heterogeneous countries in Africa, meaning that these civil wars cannot simply be viewed as conflicts between ethnic or religious identities. This analysis requires additional attention to decades of exclusionary government policies and vested interests in land-based resources - most notably, oil (see Johnson, 2011). The recent events of 2016 and 2017 still leave South Sudan on the brink of civil war as different factions vie for power and influence.

It was in the late 1990s and early 2000s that the South Sudanese plight became well known on the world stage where numerous countries began resettling them under humanitarian auspices. There are now many autobiographical accounts and documentaries that attest to the experiences of civil war in Sudan (Bixler, 2005; A. Deng et al., 2005; Eggers, 2006; Hecht, 2005; Marier \& Ford-Williamson, 2014). A number of these stories are about young males who have become famously known as the 'Lost Boys', referring back to J. M. Barrie's fictional tale, Peter Pan. Displaced by war, these boys (and also girls - see Harris, 2010) acquired this label by walking unimaginable distances without their parents. They endured vast deserts, wild animals, hunger, sickness and conflict settings to find relatively 'safe' haven in Ethiopia from 1987 to 1991 and then travelled to Kenya's Kakuma refugee camp in 1992. Others found places of asylum in Egypt, Syria and other neighbouring African countries. Many were accepted for resettlement during this time. The South Sudanese diaspora now has large groups living in the United States, Canada, Australia, Sweden, United Kingdom, Australia and New Zealand. Their refugee journeys and the sensationalized descriptor of the Lost Boys are often what captures the attention of the reader and largely places their story within the sympathies and compassions of other people's hearts and minds.

The following case study represents a two-year research project documenting the in-depth narratives of 24 South Sudanese men who had resettled in Adelaide, Australia, as former refugees. More than 30,000 South Sudanese people have migrated to Australia via humanitarian pathways (Lucas et al., 2013; Robinson, 2013). The study's focus was to establish how these men, who were fluent in English and often leaders in their community, conceptualize and respond to situations involving trauma. ${ }^{4}$ Regardless of one's definition, it would be contentious to claim that the participants' narratives did not embody elements of trauma, many of whom identified as having the experience of the Lost Boys. However, 
the experiences of trauma and being a traumatized person can be very different things as the section that follows demonstrates. Analysis was carried out through a process of initial and focused coding, writing memos, theoretical sampling and using the constant comparative method as per constructivist grounded theory (Charmaz, 2006). In total, I conducted 70 interviews with the 24 participants alongside an ethnographic interaction with their communities (see Marlowe, 2010b, 2013).

The inclusion of the trauma story and responses to it are significant. Initially, I thought that participants would need a concise definition of trauma, but it was already a term very familiar to them. It was a word they learned would help gain entry into refugee camps, establish claims for refugee status and qualify for services in Australia. In this respect, trauma represented a form of currency that laid their claims for recognition and access to vital resources (Marlowe, 2010a). It was thus decided to allow participants to express trauma on their own terms and that provided opportunities to better understand their agency, approaches to resolving difficult experiences and what they view as their most salient concerns.

What follows is that participants respond to trauma through the important social and cultural functions located within the community milieu. Others identified how agential realizations of employment and education created pathways that embodied hope and offered resonant responses to trauma. Although all participants spoke of the trauma associated with forced migration, many noted that adapting to the new social realities in a new host country was as difficult (if not more so) than the adversities associated with forced migration. Such comments reinforce the importance of understanding their challenges holistically and how people create meaning and forms of belonging within particular social, political, cultural and transnational landscapes. The social and situational expressions that I describe below provide a basis for understanding how the South Sudanese participants defined and responded to traumatic experiences. These expressions are then related to facets of belonging and its transnational possibilities.

\section{Social expressions of trauma: transnational and local intersections}

The separation from friends, family and their community as a social expression of trauma was what participants most often described and defined as trauma arising from forced migration and resettlement. While this commentary is not altogether surprising, it is worth acknowledging the ways in which participants and community members highlight how separation causes ongoing problems in their lives and the importance of transnational relationships to resolve these difficulties. As Bhabha (1992, p. 88) notes: 'For the displaced or the dispossessed, the migrant or refugee, no distance is more awesome than the few feet across borders or frontiers.' Leaving behind communities when conflict surrounded them, crossing into neighbouring African borders and ultimately deciding to step on to a plane bound for Australia illustrates the symbolic power of crossing those 'few feet' between borders and frontiers. These liminal spaces provide a particular way 


\section{Responding to trauma}

to understand trauma, as it represents the separation of important social worlds and relations. The borders demarcated by national boundaries and barbed-wire fences in African contexts are now established by means of thousands of square kilometers of ocean. Thus, social, for this case study, considers the communal aspects of people's enduring ties to others living in places both proximate and distant - often across the seas.

One participant compares such fragmentation to a disease. He speaks about how it is possible to treat symptoms that are causing psychological distress but, if the underlying disease is not addressed (the separation), negative symptoms will continue: ${ }^{5}$

So, what I am talking now is just like [you can] treat the symptom, but the disease is still there. Or if you are sleeping with the symptom, might be that it will not go away ... So, what I mean with that is when we just sit down and we talk about what can help here [in Adelaide]. I just say being together is like helping with the symptoms. So it will help, but the disease - that is the separation.

(Participant 10)

Here, the social separation is expressed as an illness in sociological terms as the person directly experiences something that is distressing and/or causes pain in their lives. Even in the absence of diagnostic symptoms or pathology, the pain of the separation is very real, as illustrated in Coker's (2004) research with South Sudanese refugees and somatization (see also Kirmayer, 2007; Milner \& Khawaja, 2010; Westoby, 2009). Thus, the distinction between an illness (something that people experience as having an unpleasant impact upon their lives) and a disease (an abnormal and harmful condition in the human body) intersects with how a person's culture and social being influence these understandings (see Moore, 2004). A participant relates to the somatization of separation in the absence of a Western diagnostic condition:

Jay: So you have not seen your parents since $1987 ?$

Yeah. [Laughs] A long time. And where they are I do not know. I do not know what has happened. There are other people who I do not know about. It keeps me thinking a lot. But when I go to the hospital they tell that there is nothing at all, I am healthy.

(Participant 12)

In response to these social expressions of trauma, several participants state that being with other members of the South Sudanese community helps to alleviate the associated symptoms. As South Sudan had become increasingly stable, numerous participants returned home for the first time since being displaced. And social media provided a form of co-presence on a regular basis for many. These connections, local and transnational, provide a basis for understanding 
how everyday interactions (whether face-to-face or digital) significantly contribute to people's experiences of daily life and their capacity to respond to traumatic circumstances. These social connections were highly evident at community events as sites of belonging in which the group helps to shoulder the burden of individual difficulties: 'So problems become a shared kind of community problem so it is not an individual problem. When you take problem from an individual problem to a community problem, you have lessened that effect of it' (Participant 7).

Knowing that community support is available during hard times serves a vital role in giving people confidence that they need not face future difficulties alone. This knowledge underpins the expression 'putting hope in front of you' that many participants emphasize, thus demonstrating the importance of acknowledging people's endogenous pathways for resolving challenges. ${ }^{6}$ Similar studies with resettled South Sudanese communities also document the important local and endogenous social roles of healing (Harris et al., 2014; Khawaja et al., 2008; Shakespeare-Finch \& Wickham, 2010; Simich et al., 2010; Walker et al., 2015; Westoby, 2008; Wille, 2011).

In relation to the new social landscapes that the South Sudanese community members in Adelaide found themselves, they developed weekend language classes for their children and other initiatives to bring family and friends together and reinforce honoured memories and traditions. I was invited to community functions on numerous occasions because someone in Africa had died due to sickness, violence or lack of basic amenities such as food and shelter. Other events involved meetings where the community would discuss how to respond to crises that were occurring back in South Sudan on local, regional and national levels. Numerous members of the community (young and old) have Facebook pages with sometimes more than 300 South Sudanese online friends with whom they actively communicate. Skype, WhatsApp and Viber have become part of some people's weekly, if not daily, interactions with the South Sudanese diaspora where everyday life in Australia and South Sudan at times coincides.

Thus, navigating a new social reality in resettlement contexts highlights the importance of belonging and transnational relations to navigate/reconcile a workable synthesis between one's past and present. These interactions also demonstrate the potential of transnational portals that allow people to interact across borders through digital communications and remittances. At other times, these social engagements represented more of a transnational gaze where they are able to look from afar but their participation is limited due to personal choice or because of ongoing protracted conflict, limited infrastructure and other access issues, such as poverty and literacy, constrain opportunities. This transnational gaze/portal highlights how many people maintain responsibilities, roles and commitments in two or more countries. It also helps explain why separation from community and family is one of the most common expressions of, and responses to, trauma.

The associated transnational interactions provide the South Sudanese with a powerful link to their past histories and social relations that places them as being here and there and thereby extending their possibilities of belonging. As Rosińska 
(2011) suggests, these multi-stranded and multi-local socialities reinforce memory and belonging by encouraging a South Sudanese identity that supports resettled communities to bear hardships and encourages a sense of community through collective recollection. Such forms of social networking provide an enduring bond for the South Sudanese diaspora that inculcates a sense of belonging and offers resonant approaches to respond to trauma. And, while the importance of community is clear (with some caveats presented in the discussion that follows), participants importantly position belonging alongside wider opportunities to engage with the host society.

\section{Situational expressions of trauma: everyday belonging and misrecognition}

The second most common expression of trauma relates to what I term the 'situational' that refers to reduced or non-existent opportunities to pursue meaningful civic engagement in forced migration and settlement contexts. Many participants mention that resettlement opportunities are where they place their hopes of effectively addressing past traumatic experiences, most notably through education and employment. However, the multiple social, cultural and historical contexts that new arrivals must navigate can make the tacit assumptions of Australian life extra burdens to negotiate. These situational expressions of trauma challenge their (gendered) sense of self-concept as providers for family and community wellbeing. Correspondingly, opportunities for employment and education as forms of self-determination are pathways to address these challenges.

Well, keeping [hope] constant in the sense that I looked at myself as a person who was resourceful in the first place. And through all of that, I had no opportunity to use my personal resources or contribute but through that hope - I believed that I had something to offer - it kept me going.

(Participant 23)

This example, similar to those from many participants, demonstrates that believing one has something to offer and the hope to contribute in the future sustains the person through harrowing experiences. Another participant speaks of 'diploma disease' that makes it difficult to secure a job:

Because in the Western World, there is this practice which I call getting the certificate in order to be accepted. I call it diploma disease. When they [employers] say, 'But where is your diploma?' even if you are able to do the job properly.

(Participant 21)

This situation is evident in Australia where the literature acknowledges that African migrants have higher unemployment rates, and, when employed, occupy 
lower-status jobs (see Colic-Peisker \& Tilbury, 2006; Fozdar \& Torezani, 2008; Tilbury \& Colic-Peisker, 2006). These concerns, while not negating the impact of war trauma and negative mental health outcomes, highlight the relevance of situational expressions of trauma in settlement contexts. Failing to recognize people's responses and focusing on extraordinary stories of trauma effectively misrecognizes refugees as permanently traumatized and limits possibilities for their civic engagement and participation.

As a refugee, we are concerned about how refugees are portrayed. One of these problems is that people assume that refugees are traumatized people. And actually this assumption has become one of the factors that has led to some of us not getting work because employers think, 'Why should I employ people who are traumatized?

(Participant 19)

We need to get rid of that thinking that our people are traumatized. We were traumatized - yes, this is true and that is fine. But that does not mean what we are. We are something different and we can provide. We can offer. We can contribute.

(Participant 18)

These men are not only expressing concerns about being labelled as traumatized, but also about the parity of participation in employment, education and other aspects of civic life. Almost all participants emphasize how opportunities for meaningful work and receiving an education have been pathways to rekindle hope and respond to trauma for themselves, their families, community and transnational relations. Such opportunities, however, are potentially blocked by exclusionary practices, exemplified through sensationalized media presentations, polarizing political commentary and unfounded racist claims. These powerful voices and mediums create exclusionary spaces, thereby diminishing opportunities for participation as peers in society. As established in the last chapter, politics is the business of having a say in something that counts.

\section{The politics of belonging}

As established in Chapter 2, political projects shape the facets of belonging. Correspondingly, accepted trauma discourses situated within the extraordinary can powerfully influence the opportunities people have to belong. These dynamics are exemplified when the then Australian Immigration Minister, Kevin Andrews, argued that South Sudanese people were failing to integrate into the fabric of Australian society. His comments came just several weeks before a major federal election highlighting how powerful ethical value systems inform people's perspectives on who belongs. He stated his concern that some groups of refugees 'don't seem to be settling and adjusting into the Australian 
way of life as quickly as we would hope' (Hart \& Maiden, 2007). Windle's (2008) analysis exemplifies how such commentary was further emboldened by media representations of South Sudanese youth in racialized and discriminatory ways. Nearly every participant in my study critically mentioned the minister's statements and spoke of the increased experiences of racism and discrimination that followed, highlighting how particular discourses about refugees can powerfully impact on people's sense of belonging in a wider society (see also Baak, 2011).

Sometimes people can abuse you, and the things like Kevin Andrew says, what brought us here to Australia is not because we are looking for something to eat, it is war. That is what brought us here. We ran there because we wanted the freedom. That is why we came here. To be safe. So, it affects us and it is a new place for us here now, we are not settled. It is hard for me and my children.

(Participant 12)

Andrews's comments, as echoed sentiments of the state, are exclusionary in that they create an othering dynamic (see Bhabha, 1994; Dona, 2007; Said, 1993). The previously discussed process of identifying a refugee as a traumatized person alongside a supposed inability to integrate with Australian values (whatever these are) further limits Sudanese people's parity of participation as peers in social life.

As previously discussed, Yuval-Davis (2011) claims that what makes belonging political is when a person's sense of belonging is threatened or challenged in some way. Just several weeks before a federal election, the politics of belonging demonstrated that refugee settlement is about having a say in something that counts - in this case, the acceptance of a relatively small community to bolster wider electoral perceptions of protecting 'Australian values' and keeping the country 'safe'. Australia has a history of these divisive forms of politics (Fiske \& Briskman, 2016). And these politics of fear and forms of othering are by no means unique to Australia - stringent forms of xenophobic nationalism are taking strong root in North America, across Europe and other places impacted by mass migrations of displaced people.

While examples of overt racism and blatant exclusionary policies are relatively easy to recognize, it is the tacit and often well-intentioned forms of misrecognition that can be much harder to pinpoint. An example of the well-meaning, but somewhat misguided approach to assisting refugees is contextualized through my experience working with universities in New Zealand and Australia. Across a number of faculties, these universities have identified that a significant number of tertiary refugee background students are struggling to pass their coursework. In relation to this, a university- based academic support service sent the following email correspondence asking if I would meet with them to discuss finding approaches to better meet the needs of the South Sudanese student body: 
Hi Jay, a colleague gave me your name as a person I might speak to regarding Sudanese students. There have been some calls for extra support for Sudanese students who are struggling academically. We are trying to find out if there has been any research on the problems/progress of Sudanese students at university and how we might best support them. We are aware that there are many issues and that it is not only Sudanese students who have suffered atrocities and who are encountering some difficulties.

(Personal correspondence)

This support service obviously has good intentions to assist refugee background students. However, the atrocities experienced and the underlying assumptions of trauma show that the locus of enquiry (and associated value systems) is, in significant part, upon traumatized students, rather than possibly how university structures are not meeting the needs of increasingly diverse student bodies or how a Western education often unknowingly promotes a predominant discourse and pedagogy.

The misrecognition of traumatized students obscures the important consideration of how university structures may unwittingly create learning spaces or academic policies that can be exclusionary and non-reflective - i.e. the problem is about them. This extraordinary focus significantly reduces the possible ways in which people might belong. Much like the former minister's comments about South Sudanese people failing to integrate, these particular statements, often couched within biomedical conceptualizations of trauma and negative mental health outcomes, render discriminatory practices and institutional oppression invisible. This shift depoliticizes and decontextualizes refugee lives in settlement contexts within a narrowly defined purview and limits opportunities for belonging.

\section{Transnational settlement, trauma and belonging}

Bourdieu's (1977) concept of habitus, which highlights the interplay between the conscious strategic actions of people and the often unconscious elements that place powerful influences upon them, is particularly relevant here. It highlights how constructions informing the terms such as culture, trauma and masculinity are often indiscernible, and how the subjective nature of people's actions and forms of belonging become entwined with cultural dynamics and powerful institutional structures (Webb et al., 2002, p. 58). As noted in Chapter 2, the facets of belonging involve political projects that define the ways in which people can, and cannot, belong. The associated politics (as in having a say in something it counts) occurs at the intersections within and between different groups that include considerations of gender, age, ethnicity, spatial distribution and structure.

The social and situational ways of understanding and responding to trauma illustrate that the facets of belonging are powerfully intertwined with its associated politics; these occur within family, community, wider society, institutional 
and in transnational contexts. This case study outlines how a focus on the extraordinary and on trauma impacts on the experiences of recognition and redistribution as follows:

- Participants most often situate expressions of trauma within the social and situational domains in which there are limited opportunities to contribute to their own community's well-being and that of the greater society.

- Participant responses to trauma are often located in their social and cultural milieu. In addition, opportunities to participate in civic society can help people put 'hope in front of them', address past transgressions and support everyday forms of belonging through social interaction, employment and education.

- The resettlement experience can be just as (if not even more so) traumatizing as forced migration due to negotiating a new social reality, highlighting the need for a concurrent everyday analysis.

- Trauma is a word highly familiar to participants - in many respects it represents a currency that has helped them lay claims for recognition (entry into camps, refugee status determination and access to services in Australia). This currency, while providing a justification for particular forms of support, also reinforces a form of othering that limits the parity of participation in civic society.

What emerges is that the associated social and situational expressions of trauma and the participants' responses to it have clear links to their local and transnational networks highlighting the importance of the everyday and multiple forms of belonging. For many, ongoing transnational relations help to provide forms of support through othering and discriminatory practices in settlement contexts (see Kassaye et al., 2016). Van Hear (2014) acknowledged transnationalism as a potential 'enduring solution' for families and communities separated by the circumstances of conflict and ongoing persecution. As an enduring solution, it is clear that the experience of trauma, whether past-oriented or ongoing, can have significant repercussions for belonging in local and distant places.

The significant body of literature documenting the incidence of remittances being paid to family members and friends who are living in a migrant/refugee's place of origin or elsewhere in the diaspora highlights the importance of work in settlement contexts to a wider transnational commitment (Akuei, 2005; Esnard \& Sapat, 2011; IOM, 2016; Lindley, 2007; Stoll \& Johnson, 2007; World Bank, 2016). Zetter (2007) cites several sources, noting that migrant remittances in some countries substantially exceed the financial aid provided by OECD countries for development. The responsibilities associated with these duties are manifold and create additional pressure in already difficult settings. Finding the right balance between one's obligations in settlement contexts and supporting family and friends back in their home countries and the wider diaspora can be a difficult, if not nearly impossible, situation to navigate and shows how the lived experiences of trauma are both transnational and ongoing. Stoll and Johnson (2007, 
p. 627) acknowledge the immense emotional and financial strain that these people can experience when trying to fulfil their role as local and transnational 'breadwinners'. These ongoing relationships illustrate the possibilities and tensions of transnational flows that relate to a diverse set of cultural, social, financial and political exchanges.

It is also necessary to recognize that transnational possibilities are powerfully coupled with local experiences, relationships and opportunities. In many ways, the present informs the past and vice versa. If people are employed and feel that they belong in resettlement localities, this can shape their perspectives of trauma in powerful ways. Likewise, if meaningful connections to their pasts are inculcated, often through bringing these relationships and honoured histories into the present via increased mobility and digital connectedness, this can also have an important impact. What these dynamics mean is that there is a need to consider trauma within transnational and local frames in relation to how traumatic experiences might play out across numerous localities and how these are effectively responded to and informed by multiple sources and places.

While it is important to consider the potential of particular local and transnational relationships for trauma recovery, these should not be romanticized. Several authors write about when communities are predominantly defined along one social axis (often an ethnic or ethno-national identifier) that it is easier for there to be invisible power structures to outsiders that may be uncompromising, unhelpful and potentially oppressive (Marlowe, 2011; Simich, 2004; Stoll \& Johnson, 2007; Wessells, 2007; Westoby, 2009). This is why the recognition of the facets of belonging is helpful as it locates the ways in which people belong within multi-scalar and multi-local sites. Thus, belonging is not just about an ethnic or ethno-national identifier. It involves numerous actors and institutions that may be both proximate and distant geographically.

\section{The facets and intersectionality}

Returning to Yuval-Davis's call to consider belonging from an intersectional frame, it is possible to move beyond reified understandings of particular communities and the dangers of identity politics. This recognition, however, is not just about taking a culturally flexible or relativist position as it is also necessary to acknowledge how people are able to maintain, honour and validate the important past histories that they carry with them. An intersectional analysis demonstrates this dynamic as various forms of identify, affiliation, history and power relations come together.

\section{Social locations}

The social locations that inform belonging are, at times, powerfully ascribed in ways that may afford little choice over the voluntariness of association. For many South Sudanese people, they are first and foremost seen as such, and this is the master status that they themselves and the wider society associate. While this is 
not necessarily problematic, it becomes so when this singular social location is used in such a way that it limits the means by which this group can be understood and potentially reifies an ethnic or ethno-national label. Yet, the people from South Sudan come from many different and diverse ethnic groupings. There are incredibly powerful gender roles and age-based hierarchies. Diverse cultural and social histories shape how South Sudanese people create meaning. And, like so many other people from refugee backgrounds, they continue to negotiate these various social locations in a new settlement context.

Significant social and cultural changes that often accompany the experience of refugee settlement cannot be adopted or accommodated flippantly. The difficulty of compromise between one's past and present is an important consideration and highlights the potential losses in the contradiction of cultures and gender roles. The men in this case study spoke about the tensions involved with increased childcare and household-based tasks. Others spoke about how women were sometimes able to secure work more easily than the men, challenging traditional notions of masculinity and the local and transnational breadwinner.

Numerous Sudanese community members spoke about how raising children was a shared community responsibility in Africa, whereas in Adelaide, they found themselves widely dispersed. The fragmentation of living spaces and the fact that many Sudanese people do not know the names of their neighbours highlight how childcare practices that work in one setting may not be as viable in another. The children themselves are thrust into powerful peer culture environments that may contradict their parents' teachings. The male participants expressed how women now had access to bank accounts, were enrolling in tertiary education and holding paid jobs (though in the minority). Others pointed to the increased prevalence of divorce and family separations as worrying developments (S. A. Deng \& Marlowe, 2013). These experiences can lead to culture shock that not only (re)defines gender relations, but also to other social locations and practices that relate to culture, parenting and everyday interactions that inform people's identifications and emotional attachments. Such dynamics can bring about a renegotiation of power within gender roles and other culturally informed practices.

\section{Identities and emotional attachments}

What makes settlement different from forced migration contexts, to a degree, is that many people have opened themselves to (and even embraced) the hope that their lives will be markedly better when they can finally address the social and situational expressions of trauma. Countries of resettlement are often presented as a utopian construct in refugee camps as lands of golden opportunities where everyone can find riches almost beyond the imagination. Such discourses are supported in American popular culture, evident in music videos that embody rampant materialism, the 'pull yourself up by your own bootstraps' folklore of capitalist enterprise and the Western promise of the market's unbiased hand. These discourses fail to acknowledge the lack of employment opportunities, 
experiences of misrecognition, discrimination and the educational obstacles that many refugees must navigate in settlement contexts.

While resettlement in Australia is far from life in refugee camps, the multiple challenges of creating a new existence have proved daunting as refugees transition from one social world to another. As Westoby (2006, p. 157) writes about Sudanese people's lives within the contested landscapes of trauma and recovery, 'there is little space for refugee voices to interrupt these colonizing processes and articulate their own aspirations for reconstructing a social world that would facilitate well-being on their terms'. Part of promoting well-being on the participants' terms is allowing them to express their conceptualizations of, and responses to, trauma rather than making a priori assumptions about it. This wider and more inclusive analysis thereby provides the basis to consider the ways in which people's identifications and emotional attachments can help transcend extraordinary circumstances.

\section{Political and ethical value systems}

Misrecognition - often with an externally represented focus on the extraordinary can easily position refugees as traumatized and reduce opportunities for wider engagement in their new host society. As already established in the earlier review of the medicalization of trauma, while there is no question that forced migration can be traumatizing, it does not necessarily follow that a refugee is a traumatized person. This perspective is highly important if resettled refugees are to be able to participate as equals in civic society, returning to Fraser's (2003) concept of the parity of participation, as discussed in Chapter 2.

Gainful employment relates to one's capacity to help oneself and others - it is a direct link to agency and forms of belonging that provide alternatives to dwelling on traumatic experiences. A well-documented experience for many migrants and refugees, however, is that their background and training are neither highly valued nor acknowledged in a new country (Correa-Velez et al., 2013; Fozdar, 2012; Losoncz, 2011; Marfleet, 2006; Nunn et al., 2014; O’Donovan \& Sheikh, 2014; Tomlinson, 2010). The critique outlined earlier in this chapter demonstrated that trauma-dominated perspectives, looking into negative mental health outcomes, can encompass people within the pathologized and victimized master status of refugee. This master status, once ascribed as a dominant social location, predictably limits the opportunities for meaningful employment and social engagement in resettlement contexts.

Recognizing the everyday stories of refugee lives is just a beginning step towards acknowledging people beyond trauma-dominated perspectives. As Markell (2003) acknowledges, the mirror must be turned on the misrecognizers who often rely upon the extraordinary to develop, at best, an overly simplistic generalization of a group of people and requires a critical examination of why such misrecognition is happening and what might be the consequences, in relation to both distribution and recognition. Such reflexive practices (provided with the political and social will) are foundational starting points to place higher value 
on the everyday stories of refugee lives, something I focus in greater detail in Chapter 5 through a human rights lens and a conceptual practice framework.

Billig's (1995) conceptualization of 'banal nationalism' highlights how migration can make the everyday ordinary into 'exceptional' as it creates opportunities for identification that are not readily available in settlement contexts. It also signifies how belonging needs to be conceptualized beyond merely an ethnic frame or within one dominant social location. The associated shift in thinking about traumatized individuals to asking why particularly difficult experiences have occurred can also help to render other important considerations visible that include structural inequalities; unjust social policies; uneven social locations and the domains of power as to who has a say in something that counts. These broader levels can directly impact upon local and transnational forms of healing, resistance and recovery. I now shift this chapter's focus to what is seen as perhaps the most contemporary pressing issue related to forced migration, persecution and the search for durable solutions - the displacement of millions of Syrian people.

\section{Syria: a global resettlement response}

The number of forcibly displaced Syrians is a rapidly evolving situation and one that is difficult to accurately quantify because of the various movements of people and multiple border crossings. The conflict arose from the 2011 Arab Spring protests that occurred with armed insurgencies in Libya, Yemen and Syria, and significant civil demonstrations across Egypt, Algeria, Tunisia and several other countries. In Syria, President Bashar al-Assad's government forces violently opposed these protests and this led to a civil war that is being fought across numerous fronts. There are international forces fighting for and against the government, several jihadist groups (most notably the Islamic State of Iraq and the Levant) and Kurdish militias. This regional conflict characterized by complex sectarian oppositions and proxy war demonstrates an international geopolitical struggle that posit superpowers in tension with one another (Ferris \& Kirisci, 2016). And while these local, regional, national and international battle lines are being waged through conflict and diplomacy, it is the Syrian people who largely have little to do with the associated politics and positioning for power and who bear the brunt of the associated actions (and inactions).

The UNHCR (2016) notes that there are now close to 5 million Syrian refugees in neighbouring countries of asylum, Europe and in other locations. More than 6.5 million people are displaced internally. The High Commissioner for Refugees, Fillipo Grandi, has emphasized that the Syrian crisis is global, noting the numerous countries and continents to which Syrians have now fled. The UNHCR reports that more than 2.8 million Syrian refugees have been registered by the government of Turkey. Lebanon has received more than 1 million and Jordan 650,000. During March 2016, the EU signed a deal with Turkey that would allow Greece to return all 'new irregular migrants' to Turkey in exchange for EU member states' increased resettlement of recognized Syrian refugees residing in Turkey as well as visa liberalization for Turkish nationals. This agreement raises 
questions about potential EU law violations and is also under a cloud of controversy after the failed Turkish coup that occurred in July 2016.

The numbers of Syrian refugees who are being resettled across Europe, North America and Oceania also highlight heated debates about international obligations to settle them and the associated consequences (good and bad) for receiving societies and countries of asylum (Ignatieff, Keeley, Ribble, \& McCammon, 2016). The political projects of belonging are strikingly apparent here as different groups make cases for welcoming refugees and others argue to shut them out. Questions arise about refugees' ability to integrate, about the impacts of traumatized people, whether they can be trusted and their commitments to local places and their associated values.

Recent headlines of media stories covering Syrian refugees resettling in numerous countries shows how trauma can easily paint a picture of damaged people with unpredictable mental health outcomes, making it an easy step for the public to shift their views on refugees as at risk to a risk.

- Migrant crisis: Trauma takes toll on mental health (United Kingdom, 22 December 2015).

- Syrian refugees plagued by high rates of PTSD (Canada, 22 November 2015).

- Separation anxiety: trauma of underage refugees alone in Germany (Germany, 6 November 2015).

- Refugees at High Risk of Schizophrenia, Study Says (Sweden, 17 March 2016).

- Fears underfunding of Wellington health services will 're-traumatize' Syrian refugees (New Zealand, 18 February 2016).

- Syria's refugee children - Germany underprepared for trauma therapy (Germany, 3 September 2015).

- As US braces for Syrian refugees, mental health services lag (United States, 28 October 2015).

Echoing Silove and Ekblad's (2002) warning, if refugees are presented to host countries as psychologically traumatized, the debate over asylum can easily move from humanitarian responsibilities and protection to inevitable economic implications and associated public fears of accepting refugees. Alongside this concern is the caution of minimizing trauma's impact. Some of the associated stories (above) try to find a balance in presenting trauma. How these stories are interpreted and re-represented by particular political parties and received by the wider society highlights the politics of belonging and how multiple interests are at stake.

The United States government, under the Obama administration, announced that it would accept 85,000 and 100,000 refugees in the 2016 and 2017 fiscal years (each begins on 1 October), largely in response to the mass displacement of Syrians. The previous year the number had been set at 70,000. This announcement has set the scene of some heated exchanges with state governments that 
have actively looked to curtail such initiatives. As of early 2017, the newly sworn in Trump administration pronounced a 120-day suspension of the refugee resettlement programme, with a cap of 50,000 admissions upon resumption - refugees from Syria are to be excluded indefinitely. The associated outcomes of such sentiments create a sense of alienation and non-belonging for the communities labelled by such broad approaches. President Trump proclaimed a halt to immigration from seven Muslim majority countries as part of his campaign promises and signed an executive order to that effect within a week of taking office. ${ }^{7}$ Political parties across the globe are forwarding similar policies. These developments impact on the receiving society's acceptance of particular groups and substantially influence people's sense of belonging, arguably one of the most potent forces to combat radicalization and terrorism (see Croucher, 2003).

The principal discourse that informs such intransigence is of terror and a fear of Islam. However, the economic toll on state coffers and resources for supporting 'traumatized populations' is also part of the associated political and populist thinking. The Governor of Alabama was quoted as stating, 'I will not stand complicit to a policy that places the citizens of Alabama in harm's way.' ${ }^{8}$ A series of other governors, predominantly Republican, also made similar statements regarding wariness and, at times, complete opposition to Syrians being resettled in their respective states. ${ }^{9}$ During his presidential campaign, Donald Trump encouraged supporters to 'lock [their] doors' to remain safe from the Syrian refugees who would be settled where people are living.

Germany has welcomed more than a million refugees over the last two years with the majority coming from Syria and Iraq. Although the country under Chancellor Merkel's leadership has received international recognition for its humanitarian commitment, cracks are showing within the political and populist landscape. The allegations of sexual assaults over the New Year and 2016 terror attacks in Paris and Brussels have ignited concerns about the country's security and its identity with such large influxes. A group of German psychotherapists sensationally claimed that at least half of the refugees who have come to the country have a psychological illness. ${ }^{10}$ While no evidence from reputable studies were provided, this alarmist headline reported in numerous media outlets furthers the othering of Syrians who come to Germany.

The politics of fear through trauma and terror have provided a context where right-wing, anti-immigration groups in Germany such as the PEGIDA (Patriotic Europeans Against the Islamization of the West) and Alternative fuer Deutschland (Alternative for Germany) have made recent electoral gains. And, more broadly, neighbouring countries are blaming Germany's welcoming approach for the increased numbers of 'migrants' at their borders. Multiple polls and analysts suggest that Chancellor Angela Merkel and her Christian Democratic Union (CDU) stance toward asylum seekers may represent their downfall.

The status of the Schengen and the EU in general is now more tenuous than ever, highlighting the interplay between everyday/extraordinary stories, multiple belongings and how the securitization of borders can impact upon people's mobility and opportunities for transnational relationships. The UK referendum 
that brought about the processes for an exit from the EU was powerfully informed by anti-immigration sentiment. The risk of terrorism is predominantly fuelling this fear and populist concern within these countries. Alongside an extraordinary focus on trauma arising from forced migration, these perspectives create a stark distinction between $u s$ and them, or, more specifically, refugees and the receiving society. Again, it is in these contexts that belonging suddenly becomes apparent as it appears under threat, making the receiving society suspicious and often defensive.

This politics of fear is not the rule, however. Pockets of resistance to these orders have emerged all over the United States and these have come from government, non-government, faith-based and civil society groups. Canada successfully committed to settling 25,000 Syrians. Australia agreed to resettle an additional 12,000 Syrians over its annual quota and in 2015, New Zealand made a commitment to take an extra 600 people. While these institutional initiatives and support show positive signs of negotiation, there are also many others that show a strong resistance to, and fear of, refugees and asylum seekers.

Although trauma is a powerful medium to communicate forced migration experiences, it is only part of the picture as to how refugees are represented and understood - at times in justified ways and at others less so. The experiences of trauma are important to recognize, and also that traumatic experiences do not result in irreparably traumatized people, a perspective often forgotten in the moral panic of mass migrations, nationalistic concern and political opportunism. The focus of this chapter is not intended to further polemicize the debate between Western approaches to healing and otherwise. Rather, it echoes the call to critically engage with dominant and extraordinary discourses to examine a number of possible perspectives and pathways towards understanding and working alongside everyday lives within an intersectional and multi-local analysis.

\section{Conclusion}

Thuan Pham fled Vietnam in 1979 as an unaccompanied minor on a harrowing journey to the United States when he was only 10 years old. He is now the chief technology officer of Uber, the multinational online transport network company. When interviewed on the $\mathrm{BBC}$ radio programme, The World Tonight, about this journey he noted: 'The experience did not scar me. If you live in a place where there is freedom and opportunity, you can make it. ${ }^{11}$ His comments reiterate the importance of differentiating between the experience of trauma and of being traumatized. Mitchell Pham, another unaccompanied minor from Vietnam came to New Zealand in the mid-1980s after surviving a dangerous voyage in the South China Sea and living in a refugee camp in Indonesia. In 1993, he co-founded and is now director of an international company (Augen Software) that employs 40 people to find innovative business solutions through technology. He has given numerous talks about this experience and has summarized it as 'born in Vietnam and made in New Zealand'. 
As an enduring solution, transnational relations demonstrate how people respond to trauma not only through the support of those who live around them and local opportunities but also across borders. Recognizing that less than 1 per cent of the world's refugees will be resettled highlights the possibilities of ongoing relationships and interactions with transnational family and friends. And while these connections to the 99 per cent are important to consider, meaningful local relationships and civic engagements are also needed. It is in this sense that transnational settlement is best envisaged as the spatial interplay between people, experiences and opportunities to participate in societies that are proximate and distant. The conceptual practice framework in Chapter 5 provides a basis to think through such possibilities.

Despite the traumas associated with forced migration, other people from refugee backgrounds have gone on to make amazing contributions to their communities that include scientist Albert Einstein; co-founder of Google, Sergey Brin; professor and political activist, Elie Wiesel; writer, Mulan Kundera; ethnologist, Claude Lévi-Strauss, and singer, Miriam Mabeka, among many other examples. ${ }^{12}$ Whilst recognizing these successes, it also necessary to acknowledge that the experience of trauma can have significant impacts on individual, family and community health. Because of this, biomedical perspectives can provide important insights into increased risk factors for both physical and mental health and well-being. And critically, alternative perspectives that incorporate a more holistic understanding of people's lives are also needed.

A focus that embraces both the extraordinary and the everyday can broaden dominant discourses whereby refugees are able to achieve civic parity and offer meaningful contributions to a host society. The next chapter introduces a case study that involves the experience of disasters that are also often positioned within extraordinary purviews. Alongside pathologizing discourses, refugees are predominantly viewed (misrecognized at times) as indelibly vulnerable in the extraordinary contexts of a disaster. The focus on disasters also highlights how belonging, transnational relations and a joint emphasis on the everyday and the extraordinary help to navigate such theoretical terrain and pathways to recovery.

\section{Notes}

1 This chapter presents previously published material from the Journal of Refugee Studies, Australasian Review of African Studies and Studies in Symbolic Interaction. The references are as follows:

Marlowe, J. (2009) Conceptualising refugee resettlement in contested landscapes. Australasian Review of African Studies, 30(2): 128-51.

Marlowe, J. (2010) Beyond the discourse of trauma: Shifting the focus on Sudanese refugees. Journal of Refugee Studies, 23(2), 183-98. doi:10.1093/jrs/feq013

Marlowe, J. (2013) Going Slowly Slowly: An Ethnographic Engagement with the South Sudanese. Studies in Symbolic Interaction, 40(1): 153-73.

2 There are exceptions to this, of course, where media representations and statements from politicians focus on refugees as people and have a positive focus where they are able to make meaningful contributions to society. However, the power of negative reporting and the headlines of extraordinary stories can easily overpower and obscure such understandings. 
3 The term salutogenesis was coined in 1979 by medical sociologist Aaron Antovoksy who suggested that the primary emphasis of healthcare should be on the development of promoting health rather than placing the major attention on pathology or disease. This shift meant that, instead of starting from a disease- or problem-focused perspective, the beginning point centred on people's and communities' health potential that support conditions of optimal social, physical and mental well-being. Salutogenic principles do not deny the presence or importance of pathology, although its health focus means that it looks for the precursors to well-being rather than making a primary emphasis on reducing risk and treating disease.

4 It is also necessary to acknowledge that the men interviewed do not include nonEnglish speaking South Sudanese community members. Despite initial intentions to use interpreters, it proved extremely difficult to locate interpreters who were acceptable to the different subcommunities of the South Sudanese community in Adelaide. While this study has not incorporated these voices, it is important to acknowledge that a better understanding of this population (which is more difficult to access) is very much needed. The fact that the participants come from a relatively privileged position within their communities (as evidenced by status and educational levels) highlights again the importance of locating the multiple social locations of the South Sudanese men that this study accommodates.

5 All participant quotes are placed in italics and a number is provided to illustrate the broad range of participant comments that speak to the associated analysis.

6 Many times I observed the community's ability to respond to difficulties situated in both the past and present. These comments are bolstered by fieldwork observations at community mourning events where there were multiple mattresses lying on the floor and women were cooking for almost 100 people, with children running in every direction. A number of these people would remain in the person's home and sleep there to ensure that the person was never alone in the early stages of a major loss. On many levels, the community provides support as a given rather than from a special request where the community provides a resonant social pathway for working through major difficulties and obstacles.

7 The timing of this order was particularly criticized for its signing on International Holocaust Remembrance Day.

8 See Governor Bentley's tweet from his twitter account: https://twitter.com/ governorbentley/status/666094657487642624

9 Governors from Arkansas, Arizona, Colorado, Florida, Georgia, Illinois, Iowa, Indiana, Kentucky and Texas have made similar statements. It is worth acknowledging that not all Republican governors expressed such views. The Governor of Michigan, for instance, acknowledged the contributions that refugees had made to the state and that they would consider additional Syrians with the appropriate security clearances.

10 See: http://medicalxpress.com/news/2015-09-refugees-traumatised-germanpsychotherapists.html

11 See: www.bbc.co.uk/programmes/p03vbrp5 for the full audio of the interview.

12 See: www.unhcr-centraleurope.org/en/about-us/unhcr-people/prominent-refugees.html? start $=0$ for a list of 20 prominent people from refugee backgrounds.

\section{References}

Akuei, S. (2005) Remittances as unforeseen burdens: The livelihoods and social obligations of Sudanese refugees. Retrieved from: www.iom.int/jahia/webdav/site/myjahiasite/ shared/shared/mainsite/policy_and_research/gcim/gmp/gmp18.pdf

Aroche, J. \& Coello, M. (2004) Ethnocultural considerations in the treatment of refugees and asylum seekers. In J. Wilson \& B. Drozdek (eds) Broken spirits: The treatment of 
traumatized asylum seekers, refugees, war and torture victims. New York: BrunnerRoutledge.

Baak, M. (2011) Murder, community talk and belonging: An exploration of Sudanese community responses to murder in Australia. African Identities, 9(4): 417-34.

Bhabha, H. (1992) Double visions. Artforum, January, 82-90.

Bhabha, H. (1994) The location of culture. London: Routledge.

Billig, M. (1995) Banal nationalism. London: Sage.

Bixler, M. (2005) The lost boys of Sudan: An American story of the refugee experience. Athens, GA: The University of Georgia Press.

Bourdieu, P. (1977) Outline of a theory of practice. Cambridge: Cambridge University Press.

Bracken, P., Giller, J. \& Summerfield, D. (1997) Rethinking mental health work with survivors of wartime violence and refugees. Journal of Refugee Studies, 10(4): 431-42. doi:10.1093/jrs/10.4.431

Charmaz, K. (2006) Constructing grounded theory. London: Sage Publications.

Cienfuegos, A. \& Monelli, C. (1983). The testimony of political repression as a therapeutic instrument. American Journal of Orthopsychiatry, 53(1): 43-51.

Coker, E. M. (2004) 'Traveling pains': Embodied metaphors of suffering among Southern Sudanese refugees in Cairo. Culture, Medicine and Psychiatry, 28(1): 15-39.

Colic-Peisker, V. \& Tilbury, F. (2006) Employment niches for recent refugees: Segmented labour market in twenty-first century Australia. Journal of Refugee Studies, 19(2): 203-29. doi:10.1093/jrs/fej016

Cook, T. L., Shannon, P. J., Vinson, G. A., Letts, J. P. \& Dwee, E. (2015) War trauma and torture experiences reported during public health screening of newly resettled Karen refugees: A qualitative study. BMC International Health and Human Rights, 15(1): 1-13. doi:10.1186/s12914-015-0046-y

Correa-Velez, I., Barnett, A. G. \& Gifford, S. (2013) Working for a better life: Longitudinal evidence on the predictors of employment among recently arrived refugee migrant men living in Australia. International Migration, 53(2): 321-37. doi:10.1111/imig.12099

Crosby, S. S. (2013) Primary care management of non-English speaking refugees who have experienced trauma: A clinical review. Journal of the American Medical Association, 310. doi:10.1001/jama.2013.8788

Croucher, S. L. (2003) Globalization and belonging: The politics of identity in a changing world. Lanham, MD: Rowman \& Littlefield.

Davidson, G., Murray, K. \& Schweitzer, R. (2008) Review of refugee mental health and wellbeing: Australian perspectives, Australian Psychologist, 43(3): 160-74.

de Jong, J., Komproe, I., Van Ommeren, M., El Masri, M., Araya, M., Khaled, N., ... Somasundaram, D. (2001) Lifetime events and posttraumatic stress disorder in 4 postconflict settings. Journal of the American Medical Association, 286(5): 555-62.

de Jong, K., Mulhern, M., Ford, N., van der Kam, S. \& Kleber, R. (2000) The trauma of war in Sierra Leone. The Lancet, 355(9220): 2067-68.

Deng, S. A. \& Marlowe, J. (2013) Refugee resettlement and parenting in a different context. Journal of Immigrant \& Refugee Studies, 11(4): 416-30. doi:10.1080/1556294 8.2013.793441

Deng, A., Deng, B., Ajak, B. \& Bernstein, J. (2005) They poured fire on us from the sky: The true story of three lost boys from Sudan. New York: Public Affairs.

Dona, G. (2007) The microphysics of participation in refugee research. Journal of Refugee Studies, 20(2): 210-29. doi:10.1093/jrs/fem013

Eggers, D. (2006) What is the what. New York: Vintage Books. 
Ellis, B. H., Murray, K. \& Barrett, C. (2014) Understanding the mental health of refugees: Trauma, stress, and the cultural context. In R. Parekh (ed.) The Massachusetts General Hospital textbook on diversity and cultural sensitivity in mental health (pp. 165-87). New York: Springer.

Esnard, A.-M. \& Sapat, A. (2011) Disasters, diasporas and host communities: Insights in the aftermath of the Haiti earthquake. Journal of Disaster Research, 6(3): 331-42.

Fassin, D. \& D'Halluin, E. (2005) The truth from the body: Medical certificates as ultimate evidence for asylum seekers. American Anthropologist, 107(4): 597-608.

Fassin, D. \& Rechtman, R. (2009) The empire of trauma: An inquiry into the condition of victimhood. Princeton, NJ: Princeton University Press.

Fazel, M., Wheeler, J. \& Danesh, J. (2005) Prevalence of serious mental disorder in 7000 refugees resettled in western countries: A systematic review. The Lancet, 365(9467): 1309-14.

Ferris, E. G. \& Kirisci, K. (2016) The consequences of chaos: Syria's humanitarian crisis and the failure to protect. Washington, DC: Brookings Institution Press.

Fiske, L. \& Briskman, L. (2016) Creating criminals: Australia's response to asylum seekers and refugees. In R. Furman, G. Lamhear \& D. Epps (eds), The Immigrant Other: Lived experiences in a transnational world (pp. 225-39). New York: Columbia University Press.

Fozdar, F. (2012) Social cohesion and skilled Muslim refugees in Australia: Employment, social capital and discrimination. Journal of Sociology, 48(2): 167-86. doi: $10.1177 / 1440783311413482$

Fozdar, F. \& Torezani, S. (2008) Discrimination and well-being: Perceptions of refugees in Western Australia. International Migration Review, 42(1): 30-63.

Fraser, N. (2003) Social justice in the age of identity politics: Redistribution, recognition and participation. In N. Fraser \& A. Honneth (eds) Redistribution or recognition. London: Verso.

Furedi, F. (2004) Therapy culture: Cultivating vulnerability in an uncertain age. London: Routledge.

Harris, A. (2010) I ain't no girl: Representation and reconstruction of the 'found girls' of Sudan. Race/Ethnicity: Multidisciplinary Global Contexts, 4(1): 41-63.

Harris, A., Marlowe, J. \& Nyuon, N. (2014) Rejecting Ahmed's 'melancholy migrant': South Sudanese Australians in higher education. Studies in Higher Education, 40(7): 1226-38. doi:10.1080/03075079.2014.881346

Hart, C. \& Maiden, S. (2007) Race to Point Finger of Blame. The Australian, available at: www.theaustralian.news.com.au/story/0,25197,22538228-28737,00.html (accessed 6 October 2008).

Hecht, J. (2005) The journey of the lost boys. Jacksonville, FL: Allswell Press.

Heeren, M., Mueller, J., Ehlert, U., Schnyder, U., Copiery, N. \& Maier, T. (2012) Mental health of asylum seekers: A cross-sectional study of psychiatric disorders. BMC Psychiatry, 12(1), 114-22.

Herman, J. (1997) Trauma and recovery. New York: Basic Books.

Hollander, A.-C., Dal, H., Lewis, G., Magnusson, C., Kirkbride, J. B. \& Dalman, C. (2016) Refugee migration and risk of schizophrenia and other non-affective psychoses: Cohort study of 1.3 million people in Sweden. British Medical Journal, 352. doi:10.1136/bmj. i1030

Ignatieff, M., Keeley, J., Ribble, B. \& McCammon, K. (2016) The United States and the European refugee crisis: Standing with allies. Retrieved from: http://dx.doi.org/10.2139/ ssrn. 2782480 


\section{Responding to trauma}

Ingleby, D. (2005) Editor's introduction. In D. Ingleby (ed.) Forced migration and mental health: Rethinking the care of refugees and displaced persons. New York: Springer.

IOM (2016) 2015 Global migration trends: Factsheet. Retrieved from: http://iomgmdac. org/global-trends-2015-factsheet/

Jaranson, J. M., Butcher, J., Halcon, L. \& Johnson, D. R. (2004) Somali and Oromo refugees: Correlates of torture and trauma history. American Journal of Public Health, 94(4): 591-98.

Johnson, D. H. (2011) The root causes of Sudan's civil wars: Peace or truce. Woodbridge: Boydell \& Brewer.

Jok, J. M. (2015) The paradox of peace in Sudan and South Sudan: Why political settlements failed to endure. Retrieved from Berlin: www.berghof-foundation.com/ www.ips-project.org

Kassaye, A., Ashur, I., \& van Heelsum, A. (2016) The relationship between media discourses and experiences of belonging: Dutch Somali perspectives. Ethnicities, 16(6): 773-97. doi:10.1177/1468796816653627

Khawaja, N., White, K., Schweitzer, R. \& Greenslade, J. (2008) Difficulties and coping strategies of Sudanese refugees: A qualitative approach. Transcultural Psychiatry, 45(3): 489-512. doi:10.1177/1363461508094678

Kirmayer, L. (2007) Failures of imagination: The refugee's predicament. In L. Kirmayer, R. Lemelson \& M. Barad (eds) Understanding trauma: Integrating biological, clinical, and cultural perspectives (pp. 363-80). New York: Cambridge University Press.

Kleinman, A. (1987) Anthropology and psychiatry: The role of culture in cross-cultural research on illness. The British Journal of Psychiatry, 151(4): 447-54.

Kleinman, A. (1995) Writing at the margin: Discourse between anthropology and medicine. Berkeley, CA: University of California Press.

Lie, B. (2002) A 3-year follow-up study of psychosocial functioning and general symptoms in settled refugees. Acta Psychiatrica Scandinavica, 106(6): 415-25.

Lindley, A. (2007) The early morning phonecall: Remittances from a refugee diaspora perspective. Centre on Migration, Policy and Society, University of Oxford.

Losoncz, I. (2011) Blocked opportunity and threatened identity: Understanding experiences of disrespect in South Sudanese Australians. The Australasian Review of African Studies, 32(2): 118-42.

Lucas, D., Jamali, M. \& Edgar, B. (2013) A statistical profile of the Sudan-born in Australia. In J. Marlowe, A. Harris \& T. Lyons (eds) South Sudanese diaspora in Australia and New Zealand: Reconciling the past with the present (pp. 48-66). Newcastle upon Tyne: Cambridge Scholars Publishing.

Malkki, L. (1995) Refugees and exile: From 'refugee studies' to the national order of things. Annual Review of Anthropology, 24(1): 495-523. doi:doi:10.1146/annurev.an. 24.100195.002431

Marfleet, P. (2006) Refugees in a global era. New York: Palgrave Macmillan.

Marier, M. \& Ford-Williamson, E. (2014) Seed of South Sudan: Memoir of a 'lost boy' refugee. Jefferson, NC: McFarland \& Company.

Markell, P. (2003) Bound by recognition. Princeton, NJ: Princeton University Press.

Marlowe, J. (2009) Conceptualising refugee resettlement in contested landscapes. Australasian Review of African Studies, 30(2): 128-51.

Marlowe, J. (2010a) Beyond the discourse of trauma: Shifting the focus on Sudanese refugees. Journal of Refugee Studies, 23(2): 183-98. doi:10.1093/jrs/feq013

Marlowe, J. (2010b) Using a narrative approach of double listening in research contexts. International Journal of Narrative Therapy and Community Work, 3: 43-53. 
Marlowe, J. (2011) Sudanese settlement: Employing strategies of intercultural contact and cultural maintenance. The Australasian Review of African Studies, 32(2): 101-17.

Marlowe, J. (2013) Going slowly slowly: An ethnographic engagement with the South Sudanese. Studies in Symbolic Interaction, 40(1): 153-73.

Marlowe, J. \& Adamson, C. (2011) Teaching trauma: Critically engaging with a troublesome term. Social Work Education, 30(6): 623-34.

McFarlane, A. (2004) Assessing PTSD and comorbidity: Issues in differential diagnosis. In J. Wilson \& B. Drozdek (eds) Broken spirits. New York: Bruner-Routledge.

Miller, K., Kulkarni, M. \& Kushner, H. (2006) Beyond trauma focused psychiatric epidemiology: Bridging research and practice with war affected populations. American Journal of Orthopsychiatry, 76(4): 409-22.

Milner, K. \& Khawaja, N. G. (2010) Sudanese refugees in Australia: The impact of acculturation stress. Journal of Pacific Rim Psychology, 4(1): 19-29.

Mollica, R., Sarajlic, N., Chernoff, M., Lavelle, J., Vukovic, I. S. \& Massagli, M. (2001) Longitudinal study of psychiatric symptoms, disability, mortality, and emigration among Bosnian refugees. Journal of the American Medical Association, 286(5): 546-54.

Moore, S. (2004) Health medicine and the body. In M. Harambolos \& M. Holborn (eds) Sociology: Themes and perpectives (6th edn, pp. 290-329). London: Polity.

Murray, K., Davidson, G. \& Schweitzer, R. (2008) Psychological wellbeing of refugees resettling in Australia. The Australian Psychological Society, 1-28.

Nunn, C., McMichael, C., Gifford, S. M. \& Correa-Velez, I. (2014) 'I came to this country for a better life': Factors mediating employment trajectories among young people who migrated to Australia as refugees during adolescence. Journal of Youth Studies, 17(9): 1205-20.

O'Donovan, T. \& Sheikh, M. (2014) Welfare reforms and the refugee resettlement strategy: An opportunity to achieve meaningful employment outcomes for New Zealanders from refugee backgrounds? Kōtuitui: New Zealand Journal of Social Sciences Online. Retrieved from: www.tandfonline.com/doi/pdf/10.1080/1177083X.2014.944193

Parsons, T. (1965) Social structure and personality. New York: Free Press.

Porter, M. \& Haslam, N. (2005) Predisplacement and postdisplacement factors associated with mental health of refugees and internally displaced persons: A meta-analysis. Journal of the American Medical Association, 294(5): 602-12.

Pupavac, V. (2006) Refugees in the 'sick role': Stereotyping refugees and eroding refugee rights. Retrieved from: www.unhcr.org/research/working/44e198712/refugees-sickrole-stereotyping-refugees-eroding-refugee-rights-vanessa.html

Robinson, J. (2013) People of Sudanese heritage living in Australia: Implications of demography for individual and community resilience. In J. Marlowe, A. Harris \& T. Lyons (eds) South Sudanese diaspora in Australia and New Zealand: Reconciling the past with the present (pp. 12-47). Cambridge: Cambridge Scholars Publishing.

Rosińska, Z. (2011) Emigratory experience: The melancholy of no return. In J. Creet \& A. Kitzmann (eds) Memory and migration: Multidisciplinary approaches to memory studies (pp. 29-42). Toronto: University of Toronto Press.

Rosseau, C. \& Measham, T. (2007) Posttraumatic suffering as a source of transformation: A clinical perspective. In L. Kirmayer, R. Lemelson \& M. Barad (eds) Understanding trauma: Integrating biological, clinical, and cultural perspectives (pp. 275-93). New York: Cambridge University Press.

Ryan, D., Dooley, B. \& Benson, C. (2008) Theoretical perspectives on post-migration adaptation and psychological well-being among refugees: Towards a resource-based model. Journal of Refugee Studies, 21(1): 1-18. doi:10.1093/jrs/fem047 


\section{Responding to trauma}

Said, E. (1993) Culture and imperialism. London: Vintage.

Shakespeare-Finch, J. \& Wickham, K. (2010) Adaptation of Sudanese refugees in an Australian context: Investigating helps and hindrances. International Migration, 48(1): 23-46. doi:10.1111/j.1468-2435.2009.00561.x

Silove, D. (2004) The global challenge of asylum. In J. Wilson \& B. Drozdek (eds) Broken spirits: The treatment of traumatized asylum seekers, refugees, war and torture victims. New York: Brunner-Routledge.

Silove, D. \& Ekblad, S. (2002) How well do refugees adapt after resettlement in Western countries? Acta Psychiatrica Scandinavica, 106(6): 401-2.

Silove, D., Steel, Z., Bauman, A., Chey, T. \& McFarlane, A. (2007) Trauma, PTSD and the longer-term mental health burden amongst Vietnamese refugees: A comparison with the Australian-born population. Social Psychiatry and Psychiatric Epidemiology, 42(6): 467-76.

Simich, L. (2004) The study of Sudanese settlement in Ontario: Final report. Toronto: Culture, Community and Health Studies Program, Centre for Addiction and Mental Health, University of Toronto.

Simich, L., Este, D. \& Hamilton, H. (2010) Meanings of home and mental well-being among Sudanese refugees in Canada. Ethnicity \& Health, 15(2): 199-212. doi:10.1080/13557851003615560

Slobodin, O. \& de Jong, J. T. V. M. (2015) Mental health interventions for traumatized asylum seekers and refugees: What do we know about their efficacy? International Journal of Social Psychiatry, 61(1): 17-26. doi:10.1177/0020764014535752

Stoll, K. \& Johnson, P. (2007) Determinants of the psychosocial adjustment of Southern Sudanese men. Journal of Refugee Studies, 20(4): 621-40. doi:10.1093/jrs/fem037

Summerfield, D. (1999) A critique of seven assumptions behind psychological trauma programmes in war-affected areas. Social Science \& Medicine, 48(10): 1449-62.

Summerfield, D. (2005) My whole body is sick ... My life is not good. In D. Ingleby (ed.) Forced migration and mental health. New York: Springer.

Tilbury, F. \& Colic-Peisker, V. (2006) Deflecting responsibility in employer talk about race discrimination. Discourse \& Society, 17(5): 651-76. doi:10.1177/0957926506066349

Tomlinson, F. (2010) Marking difference and negotiating belonging: Refugee women, volunteering and employment. Gender, Work \& Organization, 17(3): 278-96. doi: 10.1111/j.1468-0432.2008.00399.x

UNHCR (2016) Regional refugee and migrant response plan for Europe. Eastern Mediterranean and Western Balkans route. Jan-Dec 2016. Retrieved from: http:// reliefweb.int/report/world/regional-refugee-and-migrant-response-plan-europe-easternmediterranean-and-western

UNHCR (2017) 2017 Regional refugee response plan: Overview. Retrieved from: United Nations High Commisioner for Refugees, availablel at: http://data.unhcr.org/ southsudan/

Van Hear, N. (2014) Refugees, diasporas, and transnationalism. In E. Fiddian-Qasmiyeh, G. Loescher, K. Long, \& N. Sigona (eds) The Oxford Handbook of Refugee and Forced Migration Studies (176-87). Oxford: Oxford University Press.

Walker, R., Koh, L., Wollersheim, D. \& Liamputtong, P. (2015) Social connectedness and mobile phone use among refugee women in Australia. Health \& Social Care in the Community, 23(3): 325-36. doi:10.1111/hsc.12155

Webb, J., Schirato, T. \& Danaher, G. (2002) Understanding Bourdieu. Crows Nest, NSW: Allen \& Unwin. 
Wessells, M. G. (2007) Trauma, culture and community: Getting beyond dichotomies. Coalition to Stop the Use of Child Soldiers. Retrieved from: www.child-soldiers.org/ resources/psychosocial

Westoby, P. (2006) The sociality of healing engaging Southern Sudanese refugees resettling in an Australian context: A model of social healing (unpublished doctoral thesis). University of Queensland.

Westoby, P. (2008). Developing a community-development approach through engaging resettling Southern Sudanese refugees within Australia. Community Development Journal, 43(4): 483-95.

Westoby, P. (2009) The sociality of refugee healing: In dialogue with Southern Sudanese refugees resettling in Australia. Sydney: Common Ground Publishing.

White, M. (2006) Working with people who are suffering the consequences of multiple trauma: A narrative perspective. In D. Denborough (ed.) Trauma: Narrative responses to traumatic experience (pp. 25-85). Adelaide: Dulwich Centre Publication.

Willard, C., Rabin, M. \& Lawless, M. (2014) The prevalence of torture and associated symptoms in United States Iraqi refugees. Journal of Immigrant Minority Health, 16. doi:10.1007/s10903-013-9817-5

Wille, J. (2011) Agency and belonging: Southern Sudanese former refugees' reflections on life in Australia. The Australasian Review of African Studies, 32(2): 80-100.

Windle, J. (2008) Racialisation of African youth in Australia. Social Identities, 14(5): 553-66.

World Bank (2016) Migrations and remittances factbook 2016. Retrieved from: www.worldbank.org/en/topic/migrationremittancesdiasporaissues

Yuval-Davis, N. (2011) The politics of belonging: Intersectional contestations. London: Sage.

Zetter, R. (2007) More labels, fewer refugees: Remaking the refugee label in an era of globalization. Journal of Refugee Studies, 20(2): 172-92. doi:10.1093/jrs/fem011 


\section{Responding to disasters}

\section{Introduction}

A Category Two hurricane in the Gulf of Mexico unexpectedly changes path, doubles in strength and heads straight for Houston on a Tuesday afternoon. While the city is located 40 miles inland, it is only slightly above sea level, leaving it highly vulnerable to storm surges, flooding and high winds as previous hurricanes of the last 100 years attest. ${ }^{1}$ As the top US refugee resettlement locality for the last several years, there are significant groups of people who do not confidently speak English or Spanish - the primary languages in which disaster risk for this area is communicated. In fact, more than ninety languages are spoken in the greater Houston area. ${ }^{2}$

As the hurricane approaches, the women from refugee backgrounds have limited awareness of what is happening because of linguistic barriers and all public transportation has been cancelled. The roads are gridlocked, leaving numerous communities isolated from family and friends with limited communications available. Many of the men who commute significant distances for work are unable to travel home as people begin evacuating en masse as the storm's threat becomes very real. The unfolding situation becomes clear that this 'what if' scenario had not been discussed, much less imagined for many refugees who have recently resettled. A number of people go to their trusted social media sites for information to help them anticipate the associated dangers and cope with its resulting aftermath. As the storm intensifies and winds reach hurricane force, the power goes out. Many refugees have never met the neighbours living around them. Nightfall will soon approach and numerous homes have limited supplies. ${ }^{3}$

This scenario, among many other possibilities, highlights how disasters can have greater impacts on particular groups where relationships, resources and access to information play a critical role in mitigating negative impacts. Disasters are events that cause significant damage and disruption that overwhelm the affected population's capacities to respond effectively. Whether these events are human-induced (as in the case of wars, atrocities and industrial catastrophes) or natural hazards (earthquakes, tsunamis, floods and famines) - there is a human element that transforms a major event into a disaster. Within a specific locality, the lived experience of a disaster is varied and represents a key determinant in 
defining an event as a disaster or not. In particular, disasters impact groups and communities unevenly and differently across a given society; this requires a multi-scalar and intersectional analysis. This chapter deconstructs what is understood by 'natural disasters' to consider the implications of belonging for disaster risk reduction (DRR) with refugees.

The unprecedented levels of forced migration since the Second World War and the risks people are taking to secure safe and sustainable livelihoods for themselves and their families highlight a pressing need to consider what constitutes effective DRR for culturally and linguistically diverse communities. One only needs to look at the estimated 3,295 people killed by the heatwave in France during 2015 to consider how such events may affect people living in already tenuous circumstances such as in the migrant encampment called 'The Jungle' in Calais. ${ }^{4}$ Major disaster-related events in 2016 include: earthquakes in Italy, Ecuador and Japan and Ecuador; flooding across France and Germany; and massive thunderstorms in the United States. And, for the Syrians recently settled in Fort McMurray, Canada, the enormous wildfires of May 2016 required responding to a rapidly moving front with limited information (almost predominantly communicated in English and, to a lesser extent, French).

Bradshaw (2013) acknowledges that disasters can reveal and exacerbate particular societal fault lines and fissures that exist within and across particular group identities and locations. This is why, in this book, I focus on the interplay of the everyday and the extraordinary experiences occurring before, during and long after a catastrophe has occurred. I present a case study of refugees affected by the Canterbury earthquakes in New Zealand to deepen these understandings. In particular, this study demonstrates the intersectional, chronological and transnational dimensions of belonging in disaster contexts that powerfully inform people's pathways to, and opportunities for, recovery. These findings are then related to the broader global implications of DRR with forcibly displaced populations. $^{5}$

\section{Refugees and disasters}

Overall, there is limited literature that examines the experiences, perspectives and responses of resettled refugee communities affected by disasters. While several authors have written about disasters in refugee camps and other areas of displacement and in development contexts more generally (Esnard \& Sapat, 2011, 2016; Goenjian et al., 2000; IFRC, 2012), studies on resettled refugees are limited. Several notable exceptions focus on resettled refugees specifically that include the Queensland floods (Correa-Velez et al., 2014), Canterbury earthquakes (Osman et al., 2012) and disasters generally in Australia (Spittles \& Fozdar, 2008) and the United States (Xin et al., 2013). Most notably, the IFRC (2012) report on disasters, and forced migration provides a comprehensive understanding of the ways that disasters impact displaced populations disproportionally.

Part of the issue with identifying refugees in disaster studies is that many people do not necessarily readily identify as such. For instance, there is not one 
study that focuses exclusively on refugees from the massive destruction of Hurricane Katrina, ${ }^{6}$ even though more than 13,000 refugees have been resettled there from 1980 to 2005, with nearly 7,000 of these people identifying as Vietnamese (US Department of Health and Human Services, 2009). This statement should be interpreted cautiously as it assumes that the refugee identifier is the dominant label through which certain groups of people are understood. There is, however, a study that mentions three different waves of Vietnamese diasporas that were impacted by Katrina that includes those resettled to the United States as refugees (Edwards, 2010). Although this group may be from a refugee background, it may no longer be a primary identifier - either for themselves or the predominant way that wider society views them. For others, however, the refugee label may be a powerful, even singular social location, through which people's lives are understood.

The term refugee is often used universally to describe people who have been displaced by a disaster. Following a catastrophic event, it is accurate that people have been displaced from their homes and find themselves rebuilding their lives in the contexts of significant destruction. They may experience complete loss of livelihoods with little prospect of returning to their previous lives. Houses can be levelled, businesses ruined, economies made unviable and social fabrics altered. These forms of displacement and dislocation cannot, and should not, be minimized. However, when this term is used to describe all people displaced by disaster, those who were former refugees as established under the UN 1951 Convention are rendered invisible because everyone is a refugee. The newspaper headlines of several major disasters below illustrate this trend:

- Hurricane Katrina refugee shares his story of life after disaster (USA, August 2015).

- Christchurch earthquake: Thousands of refugees head for Auckland (NZ, March 2011).

- $\quad$ The untold story of Japan's tsunami refugees (USA, March 2014).

- $\quad$ N.J. renters and low-income refugees from Hurricane Sandy find housing help scarce (USA, December 2013).

- Calgary refugee camp opens for Alberta residents displaced by June floods (Canada, October 2013).

- Three years, three floods: the refugees of St George (Australia, February 2012).

These stories are all based in countries that have refugee resettlement programmes and yet none is specifically about refugees as defined by the UN 1951 Convention. Countless other examples are found in everyday news broadcasts, political commentary and academic articles/reports in relation to major disasters.

Every major refugee resettlement receiving locality is exposed to different hazard risks that create unique riskscapes. ${ }^{7}$ New York City is exposed to winter storms, hurricanes and floods. Los Angeles is built close to several major 
fault-lines and can experience dangerous heatwaves. Hurricane Andrew in 1992 is testament to how Miami and Florida in general are vulnerable to major storms. Minneapolis, which hosts many refugees, can have major winter storms and extreme cold events. Houston's riskscape includes exposure to high heat, hurricanes and flooding. The varying levels of risk in relation to particular hazards highlights how effective disaster mitigation strategies need to be tailored to the locality that refugees are resettled. A similar analysis can be made in other resettlement localities across Europe, Australia, Canada, New Zealand and elsewhere.

In addition, each settlement locality has diverse refugee intakes in relation to who is settled. New York, for instance, has resettled many people from the former Soviet Union. Los Angeles has hosted many refugees from Southeast Asia. Chicago has historically resettled many who fled persecution in Europe and the Middle East (Singer \& Wilson, 2006).

There can also be significant differences within a particular refugee group when a singular ethno-national label is used to describe them. For instance, an earlier theorization on refugee settlement relates to Kunz's (1973) kinetic and motivational model that focuses on how refugees from the same country and ethnicity can represent different vintages and waves. He argued that the various vintages (when a particular group left the country) and waves (when a particular group arrived to a new host country) have differential settlement experiences and outcomes. This work highlights how distinct vintages can be characterized by anticipatory and acute decisions to flee. Those who leave the country first may be particularly better resourced to do so or it may be that those who fled first were fleeing from different forms of persecution (hence, they are different vintages). And some refugees may arrive in a new host country quickly over the course of days or weeks, and then there are others who may live in protracted situations such as refugee camps for decades before coming to a host country. Thus, refugees can also come in different waves. Examples of these trends are evident in many contemporary contexts that include civil wars in Syria, South Sudan, Somalia and Colombia. These intersections demonstrate the need to match geographic riskscapes with demographic diversity and the socio-political contexts that resettlement and settlement occurs.

\section{Disasters: rendering the familiar strange}

Like the terms refugee and trauma, the concept of disasters is another that warrants further critical examination. The Centre for Research on the Epidemiology of Disaster (CERD) establishes that there were 346 natural disasters worldwide in 2015, affecting 98 million people with nearly 23,000 fatalities and an estimated cost of US\$65.5 billion (Below \& Vanderveken, 2016). ${ }^{8}$ According to CERD, the year 2015 was the hottest on record and the UN estimated that 2016 was on track to surpass it. The International Federation of the Red Crescent (IFRC, 2016) illustrates that, although the total number of disasters varies each year, the number of people affected generally continues to increase. This is in part due to 
a growing global population, a warming global climate and the concentration of wealth and people in urban centers (Keiler, 2013).

Numerous authors now argue that natural disasters do not exist, but, rather, there are natural hazards - what makes any particular hazard a disaster or not is how it is socially and politically mitigated (Gaillard, 2007; Lauta, 2014; Tierney, 2014). The term hazard basically means something that is a threat to life. A natural hazard is one that can relate to earthquakes, storms, flooding, landslides, volcanic eruptions and other nature-based phenomenon. Some natural hazards may be coupled, such as a tsunami that follows a large earthquake (e.g. the 2004 Indian Ocean mega-thrust earthquake) or extensive flooding following a hurricane (Hurricane Katrina in 2005). These events take place whether humans are there or not, although the arguments that human activity has increased the risks and impacts of natural hazards are compelling. What transforms a hazard into a disaster generally depends upon the large negative impact it has on human populations in terms of casualties, mortalities and loss of livelihoods. The ways in which notions of vulnerability intersect with major hazards highlight the need to critique familiar constructions of natural disasters and what is natural about them.

For instance, the Armero tragedy that occurred in Colombia provides a stark example of how a natural hazard turned into a major disaster due to human actions and decisions (or the lack thereof) on multiple levels. During September 1985, a previously active volcano known as Nevado del Ruiz began showing activity that suggested the risk of an eruption. The government largely ignored this threat and did not adequately inform the people living in the associated evacuation zone of the associated dangers. Two months later, this volcano erupted causing a pyroclastic flow of fast-moving hot gases, ash and rock that melted the mountain's glaciers and resulted in several lahars. ${ }^{9}$ These volcanically induced high-speed mudslides of rock and debris, in the middle of the night, slammed into the unsuspecting town of Armero killing more than 22,000 people. Had local authorities and others working in civil defence acted on the warnings, Voight (1990) argues that the loss of life could have been significantly minimized or even completely negated.

What made this natural hazard a major disaster was that, in many ways, it was caused by human factors - in this case from scientific misjudgement of risk, bureaucratic inefficiencies and government inaction. ${ }^{10}$ While the lahars would have still destroyed people's homes, the loss of life could have been largely avoided (see Cohen, 1987). Even if the people of Armero had been evacuated, the loss of homes could also be seen as human influenced. Humans make decisions (usually by those within the corridors of significant institutional power) to build on flood plains, in coastal areas, within eruption zones or on fault-lines. And the associated regulatory frameworks that govern building codes, environmental management and crisis response, among others, can represent the defining features that transform a hazard event into a disaster. Several news stories that covered the funerals of the thousands buried noted a banner which those who survived this tragedy were holding. The translation explosively claimed: 
'The volcano did not kill 22,000 people. The government killed them' (see Montalbano, 1985).

Other hazards may be directly related to human activities where the risks of landslides are exacerbated by deforestation and development. Catastrophic forest fires are influenced by human decisions to permit burning that allows for massive storages of fuel, land conversion burning (for agriculture or animal husbandry) and logging activities. The massive scale of destruction from Hurricane Katrina represented the confluence of a number of factors related to suburb locations, poorly constructed and maintained levee systems, environmental degradation, inadequate warning and evacuation procedures, and failures to ensure an adequate and speedy response (Eisenman et al., 2007). The flooding was caused, in part, by the destruction of mangroves to provide better shipping channels that provided natural protection to New Orleans. Tierney (2014) notes this dredged channel facilitated a 'hurricane highway' that accelerated the passage of flood waters that overwhelmed the city. She maintains that these 'socio-natural' disasters are becoming increasingly common, in large part because of the build-up of risk with increased concentrations of people and wealth in particular locations.

There are also technologically induced or industrial disasters. Examples include nuclear radiation from meltdowns at Chernobyl and Three Mile Island (Pennsylvania), and toxic waste catastrophes such as the BP Deep Water Horizon explosion in 2010 and the Exxon Valdez oil spill in 1989. The 1984 Bhopal gas leak in India exposed more than 500,000 people to toxic substances used to make pesticides. These so-called technological disasters can also be coupled with natural hazards. The 'triple disaster' of the 2011 Japanese magnitude 9.0 earthquake, massive tsunami and subsequent three partial core nuclear meltdowns at Fukushima Daiichi highlight how regulatory failure and poor monitoring magnified the impacts of the first two natural phenomena (IFRC, 2012; Nakamura \& Kikuchi, 2011).

The IFRC (2012) report details how natural hazards and human-induced crises can result in massive numbers of forced migrants who are vulnerable to people smugglers and human trafficking. One only needs to look at the thousands of people drowned in the Mediterranean to recognize that human activity directly relates to the production of risk. More than 1 million people crossed the Mediterranean to seek safety in Europe in 2015 (Crawley et al., 2016). The estimated 6,600 people who drowned in 2015 and in the first half of 2016 demonstrate how oppressive regimes, failed states, international military campaigns, human traffickers and Europe's increased securitization of asylum play significant parts leading to people's decision to step on to a crowded boat.

Some disasters happen immediately, as in the case of earthquakes where thousands of homes can be destroyed in seconds, which has recently happened in Nepal, China, New Zealand and Haiti. Other disasters may have a slower onset that relates to desertification, water scarcity and droughts that gradually erode away livelihoods in places such as North Africa. These so-called slow onset disasters generally result in a greater number of deaths relative to immediate events, but do not get the coverage or sense of urgency of acute episodes (Wisner 
et al., 2014). These gradual disasters perhaps represent one of the most pressing concerns for people forcibly displaced. The global impacts and toll of rising sea levels and climate change raise the spectre of environmental refugees that could dramatically increase the number of forced migrants looking to find alternative forms of living that have been irretrievably lost.

Clearly, the experiences of forced migration through persecution can exacerbate the impacts of particular technological, socio-natural and natural hazards. Weak forms of governance and structures that actively oppress certain groups can easily transform hazards into large-scale disasters. The ongoing conflict in Somalia and the simultaneous droughts (particularly in 2011 and 2015-2016) expose people to greater levels of vulnerability and reduce community resilience to respond to such adverse events (see IRFC, 2012). Kelley et al. (2015) compellingly establish how the Fertile Crescent drought of 2007-2010 contributed to, and exacerbated the impacts of, the Syrian civil war that began in 2011. They also note how these droughts can be attributed to human-influenced climate change demonstrating the multiple ways that the environment, society and politics come together to influence forced migration trends and movements.

DRR relates to how society and its institutions make choices that influence the scale and impact of a particular hazard event. In this sense, the United Nations Integrated Strategy for Disaster Reduction (UNISDR, 2009) notes that DRR largely focuses on such choices as it may relate to building codes, forms of governance, the structure of financial systems, environmental management, how education is delivered and even considerations such as how food is grown. Through the associated decision-making processes, Tierney (2014) argues that these can either create additional risk and vulnerability or alternatively promote resilience. What is critical to acknowledge here is that it is the interplay between vulnerabilities, capacities and resilience that informs the pathways to recovery and effective DRR for culturally and linguistically diverse groups. After defining several key terms, I consider the associated linkages with belonging, transnational relations and recovery in the case study that follows.

\section{Belonging and disaster recovery}

The United Nations International Strategy for Disaster Reduction (UNISDR, 2009) defines recovery as the restoration and improvement of livelihoods, living conditions and facilities of disaster-affected communities. Historically, the disaster literature has discussed recovery as a linear concept, claiming that it progresses through a series of phases or stages that include sequences such as preparedness, warning, impact, search and rescue, rehabilitation and recovery. However, the reality is less clear-cut as the aforementioned stages overlap and/or merge, making it difficult to clearly define when recovery is achieved or what it necessarily means (Aldrich, 2012). Recovery can also refer to both a process as well as a final outcome that involves individuals, families, communities, cities and various government-level entities. Thus, recovery in disaster contexts includes working towards a better future, the ability to engage in meaningful activities, 
participating in the rebuild, and being part of the re-envisioning and restoration processes.

Recovery from a disaster is also multilayered: it is a function of the affected populations' existing vulnerabilities and capacities, the scale of the disaster's impact, and the provision and access to funding and assistance (Finch et al., 2010). While I will argue about the importance of belonging and transnational perspectives in this chapter, it is done alongside an acknowledgement of other aspects that mitigate disaster losses that are related to infrastructure, forms of governance, institutional support, safely constructed dwellings, effective warning and evacuation systems, and others. Thus, I present belonging as an important component of DRR that sits alongside many considerations, including people's translocal commitments.

A focus on the politics of belonging and who has a say about who belongs and who does not, plays an important part in how well a particular community or locality can effectively cope in a disaster. Significantly, some communities already have existing risk factors that can exacerbate vulnerability in large-scale events. Those who have access to particular social, financial and physical resources are likely to have greater sources of external resilience to respond to a disaster situation (Johnston et al., 2012). I now examine the concepts of vulnerability, capacities, resilience and social capital before presenting a case study that illustrates how these relate to the experience of refugee settlement.

\section{Vulnerability}

Communities that are already on the peripheries of society can be pushed even further out from particular supportive centres in disaster contexts. In addition, resettled refugees may have additional vulnerabilities that relate to traumatic experiences, forms of discrimination and limited relationships with the wider society. Thus, a disaster setting can potentially expose refugees to greater risk of harm as particular social locations and identifications create or define the contexts of increased (and often rendered) vulnerabilities. This is in part where the politics of belonging can come powerfully into play as some groups can leverage resources and forms of support at the expense of other groups. And disasters particularly illustrate what is at stake when limited resources are available.

The UNISDR (2009) defines vulnerability as the 'characteristics and circumstances of a community, system or asset that make it susceptible to the damaging effects of a hazard'. The levels of susceptibility, however, can vary significantly across a given society. While some people's vulnerabilities may be intrinsic (i.e. relating to personality, natural dispositions, the presence of or susceptibility to mental/physical health issues), these understandings must also be considered from structural and extrinsic frames. Like disasters, the naturalness of intrinsic vulnerabilities warrants critique as forms of privilege and hegemony often make particular groups vulnerable.

Gaillard (2007) argues that extrinsic factors directly impact people's vulnerability to disasters, which include political, social and economic exclusion; 
financial insecurities and poverty; inadequate healthcare and housing; and discrimination. These disadvantages interface with intersectional considerations of culture, ethnicity, class and age to highlight how disasters impact people unequally (Mercer et al., 2012; Tierney, 2006, 2014; Wisner et al., 2014). For example, studies show how women are disproportionately impacted by major events and experience disasters differently as the Women's Refugee Commission clearly shows (see also Bradshaw, 2013; Enarson \& Meyreles, 2004). ${ }^{11}$ The same disaster can have varied impacts for children (Peek, 2008), queer communities (Dominey-Howes et al., 2014), those with disability (Peek \& Stough, 2010) and those who do not speak the dominant language of a given locality. Additional categories of affiliation such as migration status, digital connectedness, place of residency and proximity to particular hazards are also important. These realities demonstrate that communities are not homogeneous which, again, underscores the necessity of an intersectional analysis. Alongside this awareness is the recognition that extrinsic factors make some people more vulnerable than others (Wisner et al., 2014).

Zakour and Gillespie (2013) acknowledge the increased likelihood of social injustices that vulnerable populations can experience in a disaster, many of which may have already been interwoven within the fabric of society long before a major event occurs. Klinenburg's (2002) 'social autopsy' of a 1995 heat wave in Chicago, for instance, highlights how everyday pre-disaster vulnerabilities exposed some people to far greater levels of risk and demonstrates how location, class, ethnicity and structural supports and responses comprise 'geographies of vulnerability' to extraordinary events. Carney's (2012) harrowing book entitled Red Market details how the 2004 Indian Ocean tsunami created displacement camps in India where people had to sell their organs to survive. One location was menacingly called Kidneyvakkam - translated in English to 'Kidneyville' - for the women whose midsection scars provide silent testimony of opportunistic predation and increased vulnerabilities after a major disaster.

While disasters can significantly disrupt people's livelihoods, social relations and forms of well-being, it is important to emphasize that many people buffer the associated stress and adversity through internal and external forms of resilience and support. The focus on capacities and resilience follows the previous chapter's discussion on trauma. Although the forced migration experience and particular types of trauma may expose people to greater risk of negative mental health outcomes, the vast majority of refugees do not develop such conditions. Again, this awareness highlights the need to render familiar perspectives on refugees, disaster and vulnerability as strange. A focus on the interplay between the everyday and extraordinary can assist with this process and broaden understandings of belonging and transnational relations for effective and empowering approaches to DRR.

\section{Capacities and resilience}

It is critical to recognize that refugees are not inherently vulnerable, as an analysis solely on risk does not capture their capacities and strengths that exist at 
individual, family, community, societal, institutional and transnational levels. The UNISDR (2009) defines capacities as the 'combination of all the strengths, attributes and resources available within a community, society or organization that can be used to achieve agreed goals'. Potential capacities include individual coping skills, community leadership, access to various forms of social capital, institutional support and existing infrastructure. In a disaster context, Tan and Yuen (2013) emphasize how local capacities and resources are essential for community recovery during crises and help facilitate rehabilitation and reconstruction processes. The disaster literature generally demonstrates that people with access to internal and external resources and forms of support are more likely to respond effectively to a major event and overcome existing vulnerabilities (Aldrich, 2012; Elliott et al., 2010).

The concept of resilience in relation to disasters basically means the ability to bounce back or to absorb the shock from a major event (UNISDR, 2009). ${ }^{12}$ Thus, individuals, families, communities, societies, institutions and, at times, transnational relations will have particular qualities and strategies that will help people to resist, adapt to and recover from the negative impacts of a disaster. Tierney (2014) focuses predominantly on the term resilience and notes how human activity can either promote or erode forms of resilience. She argues that there are inherent, adaptive and vertical forms of resilience that can be mobilized to enhance people's capacities and ability to bounce back from adversity.

There is a wide range of sources that foster inherent resilience which relate to people's personality dispositions, cultural practices and socially constructed meaning systems. For instance, there are some refugee groups that may perceive particular hazards as a part of nature and something not to fear, while there are other groups that have histories of living alongside similar hazards and offer traditional knowledges that buffer the negative impacts of a major event (Marlowe, 2014). As noted in Chapter 3, the South Sudanese community came together in a number of ways to support one another when a tragedy occurred this response was a given rather than one that needed to be created and mobilized. These forms of resilience often emerge from the bottom up and highlight the need to consider the various forms of support and capacities from multi-local and multi-scalar locations.

Adaptive resilience refers to resourcefulness and the speed at which groups are able to respond to adversity (Tierney, 2014). Such adaptive resilience relates to the ways that particular groups are able to innovate new solutions and establish forms of support that were not previously there. The 'voluntary army' that arose from the Canterbury earthquakes in New Zealand is an example of this, where numerous people from Christchurch banded together to support local communities (Lewis, 2013). People from refugee backgrounds contributed to these initiatives and provided their skills, support and various forms of knowledge to cope with the immensity of the associated disaster. Aldrich's (2012) work also demonstrates how communities from around the world developed innovative and effective solutions to emergent problems arising from catastrophes that created and sustained forms of resilience. 
Tierney (2014) illustrates that vertical forms of resilience relate to structural forms of governance and institutional support. For example, she cites the 2010 Haiti earthquake that killed more than 150,000 people and displaced hundreds of thousands. ${ }^{13}$ Only two weeks after this earthquake, an 8.8 magnitude mega-thrust earthquake occurred off the coast of Chile with similar proximity to urban settlement (though at a greater depth). This event was 500 times more powerful than the Haiti earthquake and yet it resulted in far fewer deaths (less than 700 people) because of the country's disaster preparedness and more stringent construction standards. Again, the naturalness of a disaster and its associated impacts comes directly into question. While structural forms of resilience that arise from policy and engineering standards exist, there are also social responses that powerfully determine people's lived experience of a disaster and indeed, can be indicative of whether a major event is perceived as a disaster or not.

\section{Social capital}

The emergence of social capital theory has been widely employed to examine how particular individuals and groups are able to mobilize resources within intraand inter-community relationships. Several researchers now argue that social capital is a primary if not the principal resource for disaster preparedness and response (Aldrich, 2012). ${ }^{14}$ Numerous disaster-based studies demonstrate that the (re)creation of social connections and access to multiple forms of social capital represents a critical component to recovery processes (Eisenman et al., 2007; Mathbor, 2007; Pyles, 2007). Much of this disaster literature refers to the work of Robert Putnam (2000, pp. 22-3) who presents three typologies of social capital: bonding, bridging and linking. He summarizes the first two forms as: 'Bonding capital is good for under-girding specific reciprocity and mobilizing solidarity ... Bridging networks, by contrast, are better for linkage to external assets and for information diffusion ...'

Bonding social capital constitutes a kind of 'sociological superglue', whereas bridging social capital provides a 'sociological WD-40' that lubricates connections between people from different groups, backgrounds and networks (Putnam, 2000 , p. 23). Bonding capital refers to when people who are similar to each other work together and can facilitate strong and supportive community relationships. Bridging capital arises when people different from each other interact together which can facilitate access to new resources and opportunities (employment, education, social networking and information). Communities can also develop bridging capital by combining their assets and resources with other communities (Marlowe, 2011; Zetter et al., 2005, 2006). Perhaps most singly articulated, Putnam maintains that bonding capital is good for 'getting by' and is characterized by strong relationships. Bridging capital is good for 'getting ahead' through a network of weak ties. These forms of capital are essential for the ongoing practices of transnational family and friendship, highlighting how various forms of mobilities connect people through a network of strong and weak relations (Goulbourne et al., 2010; Le Dé et al., 2016). 
While bonding and bridging capital are defined by horizontal relationships existing among people of similar social status or identifiers, linking capital considers vertical distance between people and structures. Linking relationships are networks created between individuals or communities and institutional or authoritative structures. This capital can provide information and resources to communities that are usually marginalized or excluded. However, marginalized communities are often excluded by institutions and structures, thereby limiting their access to forms of linking capital. Such vertical relationships are also critical to building community capacities and resilience.

Social capital resources, however, do not only serve the general good. People can actively use existing social capital to oppress and gain advantage over others. Tierney (2014) establishes how those enjoying privileged social locations of power can use their bridging and linking capital to secure resources during disaster. Long before a disaster occurs, the ways in which particular people are able to gain advantage through regulatory capture and leverage structural support through their bridging, linking and bonding networks can do so for their immediate advantage. ${ }^{15}$ For instance, it is the communities and taxpayer who bear the long-term costs of destroyed homes and livelihoods rather than the developers who were able to get permissions to build on flood plains, along fault-lines and in other precarious circumstances. Aldrich (2012) highlights several case studies where strongly bonded ethnic groups with limited ties to the wider society created situations of vulnerability for minority groups. For instance, after Hurricane Katrina's devastation, he notes how neighbours with multiple forms of social capital were able to mobilize and lobby key authorities to prevent the efficient allocation of much needed emergency housing in their localities. This form of NIMBYism (not in my backyard) meant that those who needed immediate support did not receive it and were placed in areas already characterized by disadvantage that exacerbated vulnerabilities (Aldrich \& Crook, 2008; Davis \& Bali, 2008). Aldrich (2012) has clearly shown the associated dangers of strong bonding social capital characterized by the exclusive presence of an ethnically defined identity and subsequent rigid power structures that can, at times, be oppressive in disaster contexts. These dynamics again highlight how the politics of belonging can inform people's lived experiences of the everyday and the extraordinary.

While the role of social capital in disaster contexts has been widely discussed, the concept of belonging has received relatively little attention and at times the two terms have been conflated. Belonging is often linked with social capital in the context of disaster-based recovery, although it has not been adequately differentiated. For instance, it is possible for individuals to have various social capital resources and yet still not feel a sense of belonging to a particular place or community. Aldrich (2012) notes that the strength of an individual's (or a community's) assets depends on existing and newly formed relationships, and both are pivotal in recovery. Thus, the strength and reach of social relationships can directly impact on survival and well-being, and this is also true with refugee groups. In a disaster context, these social links, both within the immediate community and with the greater society, strengthen a community's ability to 
recover. The facets of belonging all have their respective places for disasterinformed recovery and will have varying levels of importance depending on relational, contextual and time-based factors.

The interplay between vulnerabilities, capacities and sources of resilience are powerful determinants that influence the effectiveness of particular disaster risk reduction and disaster recovery initiatives. While this interplay involves many considerations that have political, environmental, built, social, cultural and geographic dimensions, this chapter forwards the possibilities of belonging and transnationalism as additional considerations. Through an analysis of the extraordinary event of the Canterbury earthquakes and refugees' everyday lives, I present a case study that considers the possibilities of envisaging settlement as an ongoing transnational experience and the role of belonging.

\section{Case study: Canterbury earthquakes and refugee settlement}

The case study that informs this chapter focuses on the refugee community perspectives of, and responses to, the Canterbury earthquakes in New Zealand. The city of Christchurch was a principal refugee resettlement locality before the earthquakes and these communities experienced the disaster and the subsequent steps towards what recovery might represent. ${ }^{16}$ From the ensuing devastation, stories of resilience, the overcoming of adversity and forging new solidarities have emerged alongside tragic experiences of loss and trauma.

The previous section established that disasters can disrupt daily lives and forms of support in uneven and unequal ways. By discussing how refugee background communities speak about belonging over time, I present a case study of the Canterbury earthquakes to illustrate the destabilization, emergence and possibilities of belonging in a disaster context. The participant expressions highlight how belonging is structured across transnational, gendered, spatial and chronological dimensions. In particular, I emphasize how these dimensions were informed through the everyday that helped them respond to extraordinary circumstances.

On 4 September 2010, the Canterbury region experienced a magnitude 7.1 earthquake, causing widespread damage. A few months later, a magnitude 6.3 earthquake rocked the centre of Christchurch city with far greater destructive force, due to its relative shallowness and proximity (see Corin, 2011). The central business district was devastated and 185 lives were lost, making it the seconddeadliest and most costly natural disaster in the country's history. ${ }^{17}$ The New Zealand Government (2013) estimated the rebuild at $\$ 40$ billion - the equivalent of 20 per cent of GDP. Since the initial earthquake, there have been more than 15,000 aftershocks, demonstrating the ways in which the extraordinary events in some ways can become the everyday. ${ }^{18}$

A particular strength of this study is that a Somali male and an Afghan female peer researcher, both from refugee backgrounds, were trained and employed to conduct focus groups and semi-structured interviews to gain greater levels of access and ensure that the analysis was accountable (Marlowe et al., 2014). Ongoing supervision during data collection and approaching the analysis as an 
iterative process with the peer researchers helped to address cross-cultural considerations and unintentional bias in the associated interpretation of the data.

Most participants came from four primary countries of origin (Afghan, Bhutanese, Ethiopian and Somali), and the study included a near-equal representation of men and women within each community group. In total, 101 participants were involved in the 27 interviews and 10 focus group discussions. All participants were asked to comment on their perspectives of belonging before and after the four major earthquakes of 2010-11. Participants interviewed later in the study (late 2012 to early 2013) were also asked to reflect on whether their experiences of belonging had changed two years after the most devastating earthquake in February 2011. Through this predominantly inductive process, the ways in which participants expressed belonging over time and various social locations highlights the emergence and destabilization of this concept and its relevance to DRR and settlement support.

\section{Canterbury earthquakes: the emergence and destabilization of belonging}

The participant voices illustrate the ways in which their experiences and perspectives on belonging shifted over the course of the Canterbury earthquakes. The focus on the facets of belonging provides a lens that illustrates how participants conceptualized this term and its meanings within a disaster context. I relate these three facets to how belonging was relevant before, during and after the last major earthquakes of 2010 and 2011. For instance, the various participants' social locations determined how particular categories of identification positioned their opportunities to belong and respond to the earthquakes. What emerges is that ethnicity is a powerful and, at times, deterministic location that limits opportunities for wider societal engagement but provides a solid, and often principal, foundation of support. This awareness, however, is not adequate as other social locations such as gender and age are also important. The identifications and emotional attachments facet relates more to the stories of common belonging and shared solidarity that participants identify. Most strikingly, the shaping and meanings of such narratives shifted over the course of this study. And finally, the political and ethical value facet relates strongly to the ways that participants were able to engage with civic life, whether this was in relation to work, education or other forms of participation. And although the chronological presentation that follows demonstrates how their sentiments of belonging shifted, it is important to emphasize that these were not uniform, highlighting the need for an intersectional analysis that goes beyond ethno-national and ethnic identifiers.

\section{Belonging: pre-earthquake perspectives}

Before the earthquakes, participant expressions were primarily structured along ethnic-based social locations and the objective aspects of being able to participate in civic society. Participants spoke of their perspectives of belonging in 
Christchurch before the earthquakes predominantly as having access to employment and education (or the possibility thereof), being selected to resettle by the government and having the same entitlements accorded to all New Zealand citizens and permanent residents.

I like living in Christchurch because it taught me a lot of things. It got me to start primary, intermediate, high school and jobwise it's really good, it has a lot of opportunities.

(Somali male)

Better life means when I was back in my country I haven't got any chance of going to university, doing computer course or some sort of facility but when I came here I was very happy to get those facilities, those subsidized for caring of home and everything.

(Bhutanese focus group)

These comments focus largely on the objective proof of being able to participate in civic society - this was evidence that they belonged particularly within the political/ethical value systems that granted them these rights. Almost all participants spoke about how they were grateful to the New Zealand government for accepting them to resettle that also relates to wider narratives and emotive aspects of belonging - having been invited into the country.

The sentiments of feeling welcome, however, were not as evident. Participants generally commented on a lack of belonging to the wider society whereby shared common narratives were almost non-existent. Most noted that they were not well connected to the broader Christchurch community. Their expressions of belonging tended to relate to an ethnic-based social location, with participants identifying links, supports, shared understandings and experiences with individuals from their own backgrounds, but not generally beyond this affiliation.

It was still the same within our community. A lot of help - our community helped each other more than we got help from outside.

(University student focus group)

New Zealanders ... Too much quiet, I call them, and they keep it to themselves. (Ethiopian female)

The interviews also revealed that very few participants readily identified themselves as Kiwi (a national identifier for someone from New Zealand), even though some had been settled in Christchurch for many years. This reticence suggests that they did not share a strong collective narrative with the wider (largely New Zealand born) Christchurch community. However, these relational dynamics shifted in the extraordinary contexts of the earthquakes by disrupting ingrained practices of the everyday and opened new possibilities to belong. 


\section{Belonging: immediate post-earthquake perspectives}

Following the last major earthquakes of 2011, participant expressions of belonging that related to civic engagements were still present. Most strikingly, when asked about belonging after the earthquakes, nearly all participants spoke of a shared societal narrative that was not experienced in the pre-disaster environment. They noted feeling that they knew their neighbours for the first time and that people outside their ethnic community cared about them.

Actually, the host community of Christchurch, they are so great at the time of earthquake. Before the earthquake, we don't know each other, but after the earthquake we developed some sort of relationship, that distraction bring some sort of relationship between our neighbours. They said they had some things, and they come and discuss about something. As to my [Bhutanese] community, they are so great. We are connected.

(Bhutanese focus group)

Some friends helped me and my neighbour. We never say hi [before the earthquakes] and it's good, after earthquake [our relationship] was very close. Actually, we stayed overnight at the same house, which is good.

(Ethiopian female)

But when earthquake happened, they [neighbours not from their ethnic community] came and knocked my door ... They came and help us. That's my first experience to know them, how they cared.

(Hazara, Afghan men's focus group)

Thus, a common adversity provided a shared solidarity and new opportunities for social connectedness, collective affiliation and adaptive resilience. Examples include numerous refugee communities helping to shovel liquefaction (soil acting like a liquid under extreme stress) that blocked roads, drainage and access within their local areas. Somali women baked muffins and other goods to deliver to the police officers who were managing the cordons.

In addition, the anticipated rebuild and recovery efforts provided the participants with a promise of further belonging through the possibility of better employment opportunities.

If you can get a better life condition, about health and job opportunity and other type of facility and then you feel better and you say okay, I'm busy and I can do whatever I like and then you're feeling better and you say okay, I'm hundred per cent belong to here, I can stay here. And then some better opportunity in the life to myself and my children if I stay here.

(Hazara, Afghan male) 


\section{Responding to disasters}

Numerous refugee background adults and youth began training in apprenticeship programmes to assist with the rebuild. Schools had coalesced around each other in ways that broke down difference in ways that did not seem previously possible. It seemed that the extraordinary contexts of the earthquakes created new forms and mobilities of belonging. However, participant comments suggest that the promise of further belonging through civic forms of participation and a sense of sharing a societal narrative had largely diminished only 10-14 months later.

\section{Belonging: two years after the most destructive earthquake}

Almost two years after the devastating earthquake in February 2011, the way that participants spoke about belonging had again shifted. Similar to before the earthquakes, while participants spoke of a relational and more emotive type of belonging, this sense primarily emerged from their intra-ethnic relations rather than across the wider Christchurch community. The immediacy of the earthquakes had allowed for greater movement across particular social locations and entry into wider shared narratives. This mobility, however, appeared to be largely ephemeral as the intensity of aftershocks continued to decrease.

Across the interviews and focus groups, examples of belonging that related to shared societal narratives were rarely mentioned. Participants explained that their neighbours had largely returned to their everyday lives and traditional/previous social networks. Moreover, the promises of increased civic participation due to the city rebuild and recovery had lost much of its lustre. Participants noted that they were unable to gain employment and felt excluded from employment possibilities, even when they had done the appropriate and related training for the rebuild:

If I apply for a job, straight away when I call them or I talk to them, straight away they can feel my accent and I'm not born here, I'm not Kiwi, so sometimes I get a little bit rejected there, so that's why I feel sometimes I'm not belonging here.

(Somali male)

Most of the focus groups revealed that 18 months after the February 2011 earthquake, a large number of community members did not have jobs, and this situation directly influenced how participants spoke about a sense of belonging. The social location of ethnicity that provided participants with a sense of belonging also seemed a category that made employers reticent to employ them.

While expressing concerns about the risks of another major earthquake, participants emphasized that opportunities for belonging through wider societal civic engagements and participation, alongside support from their ethnic community greatly influenced their decisions to leave or stay in the region. Correspondingly, the departure of some refugee background communities had a significant impact on the associated communities' intra-ethnic relationships and networks. Somali 
participants estimated that half their community had left, and Ethiopian participants suggested that nearly 75 per cent of their community had relocated (predominantly due to work opportunities). The Bhutanese community, Christchurch's second-largest group but the most recently resettled (in 2008), was still considering their options - some were resolute to stay and others were not so sure. The already small Kurdish and Eritrean communities noted that there was almost no one left following the earthquakes. Numerous participants emphasized that members of their community had moved to Australia where there were greater numbers of people (usually defined by ethnicity) and the promise of work. Others were in ongoing contact with their Australian and other international communities trying to weigh up their options highlighting how transnational relations informed people's responses to disasters. These various relational and contextual dynamics highlight again how disasters are experienced unevenly across a given society - this is again where the facets of belonging and its associated politics come into play.

\section{Gender, transnationalism and community demographics: intersections with} belonging

The ways in which particular community groups experienced the earthquakes and their related perspectives of belonging were not always uniform. A further examination of the data also shows that other social locations and narratives of belonging were important that illustrate its gendered, technological and transnational dimensions. While ethnicity and culture were essential considerations for disaster responses, there still remains the necessity for an intersectional analysis to ensure that these social locations do not obscure a wider analysis for DRR.

For instance, the ways that women spoke about belonging were often different from the men's narratives. The men focused mainly on civic features of belonging to a place, such as access to, and participation in, employment and education. On the other hand, the women emphasized their children's relations to Christchurch, rather than their own personal belonging. Female participants stated that 'my kids like it here' and that Christchurch was 'a good place for my kids to be'. Beyond their children, most of the women's comments alluded to ethnic conceptions of belonging. For example, women from the Bhutanese, Ethiopian and Afghan focus groups noted their increased isolation because they were less likely to have a driver's licence, be employed or to speak fluent English. Others noted how the loss of a swimming pool and the dedicated time for Muslim women to swim together negatively impacted on their support networks. These sentiments are reflected in the larger literature that highlights how disasters are gendered in the ways in which they are responded to, perceived and experienced (Bradshaw, 2013).

Time settled was also significant for refugee groups. Communities that had been in Christchurch for more than twenty years, such as the Afghan Hazaras, were more likely to have greater, and more stable, community-led forms of support than newly arrived communities. The Bhutanese community that settled from 2008 was 


\section{Responding to disasters}

unsure as to whether they would stay or go and lacked social connections that other groups may have built over time. Other groups such as the Kurdish had almost completely left Christchurch. Thus, the smaller and recently settled communities experienced support and a sense of belonging in different ways from larger and more established communities. Participants also stated that the presence of a communal space (e.g. a community centre) provided for a greater sense of belonging within their respective intra-ethnic and broader Christchurch neighbourhood communities (Marlowe, 2013, 2015). Communities that had been settled for longer were more likely to have established these meeting centres and the associated relational networks to support such proactive plans and transcend particular social locations related to ethnicity, gender and linguistic competencies.

For many participants, the maintenance of ongoing transnational interaction assisted with people's daily lives and access to information about the earthquakes. Numerous participants noted how their correspondence with their transnational (ethnic) communities was one of the strongest drivers for their decisions to stay or go alongside the prospect of sustaining a meaningful livelihood in Christchurch. They acknowledged that having ongoing interactions with these social networks (through phone calls, Skype, email and social media) provided support from the ongoing uncertainties associated with the daily aftershocks. Several participants emphasized how their transnational ties provided valuable sources of information about the disaster in Christchurch and also emotional support. And young people in particular served as an important conduit that connected these community groups through specific digital platforms, highlighting the potential of 'digital natives' for DRR and recovery-based pathways (Marlowe \& Bogen, 2015).

Finally, it is also necessary to consider the socially constructed meanings that a particular cultural group will ascribe to disasters. For some, the earthquakes were an act of God and said that fate would decide their outcomes. Others relied on personal experience to say that they could handle the earthquakes because their forced migration experiences had given them a steeling effect against adversity. As they had survived extreme experiences of persecution and uncertainty and were targeted for what they believed or who they were, they noted that they could cope with the uncertainties of earthquakes. Others, however, spoke of the spectre of being displaced twice, albeit under very different circumstances from forced migration contexts, and were wary of leaving their homes, even if these were in dangerous states of disrepair. For instance, one person commented: 'Yes, I can assure that because for someone who never lived a war, for him maybe a crack in the wall will mean I shouldn't be here. For us, maybe we'll paint over it.'

These different meaning structures highlight the ways in which their everyday understandings powerfully influenced their responses to earthquakes. Effective DRR and an understanding of vulnerability requires an intersectional analysis of what refugee background communities are willing to do in a disaster event alongside the levels of support the systems are willing or able to provide. It is how this gap is bridged, often through community development and dialogic approaches to engagement that vulnerability is minimized and capacities are promoted. 
While this case study presents considerations across several demographic characteristics, it is important to recognize that this focus is not exhaustive. For instance, Osman et al.'s (2012) survey involving refugee communities living in Christchurch found that spirituality and religious practices were particularly important for coping with the earthquakes and represents another key area for recovery. Others noted the importance of community-endorsed interpreters, pre-existing relationships with communities before a disaster and distributed leadership structures that provide redundant forms of support if one leader is not available and the role of indigenous perspectives to support refugee groups (Christchurch Migrant Inter-Agency Group, 2011; Wylie, 2012). These considerations sit alongside linguistic competencies, age, socioeconomic status, health and broader aspects related to the physical, natural and built environment which also influence understandings of belonging. This is why an intersectional analysis of belonging is so important and how it represents only part of DRR praxis that addresses vulnerabilities and promotes people's capacities to recover and their affordances to belong.

\section{Disaster recovery and its social context: belonging and its politics}

The New Zealand case study supports the theoretical utility of considering the ways in which belonging can inform DRR. The participant comments suggest that their past experiences as refugees provide sources of resilience to cope with the earthquakes and on-going aftershocks. While refugees may have much to teach the wider society about how to cope when everyday routines, rules and access to resources do not apply, it is also necessary to recognize vulnerability. Not all refugees coped well in the earthquakes. For some, it was incredibly retraumatizing and may have even brought them to face again previous traumatic experiences.

Effective DRR with refugee groups means understanding not only ethnic background, national affiliation or culture. Other demographics need further consideration that include forced migration experiences, gender (Enarson \& Meyreles, 2004; Pittaway, Bartolomei, \& Rees, 2007), age (Becker, 2006; Zakour \& Harrell, 2003), linguistic competencies (Shiu-Thornton et al., 2007), spirituality (Osman et al., 2012) and disability (Peek \& Stough, 2010; Wolbring, 2011). Bringing these aspects into a structural awareness demonstrates how the facets of belonging and intersectional analyses can inform deeper understandings of what helps particular groups survive and even thrive following a disaster. This nuanced analysis also highlights how participants spoke about a belonging that requires a gendered, chronological and contextual awareness to unpack its meaning and significance in relation to its associated facets.

\section{Social locations}

Commenting on what is needed to support positive psychological outcomes after disasters, Kirmayer et al., (2010, p. 168) maintain that 'post-disaster strategies 


\section{6}

must address the broad impact of disasters, promoting a sense of safety, calming, self- and collective efficacy, feelings of connectedness and hope'. The importance of these outcomes was evident in the participants' responses, and these vary across gender, ethnicity, language comprehension and age. It highlights the fact that the term refugee is only a starting point and that people's settlement experiences provide critical information about developing effective disaster preparedness and response.

While noting that the responses in this study were both gender and community dependent, participant expressions of belonging and what was most helpful in responding to the earthquakes were predominantly ethnic-based sentiments, in both the short and longer term. Effective community leadership and having established meetings centres were crucial for recovery efforts. These findings reinforce the importance of proactive, community-driven and endorsed disaster plans across the 'disaster cycle' of preparedness, response and recovery. Alongside this form of support, civic expressions of belonging provided opportunities to participate in the wider society. The realization of these opportunities was one of the primary determinants to whether a community would remain in Christchurch. And importantly, it is necessary to remain cognizant of who is labelling whom in relation to particular social locations.

It is also necessary to recognize that, although ethnic belonging is an important starting point, it does not represent a singular end goal. Belonging is also influenced by time, gender, size of the associated refugee background community, the amount of time resettled and importantly, the wider society's acceptance of them. Social locations can powerfully determine the ways in which people experience a disaster. The disaster literature clearly illustrates that disasters are gendered, dynamic and contextual events where considerations of power, who has a voice and marginality come into focus (Enarson \& Meyreles, 2004; Pittaway et al., 2007). Therefore, it is important as a disaster event unfolds that those involved in disaster risk reduction and policy are responsive to the ways in which belonging can shift around relational connections, time, gender and civic participation.

The need to make more inclusive spaces and opportunities within and across civil society represents a cornerstone of effective DRR with culturally and linguistically diverse populations. Part of this can be achieved through the elevation of the everyday that can help position people as peers in civic society rather than seen through the dominant social locations of ethnicity and refugee background - a focus of Chapter 5. This analysis specifically applies when a particular locality can be home to numerous refugee background communities that may have significant differences in their relationships with the wider soceity and their preparations, interpretations and responses to a given disaster.

\section{Identifications and emotional attachments}

Except for immediately following the earthquakes, when all residents of Christchurch were connected through the shared experience of survival and recovery from the disaster, the study's participants did not describe a wider 
societal sense of belonging. In the post-earthquake Christchurch context within refugee communities, this concept is seemingly secondary to civic aspects of participation. However, a shared narrative between participants and the wider Christchurch society is particularly helpful to immediate post-disaster resilience and recovery.

The Canterbury case study suggested that shared societal identities and common narratives waned as the powerful aftershocks subsided, and with this a sense of shared solidarity also seemed to dissipate. Unlike forms of belonging which are rights and privileged based, a common identity narrative is more associated with affective connections that include feelings of integration and being part of a recovery process. Immediately following the earthquakes, their mutual struggles for survival and the prospects of Christchurch's recovery as a wider community allowed, at least temporarily, the participants to develop a sense of this wider societal narrative. This augmented their hopes for future integration into the Christchurch/New Zealand community. Nevertheless, these sentiments appeared to be predominantly ephemeral. Other authors have focused on the creation of new social relationships and supports that waned over time in other contexts such as Haiti and in post-conflict Tamil societies (Esnard \& Sapat, 2016; Guribye, 2013). These findings suggest an opportunity, particularly through community development models of engagement (Pyles, 2007; Tudor, 2013), to consolidate these newly formed social relationships and collective identities. This opportunity, however, is powerfully determined by the politics of belonging and various systems that judge particular groups to belong or not.

\section{Ethical and political value systems}

The third facet of belonging articulates how specific value systems define the rights and opportunities that people have to participate in public spaces whether this is education, employment, health or access to social security. Participants, especially the males, identified forms of belonging through their access to services and employment. However, as time passed, the promises of further inclusion in recovery efforts through employment waned as contractors failed to hire these individuals from refugee backgrounds, even when they had adequate training. Thus, the forms of belonging at civic-based levels constitutes an exchange - these individuals, as residents and citizens, are obliged to work, contribute through taxes, participate in New Zealand society and be good citizens. In exchange, they are entitled to particular civic rights. In many cases, marginalized communities lack knowledge and access to these entitlements or meaningful participation as a result of these. Chapter 5 will focus on the ways of supporting and progressing the reception and recognition of such rights. A focus on political and ethical value systems is particularly important because the associated discourses can help facilitate (or impede) communities and individuals to return to a sense of normal daily activities, which is an important part/indicator of recovery and represents a transition back to the everyday (Aldrich, 2012). 


\section{Responding to disasters}

The emergence, destabilization and possibilities of belonging in disaster contexts require an understanding of community to map associated capacities and vulnerabilities that can help with disaster mitigation and response. While refugees arguably share far more in common with the wider population as to what constitutes effective DRR, there are additional considerations that are needed to more effectively engage with culturally and linguistically diverse populations. This focus now discusses the implications of DRR in relation to contemporary forced migration trends and movements.

\section{Disaster riskscapes and transnational implications}

The unprecedented numbers of forced migrants since the Second World War alongside the increasing losses caused by disasters in terms of fatalities, loss of livelihoods and financial costs highlight the need to consider DRR for refugees who are resettled across 33 different countries. The millions more who are living in neighbouring countries of asylum and those who are internally displaced further buttresses the importance of proactive DRR plans with such groups. The IFRC (2012) notes how the shift of forcibly displaced people living in refugee camps in the 1980s and 1990s has now significantly moved to urban areas, creating new challenges for effective DRR in areas characterized by rich diversity. While this is true of people displaced internally and in neighbouring countries of asylum, understanding this dynamic is essential in resettlement contexts where the term refugee can be applied to everyone in a given locality affected by a disaster.

Refugees arguably share far more in common with the wider society as to what would inform effective disaster preparedness and response. However, these populations should help inform local/regional DRR plans as they may have a number of distinct demographic characteristics and additional forms of vulnerability (and capacities) than the local populations who have historically resided there. Such dynamics reinforce that the refugee and emergency management sectors need to consider the various possible disasters (natural, socio-natural, financial and technological) across the demographics of a given settlement site to establish an accurate riskscape. The forms of social capital and the multiple ways that people belong help inform this analysis.

Increasingly, there is recognition of the importance of transnational connections for DRR. While much of the literature emphasizes the significance of local networks and ties, particularly in the early response/recovery stages of a disaster, the role of transnational support through forms of remittances and ongoing practices of care are emerging (Esnard \& Sapat, 2016). Rytter (2010), drawing on the Pakistani diaspora living in Denmark notes how this community practised 'intensive transnationalism' to respond to the 2005 earthquake in Kashmir. Providing examples of the multiple ways that this community looked to support those affected by the earthquake, he demonstrated the ways in which support was intensified and mobilized from afar. Esnard and Sapat (2016) found similar findings in Haiti where this form of 'transnational social capital' was not necessarily stable and, in fact, waned after the immediacy of the associated crisis. 
It is important to recognize that the impacts of a disaster can be multifaceted with various factors coming together to exacerbate a particular event. Technological, socio-natural and coupled disasters clearly show that disasters are intimately tied to the social production of risk. Human activities are also powerfully coupled with the strengthening of capacities and resilience. Social capital resources and a sense of belonging are important elements that can help make for more effective DRR, but it is also necessary to recognize that it is only part of the overall picture that makes particular groups resilient. So, too, is the increasing recognition that, while it may very well be that local forms of support will provide the immediate response to a disaster, transnational relationships can also serve as important sites for social, financial and cultural flows into an affected locality. These flows, however, can be highly uneven - some argue that these can even exacerbate existing forms of inequality where those with stronger transnational networks and various forms of social and human capital can get ahead, leaving others without such resources increasingly vulnerable (Le Dé et al., 2015).

These forms of connection illustrate that disasters do not only impact those directly affected in the localized area of a disaster, but also through diasporic networks (Marlowe \& Bogen, 2015; Takeda, 2015). As the transnational and translocal literatures attest, the impacts of, and ways of, responding to disasters often extend far beyond the locality impacted by disaster. Esnard and Sapat (2011) found that disasters can profoundly destabilize existing transnational support networks where it can be difficult to maintain regular remittance practices. In this sense, transnational responses represent promising potential, but can also be sources of strain and contestation as the distribution of different financial, cultural and social flows travel across borders.

The process of developing relationships across refugee background communities generally and acknowledging diversity within these groups specifically signals a critical role for DRR. As Desai (2007) notes, a belief in people's capacities to grow and change represents a paramount principle for empowering disaster initiatives. There is a growing need to consider (and celebrate) the diversity that refugee background communities carry along with them to inform effective disaster response and preparedness for forcibly displaced populations, whether this is in resettlement contexts or otherwise. Overall, the participant comments highlight the diversity of their experiences and the importance of proactive community plans that are community driven and agency supported. This means engaging with communities before a disaster occurs and creating collaborative contingency plans to ensure that there are multiple ways of responding as it is impossible to fully anticipate how a future disaster scenario may unfold.

\section{Sendai Framework and diversity}

The UN member states adopted the Sendai Framework for Disaster Risk Reduction 2015-2030 (UNISDR, 2015) at the Third UN World Conference on Disaster Risk Reduction in Japan. This framework replaces the ten-year 2005-15 Hyogo Framework for Action and establishes four priority areas: 
- Priority 1: Understanding disaster risk.

- Priority 2: Strengthening disaster risk governance to manage disaster risk.

- Priority 3: Investing in disaster risk reduction for resilience.

- Priority 4: Enhancing disaster preparedness for effective response and to 'Build Back Better' in recovery, rehabilitation and reconstruction.

Recognizing that there is, at best, limited and often non-existent, articulated policy in particular countries with respect to refugee and disaster risk management specifically, there is a need to look at how to respond proactively to these priority action areas. This framework makes suggestions for the reduction of vulnerabilities and hazard risks, and to improve disaster response from local to international levels (UNISDR, 2015). Its breadth allows for the adaptation of its priorities to local situations, disaster type, and specific vulnerabilities and capacities. The Sendai Framework notes that responses and DRR require a proactive stock-take of what resources are available and lacking. ${ }^{19}$ While the Framework notes the over-arching importance of considering cultural diversity, gender, age and vulnerable groups in the fulfilment of all the priorities for action, it does not provide specific details on how this is to be done. Rather, it acknowledges the importance of local solutions where the meaningful operationalization of engaging with such factors is needed.

Priority actions 1 and 3 emphasize considering the diversity of local communities living for any disaster mitigation strategy that attempts to increase public awareness and address underlying risk factors. Priority action 3 focuses on strengthening disaster response and includes capacity-building initiatives that highlight the need for collaborative engagement with refugee communities. While building community capacity represents a key component of an effective disaster response, any initiative must also account for particular markers of diversity within communities discussed above. Included in this consideration are the possibilities for transnational support that may offer additional sites of belonging, and flows of resources that may be social, financial, cultural and political.

The UNHCR has also developed a risk matrix for refugees that looks at the likelihood of a particular event multiplied by its impact. Like the Sendai Framework, it acknowledges the necessity of incorporating local knowledges to ascertain levels of risk and what resources and capacities exist to respond to associated dangers. ${ }^{20}$ In both cases, community models of engagement that are institutionally supported are likely to build and foster aspects of belonging and forms of social capital that would be beneficial within and outside disaster contexts.

Each community's local knowledge and resonant responses to a disaster situation offers a valuable resource to help inform how to work with the diversity of refugee background groups. It means that social service providers should seek to identify ways to support local community responses to best identify their specific vulnerabilities, capacities and opportunities. Despite potential vulnerabilities, refugee groups also demonstrate capacities and resilience generally and in disaster situations specifically. The fact that refugees have already survived adverse 
circumstances as part of their forced migration journey can also provide them with forms of resilience that may not be available to others without this experience.

Gaillard (2007, p. 523) asserts that disasters can be viewed as 'an extension of everyday hardships'. Pre-existing socioeconomic and demographic disparities shape individual and community-based vulnerabilities and responses to a disaster, as well as produce inequalities in the processes and patterns of recovery (Cutter \& Emrich, 2006; Zakour \& Gillespie, 2013). As Brooks (2005) wrote in an editorial to the aftermath of Hurricane Katrina, 'Floods wash away the surface of society, the settled way things have been done. They expose the underlying power structures, the injustices, the patterns of corruption and the unacknowledged inequalities.' Thus, it is critical to acknowledge that refugees are not inherently vulnerable in disaster contexts. The international literature indicates that refugees can have fewer resources and increased considerations of vulnerability that may include limited fluency in the host country language(s), varying amounts of time since resettlement, previous exposure to trauma, and higher rates of unemployment and underemployment than the wider society. Such everyday hardships can be rendered invisible and create additional adversities for particular social groupings in a disaster.

A wide gap remains between what are often vague international guidelines and specifically targeted reports on local responses to culturally and linguistically diverse groups. The tensions between top-down and bottom-up perspectives highlight the need for programmes to increase refugee involvement and selfsufficiency within and beyond their ethnic communities, including initiatives that build upon education and employment prospects. Within particular disasters, development of relationships with diverse communities can take considerable time. It is important, therefore, to take into account and honour specific communities' stories, experiences and hopes for the future in the development of effective disaster preparedness and response initiatives. The pre-disaster context powerfully influences the lived experience of disasters. As Tierney (2014) maintains, disaster risk has deep social roots. A focus on belonging and the sociology of the everyday and the extraordinary provides a helpful lens to understand where these roots go and originate. The next chapter focuses on this awareness as it relates to various forms of professional practice.

\section{Conclusion}

Even though a hazard such as an earthquake or hurricane will occur regardless of human activity, it is the decisions taken and later responses that society and the associated structures that govern it that have significant influence on whether a major event is experienced as a disaster or not. As the ground hopefully continues to settle in the surrounding Canterbury region, there is an opportunity to reflect upon and learn from people's prior histories and current aspirations to inform effective DRR. This specific case study is set in wider contexts that illustrate the latest UNHCR global trends or more than 65 million forcibly displaced people. 
Many find themselves internally displaced with limited opportunities for safe movement. Millions more find themselves in transit attempting to cross borders where they are exposed to the dangers and exploitation associated with trafficking. The receiving countries and their associated institutions can struggle to ascertain who is living within its borders.

The IFRC (2012) report on forced displacement clearly highlights, however, that most of these people do not end up in countries of resettlement where they may be exposed to additional vulnerabilities. Life may be precarious and the institutions in the new locality may not be equipped or even willing to assist those who have crossed its borders. Thus, it is important to recognize that London is different from Lebanon. The contexts of Houston or Berlin are very different from those of Istanbul, Bangkok or Kampala. Despite the significant associated differences, my intent in this chapter is to show the utility of belonging, and at times, transnational interactions, to inform DRR. Rather than a framework that can be prescribed to a given locality and translocal linkages, these concepts provide helpful lenses to consider proactive ways of ensuring effective responses long before a disaster occurs and well after.

Forms of belonging, possibilities of transnationalism and social capital resources are only part of the wider DRR ecology for refugees. And an ecological metaphor is appropriate. Access to resources, commitment to safe building standards, reliable and safe engineering practices, responsible environmental management and effective communications among many other aspects are also important in developing an ecological approach to disaster resilience. The dynamics of a system also highlight that social capital resources and a sense of belonging are not necessarily stable assets or sentiments. Both can be fleeting, changeable and context-dependent. At times these might be incredibly resilient and adaptable and at others, fragile, where a major external event such as a disaster may expose weaknesses previously not considered from deliberate to tacit perspectives. As Tierney (2014) powerfully acknowledges, it is when these different forms of DRR come together that the social production of risk can rather promote forms of resilience.

The term refugee encompasses rich diversity, and the complexities of, and opportunities for, recovery in a disaster context relate to a particular community's characteristics, such as time resettled, relative size, degrees of internal and external social cohesion and many others. The fact that refugees settle all over the world highlights the need to consider the specific riskscapes of particular locations alongside the socio-political contexts in which culturally and linguistically diverse groups find themselves. The vignette in Houston presented at the beginning of this chapter illustrates this awareness; an approach there would be very different from DRR approaches in the multitude of urban, regional and rural localities where refugee resettlement occurs globally.

When and where natural hazards do occur, the need to consider the diversity represented across values, cultural beliefs and interpersonal dynamics and how people's histories coincide becomes increasingly relevant in disaster contexts. Built into this understanding is an awareness of the epistemological, ontological 
and theoretical foundations that guide different group assumptions, personal histories and professional knowledge bases. Alongside this awareness is the need for critical engagement with definitions of vulnerability that consider the interplay of multiple actors and domains of power. Embracing the concept of possibility helps to move beyond what is routinely envisaged when a disaster occurs that opens spaces for translocal and multi-scalar responses. The next chapter on 'practice' discusses these associated implications and possibilities of the everyday and extraordinary within multiple professional domains.

\section{Notes}

1 The most notable hurricanes that have impacted Houston include Carla (1961), Alicia (1983), Ike (2008) and two unnamed storms in 1915 and 1900.

2 See the Texas Health Institute report that outlines the implications for effective disaster response with culturally diverse populations living in the greater Houston area (see the following website: www.texashealthinstitute.org).

3 The city of Houston has a strategy to work with diversity in disasters. The challenge with such strategies in the many resettlement localities globally is ensuring that the diverse populations know about the specific hazards that exist, understand the strategy that is intended to support them (if one exists) and are willing to embrace this form of support.

4 The Jungle was home to more than 7,000 migrants which was dismantled by the French government in October 2016.

5 This chapter presents previously published material of research conducted in Christchurch, New Zealand, about how the refugee background communities responded to the earthquakes. Most particularly, it presents work published in the British Journal of Social Work and also uses some material from Disaster Prevention \& Management and Aotearoa Social Work. See the following references:

Marlowe, J. (2013) Resettled refugee community perspectives to the Canterbury earthquakes: Implications for organizational response. Disaster Prevention and Management, 22(5), 434-44.

Marlowe, J. (2015) Belonging and Disaster Recovery: Refugee-Background Communities and the Canterbury Earthquakes. British Journal of Social Work, 45(suppl. 1), i188-i204. doi:10.1093/bjsw/bcv090

Marlowe, J. \& Lou, L. (2013) The Canterbury earthquakes and refugee communities. Aotearoa New Zealand Social Work, 25(2), 58-68.

6 The hurricane was the costliest disaster from a natural hazard in the history of the United States and resulted in 1,833 fatalities. More than fifty levees were breached during this storm that flooded more than 100,000 homes and businesses with 80 per cent of New Orleans flooded. In particular, Katrina highlights how hazards can impact people in unequal ways.

7 The notion of riskscapes has been used in various fields of study from disasters, conflicts, environmental management, transportation and others to visualize how various social, environmental, physical and technological risks come together and accumulate. Within disaster studies, riskscapes are used to consider the complex ways that these different forms of risk can inform effective and proactive mitigation strategies.

8 This report does not include the impact of epidemics.

9 The speed of a pyroclastic flow can exceed 150 kilometres per hour and reach temperatures of 800 degrees Celsius.

10 There have been scathing reports of the government's reluctance to conduct an early evacuation. Some suggest this was predominantly an economic decision not to issue 


\section{Responding to disasters}

an evacuation order. However, while scientists predicted that another eruption could happen, it has been noted that the science was imprecise, making it difficult to justify an evacuation and the associated financial implications of such an exercise (Voight, 1990).

11 See www.womensrefugeecommission.org/issues/livelihoods/research-and-resources/1231clara-tool that highlights how women are impacted differently from men in disaster situations and the associated tools to help establish risk, particularly with a focus on gender-based violence.

12 At times, the terms capacities and resilience are used interchangeably, but they do have different meanings.

13 The number of fatality estimates varies widely. Several academic sources cite between 150,000 and 200,000 deaths. Government figures have been much higher, with reports suggesting more than 300,000 fatalities. Some have cynically suggested, however, that these estimates represent an attempt to leverage greater claims for humanitarian aid and assistance.

14 Aldrich's (2012) work on four different 'mega disasters' (1923 Tokyo earthquake, 1995 Kobe earthquake, 2004 Indian Ocean tsunami and 2005 Hurricane Katrina) makes a compelling case that social capital resources/networks are central for disaster recovery, and are often more important than traditionally referenced factors such as socioeconomic considerations, population density and the amount of aid and financial resources that flow into a particular locality.

15 Regulatory capture occurs when a regulatory agency becomes partial and biased towards commercial and political interests that are contrary to the public good. Often this results in the regulatory authority, allowing industry and others in a position of power to define the ways in which they can be regulated.

16 At the moment, the New Zealand government has halted the resettlement of newly arrived refugees to Christchurch because of the housing shortage and recovery processes. There is discussion of reinstigating the settlement programme in the future.

17 These events have become New Zealand's largest natural disaster since 1931, when the Hawkes Bay was hit by a 7.8 magnitude earthquake that levelled the towns of Napier and Hastings, killing 256 people.

18 See www.christchurchquakemap.co.nz/ that provides a time-lapsed infographic and summary of the number and intensity of seismic events in the Canterbury region.

19 This framework acknowledges migrants, age-related considerations, indigenous people, disabilities and other forms of diversity that can inform DRR. In particular, it states, 'Migrants contribute to the resilience of communities and societies, and their knowledge, skills and capacities can be useful in the design and implementation of disaster risk reduction' (UNISDR, 2015, p. 23)

20 See https://emergency.unhcr.org/entry/53463/risk-analysis-and-monitoring-refugeeemergencies

\section{References}

Aldrich, D. P. (2012) Building resilience: Social capital in post-disaster recovery. Chicago: University of Chicago Press.

Aldrich, D. P. \& Crook, K. (2008) Strong civil society as a double-edged sword: Siting trailers in post-Katrina New Orleans. Political Research Quarterly, 61: 378-89.

Becker, S. M. (2006) Psychosocial care for adult and child survivors of the 2004 tsunami disaster in India. American Journal of Public Health, 96(8): 1397-8.

Below, R. \& Vanderveken, A. (2016) Disaster data: A balanced perspective. Retrieved from: cred.be/sites/default/files/CredCrunch41.pdf

Bradshaw, S. (2013) Gender, development and disasters. Cheltenham: Edward Elgar. 
Brooks, D. (2005, September 1) The storm after the storm, New York Times.

Carney, S. (2012) Red market: On the trail of the world's organ brokers, bone thieves, blood farmers, and child traffickers. New York: William Morrow.

Christchurch Migrant Inter-Agency Group (2011) Christchurch Migrant Inter-Agency Group: Lessons learned following the earthquakes of 22 February 2011. Retrieved from: www.communityresearch.org.nz/learning-from-christchurch/

Cohen, R. E. (1987) The Armero tragedy: Lessons for mental health professionals. Psychiatric Services, 38(12): 1316-1321. doi:10.1176/ps.38.12.1316

Corin, C. (2011) The Christchurch hospital social work service response in the first hours after the Christchurch earthquake of 22nd February 2011. Aotearoa New Zealand Social Work, 23(3): 58-62.

Correa-Velez, I., McMichael, C. \& Conteh, A. (2014) Levels of social trust among men from refugee backgrounds after the 2011 Queensland floods. International Journal of Disaster Resilience in the Built Environment, 5(3): 318-28.

Crawley, H., Duvell, F., Jones, K. \& Sigona, N. (2016) Destination Europe? Understanding the dynamics and drivers of Mediterranean migration in 2015. Retrieved from: www.medmig.info/research-brief-destination-europe.pdf

Cutter, S. L. \& Emrich, C. T. (2006) Moral hazard, social catastrophe: The changing face of vulnerability along the hurricane coasts. The Annals of the American Academy of Political and Social Science, 604(1): 102-12.

Davis, B. C. \& Bali, V. A. (2008) Examining the role of race, NIMBY, and local politics in FEMA trailer park placement. Social Science Quarterly, 89: 1175-94.

Le Dé, L., Gaillard, J. C. \& Friesen, W. (2015) Poverty and disasters: Do remittances reproduce vulnerability? The Journal of Development Studies, 51(5): 538-53. doi:10.1080/00220388.2014.989995

Le Dé, L., Gaillard, J. C., Friesen, W., Pupualii, M., Brown, C. \& Aupito, A. (2016) Our family comes first: Migrants' perspectives on remittances in disaster. Migration and Development, 5(1): 130-48. doi:10.1080/21632324.2015.1017971

Desai, A. (2007) Disaster and social work responses. In L. Dominelli (ed.) Revitalising Communities in a Globalised World (pp. 297-314). Burlington, VT: Ashgate Publishing Company.

Dominey-Howes, D., Gorman-Murray, A. \& McKinnon, S. (2014) Queering disasters: On the need to account for LGBTI experiences in natural disaster contexts. Gender, Place \& Culture, 21(7): 905-18. doi:10.1080/0966369x.2013.802673

Edwards, F. L. (2010) At home in Silicon Valley: One end to the Katrina diaspora. In J. Rivera \& D. S. Miller (eds) How ethnically marginalized Americans cope with catastrophic disasters: Studies in suffering and resiliency. New York: Edwin Mellen Press.

Eisenman, D., Cordasco, K., Asch, S., Golden, J. \& Glik, D. (2007) Disaster planning and risk communication with vulnerable communities: Lessons from Hurricane Katrina. American Journal of Public Health, 97(Supplement_1), S109-S115. doi:10.2105/ AJPH.2005.084335

Elliott, J. R., Haney, T. J., \& Sams-Abiodun, P. (2010) Limits to social capital: Comparing network assistance in two New Orleans neighborhoods devastated by Hurricane Katrina. Sociological Quarterly, 51: 624-48.

Enarson, E. \& Meyreles, L. (2004) International perspectives on gender and disaster: Differences and possibilities. The International Journal of Sociology and Social Policy, 24(10/11): 49-93.

Esnard, A.-M. \& Sapat, A. (2011) Disasters, diasporas and host communities: Insights in the aftermath of the Haiti earthquake. Journal of Disaster Research, 6(3): 331-42. 
Esnard, A.-M. \& Sapat, A. (2016) Transnationality and diaspora advocacy: Lessons from disaster. Journal of Civil Society, 12(1): 1-16. doi:10.1080/17448689.2015.1114737

Finch, C., Emrich, C. \& Cutter, S. (2010). Disaster disparities and differential recovery in New Orleans. Population and Environment, 31(4): 179-202. doi:10.1007/s11111-0090099-8

Gaillard, J. C. (2007) Resilience of traditional societies in facing natural hazards. Disaster Prevention and Management, 16(4): 522-44.

Goenjian, A. K., Steinberg, A. M., Najarian, L. M., Fairbanks, L. A., Tashjian, M. \& Pynoos, R. S. (2000) Prospective study of posttraumatic stress, anxiety, and depressive reactions after earthquake and political violence. American Journal of Psychiatry, 157(6): 911-16.

Goulbourne, H., Reynolds, T., Solomos, J. \& Zontini, E. (2010) Transnational families: Ethnicities, identities and social capital. London: Routledge.

Guribye, E. (2013) "Quislings": Barriers to linking social capital amongst members of pro-liberation Tigers of Tamil Eelam non-governmental organizations in Norway in a post-conflict situation. Journal of Civil Society, 9(3): 233-47. doi:10.1080/17448689. 2013.807045

IFRC (2012) World disasters report 2012: Focus on forced migration and displacement. Retrieved from: www.ifrcmedia.org/assets/pages/wdr2012/download/index.htmlIFRC

IFRC (2016) The 2015 world disasters report: Focus on local actors, the key to humanitarian effectiveness. Retrieved from: http://ifrc-media.org/interactive/world-disastersreport-2015/

Johnston, D., Becker, J. \& Paton, D. (2012) Multi-agency community engagement during disaster recovery: Lessons from two New Zealand earthquake events. Disaster Prevention and Management, 21(2): 252-68. doi:http://dx.doi.org/10.1108/ 09653561211220034

Keiler, M. (2013) Worldwide trends in natural disasters. In P. T. Bobrowsky (ed.) Encyclopedia of Natural Hazards (pp. 1111-14). Dordrecht: Springer Netherlands.

Kelley, C. P., Mohtadi, S., Cane, M. A., Seager, R. \& Kushnir, Y. (2015) Climate change in the fertile crescent and implications of the recent Syrian drought. Proceedings of the National Academy of Sciences, 112(11): 3241-6. doi:10.1073/pnas.1421533112

Kirmayer, L., Kienzler, H., Hamid Afana, A. \& Pedersen, D. (2010) Trauma and disasters in social and cultural context. In C. Morgan \& D. Bhugra (eds) Principles of social psychiatry. London: John Wiley \& Sons.

Klinenberg, E. (2002) Heat wave: A social autopsy of disaster in Chicago. Chicago: University of Chicago Press.

Kunz, E. F. (1973) The refugee in flight: Kinetic models and forms of displacement. The International Migration Review, 7(2): 125-46. doi:10.2307/3002424

Lauta, K. C. (2014) Disaster law. London: Routledge.

Lewis, K. V. (2013) The power of interaction rituals: The Student Volunteer Army and the Christchurch earthquakes. International Small Business Journal, 31(7): 811-31. doi: $10.1177 / 0266242613478438$

Marlowe, J. (2011) Sudanese settlement: Employing strategies of intercultural contact and cultural maintenance. The Australasian Review of African Studies, 32(2): 101-17.

Marlowe, J. (2013) Resettled refugee community perspectives to the Canterbury earthquakes: Implications for organizational response. Disaster Prevention and Management, 22(5): 434-44.

Marlowe, J. (2014) A social justice lens to examine refugee populations affected by disasters. Advances in Social Work and Welfare Education, 16(2): 46-59. 
Marlowe, J. (2015) Belonging and disaster recovery: Refugee-background communities and the Canterbury earthquakes. British Journal of Social Work, 45(suppl. 1): i188i204. doi:10.1093/bjsw/bcv090

Marlowe, J. \& Bogen, R. (2015) Young people from refugee backgrounds as a resource for disaster risk reduction. International Journal of Disaster Risk Reduction, 14(2): 125-31. doi:http://dx.doi.org/10.1016/j.ijdrr.2015.06.013

Marlowe, J. \& Lou, L. (2013) The Canterbury earthquakes and refugee communities. Aotearoa New Zealand Social Work, 25(2): 58-68.

Marlowe, J., Lou, L., Osman, M. \& Alam, Z. Z. (2014) Conducting post-disaster research with refugee background peer researchers and their communities. Qualitative Social Work. doi: $10.1177 / 1473325014547252$

Mathbor, G. M. (2007) Enhancement of community preparedness for natural disasters: The role of social work in building social capital for sustainable disaster relief and management. International Social Work, 50(3): 357-69.

Mercer, J., Gaillard, J. C., Crowley, K., Shannon, R., Alexander, B., Day, S. \& Becker, J. (2012) Culture and disaster risk reduction: Lessons and opportunities. Environmental Hazards, 11(2): 74-95. doi:10.1080/17477891.2011.609876

Montalbano, W. (1985, December 5) Official negligence alleged in Colombia: Volcano aftermath: Cries of recrimination erupt. Los Angeles Times. Retrieved from: http://articles.latimes.com/1985-12-05/news/mn-353_1_public-officials

Nakamura, A. \& Kikuchi, M. (2011) What we know, and what we have not yet learned: Triple disasters and the Fukushima nuclear fiasco in Japan. Public Administration Review, 71(6): 893-9. doi:10.1111/j.1540-6210.2011.02437.x

New Zealand Government (2013) 2013 Budget speech: Supporting the rebuilding of Christchurch. Retrieved from: www.treasury.govt.nz/budget/2013/speech/06.htm

Osman, M., Hornblow, A., Macleod, S. \& Coope, P. (2012) Christchurch earthquakes: How did former refugees cope? New Zealand Medical Journal, 125(1357): 113-21.

Peek, L. (2008) Children and disasters: Understanding vulnerability, developing capacities, and promoting resilience - An introduction. Children, Youth and Environments, 18(1): 1-29. doi:10.7721/chilyoutenvi.18.1.0001

Peek, L. \& Stough, L. M. (2010) Children with disabilities in the context of disaster: A social vulnerability perspective. Child Development, 81(4): 1260-70. doi: 10.1111/j.1467-8624.2010.01466.x

Pittaway, E., Bartolomei, L. \& Rees, S. (2007) Gendered dimensions of the 2004 tsunami and a potential social work response in post-disaster situations. International Social Work, 50(3): 307-19.

Putnam, R. (2000) Bowling alone: The collapse and revival of American community. London: Simon \& Schuster.

Pyles, L. (2007) Community organizing for post-disaster social development: Locating social work. International Social Work, 50(3): 321-33.

Rytter, M. (2010) Events and effects: Intensive transnationalism among Pakistanis in Denmark. 54(3): 90-106. doi:10.3167/sa.2010.540306

Shiu-Thornton, S., Balabis, J., Senturia, K., Tamayo, A. \& Oberle, M. (2007) Disaster preparedness for limited English proficient communities: Medical interpreters as cultural brokers and gatekeepers. Public Health Reports, 122(4): 466-71.

Singer, A. \& Wilson, J. H. (2006) From "there" to "here": Refugee resettlement in Metropolitan America. Brookings Institution. Retrieved from: www.brookings.edu/ wp-content/uploads/2016/06/20060925_singer.pdf 


\section{Responding to disasters}

Spittles, B. \& Fozdar, F. (2008) Understanding emergency management: A dialogue between emergency management sector and CALD communities. Retrieved from: http:// researchrepository.murdoch.edu.au/10933/

Takeda, A. (2015) Intensive transnationalism amongst Japanese migrants after the great East Japan Earthquake: Voices from diasporic blogs. Studies in Ethnicity and Nationalism, 15(3): 492-507. doi:10.1111/sena.12162

Tan, N. T. \& Yuen, F. (2013) Social work, strengths perspective, and disaster management: Roles of social workers and models for intervention. Journal of Social Work in Disability \& Rehabilitation, 12(1-2): 1-7. doi:10.1080/1536710x.2013.784170

Tierney, K. (2006) On risk and disaster: Lessons from Hurricane Katrina. In Ronald J. Daniels, Donald F. Kettl \& H. Kunreuther (eds) Social inequality, hazards, and disasters, pp. 109-28. Philadelphia, PA: University of Pennsylvania Press.

Tierney, K. (2014) The social roots of risk: Producing disasters, promoting resilience. Stanford, CA: Stanford University Press.

Tudor, R. (2013) Social work in the Quake zone: Supporting the sustainable development of Christchurch's eastern communities. Aotearoa New Zealand Social Work, 25(2): $18-26$.

UNISDR (2009) Terminology on disaster risk reduction. Retrieved from Geneva: www.unisdr.org/we/inform/terminology

UNISDR (2015) Sendai Framework for disaster risk reduction 2015-2030. Geneva: United Nations Office for Disaster Risk Reduction.

US Department of Health and Human Services (2009) Report to Congress. Office of Refugee Resettlement. Retrieved from: www.acf.hhs.gov/orr/resource/annual-orrreports-to-congress

Voight, B. (1990) The 1985 Nevado del Ruiz volcano catastrophe: Anatomy and retrospection. Journal of Volcanology and Geothermal Research, 42(1): 151-88. doi:http:// dx.doi.org/10.1016/0377-0273(90)90075-Q

Wisner, B., Blaikie, P., Cannon, T. \& Davis, I. (2014) At risk: Natural hazards, people's vulnerability and disasters (2nd edn). London: Routledge.

Wolbring, G. (2011) Disability, displacement and public health: A vision for Haiti. Canadian Journal of Public Health, 102(2): 157-9.

Wylie, S. (2012) Best practice guidelines: Engaging with culturally and linguistically diverse (CALD) communities in times of disaster. Christchurch City Council. Retrieved from: www.civildefence.govt.nz/assets/Uploads/

Xin, H., Aronson, R. E., Lovelace, K. A., Strack, R. W. \& Villalba, J. A. (2013) Resilience of Vietnamese refugees: Resources to cope with natural disasters in their resettled country. Disaster Medicine and Public Health Preparedness, 7(4): 387-94. doi:10.1017/ dmp. 2013.44

Zakour, M. \& Gillespie, D. (2013) Community disaster vulnerability: Theory, Research, and Practice: New York: Springer.

Zakour, M. \& Harrell, E. B. (2003) Access to disaster services: Social work interventions for vulnerable populations. Journal of Social Service Research, 30(2): 27-54.

Zetter, R., Griffiths, D. \& Sigona, N. (2005) Social capital or social exclusion? The impact of asylum-seeker dispersal on UK refugee community organizations. Community Development Journal, 40(2): 169-81. doi:10.1093/cdj/bsi025

Zetter, R., Griffiths, D. \& Sigona, N. (2006) Immigration, social cohesion and social capital: What are the links? Oxford: Joseph Roundtree Foundation. 


\section{Professional practice}

\section{Introduction}

A social worker trained to assist people living through experiences of trauma meets with a Bhutanese single mother who has resettled in Australia. He discovers that, while enduring great hardship during her time in a refugee camp, she is currently experiencing significant housing issues, her kids are being bullied at school and she has not been able to secure employment for more than three years. She does not fully trust the Bhutanese community living there and has few local friends. Her primary supports are the people who have resettled in the United States, New Zealand, Canada and the Netherlands. She and her children are connected to this network daily through social media. Although past adversities still haunt her, she is primarily interested in trying to help other family members resettle in Australia and to resume her career as a teacher. This social worker (who is not from a refugee background) wonders about the remit of his role relating to the multiple issues she presents.

Throughout this book, I have presented the sociology of the everyday and the extraordinary to highlight the theoretical utility of belonging and transnational refugee settlement. This chapter discusses the more applied aspects of this orientation to various forms of health and social practices. Like the concepts of trauma, disasters and the term 'refugee', the notion of practice is another that benefits from a critical and reflexive consideration (again, through rendering the familiar strange). Within this chapter I address the third question addressed in this book: What are the associated implications of belonging for professional practice in local places? As this is being established, I consider the potential roles of transnational networks to support belonging by presenting a conceptual framework that broadens the ways of thinking about refugees and practice through a concurrent examination of the everyday and the extraordinary.

This chapter predominantly concentrates on health and social practice broadly envisaged to include social work, psychology, counselling, case management and many others. It is perilous to consider these professions without including the populations that it is tasked to work alongside - the people from refugee backgrounds themselves. ${ }^{1}$ Thus, the conceptual practice framework positions understandings of refugees and of practice together to help shift what is known and 
familiar to what might be possible to know relating to transnational settlement and belonging.

\section{Conceptual practice framework}

Within the 33 countries offering refugee resettlement programmes, there are a multitude of ways that practice is conceptualized to assist with the short- and long-term aspects of settlement and integration. The professional bodies and associations that define the parameters of practice highlight how the related discourses intersect with dominant understandings about refugees - sometimes in empowering ways and others less so.

There is often a gap in understanding between professional practice assumptions and refugee worldviews as different perspectives and histories come together. Such intricacies mean that practitioners, policy makers and researchers who are outsiders to refugee background communities may have limited access and appreciation of insider politics. Practitioners inevitably bring their own experiences, values and beliefs to any interaction. They may not have had an experience of forced migration themselves. For those who work in general service delivery, they may have had limited to no experience working with people from refugee backgrounds. How is it, then, that they can relate to a woman who was placed on a boat at 8 years of age and sailed off as an unaccompanied minor from Jaffna in Northern Sri Lanka to escape persecution? These tasks are easier stated than done. There are also complexities for those who are closer to an insider designation, possibly defined by having a forced migration experience or coming from the same religious or ethnic background. This chapter presents a conceptual practice framework to consider these dynamics, and how belonging and transnational settlement can open new possibilities of understanding and practice.

Within this chapter, I present a conceptual framework that provides a dual focus on understandings of refugees and professional practice. The types of practice that I emphasize are by no means comprehensive, in terms of depth and breadth. Entire books have been written about interpersonal practice, trauma, community development, mental health, education and research with refugees. There are aspects of professions that this book has only briefly focused upon that are related to various aspects of domestic and international law. Rather than looking to provide a comprehensive appraisal of different aspects of practice, my intention is to present a conceptual framework that considers how belonging and transnational settlement relate to various forms of health and social practice with refugees.

The terms at the left and right of the diagram, known and familiar and knowledge of refugee settlement, relate to Vygotsky's (1978, 1986) work on social scaffolding and the zone of proximal development. Focusing on childhood development, he argued that learning is the outcome of social collaboration which involves moving from what a person can know and achieve to fostering new understandings and possibilities through the process of scaffolding. Often used in building, scaffolding provides the support to reach higher levels in safe ways. The 


\section{WHAT IS POSSIBLE TO KNOW ABOUT REFUGEE SETTLEMENT}

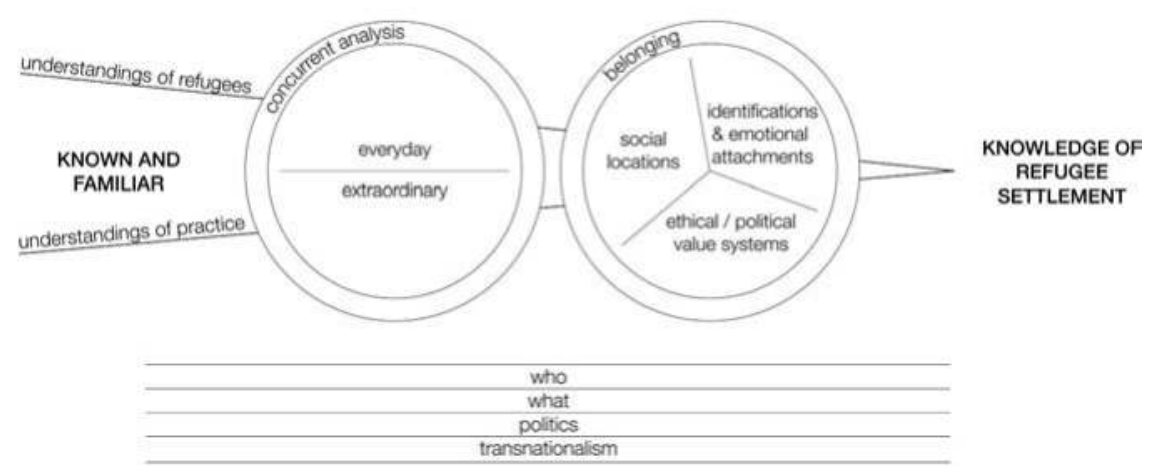

Figure 5.1 Conceptual practice framework

same idea can be used for encouraging new understandings and providing opportunities to challenge dominant thinking as it relates to knowledge of refugee settlement. ${ }^{2}$

The text at the top of the diagram, what is possible to know about refugee settlement, focuses on this scaffolding process to help shift familiar assumptions about refugees and practice to new forms of knowledge and insight. I use these perspectives as informed through narrative practices (discussed further in this chapter) to unsettle dominant discourses and scaffold opportunities to new ways of thinking about refugee settlement. The conceptual framework is broken into three principal components: 1) two horizontal dimensions; 2) two vertical dimensions; and 3) four scaffolding perspectives.

The two horizontal dimensions represent lines that merge together, which are understandings of refugees and understandings of practice. These two dimensions come together to consider how these interact, as it all too easy to consider what is known about refugees without engaging the practices that inform how refugees are understood and consequently justify particular interventions and approaches. These horizontal dimensions traverse across the conceptual framework, and its understandings and possibilities are informed through the vertical dimensions and scaffolding perspectives articulated in the sections that follow.

The two vertical dimensions provide a nuanced analysis of the two horizontal dimensions. Within the first vertical dimension, the concurrent everyday and extraordinary analysis considers how understandings of refugees and practice are constructed. By returning to Bourdieu's call to conceptualize familiar concepts as strange, this exercise opens new possibilities to envisage how 


\section{2}

everyday and extraordinary understandings of refugees and professional practices can come together. The second vertical dimension relates to belonging and its associated facets. As presented in Chapter 2, these three facets (social locations, identifications and emotional attachments and political/ethical value systems) position the various actors together to consider the opportunities and challenges for belonging.

Across the entire framework, there are four scaffolding perspectives that sensitize new understandings about refugees and professional practice. The who requires an awareness of those involved in labelling something as everyday or extraordinary and includes refugees, the receiving society, government institutions, NGOs, professional bodies, practitioners, the general society and others. The what can refer to trauma, refugee flight, persecution, life in refugee camps and other aspects of forced migration. It might also be in relation to settlement experiences that include housing, poverty, discrimination, health and others. A focus on politics (again defined as having a say in something that counts) illustrates the importance of recognizing power and the contestations related to representation. And finally, a consideration of transnationalism can help broaden the scope in which refugees and the ways of working alongside them are conceptualized, even in local places.

I first present the two vertical dimensions relating to how the everyday/extraordinary and belonging inform this analysis. As much of this book has focused predominantly on refugees, I place greater attention to understandings of health and social practices and make linkages to the previously presented case studies. I then present the four scaffolding perspectives as these provide the basis to rethink familiar conceptualizations about understandings of refugees and practice.

\section{Vertical dimension one: concurrent everyday and extraordinary analysis}

The secondary title of this book is 'unsettling the everyday and extraordinary'. I chose the term unsettling, as it is necessary to critique familiar terms and assump-

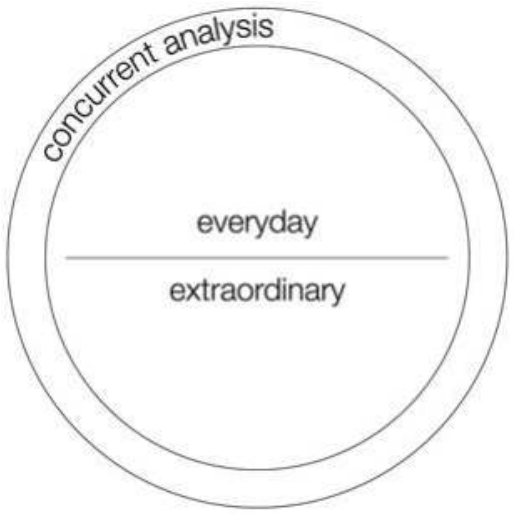

Figure 5.2 Vertical dimension one tions about refugees, trauma, disasters, integration and indeed, practice. One of the book's key arguments is that mediabased representations, political commentary and professional practice discourses often generate dominant understandings of refugee communities through extraordinary stories of adversity. The associated stories of the 'refugee experience' become powerful, even singular, descriptors of people's experiences of that 'other' and label them as traumatized, thereby limiting opportunities to participate as peers in civil society. 
The sole or primary focus on extraordinary events speaks to Bourdieu's (1991) discussion on symbolic power whereby those with the power to represent issues or groups are able to name and categorize them - in these cases, an individual, community or ethnic group labelled as dangerous, different, deviant and/or damaged. However, it is important to emphasize that the intent of this approach is not to privilege the everyday over the extraordinary or vice versa. The story of a person as a child solider, while important, provides only a partial understanding of their life. The Yazidis who were killed and abducted by ISIL is an important history indeed, but it does not adequately encompass who these people are and their aspirations. The Rwandan genocide that occurred between what is typically understood as the Hutus and the Tutsis is only the partial history representing these groups.

As established in Chapter 2, there is value in knowing about the extraordinary, as illuminating the stories of oppression and injustice can elevate the voices of those most marginalized on the world stage. While stories of despair, trauma and hardship unveil the oppressive and marginalized environments in which people are living, professionals and associated support agencies can, dangerously, give overriding value to these accounts at the expense of information outside the refugee-related context. From a trauma perspective, a thin description of the individual is created where other important considerations of identity and history (social, political, cultural) are lost or hidden. Thus, the extraordinary stories of refugee lives are often characterized, and at times sensationalized, through experiences of hardship and adversity. However, the everyday stories go beyond what makes a person a refugee and attest to what sustained them through difficult situations.

Again, I refer to the everyday in a non-pejorative sense to conceptualize the commonplace experiences of refugee settlement that include education, employment, housing, community relations and other routine practices. These considerations often escape critical examination because such activities and commitments are viewed as mundane, routine and ordinary, aspects generally shared with the wider society. This is not to say that I am equating everyday with good and extraordinary with bad. For instance, everyday racism is very prevalent in numerous settlement contexts, so much so that it is ingrained into the practices of a particular society and goes unnoticed. Those working in community development roles may define the extraordinary in relation to a disaster such as a tsunami or trauma arising from forced migration experiences. The community affected by such events, however, may conceptualize the extraordinary differently. For example, refugees may view what constitutes a disaster as ongoing daily poverty, endemic gender or family-based violence. And the opposite may be true where forms of adversity or certain social, cultural or religious traditions may be seen as extraordinary. Others may view helpful aspects of culture or spirituality as extraordinary elements that sustained them through significant hardship. This awareness highlights the need to consider the ways that particular understandings are developed and by whom. 


\section{Dominant stories and alternative storyline development}

Story telling is a universally shared human experience. There are stories that identify social histories, ethical commitments, religious beliefs, cultural traditions and meaning structures. However, the type of story that is told varies depending upon the audience, socio-cultural norms, time and place. Power plays a central role in determining what stories are told and those that are heard. Some are officially sanctioned, others voiced in part and there are stories that are prohibited or taboo.

As acknowledged earlier, the ways in which different groups represent refugees and the experiences associated with settlement and forced migration often mean that their dominant story is informed through the extraordinary experiences of flight from country, trauma and other significant adversity. This focus has the potential of exacting Bourdieu's warning against 'domesticating the exotic' that renders extraordinary events as everyday descriptors of particular groups. While not denying the importance of the extraordinary, it is also critical that these stories do not become singular understandings of people's lives which position them as the Other. Within these contexts, it is possible to see that some stories become dominant and define how individuals, groups or communities are understood.

Michael White and David Epston (1990) developed the field of narrative practice from their seminal text, Narrative Means to Therapeutic Ends. Narrative practices have grown and developed from the more traditional interpersonal and family therapeutic domain to that of community development, garnering people's testimonies and responding to the experiences of colonization, systemic violence and genocide (Barry, 1997; Blackburn, 2010; Combs \& Freedman, 2012; Denborough, 2006; Kohli, 2006; White, 2003, 2006). ${ }^{3}$ From a narrative perspective, a person is never completely passive in the face of trauma or significant adversity through their responding to modify, endure or counteract its negative effects (White, 2004). However, these responses can be relegated to what Foucault (1980) termed 'subjugated knowledges', which are rendered hierarchically inferior, hidden or even disqualified within the purviews of more dominant discourses. When subjugated, refugee responses to adversity are rarely questioned or privileged in the face of significantly distressing and tragic events. The power of dominant stories, as told and reinforced through particular political, cultural, social or historical narratives is that these alternate stories are rarely privileged or even heard. The intent of the conceptual practice framework presented below provides a basis to critique dominant discourses about refugees.

Most simply stated, a narrative approach assumes that a person's life is multistoried, meaning there are many stories a person can tell about their life (White \& Epston, 1990). ${ }^{4}$ The principle around multi-storied lives is that, depending on narrator and audience, different stories about a person, family, community or even country can be developed (Morgan, 2000; White, 2007). However, dominant stories can easily become 'problem-saturated' as the immediacy of specific concerns overshadows other valid understandings about individuals, families or groups. Thus, the story of a person's experience(s) of adversity associated with 
forced migration and how it has negatively influenced his/her life overshadows other co-existing stories that emphasize something very different about what a person values and readily identifies. ${ }^{5}$ These accounts provide pathways to delve into the 'thick descriptions' of people's lives (Geertz, 1973). However, these rich understandings do not happen magically, and evolve and change significantly over time. And it is common for an understanding of a person or community to become so dominant that it limits other ways of conceptualizing a specific issue or group of people, as the previous chapter on the politics of belonging illustrated. Supporting other stories to sit alongside this dominant story (and at times to challenge it) allows for everyday narratives of settlement to emerge.

Dominant stories may be privileged for very good reasons. The experience of oppression, for instance, is not something that should remain in the shadows. The need to understand the adversities that refugees face can help justify humanitarian responses and warm public receptiveness, as the pictures of the Syrian boy, Aylan Kurdi, who perished in the Mediterranean Sea demonstrated in 2015. At the same time, alternative storyline development is not about denying the experiences of problems or significant adversities. If this is done, it can reinforce oppressive conditions/practices and disenfranchise or marginalize experiences of suffering. Thus, a narrative approach gives attention to and honours people's experiences that relate to the everyday and extraordinary, as all stories are potential sites for meaning-making.

\section{Vertical dimension two: belonging}

The second vertical dimension examines how belonging relates to understandings of refugees and practice. In Chapter 2, I presented Yuval-Davis's (2011) conceptualizations of belonging as having three distinct facets: 1) social locations; 2) identifications and emotional attachments; 3) political/ethical value systems. These three aspects are interlinked but are not subsumable, and they define the ways in which people belong. I present these three facets separately and consider how these relate to the two horizontal dimensions related to understandings of refugees and practice.

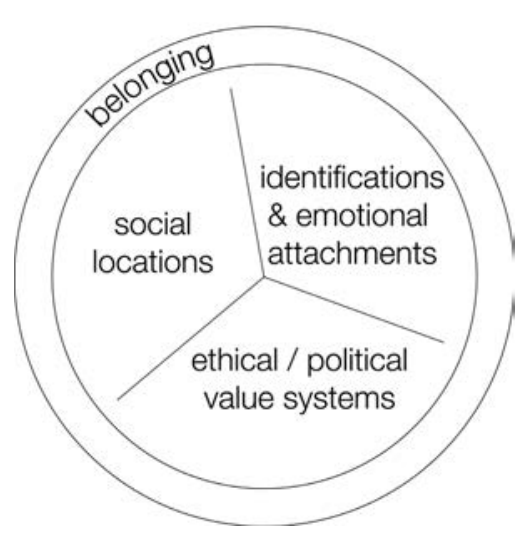

Figure 5.3 Vertical dimension two

\section{Social locations}

Health and social practices are routinely defined and mobilized relating to specific social locations in which professionals work. These locations may focus on the identifier of 'refugee', but also intersects with considerations of gender, 
sexual orientation, age, physical health, mental health, socioeconomic status, age or time resettled, among many others. What is important to recognize is that practitioners maintain a wider intersectional awareness to avoid the slippery slope of identity politics which labels refugees in problematic ways. At the same time, an intra-categorical awareness (a detailed examination recognizing diversity and difference within a category) assists in resisting the dangers of reifying social groupings possibly determined by age, gender, culture, ethnicity or religion. These dynamics illustrate the important interplay between the everyday and the extraordinary that routinely define difference in relation to hegemonic forms of identification and privilege. As established in Chapter 2, not all social locations are deemed equal, so acknowledging the rigidity and ability of voluntary association with any social location is a necessary component of this analysis.

The emphasis on social locations obviously relates to understandings of refugees, but it also has implications for professional practice. Thus, what is sometimes missing is an analysis of the various social locations that a practitioner brings with them and how these intersect with the people they are working alongside. Again, this is where it is helpful for practitioners to maintain a reflexive engagement with their own histories that informs more effective and possibly focused work with refugees. However, the ways in which politics and power dictate that practice needs further examination. This is where narrative ideas of critiquing dominant stories and scaffolding towards new possibilities of knowing about refugees and professional practice is helpful.

\section{Identifications and emotional attachments}

In relation to the second facet, identifications and emotional attachments, dominant stories often position refugees in particular ways that narrows the scope for wider belongings. Much like the discussion in Chapter 3 about the medicalization and individualizing tendencies related to trauma, these dominant understandings create the contexts that legitimate specific practice-based knowledges. At times, this is appropriate and justified, and at others, it fosters exclusionary environments. The case study in Chapter 4 also illustrates this dynamic usually communities do not label themselves as vulnerable. Those with credentials and institutional authority have the power and influence to make such labels stick.

These dynamics highlight how institutions and those in powerful positions can represent refugees and determine what constitutes accepted professional identities and practices from subtle to explicit levels. Within this awareness, it is also necessary to consider the stories and identities to which the profession is attached. There is no question that the acknowledgement of vulnerability, traumatic experience, mental health concerns and the difficulties associated with forced migration are important. The associated labelling processes, however, limit opportunities for wider belongings because of the othering tendencies this has with regard to the wider society. Therefore, recognition is required of how the profession (social worker, psychologist, etc.) identifies 
itself and where its practice is mobilized through attachment to particular value bases (often in tacit and powerful ways).

Of note is that there are differing values and professional ethos between different forms of health and social practice. Sometimes these are complementary and at others, might be discordant. For instance, different professions and employing institutions may focus on a vast array of actions and mandates that include working towards well-being; advocating for justice; establishing a cure; providing welfare; building resilience; developing community capacity; ensuring accountability; promoting integration among a range of others. This is why it is so important to render assumptions of the profession as newly strange. It can be difficult to maintain reflexivity about certain practices, particularly when people may have invested years of training to achieve specific qualifications. This reality can make it difficult and potentially confronting to have accepted professional conventions challenged.

Finally, Clifford (1997) argues that every diaspora carries profound costs. The significant losses a person, family or community experience through forced migration can mean that they will ardently hold on to the values and history that they carry with them, even at the expense of integrating into a receiving society. Such differences can run deep and people may be highly resistant to change. Nor is there necessarily an assumption that cultural practices and beliefs need to adapt. Yet these differences need to be critically acknowledged, and at times engaged, to avoid the slippery slope of ethnocentric ideology at one end of the spectrum and ethically relativist positions at the other.

\section{Political and ethical value systems}

The third facet, relating to political and ethical value systems, demonstrates that different actors can significantly determine opportunities for belonging. Following on from how certain stories and discourses become dominant, the focus on multistoried lives allows for the recognition of various social positions and the different identity narratives that speak to the preferred ways people see themselves and their future directions. These labelling tendencies, whether explicit or tacit, reinforce how particular ethical/political value systems inform a profession. As different aspects of belonging are created and denied, it is possible to see how specific social locations (as articulated by refugee status, ethnicity, religion, gender, etc.) dictate which stories are privileged and how these become dominant in relation to alternative perspectives.

This dynamic demonstrates how those who establish what constitutes the everyday and the extraordinary for refugees (and their professions) are able to justify associated practices accordingly. The moral panic of asylum so prevalent in numerous countries of resettlement across Europe, Oceania and North America clearly also illustrates this dynamic. It again highlights the various actors and associated politics in refugee settlement and how professional practices powerfully define the ways that people belong and can practice transnational settlement. 
Scaffolding perspectives

\begin{tabular}{c}
\hline who \\
\hline what \\
\hline politics \\
\hline transnationalism \\
\hline
\end{tabular}

Figure 5.4 Scaffolding perspectives
The four scaffolding perspectives help develop new understandings about refugees and professional practice across the entire conceptual framework. This involves engaging perspectives on: 1) what is the unit of analysis?; 2) who are the actors involved?; 3 ) how does politics inform understandings of practice and understandings of refugees?; and 4) how does transnationalism possibly relate? These scaffolding perspectives require a dialogic encounter to ensure that professional practices do not assume that understandings of refugees are misguided. The focus on what, whether in relation to trauma, refugee camps, PTSD, employment or community cohesion is powerfully informed by the who that represents it. The associated politics work to influence the accepted representations about refugees that powerfully determine people's opportunities to participate as peers in civil society. Finally, a consideration of transnationalism opens up an opportunity to reflect on how people maintain connection across significant distance and how this impacts on people's lives.

\section{Engaging the what}

Returning to the Bhutanese woman presented at the beginning of the chapter, there are considerations of trauma, parenting in a different culture, family relations, community cohesion, employment, housing and how her transnational relations influence her sense of well-being. There are also questions relating to the social worker and what aspects of practice are relevant to the client. The trauma-focused agency may have a relatively narrow remit in terms of the services the government funds it to deliver. Thus, the what within the conceptual practice framework considers the specific unit of analysis that relates to understandings of refugee and/or professional practice. Through a process of rendering the familiar strange, as discussed in the preceding chapters, it is possible to engage with aspects of practice pertinent to work with refugees in ways previously unexamined and potentially unimagined.

Each profession generally has recognized qualifications, memberships (at times required) and licensing that determine how practice is articulated (Callaghan, 2014). Many of these professional identities are credentialed and have specific accreditation bodies that powerfully define practice and associated values. Whether a practitioner is working with trauma, settlement support, policy development or community engagement, there are rules and roles that each profession adheres to that often escape conscious analysis. These unspoken elements relate to how concepts such as well-being, integration, social cohesion and belonging are structured and understood. Correspondingly, the assumptions that inform these understandings thereby determine how various professions articulate and justify practice with refugees. 
When first considering what professional practice entails, this might seem fairly obvious. Sternberg and Horvath (1999), however, write how tacit knowledge serves as a psychological and social phenomenon that powerfully informs professional practice. They argue for the need to question unexamined assumptions to 'see through the ambiguity' of logic (the structured and explicit elements of practice) and intuition (accumulation of tacit knowledge). This interplay of logic and intuition provides a basis for how doctors, social workers, cross-cultural workers, psychologists, psychiatrists, counsellors and other human service providers articulate and perform their practice. Many, if not all, of these professions are present in resettlement countries and operate across interpersonal, community, institutional and policy-based domains.

All of these different professional roles involve everyday activities and associations that define practice through core values - at times these are explicitly established and at others more implicitly. Various professional values may be focused on curing an illness, empowerment, social justice, providing care among others. These different foci powerfully inform practice through the what that relates to trauma, disasters, integration, social cohesion and mental health inter alia. This awareness brings us to the who - those who are able to decide how the associated what is predominantly understood.

\section{Engaging the who}

A key aspect of an everyday and extraordinary analysis is establishing who is able to focus on what is related to refugee settlement and forced migration experiences. For instance, emergency managers and organizations tasked with disaster preparedness and responses often use a vulnerability lens to consider work with refugees. The extension of this view is that those working alongside refugees can all too easily conceptualize them passively as a group needing support and care. Such assumptions are often intertwined through the extraordinary. When professional associations and their practitioners view refugees primarily through a deficit lens, these perspectives can limit refugees' opportunities to participate in civil society. Conversely, they may look to actively incorporate and collaborate with refugees following the call 'nothing about us without us' that acknowledges their agency and capacities to contribute to meaningful solutions, not only for refugee groups but also for the wider society.

As Carter-Black (2007, p. 32) establishes: 'How stories are told, by whom, to whom, under what circumstances, and for what specific purpose - vary according to sociocultural prescriptions.' What is sometimes lost, though, with numerous notable exceptions, are the voices and knowledge bases of the refugee groups themselves. Included in this discussion is how people from refugee backgrounds adopt the identity of a professional in a new resettlement context (Bartley et al., 2012; Zikic \& Richardson, 2016). Refugees' professional experiences and qualifications may not be recognized by their profession in the receiving country (Colic-Peisker \& Tilbury, 2006). The academic and popular literatures provide numerous examples of how refugees with prior training, qualifications and skills 
are not recognized by the relevant accreditation authorities and employers in resettlement contexts. Sometimes these practices and policy decisions are warranted to ensure a level of quality control and public confidence in the professional bodies with which they come into contact. However, the prevalence of taxi drivers in multiple different resettlement contexts who used to be engineers, doctors, lawyers and architects also arguably speaks to exclusionary practices (Constable et al., 2004; Imai et al., 2011; Jansen \& Grant, 2015; Krahn et al., 2000).

This is where professional assumptions about refugees and the ways in which 'we' need to support vulnerable populations (whether this is in relation to the everyday, or trauma, or disasters, or other forms of hardship), go awry. The associated knowledge bases and actions often have good intentions, but can result in misguided implications and, at times, in unintended and damaging outcomes if these are not critically examined. Thus, it is important to recognize who is able to define what constitutes professional practice and how it is operationalized in the multiple domains related to settlement. It also necessitates a structural analysis that requires an examination of who is labelling particular experiences as everyday or otherwise.

\section{Engaging politics}

Within the conceptual framework, politics influence the horizontal and vertical dimensions of the conceptual practice framework as different groups try to establish a say in something that counts, whether this is in relation to decision making in multidisciplinary teams, understandings of trauma, settlement policy or in other aspects of people's daily lives. Central to these considerations are the ways in which the profession in question is professionalized. As Callaghan (2014, p. 1511) argues, professionalization occurs in an ideological and social context that allows organizations and individuals to claim knowledges that justify their actions and position them as experts. In relation to this, Ignatieff (1994, p. 12) states: 'Politics is not only the art of representing the needs of strangers; it is also the perilous business of speaking on behalf of needs, which strangers have had no chance to articulate on their own.' Speaking on behalf of the 'needs of strangers', with a focus on how institutions, structural forces and professional practices impact people's daily lives, suggests that any given profession must maintain an awareness of power.

Zetter et al.'s (2006) study examining migration, social cohesion and social policy within the UK argues that while government rhetoric is 'generous' in its aims of achieving social cohesion, its policies often translate more towards assimilationist intentions. Further, these authors assert that 'while migrant communities remain in the spotlight, it is neither evident what it is they might be cohering to, nor clear who is, or should be, doing the cohering' (Zetter et al. 2006, p. 8). This ambiguity around cohering practices speaks to the ideological underpinnings that actively look to maintain the status quo and consolidate specific social locations in positions of power. 
Mills's (1971) sociological imagination forwards the importance of linking the experiences of private pains as public issues. In particular, this is where belonging and the politics of belonging intersect, although not always readily apparent as oppressive practices and structures are interwoven into the everyday. The neoliberal agenda prevalent in numerous refugee resettlement countries of outsourcing, short-term contracts (sometimes containing gagging clauses) and regular reporting mechanisms can help ensure that a wider structural analysis is rarely actively challenged and, at times, even imagined. After all, it is far easier to measure outcomes as the numbers of sessions an agency has had with refugees and to establish markers of well-being from specific baselines. These indicators, however, often have little to do with structural issues related to poverty, discrimination and social disadvantage. This critique is not meant to invalidate these forms of evidence, but it is also about recognizing the limitations of a predominant outcomes and measurement focus (see Gifford et al., 2007).

As different professional groups come into contact with refugees, some will have a greater say over others in relation to what counts and what constitutes effective and acceptable practices. While this dynamic is true with many client groups, the fact the refugees often represent cultural and linguistic minorities means that assumed knowledge may not always align. As the vignette at the beginning of this chapter illustrated, refugees may come with a number of issues raising questions about the multiple roles of different agencies - should services and support be delivered in parallel, sequential or in integrated fashions? How do different professions articulate the focus of its work? Is it about empowerment, treatment, finding a cure, or something else? How do funders influence such foci? What are the possibilities for structural critique in tight funding environments? It is here that imagination and openness to a reflexive examination of professional practice and the environment it is contextualized is so important. This orientation not only opens space to consider professional practice value bases and histories, but also how these are constrained by geographic spaces.

\section{Engaging transnational possibilities}

Various forms of professional practice with refugees typically occurs within bounded frames generally defined at national or lower levels of association. This means that the profession is often not conceptualized in transnational ways. ${ }^{6}$ Within this book, I am focused on the implications of transnationalism for health and social practice that consider how professionals, organizations and institutions connect and sustain meaningful relationships, both proximal and distant. ${ }^{7}$ More broadly, a human rights approach and its underpinning principles establish another basis for transnational practice, a later focus of this chapter.

It is also possible to consider how transnational relations can be incorporated into professional practices that are situated in local places. While this may not seem readily apparent, people can be connected through digital means and other communication technologies. Those resettled can send remittances as a way of maintaining commitments to social ties through increased mobilities that 


\section{2}

inculcate belonging with cultural groups, family relations and other important histories. Such cultural, economic and social flows can also travel back to settlement sites.

These transnational possibilities, however, must also consider the potential 'Janus face' of such interactions and the reality that practitioners outside a given community may not be able to identify oppressive practices from local to transnational relations. And history clearly shows that the assumption of transplanting professional and organizational values and politics into another context and location is one that needs careful consideration and, at times, a wary pessimism. For instance, there are examples of how transnational activities have delegitimized local solutions and disempowered specific groups that reinforce and create forms of oppression and international hegemony ranging from the delivery of aid (Harrell-Bond, 1986, 1999; Townsend, Porter \& Mawdsley, 2002) and psychosocial support programmes that create therapeutic governance (Pupavac, 2008). Following the devastating earthquake in Haiti, numerous reports criticized how international assistance and aid has precluded community-based participation and cynically labelled this country as 'The NGO republic of Haiti' (Klarreich \& Polman, 2012).

What emerges is the need to consider the possibilities and constraints of transnational relationships and forms of practice for refugee settlement. The associated politics highlight the need to consider an ecological perspective that recognizes how various actors and institutions directly, and indirectly, determine people's opportunities to belong. Once this is achieved, professional perspectives can move beyond what is known and familiar about practice, refugees, trauma, disasters or any other social phenomenon or issue to what it might be possible to know.

\section{Application}

The conceptual practice framework provides a basis to think through the possibilities of working with the Bhutanese woman presented at the beginning of this chapter. It is clear that understandings of refugees and of practice are positioned in particular ways. The social worker who is tasked to work with trauma needs to critique what this woman might actually even define as traumatic: does it relate to forced migration, settlement or something else? How do perspectives of the everyday and extraordinary feed into these questions and who is labelling her experiences in this way? What are the social worker's assumptions about working with trauma and does this match the woman's expectations of what support she is receiving and are these culturally appropriate and responsive? It becomes clear that she has significant transnational networks where she receives her principal support and these are the people she trusts. What are the possibilities (and cautions) for the locally based practitioner to help connect her to these groups? And finally, how does belonging figure into her situation? Her various social locations as a Bhutanese single mother with Australian citizenship seeking work as a teacher highlight that there are numerous identifications and emotional 
attachments. However, not all of these identities are readily afforded to her as she continues to seek a job. These political contexts, among many others that also include the Bhutanese community living locally and abroad, highlight the complexities of transnational settlement and opportunities to belong.

The intent of the conceptual practice framework is to provide a basis to ask new questions and rethink familiar perspectives on unquestioned assumptions and actions related to the refugee settlement space. There is nothing formulaic about it. Every situation will be different. A psychiatrist will likely have a different analysis from a case manager. A community development worker might conceptualize their work and understandings differently from a clinical psychologist. An analysis of the two vertical dimensions and the scaffolding perspectives help move from what is known and familiar to what might be possible to know in each specific circumstance.

The first vertical dimension of a concurrent everyday and extraordinary analysis provides a basis to consider the interplay of dominant stories and understandings alongside alternative ones. Narrative approaches assist with deliberating on whether dominant perspectives are strengths or deficit focused. This orientation assists practitioners to consider who constructs what is known and familiar about refugees and practice, and how these are sustained through power relations. Recognizing alternative stories that sit alongside dominant ones helps to provide additional insight into people's lived experiences and aspirations. It is not about dominant stories being bad, unconstructive or unhelpful, but it is about recognizing the ways that these understandings potentially totalize, define and, at times, pathologize specific groups.

Focusing exclusively on the negative impact of trauma and other adversities potentially pathologizes people and gives rise to misrecognition, as has already been discussed. However, it is also important to validate and dignify such experiences often positioned as extraordinary. Acknowledging the losses and taboos commonly associated with forced migration, Doka's (2002) notion of 'disenfranchised grief', where one's experiences or mourning are not socially sanctioned, highlight the importance of opening spaces to work through such losses, when and if appropriate. Included in this recognition is the importance of Westernbased approaches and biomedical understandings. This is where an understanding of people's responses to adversity and trauma need to be understood alongside the associated effects. An awareness of both everyday and extraordinary stories can illuminate further perspectives of how people voice their responses to traumatic experience, which moves the locus of traumas predicated in the past to an engagement of their lives entwined with the past, present and future.

Thus, key questions that relate to the first vertical dimension of a concurrent everyday and extraordinary analysis and the four scaffolding perspectives include:

- What is the knowledge base that underpins particular professional practices?

- How does this knowledge base inform understandings of refugees and approaches to working with them? 


\section{Professional practice}

- Tracing the associated history of these associated values and justified actions, what are the histories and politics that legitimize practice?

- Is this history and current formulation of practice collaboratively established with refugee groups? Is it open to consultation and change, and how does it interface with diversity?

- Can transnational relations (whether with individuals, families, communities or organizations) provide a basis to enrich alternative understandings about refugees?

- What is the larger ecological picture that provides a historical, social, cultural and political understanding of the ways that the profession is embedded within a larger system (often bounded at regional or national levels)?

- How do the politics of refugee settlement sit at various levels that determine what constructs everyday and extraordinary understandings of refugees?

These questions highlight that practitioners must be responsible and accountable for the questions they ask and how their practice is operationalized. If one asks about the trauma, why is this exploration being done and for whose benefit? What are the ramifications of this line of enquiry and what do these questions reinforce in this person's life (i.e. the experiences of trauma or the responses to it)? The same can be asked of the responses. As with numerous binaries presented throughout this book of everyday/extraordinary, here/there, insider/outsider and various others, it is the grey spaces in between where the most interesting social science questions and understandings of practice emerge.

The second vertical dimension that focuses on belonging and its facets provides a basis to rethink familiar understandings of refugees and practice. An intersectional analysis helps to identify these different groups and institutions that place value and afford opportunities to belong. In relation to this, politicians, professional bodies and practitioners find themselves in powerful positions to represent refugee issues and dictate the focus on what counts in relation to refugee settlement. Obviously, an awareness of how these understandings are positioned as everyday or extraordinary can have a significant impact on the facets of belonging. I emphasize some of the main considerations that relate to this orientation:

- How do various facets of belonging impact on the ways that refugees experience settlement and inform how professional practices are understood and operationalized?

- What are the differing value bases of health and social practices, and how does the interplay of logic and intuition articulate such understandings and assumptions? How do these commitments justify practice (as it relates to health, education, housing, language support, trauma informed, etc.) with refugee groups?

- Who gets to decide what social locations are important for practice and how refugees are predominantly understood? 
- How does politics (defined as having a say in something that counts) relate to the experience of meaningful settlement? Whose voices are involved? These politics occur on multiple scales that include interpersonal, familial, community, regional, national and transnational interactions.

- How do particular political projects related to the facets of belonging impact on people's opportunities to belong and who are the key players?

- How can practitioners incorporate transnational networks and relationships into their professional roles in settlement contexts - what are the possibilities and potential pitfalls?

The politics of belonging illustrates that dominant discourses privilege some people and their associated interests at the expense of others. The refugee journey is frequently interpreted, defined and treated by professionals who are often outside these specific communities - whether they are psychiatrists, psychologists, lawyers, social workers or other professional bodies - and set the stage for the opportunities that refugees have to participate in wider society. And although there are many examples of social policies, organizational approaches and professional forms of practice that help foster belonging, there are others that destabilize and erode such opportunities. This is why it is necessary to consider the multiple levels of practice. While interpersonal encounters are important, it is necessary to maintain a broader lens that incorporates how the wider society, politicians and powerful institutions influence the experience of settlement. These multi-scale considerations highlight the need for reflexive and critical examination about how practice is justified, actioned and legitimated.

The next section illustrates how a human rights framework articulates a language and orientation to unsettle familiar practices and perceptions that relate to these understandings. This approach considers practice on multiple levels and offers a language and conceptual lens to challenge entrenched and routine assumptions about refugees and associated professional practices alongside them. The chapter then concludes with the need to maintain a critical curiosity to forms of professional practice that helps to scaffold new understandings and possibilities for work alongside refugees.

\section{What is possible to know: a human rights approach}

At the beginning of this book, I distinguished the difference between resettlement and settlement whereby the former is principally about human rights protection and the latter is about belonging. There are obvious links and relationships between these two terms. While resettlement is about human rights protection, the settlement process is about the lived experience regarding particular human rights as these open up opportunities for belonging. Thus, a human rights analysis can help unpack refugees' settlement trajectories and aspirations, particularly as these relate to economic, social and cultural rights. ${ }^{8}$ 


\section{WHAT IS POSSIBLE TO KNOW ABOUT REFUGEE SETTLEMENT}

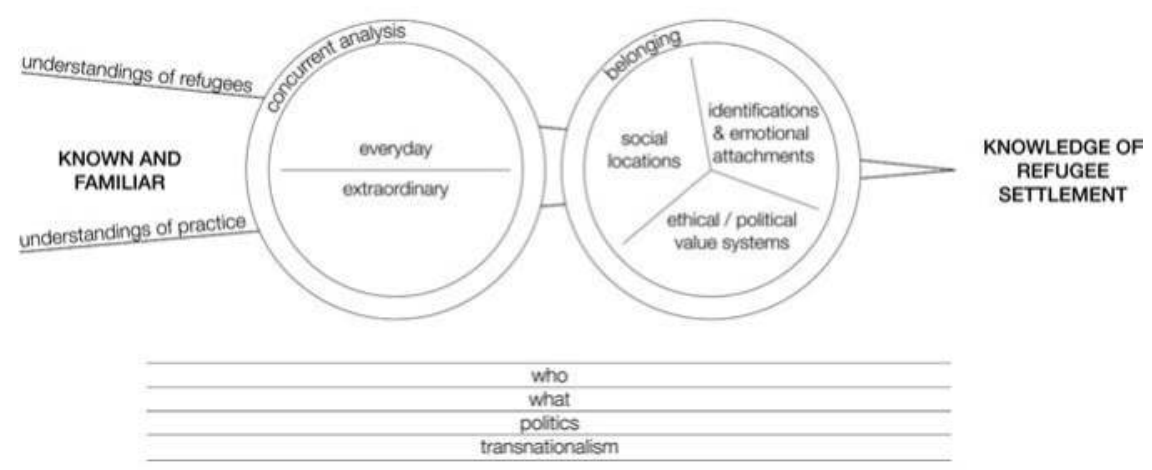

Figure 5.5 Conceptual practice framework

Since most resettled refugees receive permanent residence status on arrival in the countries with the largest resettlement programmes, they are generally entitled to the same rights granted to other permanent residents and citizens of that country. However, it is critical to examine how these rights are put into practice and subsequently lived. International human rights provisions are based on the assumption that states are responsible for promoting and realizing these for its members (typically defined as citizenship and permanent residence). And although numerous resettlement states will have signed various international covenants and treaties that relate to human rights, these are not necessarily incorporated into domestic law and provisions. This makes having a human rights analysis in relation to policy practice (and the associated ways it is delivered) critical to understanding how rights are fulfilled or not (Mahony et al., 2017).

One approach to achieving this human rights analysis is to adopt a 4A standards analysis that considers the availability, accessibility, acceptability and adaptability of any right. Katarina Tomasevski was a United Nations special rapporteur on the right to education and proposed this framework to assess the realization of the right to education. While these standards were developed in relation to the right to education, these 4A standards apply to other areas that relate to work, health, play, privacy and various others enshrined within the United Nations Declaration of Human Rights (see for instance, Human Rights Commission, 2010; Marlowe \& Humpage, 2016). From a specific emphasis on education, I generalize these 4A standards to other economic, cultural and social rights as follows:

- Availability - ensuring pathways to a right are available (and affordable).

- Accessibility - eliminating discrimination in relation to accessing a particular right. 
- Acceptability - focusing on the quality of a right and its conformity to minimum human rights standards.

- Adaptability - how well a particular right responds to culturally and linguistically diverse populations.

The 4A standards analysis within the conceptual practice framework helps to develop a deeper engagement of whether refugee needs and rights are being met in everyday policy and professional practice. Returning to the Bhutanese woman, it is possible to see that a 4A standards analysis can help unpack the availability, accessibility, acceptability and adaptability of particular rights. It can also illuminate aspects of practice, organizational culture and the policy environment that fall short of assisting to realize these rights in a settlement context. The funding environment for support refugee groups is often highly constrained and service provision may be limited in its adaptability as there might be, for instance, a shortage of female doctors who can provide culturally responsive healthcare. While it is necessary to situate this analysis within an intersectional and structural frame, it is also helpful to maintain a reflexive engagement with one's practice, personal history and understandings of the profession.

In particular, this framework unpacks certain rights, particularly as these intersect with multiple forms of diversity. It also challenges ideas represented as common sense or fair when, in fact, the provision of certain entitlements or opportunities largely benefit the majority or those in other privileged social locations. Generally speaking, most resettled refugees are entitled to the same rights granted to other permanent residents and citizens of a given country, which minimizes the debate over whether refugees are 'deserving' of assistance (Marlowe \& Humpage, 2016). The 4A standards approach provides a structured way to critique this assumption. ${ }^{9}$

\section{Availability: realizable pathways}

The availability of a particular right ensures that pathways to realizing it are possible. While the settlement opportunity provides refugees a chance to work towards a new future and should be celebrated as such, it is also an experience characterized by many challenges. This reality also requires an examination of the receiving society's receptiveness to refugees and the structural and policylevel considerations that determine the availability of a given right (Marlowe et al., 2014; Valtonen, 2008). The concept of availability relates to these considerations, among others, as follows:

- Right to education: free and compulsory education and respect for parental choice.

- Right to work: ensuring pathways to work are available.

- Right to health: functioning public health and healthcare facilities and goods, services and programmes in sufficient quantity. 
A focus on availability also relates to an awareness of the social determinants of health that link people's health outcomes and social locations to inequities related to housing, employment, education, geographic location, distribution of resources and the ways in which power operates from local, national, international and transnational levels.

There are many examples of government initiatives offering newly arrived humanitarian entrants language tuition, pathways to job training, access to welfare services and scholarships for study. Numerous countries provide case coordination assistance, on-arrival reception, accommodation support and the provision of counselling. However, usually after a brief period of time, refugees are no longer eligible for these targeted services in numerous settlement contexts. Thus, the 4A's analysis provides for significant scope for long-term outlooks and efforts to improve social inclusion and family well-being, promoting healthy lives, ensuring employable job skills training, welfare service provision and service responsiveness.

Moreover, many refugee-specific services are provided by non-government organizations that operate in challenging environments characterized by shortterm contracts, increasing evaluation pressures and underfunding. These contexts limit their ability to advocate for refugees at wider macro levels where associated policies are determined (Humpage, 2001). Again, this is where politics enters the fray. Refugee-based service providers must balance the potential tensions of advocating for refugees as these relate to the availability of particular rights at the risk of having state-sponsored or other funding removed if they critique powerful funders and policy makers.

\section{Accessibility: addressing discrimination}

Accessibility is related to ensuring that discriminatory practices do not inhibit particular groups' access to a given right. It is common to hear when people first resettle that it is a 'blur' as they attempt to incorporate massive amounts of information about life in a receiving country. This can involve learning and adapting to a new language, the welfare system, laws, transport system, community relations, societal values and norms, parenting practices, perspectives on gender and educational contexts. Within limited time frames, it can be incredibly difficult to develop the necessary linguistic skills to succeed in the many aspects of everyday life related to meaningful settlement. And the list goes on.

This reality, however, must be tempered by the opportunities that the wider society and its institutions afford to refugees. The literature evidences that it can be hard for them to get to know their neighbours who are not from their ethnically defined communities, and employers may be reluctant to hire people from refugee backgrounds. Teachers may not be aware of the unique contexts that forced migration experiences emerge in, and generalist service providers can have limited to non-existent knowledge about working alongside refugees. At higher systemic levels, the moral panic about forced migration flows into Europe and elsewhere creates the contexts where oppressive views and discriminatory actions are 
socially acceptable and even politically palatable. The touted 'Muslim ban' under President Trump's executive order that halted travel to the US from seven Muslimmajority countries does not just affect perceptions of particular people outside America's borders - it has a huge impact on those already within as well. ${ }^{10}$

A key component of accessibility is that people are free from discrimination to pursue their rights; this relates to three rights in particular:

- Right to education: eliminating discrimination in access to education.

- Right to work: eliminating discrimination in access to work.

- Right to health: scientifically and medically appropriate health services are accessible to meeting diverse needs.

As established in previous chapters, the higher rates of unemployment and underemployment for resettled refugees in numerous countries do not just point to an individual lack of effort or desire to find work. Rather, it signals an exclusionary labour force environment that may operate from overt to tacit levels. For instance, the right to education can be adversely impacted by bullying in schools and a failure of school policies and interventions to effectively identify and address it. If employers are unwilling to hire people from refugee backgrounds, then any directed social policies may fail to achieve intended outcomes. In a healthcare setting, there can, at times, be significant gaps between accepted Western biomedical interventions and service approaches with diverse cultural systems and worldviews that can affect the quality of care. Navigating these differences can be complex and may require the assistance of cross-cultural workers and interpreters.

As Marlowe and Humpage (2016) generally acknowledge, although equitable educational, employment and health opportunities are technically available to resettled refugees, access is often constrained by issues of cost, cultural appropriateness, interpreters, or a lack of genuine appreciation of the diverse pathways and experiences that refugees face. For people who come to another country as an asylum seeker or through family reunification, they may not have the same access and entitlements to rights as refugees who have been pre-selected by receiving states. Thus, accessibility also relates to an awareness of the social determinants of health that link people's health outcomes and social locations to inequities related to housing, employment, education, geographic location, distribution of resources and how power operates from local, national, international and transnational levels.

\section{Acceptability: ensuring quality}

The acceptability of a right often relates to its quality - this may be in relation to professional interpreting services, how education is delivered to diverse groups or that medical interventions are offered in acceptable ways that have resonance with cultural and social meaning systems. A human rights framework helps to unpack what acceptability represents: 
- Right to education: the quality of education is acceptable to different groups.

- Right to work: focusing on the quality of work and its conformity to minimum human rights standards.

- Right to health: respect for medical ethics and culturally appropriate services, sensitive to age and gender.

Rights that are acceptable requires an understanding of how quality relates to schooling environments that are welcoming to children of different religions and provide opportunities for the expression and practice of these faiths. The quality of work also requires an intersectional analysis where socially constructed meanings around gender, faith and numerous other social locations are able to fully participate within workplace environments. And a similar analysis can be made for the provision of healthcare services. While this situation is generally recognized by refugee-specific services, generalist services make the mistake of either labelling refugees as indelibly vulnerable or, conversely, fail to recognize diversity altogether. It highlights the need to consider the associated politics within the conceptual framework and how powerful groups inform understandings of refugees and what constitutes acceptable professional practice. The intent behind the conceptual framework is to provide perspective as to how well particular professions engage with refugees and the associated quality of its service delivery. Simply stating that a person from a refugee background has the same access to rights as anyone else represents a color-blind analysis that can easily disenfranchise those who do not enjoy privileged social locations.

\section{Adaptability: responsiveness to diversity}

The last 4A standard relates to the adaptability of a given right which relates to how well it interfaces with various forms of diversity. As a number of settlement localities become increasingly diverse and new groups of people from refugee backgrounds arrive, the need to think about how adaptable particular rights are becomes paramount. The adaptability of a right relates to the following:

- Right to education: education that responds and adapts to the best interests of the learner.

- Right to work: responding to a diverse workforce.

- Right to health: scientifically and medically appropriate health services are adaptable to meet diverse needs.

Recognizing that refugees may have different understandings of what constitutes effective educational, health-related or workplace practices, it is important to consider how adaptable particular rights are to people who may have different social constructions as to what these entail. Acknowledging that children from refugee backgrounds might have had significantly interrupted schooling experiences, a diverse workforce may require rethinking familiar workplace practices (possibly benefiting both employers and employees), and that the health 
profession is aware that the potential tensions of Western biomedical practices with other cultural meaning systems are all important.

Overall, a 4A standards framework as it relates to availability, accessibility, acceptability and adaptability is not about advocating for a culturally or ethically relativist position relating to any given right. Rather, it is that these 4As help to unpack how diverse groups live and experience particular rights. Thus, an important aspect of making these rights adaptable is when people feel a sense of belonging to the people and the institutions around them. Part of this belonging is that the receiving society is willing to accept them. The facets of belonging help to unpack the ways that various social locations, identity narratives and value systems inform such possibilities, whether it is in relation to the right to housing, health, education, work or the many other rights enshrined within the Universal Declaration.

\section{A critical curiosity towards practice}

The Bhutanese woman presented at the beginning of this chapter clearly had a number of settlement issues relating to housing, family dynamics, employment and healthcare issues that she was trying to navigate. The 4A standards provide a basis to engage with each of these experiences to consider how well settlement provision meets her associated needs as it relates to particular civil, political, economic, cultural and social rights. This human rights analysis sits behind the conceptual practice framework, so that it is possible to consider how understandings of refugees and professional practices impact on this woman's settlement experience.

The 4A standards provide a structured approach to critique the lived experience of particular rights. An important aspect of this orientation is to ensure that practitioners maintain a reflexive commitment to their own ways of working. An important element of ensuring a 4A analysis is a reflexive questioning that relates to Freire's (1990) concept of maintaining a 'critical curiosity' where practitioners are not only curious about the lives and actions of others but also their own. And a critical curiosity requires that the profession considers its own history, values and how it legitimates beliefs and actions. How does such reflexivity relate to the ways that practice affects the groups it is meant to support? As these perspectives are embraced, it becomes clear that refugee communities have tools and knowledges to respond to past and current adversities, or what is generally assumed or referred to as the extraordinary. Aspects of these relational bases are often not adequately considered at various levels, including transnational perspectives.

One of the principal issues with a focus on the extraordinary in the forced migration field is that it focuses on traumas predicated in the past, often stemming from a predominant emphasis on the forced migration journey. Increasingly, however, there is recognition that trauma can be ongoing (challenging the notion of post-trauma) and that the settlement experience can sometimes be as traumatizing, if not more so, than forced migration experiences. What these dynamics mean is that there is a need to consider trauma within a transnational frame, in terms of how traumatic experiences might play out over several countries/continents. 
This transnational reference is powerfully coupled with local experiences. In many ways, the present informs the past and vice versa. If people are employed and feel that they belong in local places, this can powerfully shape their perspectives on trauma. For instance, the South Sudanese men presented in Chapter 3 spoke of being able to 'put hope in front of you' as an expression that articulates the importance of work and education. As pathways to further agency and opportunity to support their family and community came to fruition, this provided a grounding to 'move on' from past suffering and transgressions. And likewise, if meaningful connections to their past are inculcated, often through bringing these into the present via increased mobilities and digital connectedness, this can also have an important impact in connecting people to their history and identities, and to give a sense of belonging.

It is also important to acknowledge that positive resettlement outcomes for refugees are determined by the progressive realization and interrelatedness of rights in other social policy areas such as housing, social security, family reunification and freedom from discrimination. This awareness highlights that, while specific forms of health and social practices may relate to a particular concern or issue, these require holistic examination. For durable solutions to be comprehensive, the contextual conditions within each receiving society largely determine the associated cultural, social, economic, legal and political situations that determine how particular rights are enacted and experienced.

Maintaining a critical curiosity better ensures that professional practice and engagement with client systems are able to find common ground and build essential rapport to work towards meaningful solutions. Thus, thinking about therapeutic and practical outcomes together provides a starting point to think about professional practice that considers the gamut of possibilities instead of the dichotomous thinking of one or the other. I relate the following conclusions to various forms of practice:

- The 4A standards analysis can assist with critiquing how various rights accommodate people from diverse backgrounds.

- This human rights approach provides a basis to identify hegemony, critique privilege and question the common argument that because resettled refugees are usually permanent residents or citizens, they are entitled to the same rights as everyone else.

- A critical curiosity is an integral component of this awareness; it is necessary for practitioners to examine their ways of working and maintain a reflexive engagement with their practice.

- The conceptual practice framework can help unpack unquestioned assumptions about understandings of refugees and of practice, and potentially help consider new ways of working.

In many respects, the communities from refugee backgrounds have their own tools for healing. However, the daily lived experience of poverty, unsuitable housing and community fragmentation can make it difficult to mobilize such 
resources. It is also necessary to emphasize that this analysis does not romanticize community, culture or traditional approaches to healing. As an intersectional commitment requires, it is necessary to think beyond the reified depictions of them. As highlighted earlier, community structures and cultural practices can be highly rigid and potentially oppressive. Wessells (2008) provides an important caution about both the disqualification and sanctification of the concept of 'community' when looking at healing. And Silove (2005, p. 37) emphasizes, 'As in Western medicine, there are charlatans interspersed among the true shamans.'

The necessity of speaking about trauma or the extraordinary also needs further reflection. It can be validating and healing (or dangerous and damaging) to both social relations and psychological well-being. Furlong (2008, 2013), for instance, argues that therapeutic governance can destabilize a person's relational base and emphasizes that professional practice should foster these relationships rather than focusing so strongly (at times exclusively) on clinically based encounters. This would refer to what Furedi (2004) cautions about in Western societies - 'therapy culture'. Others criticize the dominance of the Western psychological model when used with people who come from very different cultural and historical realities (Bracken et al., 1997; Pupavac, 2002; Summerfield, 1995; Tuhiwai Smith, 1999). These comments highlight the need to consider the intersections between specific professions and refugees, whether it is working with individuals, families or communities, and relates to the ways that belonging can be inculcated or destabilized.

Part of rendering the profession strange is a critical engagement with what is often a false dichotomy: that of therapeutic and practical outcomes. The word therapeutic here refers to professional work that primarily resides in addressing the individual psyche, an issue that exists in a person's mind. Therapeutic outcomes in professional domains often require specialized and expert-informed interventions, generally operationalized through Western medicalized discourse, as previously established. The word practical refers to professional work that primarily tries to address issues such as housing, employment, family relations and access to education.

While not denying the importance of therapeutically based interventions, the literature demonstrates the need for providing practical aspects of settlement support. Addressing issues such as access to housing, finding employment, helping their children succeed in school and English language acquisition are concerns that can help members of refugee communities find their own solutions to a great extent. Pupavac (2002, p. 499) cites an International Red Cross report where its workers frequently found refugees saying to them, 'Give me a roof over my head for the winter, then I will talk to you about psychosocial problems.' This emphasis points to the need for professionals to help mobilize community resources to increase social connectedness and practical support, such as language tuition, to help empower community members' sense of agency in resettlement contexts. Khawaja et al. (2008) maintain that, when these outcomes are achieved, clinically based mental health services can yield better outcomes (see also Briggs \& Macleod, 2006). It is crucial to note that social workers, 
psychologists and similar professionals incorporate practical and therapeutic outcomes. A number of interventions associated with these professions highlight the need to address both the individual and the broader issues. The argument is not about throwing Western psychology away; rather, it is about bringing the mosaic of practical and therapeutic outcomes to the table and considering the practice situation in context.

Oppression and exclusionary environments are supported and reinforced in incredibly powerful ways - sometimes explicit but often subtle. This is where an appreciation of structure is needed as the private pains related to settlement challenges cannot only be understood as occurring within particular communities. At times these challenges are ingrained at systemic levels where there is a need to remain cautious as to how terms such as 'community', 'resilience' or 'integration' are used and envisaged. Again, this is where the facets of belonging and the politics of belonging come into play. The conceptual practice framework presented in this chapter offers a lens to consider how refugees, practitioners, politicians, institutions and the wider society interact in the experiences of everyday settlement.

Numerous studies acknowledge how professionals can work collaboratively with refugee background communities to realize outcomes that address the practicalities of everyday living, such as employment, housing, education and their children succeeding in school. On the other hand, there are situations where people who have been traumatized from difficult experiences associated with forced migration and psychological and/or medical interventions may need consideration before assistance is rendered with regard to the practical outcomes of suitable housing, employment and education. Creating safe spaces in which to work through experiences associated with the refugee journey can be significantly validating and dignifying in situations where disclosure could be stigmatizing or ostracizing in community-based settings. Once the practicalities of daily living are accommodated, space opens to return to experiences of trauma if necessary. These conclusions are supported by Westoby (2006), who employs Bourdieu's (1977) concept of social suffering to maintain that experiences of poverty and limited government support in resettlement contexts often require practical rather than expert-informed psychological interventions. While the need to think further about practical outcomes is highlighted, it also necessary to avoid creating a false dichotomy through simply choosing one approach over another, reflecting the other binaries presented throughout this book.

\section{Conclusion}

Returning to the Bhutanese woman presented at the beginning of this chapter, it is clear that multiple stories come together as different groups and institutions interact. The narrative ideas of dominant storyline development and a commitment to recognizing alternative stories provides a basis to consider the possibilities of belonging and the ways that discourse informs practice. Various professions find themselves at interesting and contested crossroads of social locations, identifications and political value systems that actively promote 
specific professional value bases and associated interventions. Professional practices, whether occurring at micro to macro levels, may also reinforce existing power structures that allow for discrimination and other oppressive conditions to occur. At times, these exclusionary activities are explicitly performed, but it is the tacit and unconscious aspects of practice that require a more sensitive and reflexive approach. This is where a human rights analysis can help illuminate such concerns as different practitioners from multiple professions engage with the richness of people's lives.

This focus on the forced migration narratives of suffering suggests the need to think beyond (but not discount) the extraordinary to consider the everyday stories of people's lives. We all have such stories and they are often grounded within our history, culture, parental teachings, morals, traditions and folklore. Enquiring into people's lives outside the refugee journey provides critical insights about the impacts of the forced migration experience and how people respond. Such a shift is arguably a key step in recognizing refugees as agents in their own lives who are capable of making meaningful contributions to society.

While this chapter focuses on 'what might be possible to know', it is also important to recognize that not everything is necessarily knowable. As a mentor once told me, 'the size of people's suffering means that none of us have a monopoly on it'. This powerfully highlights the need to recognize how refugees, societies, institutions and professional practices come together, but also the associated limitations. The conceptual practice framework presented is not formulaic. It is, rather, contextualized and dynamic, which requires each professional to apply critically in relation to their specific practice. Through the process of scaffolding that examines the complexities of the everyday/ extraordinary and belonging, it is possible to shift from what is known and familiar to new knowledge about refugee settlement and various forms of health and social practices.

The final chapter discusses the process of negotiating a number of the binary positions presented throughout this book. It is in these grey spaces where the most interesting possibilities of belonging and transnational settlement can be imagined and realized. A commitment to social justice work highlights the necessity for the professional practices to embrace strong interpersonal practice coupled with an ability, awareness and desire to engage with associated concerns in more public realms. The sociological imagination forwarded by Mills (1971) provides the perspective from which to view personal experiences in relation to what is happening in the broader social arena. The wider focus is achieved by asking a number of historical, structural and reflexive questions that largely determine the ways in which understandings of practice and understandings of refugees are created, sustained and legitimated.

\section{Notes}

1 As established in Chapter 1, this book predominantly uses the term refugee to describe people who may now be former refugees or from a refugee background. While 
recognizing the contestations around the usage of these terms, this book uses the term refugee with the acknowledgement that this opens it to critique - particularly as it positions people within the dominant label of being a refugee rather than a citizen or some other identifier.

2 The notion of scaffolding typically relates to being able to reach higher levels and is associated with verticality. The conceptual practice framework is oriented in a left to right format as this provides a sense of travelling from known and familiar to new knowledge about refugee settlement. The concept of scaffolding is used in this horizontal sense to assist in this process.

3 The term narrative is used widely with many different definitions. Some refer to it in terms of simply a person's story. Others define narrative in relation to particular methodological traditions for research or as a way of describing discourse. What follows is that narrative is also a term that requires critical examination to understand the ways it is used and the philosophical underpinnings that inform it.

4 I use the term narrative approaches as opposed to therapy as I do not believe that all narrative practices involve therapy.

5 This discussion on narrative provides only a brief introduction to the developed field of narrative approaches/therapy. There are many concepts from narrative practices that are not covered in this book that are also helpful in establishing richer accounts of people's experiences and aspirations. The concepts of externalization, unique outcomes, absent but implicit, remembering, insider-outsider witness and reauthoring are just a few that provide helpful conceptual maps to reframe the ways that the profession can think about problems, people and the contexts in which discourse informs our ways of knowing.

6 There are exceptions to this where international NGOs may work alongside locally based ones or in terms of state government relations (though this usually has an international focus where borders are more rigidly conceptualized). There also transnational professional practices relates to markets and economic based activities related to trade, banking, tax, overseas work forces and large firms and companies.

7 For instance, there are numerous forms of transnational practices that relate to forms of organizational and state-sponsored support. The European Council for Refugees and Exiles (ECRE) advocates on the rights of displaced people across borders. The Asian Pacific Rights Network (APRN) is an international NGO based in New Zealand and Australia that supports other civil society organizations elsewhere. Médecins Sans Frontières (MSF), sometimes known as 'Doctors without Borders', provides various forms of medical aid in more than 70 countries, including war-torn localities. There are numerous faith-based organizations actively responding to humanitarian crises globally. In 2016, the Separated Children in Europe Programme (SCEP), representing a partnership between UNCHR and Save the Children, has developed guidelines to support separated children (many of whom had been trafficked) to help ensure the rights of children across Europe. The Reconnecting Families Program through the Red Cross helps people to find family who may be displaced or missing internationally.

8 This section is partly informed by a book chapter that used a 4As analysis in New Zealand, as follows:

Marlowe, J. \& Humpage, L. (2016) Policy responses to refugees in New Zealand: A rights-based analysis. In J. Maidment \& E. Beddoe (eds) New Zealand social policy for social work and human services: Diverse perspectives (pp. 150-63). Christchurch, NZ: Canterbury University Press.

9 I apply the 4As in relation to three specific rights (education, work and health) with the understanding that this analysis also applies to many other rights that are beyond the scope of this chapter.

10 At the time of writing this book, this first executive order has been halted by the US Court of Appeals and there are reports that a new executive order is coming. 


\section{References}

Barry, D. (1997) Telling changes: From narrative family therapy to organizational change and development. Journal of Organizational Change Management, 10(1): 30-46. doi:10.1108/09534819710159288

Bartley, A., Beddoe, L., Fouché, C. \& Harington, P. (2012) Transnational social workers: Making the profession a transnational professional space. International Journal of Population Research. http://dx.doi.org/10.1155/2012/527510

Blackburn, P. (2010) Creating space for preferred identities: Narrative practice conversations about gender and culture in the context of trauma. Journal of Family Therapy, 32(1): 4-26.

Bourdieu, P. (1977) Outline of a theory of practice. Cambridge: Cambridge University Press.

Bourdieu, P. (1991) Language \& symbolic power (G. Raymond \& M. Adamson, trans.). Cambridge: Polity Press.

Bracken, P., Giller, J. \& Summerfield, D. (1997) Rethinking mental health work with survivors of wartime violence and refugees. Journal of Refugee Studies, 10(4): 431-42. doi:10.1093/jrs/10.4.431

Briggs, L. \& Macleod, A. (2006) Demoralisation: A useful conceptualisation of nonspecific psychological distress among refugees attending mental health services. International Journal of Social Psychiatry, 52(6):512-24.doi:10.1177/0020764006066832

Callaghan, J. (2014) Professions and professionalization. Encyclopedia of critical psychology (pp. 1509-15).

Carter-Black, J. (2007) Teaching cultural competence: An innovative strategy grounded in the universality of storytelling as depicted in African and African American storytelling traditions. Journal of Social Work Education, 43(1): 31-50.

Clifford, J. (1997) Diasporas. In J. Clifford (ed.) Routes: Travel and translation in the late twentieth century. Cambridge, MA: Harvard University Press.

Colic-Peisker, V. \& Tilbury, F. (2006) Employment niches for recent refugees: Segmented labour market in twenty-first century Australia. Journal of Refugee Studies, 19(2): 203-29. doi;10.1093/jrs/fej016

Combs, G. \& Freedman, J. (2012) Narrative, poststructuralism, and social justice: Current practices in narrative therapy. The Counseling Psychologist, 40(7): 1033-1060. doi:10.1177/0011000012460662

Constable, J., Wagner, R., Childs, M. \& Natoli, A. (2004) Doctors become taxidrivers: Recognising skills: Not as easy as it sounds. Sydney, NSW: Office of Employment Equity and Diversity, Public Employment Office, Premier's Department of NSW.

Denborough, D. (2006) A framework for receiving and documenting testimonies of trauma. In D. Denborough (ed.) Trauma: Narrative responses to traumatic experience (pp. 115-31). Adelaide: Dulwich Centre Publications.

Doka, K. (2002) Disenfranchised grief: New directions, challenges and strategies for practice. Champaign, IL: Research Press.

Foucault, M. (ed.) (1980) Power/knowledge: Selected interviews and other writings, 1972-1977. New York: Pantheon Books.

Freire, P. (1990) A critical understanding of social work. Journal of Progressive Human Services, 1(1): 3-9.

Furedi, F. (2004) Therapy culture: Cultivating vulnerability in an uncertain age. London: Routledge. 
Furlong, M. (2008) Captured by the game: Might a focus on the 'therapeutic relationship' diminish the attention we give to the client's intimate network? Australia and New Zealand Journal of Family Therapy, 29(1): 25-33.

Furlong, M. (2013) Building the client's relational base: A multidisciplinary handbook. Bristol: Policy Press.

Geertz, C. (1973) The interpretation of cultures. New York: Basic Books.

Gifford, S., Bakopanos, C., Kaplan, I. \& Correa-Velez, I. (2007) Meaning or measurement? Researching the social contexts of health and settlement among newly-arrived refugee youth in Melbourne, Australia. Journal of Refugee Studies. doi:fem004.10.1093/ jrs/fem004

Harrell-Bond, B. (1986) Imposing aid: Emergency assistance to refugees. Oxford: Oxford University Press.

Harrell-Bond, B. (1999) The experience of refugees as recipients of aid. In A. Ager (ed.) Refugees: Perspectives on the experience of forced migration (pp. 136-68). New York: Continuum.

Human Rights Commission (2010) Human rights in New Zealand: Ngä tika tangata o Aotearoa. Wellington, Aotearoa New Zealand: Human Rights Commission.

Humpage, L. (2001) Systemic racism: Refugee, resettlement, and education policy in New Zealand. Refuge: Canada's Journal on Refugees, 19(6): 33-44.

Ignatieff, M. (1994) The needs of strangers. London: Vintage Books.

Imai, S., Stacey, D. \& Warman, C. (2011) From engineer to taxi driver? Occupational skills and the economic outcomes of immigrants. Queen's University, Department of Economics Working Paper, 1275, W04.

Jansen, A. \& Grant, L. (eds.) (2015) Migrant journeys: New Zealand taxi drivers tell their stories. Wellington, NZ: Bridget Williams Books.

Khawaja, N., White, K., Schweitzer, R. \& Greenslade, J. (2008) Difficulties and coping strategies of Sudanese refugees: A qualitative approach. Transcultural Psychiatry, 45(3): 489-512. doi:10.1177/1363461508094678

Klarreich, K. \& Polman, L. (2012) The NGO Republic of Haiti: How the international relief effort after the 2010 earthquake excluded Haitians from their own recovery. Retrieved from: www.thenation.com/article/ngo-republic-haiti/

Kohli, R. (2006) The sound of silence: Listening to what unaccompanied asylum-seeking children say and do not say. British Journal of Social Work, 36: 707-21.

Krahn, H., Derwing, T., Mulder, M. \& Wilkinson, L. (2000) Educated and underemployed: Refugee integration into the Canadian labour market. Journal of International Migration and Integration, 1(1): 59-84.

Mahony, C., Marlowe, J., Humpage, L. \& Baird, N. (2017) Aspirational yet precarious: Compliance of New Zealand refugee settlement policy with international human rights obligations. International Journal of Migration and Border Studies, 3(1): 5-23.

Marlowe, J., Bartley, A. \& Hibtit, A. (2014) The New Zealand Refugee Resettlement Strategy: Implications for identity, acculturation and civic participation. Kötuitui: New Zealand Journal of Social Sciences Online, 9(2): 60-69. doi:10.1080/1177083x. 2014.934847

Marlowe, J. \& Humpage, L. (2016) Policy responses to refugees in New Zealand: A rightsbased analysis. In J. Maidment \& E. Beddoe (eds) New Zealand social policy for social work and human services: Diverse perspectives (pp. 150-63). Christchurch: Canterbury University Press.

Mills, C. (1971) The sociological imagination. London: Harmondsworth Penguin. 
Morgan, A. (2000) What is narrative therapy? An easy-to-read introduction. Adelaide: Dulwich Centre Publications.

Pupavac, V. (2002) Pathologizing populations and colonizing minds: International psychosocial programs in Kosovo. Alternatives, 27: 489-511.

Pupavac, V. (2008) Refugee advocacy, traumatic representations and political disenchantment. Government and Opposition, 43(2): 270-92.

Silove, D. (2005) From trauma to survival and adaptation: Towards a framework for guiding mental health initiatives in post-conflict socieities. In D. Ingleby (ed.) Forced migration and mental health (pp. 29-52). New York: Springer.

Sternberg, R. J. \& Horvath, J. A. (eds) (1999) Tacit knowledge in professional practice: Researcher and practitioner perspectives. Mahwah, NJ: Lawrence Erlbaum Associates.

Summerfield, D. (1995) Debriefing after psychological trauma: Inappropriate exporting of western culture may cause additional harm. British Medical Journal, 311(7003): 509-20.

Townsend, J. G., Porter, G. \& Mawdsley, E. (2002) The role of the transnational community of non-government organizations: Governance or poverty reduction? Journal of International Development, 14(6): 829-39. 10.1002/jid.928

Tuhiwai Smith, L. (1999) Decolonizing methodologies. London: Zed Books.

Valtonen, K. (2008) Social work and migration immigrant and refugee settlement and integration: Burlington, VT: Ashgate Publishing.

Vygotsky, L. (1978) Interaction between learning and development. In M. Gauvian \& M. Cole (eds) Readings on the development of children (pp. 34-40). New York: Scientific American Books.

Vygotsky, L. (1986) Thought and language. Cambridge, MA: MIT Press.

Wessells, M. G. (2008) Do no harm: Challenges in organizing psychosocial support to displaced people in emergency settings. Refuge, 25(1): 6-14.

Westoby, P. (2006) The sociality of healing engaging Southern Sudanese refugees resettling in an Australian context: A model of social healing (unpublished doctoral thesis). University of Queensland.

White, M. (2003) Narrative practice and community assignments. International Journal of Narrative Therapy \& Community Work, 17(2): 17-55.

White, M. (2004) Working with people who are suffering the consequences of multiple trauma: A narrative perspective. The International Journal of Narrative Therapy and Community Work, 1: 45-76.

White, M. (2006) Working with people who are suffering the consequences of multiple trauma: A narrative perspective. In D. Denborough (ed.) Trauma: Narrative responses to traumatic experience (pp. 25-85). Adelaide: Dulwich Centre Publication.

White, M. (2007) Maps of narrative practice. London: W. W. Norton \& Company.

White, M. \& Epston, D. (1990) Narrative means to therapeutic ends. New York: Norton.

Yuval-Davis, N. (2011) The politics of belonging: Intersectional contestations. London: Sage.

Zetter, R., Griffiths, D. \& Sigona, N. (2006) Immigration, social cohesion and social capital: What are the links? Oxford: Joseph Rowntree Foundation.

Zikic, J. \& Richardson, J. (2016) What happens when you can't be who you are: Professional identity at the institutional periphery. Human Relations, 69(1): 139-68. doi: $10.1177 / 0018726715580865$ 


\section{Conclusion}

\section{Introduction}

The contestations and assumptions about refugees, forced migrants, IDPs, boat people, and documented and undocumented migrants represent some of the most pressing social issues of current times. Politicians and their electorates influence social policies that can either be empowering or incredibly oppressive. When countries experience the inevitable ebbs and flows of economic prosperity and shifting public perceptions, resettled, settling and settled communities present an easy scapegoat during hard times. Such dynamics are powerfully reflected as forced migration discourses become part of a larger geopolitical struggle that informs the understandings of refugees and of professional practice.

An orienting perspective for this book has been differentiating the terms of resettlement and settlement. I have maintained that resettlement is about protection from persecution and gross human rights violations and settlement is about belonging, which involves crafting a new existence in a receiving society. Focusing on the latter, this book concludes with a focus on social justice and how it informs the horizons of what is possible to know about refugees on local and transnational levels. The notion of horizons provides a basis to return to the conceptual practice framework presented in the last chapter to suggest an ongoing process of movement and reflection between binary positions. It is in this space that the understandings of refugees and professional practices can be helpfully extended.

Resettlement from a country of origin to another is often a journey between worlds, where one must forge a workable synthesis of the past with the present. This recognition eschews monolithic assumptions about culture or other dominant forms of identity that bring together various actors in the settlement space. These dynamics create a horizon that recedes every time one approaches it. What follows is a call for more nuanced understandings of the dynamic cultural, social and political exchanges between multiple players as these horizons intersect. Throughout this book, I have argued about the possibilities of transnational settlement, alongside the multiple ways that people belong, through an intersectional analysis. What emerges is that, for some people, transnational interactions provide an enduring solution and a sense of belonging that allows ongoing connection with their wider diaspora and countries of origin. 


\section{A decent society}

Margalit (1996, 2001) claims that the experiences of injustice rather than the endeavor for justice is what brings an engagement with politics - and this is where questions of who has a say, whose representations related to refugees count, and how these understandings become dominant and accepted by the wider society come to the fore. ${ }^{1}$ To address the experience of injustice, Margalit forwards the need for a 'decent' society (rather than a 'just' one) as a higher first priority, which addresses the manifestations of injustice. Margalit (1996, p. 9, 1997) offers a significant distinction between a civilized society and a decent one through the concept of humiliation, which he defines as a behaviour or condition resulting in damage or compromise to a person's self-respect: 'A civilized society is one whose members do not humiliate one another, while a decent society is one in which the institutions do not humiliate people' (Margalit 1996, p. 1, emphases added).

There would be few who would argue against the idea that professional practice (however conceptualized) needs to embody the ideals of a civilized society where interpersonal practices do not humiliate others. However, attending to the concept of a decent society is more difficult once it moves outside interpersonal practice. Recognizing that institutions have far-reaching powers to influence the lived experience of people's daily lives, the concept of a decent society is helpful. For Margalit, a decent society is one 'that fights conditions which constitute a justification for its dependents to consider themselves humiliated' (1996, p. 10). The rise of right-wing politics across Europe, the Trump administration's executive order in January 2017 that halted and halved annual US refugee resettlement intake alongside the oft-touted 'Muslim ban' of seven countries arguably highlights the challenges of addressing institutional humiliation at structural levels. How professional bodies, associations and practitioners attend to such conditions and illuminate such concerns remains elusive regarding the many obstacles presented in challenging institutional policy, practice and power (Irizarry et al., 2015). ${ }^{2}$

For Margalit, both behaviours (racism, threats, discrimination) and humanimposed conditions (poverty and exclusionary policies), provide justification for society's members to feel humiliated. The concept of humiliation offers a sound reason for why practitioners should remain critical and reflective in both the interpersonal and broader realms embodied by the profession. ${ }^{3}$ While there is much to celebrate in the countries that provide resettlement programmes, it is also necessary to recognize the evidence of humiliating conditions characterized by a segmented labour market, high unemployment, lower annual income and other markers of social inequality. Disparities can be explained, in part, by the fact that refugees are adjusting to a foreign resettlement reality, even years down the track. However, these indicators of social disadvantage do not solely speak to individual acculturation processes but relate in significant part to exclusionary spaces. It becomes clear how the rhetoric of equality, belonging, social cohesion and multiculturalism is far easier to disseminate than to realize or truly embrace. 
The question needs to be asked, in reference to Margalit: Do government initiatives delivered by particular state-sponsored programmes create the long-term conditions for realizing a decent society for refugees? There is no one answer to this complex question and there are numerous programmes and policies in place that have good intentions and some have been very successful. Policies have also been created to arguably achieve the opposite - one only has to look at Australia's sordid policy responses to asylum seekers to see that this is the case. The United States finds itself at a crossroads as to what to do with the 11 million undocumented migrants, and a political and populist backlash (largely misinformed) to its refugee resettlement programme. The fact that New Zealand's refugee resettlement strategy and associated support provisions currently does not extend to people who apply for asylum (on shore) is another (see Bogen \& Marlowe, 2015). Across Europe, states are legislating to make it more difficult for forced migrants to cross borders and for them to stay if they actually arrive. And the 33 countries that provide refugee resettlement programmes all have different provisions and forms of support for asylum seekers, refugees and other groups of forced migrants, sometimes with radically different support provisions depending on what forced migration category or label a person is ascribed.

Recognizing structural forms of oppression is easier said than done. It is tempting to operate within the safer (for the professional and client system) domains of interpersonal practice, rather than address broader and more powerful structural inequalities. As Surwaski et al. (2008) discuss, advocates' experiences of resisting oppressive refugee policies is not without danger or difficulty. Challenging institutional humiliation at broader levels has the potential to ignite a wider societal backlash, ostracize individuals within their community and can comprise practitioner relationships with managers and funders - all considerations that should not be taken lightly. It means questioning powerful players: employers, elders, community leaders, funding providers and those directly involved in creating policy. Questioning the status quo has inherent dangers. Naming forms of institutional humiliation and going public represents a risk not only to the client; it can also threaten the practitioner's standing within the agency and their relationship with managers. Critiquing the politics of those with a say in something that counts potentially impacts on future employment prospects. Awareness of these ramifications provides a sobering reminder that practitioners work within institutions and encounter powerful discourses about what is possible within professional identities.

This is again where having an awareness of recognition and redistribution dynamics is so important. One without the other can mean that wider forms of acceptance and belonging are not as forthcoming on the part of the wider society and those in positions of power and influence. As discussed in Chapter 3, the historic shift towards medicalizing refugee lives (as informed through an individualized trauma-dominated focus) contributes to a refugee discourse on notions of damage, deficit and despair. This discourse results in construction of refugee communities and individuals as a risky enterprise for the wider society to embrace - as employers, educators or even fellow neighbours (see Beck, 1992; Gale, 2004; Hage, 2003). These perspectives negate Fraser's (2001) perspectival 
dualism of recognition and redistribution that enable refugee participation as peers in public life.

Margalit (2001, p. 261) recognizes the power of institutions and the media stating, 'Who gazes at whom and how depend on powerful relations.' This gaze highlights the need not only to think about interpersonal practice, but also to consider macro-practice and structural domains of power. It necessitates professions to consider the different levels of government and policy, service provider practice and provision, and media representations. Esping-Anderson (1990, p. 159) takes this broader view: 'The welfare state is not just a mechanism that intervenes in, and possibly corrects, the structure of inequality; it is, in its own right, a system of stratification. It is an active force in the ordering of social relations.' More than twenty years after writing this statement, it is clear how institutional perspectives and professional discourses continue to shape the debate of global asylum - the transition of seeing refugees as a risk instead of at risk shifts the discussion from protection and human rights to economic implications, security fears and loss of national identities.

Thus, it can be a relatively small step to envision social justice within the microcosms of interpersonal practice, as necessitated by a civilized society; but to consider and address macro-level issues of unjust policies and institutional abuse, as is needed for a decent society within the purviews of day-to-day professional practice, remains far more difficult to realize. The South Sudanese case study in Chapter 3 illustrates that understandings of trauma were predominantly situated within social and situational domains in forced migration and resettlement contexts. The ways in which refugee background groups located their perspectives and responses to the earthquakes were very much based in the everyday implications of work, education, family life and wider community cohesion. These expressions direct us to the importance of acknowledging the present and the manifestations of exclusionary spaces, often reinforced and often originated from institutional domains.

\section{The twilight of knowing}

Haebich $(2007$, p. 21) introduces a type of public unawareness she terms the 'twilight of knowing and not knowing' in which 'discriminatory treatment becomes normalized to the extent that it is rendered unremarkable and virtually invisible to the wider society'. She cautions that, while the public might be aware of existing forms of oppression on some level, they generally remain unaware of unjust policies, one-sided media discourses and humiliating practices because these issues are interwoven into the fabric of society, often rendering them indiscernible. In a similar analysis, Dominelli (2007, pp. 7-8) cautions how the public can (often unconsciously) become agents of powerful institutions by passively accepting the status quo of coercive practices, policies and representations. These concerns necessitate that those working alongside refugees not only situate their practice within the 'private troubles' of people's lives but also within the realm of public issues (Schwartz, 1969). 
How do we see beyond the 'twilight of knowing and not knowing'? How do we expand our view of refugee's private troubles beyond the individual and interpersonal to the broader public and social justice sphere? And returning to a principal focus of this book, how does this awareness relate to transnational settlement and belonging?

Pedersen et al. (2006) suggest that, if discursive practices of presenting asylum seekers and refugees as Others are challenged and changed, so too can the wider society's conclusions about them be. It also highlights a role that the professions can take to challenge dominant discourses that limit forms of wider belonging and ways of working alongside refugees. Included in this orientation is the recognition that maintaining transnational relations has the potential to meet basic levels of human connection to friends and family who may be living in multiple countries and continents. While this connection needs to be considered alongside people's commitments to local places, the prevalence of remittances and forms of digital connection herald the potential of cultural, social and financial flows that traverse, and at times, transcend, borders.

The conceptual practice framework presented in Chapter 5 focuses on moving from what is known and familiar to what is possible to know through a process of scaffolding. Maintaining an imagination that allows space to critique familiar assumptions about refugees and practice opens new possibilities to think through how transnational relations and various experiences of belonging relate to settlement. Kirmayer (2007, p. 378) acknowledges the importance of imagination as a vital tool for addressing ingrained oppressive practices, policies and perspectives:

The media do manage to fill our heads with ideas about the other, but the stereotypes we absorb are more likely to be obstacles than bridges to entering other worlds. ... The stories we find credible on a backdrop of narratives in constant circulation are controlled by interests that are not neutral and would have us imagine our world in a certain way. This is not the best of all possible worlds. And imagination is the only faculty we have that lets us see beyond the horizon of the convention.

Embracing an imagination that can help us move beyond understandings of oppressive practices situated within the twilight of knowing presents a very real and contemporary challenge in various forms of health and social practice. Margalit's (1996) concepts of a civilized society (where individuals do not humiliate one another) and a decent one (where society's institutions do not humiliate its members) provide an important backdrop for examining the way in which refugees can meaningfully settle in a receiving society. This orientation relates to moving social justice concerns beyond the twilight of knowing to what it might be possible to know/achieve in both the interpersonal and broader realms that encompass the roles of practitioners, researchers and fellow community members. 


\section{Horizons}

This book emphasizes a critical engagement with numerous representations of the refugee background communities as a traumatized group and the primacy placed upon extraordinary stories predicated in the past. A range of professions and popular discourses all too often position these understandings that contribute to othering and limits opportunities for an everyday and intersectional analysis. The conceptual framework presented in Chapter 5 provides a basis to critique this tendency. Through the process of rendering familiar perspectives strange, I have endeavoured to critique what are often unquestioned and uncritical appraisals of what is understood by trauma, disasters, cohesion, integration and the term refugee itself. The case studies presented highlights that refugee communities have the tools and knowledge to respond to profound difficulties and locate appropriate social, spiritual and agential pathways to meaningful settlement experiences and a sense of belonging. It is argued, however, that the exclusionary experiences of poverty, unemployment and racism can limit this community's ability to access such resources. While there is little argument that refugees often experience very difficult events through their forced migration journeys, it does not necessarily follow that they are irretrievably damaged people - this is why a concurrent everyday and extraordinary analysis is so necessary.

Visualizing the processes of professional practice beyond routine and everyday assumptions provides scaffolding to recognize the complex settlement journey that refugees must navigate and the ways in which society and its structures shape it. ${ }^{4}$ As this scaffolding process continues, it becomes apparent that the experiences of settlement and belonging are akin to moving towards a horizon that recedes every time one approaches it. The focus on horizons highlights the strategic necessity of the present and illustrates how the facets of belonging of: (1) social locations; (2) identifications and emotional attachments; and (3) political and ethical value systems intersecting with multiple experiences of refugee settlement. This geographic metaphor gains greater salience with movement as participants identify a series of waypoints (education, employment, participation in public life) amidst a number of contested landscapes they must navigate (political, economic, cultural, social and transnational). Embracing complexity within this dynamic context is a challenge that needs to be met in various forms of health and social practice. This orientation returns to the calls of Benhabib (2002), Papastergiadis (2000) and Honig (1993) to shift 'antagonistic' polemics to 'agonistic' interactions, where the ways of thinking about refugees and practice are extended helpfully, and necessarily so.

Various professions and researchers are well placed to recognize and address both the concerns and well-being of people who are oppressed, vulnerable and marginalized within society. It is within this landscape that people's private pains can be seen as public issues (Mills, 1971). By thinking outside the domain of personal expressions of pain and trauma, it becomes possible to consider larger social, political and economic structures that impact upon people's daily lives. Turton $(2003$, p. 8 ) calls on scholars, practitioners, policy makers and everyday 
citizens to maintain critical perspectives that 'Require us to consider issues of membership, citizenship and democratic liberalism ... They require us, in other words, to consider who we are - what is or should be our moral community and, ultimately, what it means to be human.'

Turning the mirror on oneself is an important exercise. It highlights that work with refugees is not just about understanding 'them'; it necessitates self-reflection and reflexivity. This orientation seems more pressing now than it has been in most people's living memory as the politics of forced migration influence the contested terrain regarding geopolitical relations, the distribution of finite resources, the ways in which borders are maintained and imagined, and everyone's responsibility as global citizens.

Overall, this book echoes the voices of other scholars who also call for embracing complexity and moving beyond dichotomous thinking by recognizing that we, too, need to render the familiar strange in the various ways that refugee settlement is understood and professional practices are enacted. Considering the numerous binaries presented throughout this study, it is worth looking at these as a conglomerate to illustrate further the contested domains of refugee lives and professional practice. I conclude by operationalizing these binaries together as it relates to the book's focus on belonging and transnational settlement and the conceptual practice framework. A focus on horizons presents an imperative: not choosing one binary over another, or just finding a perfect middle point between the two. Rather, it is about looking at the merits of a particular situation that requires a thoughtful encounter with spectral endpoints to locate the in-between, or grey, spaces that foster a deep respect for people's lives and the broader considerations that surround them.

\section{Transnational and local perspectives}

Throughout this book, I have maintained that refugee settlement needs to be conceptualized as an ongoing transnational experience. The dynamic between positive and negative factors in transnational settlement is complex and contextspecific. Politicized rhetoric in host countries regarding the impact of new arrivals influences public sentiment and provides an easy scapegoat for explaining particular societal challenges and justifies policy directions. At the same time, recognizing the possibilities of transnational interaction also demonstrates the possibilities for economic prosperity, social understanding and opportunities to bring people together across significant distance. In particular, transnational relations present an enduring solution whereby the 1 per cent of those resettled are able to maintain contact with the 99 per cent who are not.

The practices of transnational family and friendship transcend nation-state borders through a sense of connectedness across distance, by sustaining a sense of 'family-hood' in the context of ongoing separation. Yet they are simultaneously constrained by these borders. Higher walls, razor wire, cancelling visas and various other uses of border technologies do not necessary make a given locality safer. As Yuval-Davis (2011) notes, citizenship is performative, relational and 
defined at levels that are not limited to national affiliations. The layers of citizenship may be multiple and contested, highlighting the various and contextual ways that people can belong. When people feel a lack of belonging (even if they are citizens), it creates alienation and a sense of marginalization where other forms of belonging can fill the void, sometimes with significant human costs, as the numerous conflicts and terrorist attacks globally testify.

Finally, transnational interactions are increasingly inculcated into the experience of everyday settlement. Current thinking about refugee resettlement within research, policy and practice is largely built on an assumption of state-centrism and methodological nationalism. The need to recognize how various mobilities from travel, social media and globalization inform the settlement experience is only becoming more relevant as increased numbers of forced migrants seek asylum. The ways in which concurrent multi-local links impact the goals of social cohesion, integration and belonging represent some of the most pressing social science questions that will powerfully inform how settlement provision is resourced and enacted. Embracing a stronger transnational imagination is not just an academic exercise; it is something that needs greater consideration in the policy and practice domain. As an enduring solution, transnational settlement reflects the realities of people on the move and the ways in belonging is sourced in places proximate and distant.

\section{Everyday/extraordinary stories}

This book maintains throughout that both everyday and extraordinary stories are important. Dignifying and validating refugees' stories and providing space to work through the experiences of trauma can have tremendous healing value. Creating a safe place to share such stories develops a broader awareness, within which it is possible to address manifestations of oppression that operate from micro- to macro-level realities. There is also a need to further recognize the importance of the everyday so that the power of the trauma story does not encompass a person within a victimized and pathologized perspective. When elevated in value, everyday stories help situate people beyond an Othering discourse in resettlement contexts and highlight them as agents capable of responding to trauma. As such understandings begin to emerge, new opportunities are generated where people from refugee backgrounds can participate in civil society more as peers than as victims living within it.

Trauma is a term with polysemic understandings that inform popular and academic understandings of refugees. The ways in which the everyday and extraordinary intersect with the associated dominant discourses highlight the importance of narrative approaches as presented in Chapter 5 that recognize alternative ways of knowing. Again, biomedical focuses on trauma and traumatized populations makes for a powerful electoral argument for maintaining national values and border security. It makes employers reluctant to hire refugees and labels them as damaged within numerous health and social service providers. This is where misrecognition often exacerbates, and at times creates, new forms 
of trauma as it negatively impacts on people's opportunities to participate in civil society and a broader sense of belonging.

Understanding of the effects of trauma is certainly needed. It can provide powerful justifications for advancing social policies and funding programmes to help with the settlement process. However, there is also a call to examine people's lives beyond the purviews of trauma-dominated perspectives. This shifted focus helps render other important everyday considerations visible in settlement contexts. This book maintains that, if people with refugee status are presented as outsiders through a predominant emphasis on the extraordinary, they will remain precisely that - outsiders relegated to the peripheries of civil society. It highlights the need to recognize people's diverse histories and backgrounds while remaining mindful that the politics of difference does not descend into an environment that justifies intolerance and Othering dynamics. Conversely, simply claiming that we are all insiders through a shared bond of humanity fails to acknowledge important markers of diversity and the social, political and historical realities of people with refugee status's lives.

In many respects, the past and the present are intertwined. When people are employed, studying and seeing their children live better lives - these positive outcomes can help reconcile the transgressions of the past. And likewise, failing to acknowledge a person's past can make understanding the present a myopic exercise whereby refugee voices are marginalized or worse, silenced altogether. The need here is to locate both people's unique histories alongside a common solidarity and commitment to social justice that recognizes and values the rich diversity that refugees bring to various settlement sites.

People from refugee backgrounds are capable of exercising agency to realize their aspirations and values. Structures play both visible and invisible roles in influencing the lived experience of this agency. Fraser's (2000) focus on recognition and redistribution highlights the need for health and social practice to engage critically with people's lives on a number of levels that include the embodiments of both a civilized and decent society, as defined by Margalit (1996). The analytic focus is not about keeping the multiple pathways of enquiry and practice separate; rather, it is to see how these interact in complex ways.

\section{Conclusion: building castles}

Are these conclusions and engagements with binaries just the 'good' social science answer? - that is, 'it's not one or the other but somewhere in between'. Perhaps, yes. Some of the conclusions of this book speak (to me) of the obvious, such as we should not pathologize people within the trauma story but, at the same time, we need to recognize the power and importance of it. One must balance an analysis between vulnerabilities and capacities whether this relates to a disaster event or the everyday. It is about the interplay of practical and therapeutic outcomes and the concurrent recognition of past present realities - and so on ... However, binary positions can easily become endpoints where it is about one or the other - the welcome and deterrence debate is one example where this 
has become increasingly entrenched across numerous countries as an 'us' and 'them' defines current policy and practice relating to the forced migration 'crisis'. The facets of belonging and an everyday/extraordinary analysis provides a structured way to consider how numerous social locations, identities and various value systems come together in a complex settlement ecology to rethink entrenched and dichotomized positions.

This book is written during polarizing global times where the fate of refugees in numerous receiving countries is heatedly debated from local to international levels. There is a growing and significant concern across numerous countries over how to accommodate vast numbers of forced migrants and what this means for local identities, values and capacities. Numerous anti-immigration parties are on the ascendancy. Across Europe, the Americas and elsewhere, refugee-receiving countries find themselves embroiled in this welcome-versus-deterrence debate. Should policy focus on inclusion or exclusion as it relates to forced migrants? Are we safe? What are our commitments beyond national borders? Do ongoing transnational relationships dilute people's commitments to the receiving society? And the list continues...

Refugee settlement is best conceptualized when it is done from a possibility focus. The conceptual practice framework provides a basis for traversing beyond from what is known and familiar about refugees and professional practice. It highlights the importance of using one's imagination and not simply to accept the status quo. It requires thinking critically and imagining what might be possible in the refugee settlement space - from local to transnational levels and then to collaboratively work towards these visions. This quote from Henry James Thoreau (1904, p. 249) in his book Walden, I believe, speaks to such endeavours:

I learned this, at least, by my experiment; that if one advances confidently in the direction of one's dreams, and endeavors to live the life which she/he has imagined, they will meet with a success unexpected in common hours... If you have built your castles in the air, your work need not be lost; that is where they should be. Now put the foundations under them.

Recognizing the twilight of knowing and then working towards improving the experience of meaningful settlement requires a collaborative and imaginative building process. Various forms of health and social practice are placed and privileged to work alongside some of society's most marginalized and disadvantaged. Simply accepting the way things are is not a sustainable or ethical position for these professions. It is about asking questions, thinking about what might be possible and building castles in the sky. Effective and empowering approaches to garnering refugee stories alongside a critical structural analysis create those solid foundations under such imaginative conditions.

Multiple binaries are only starting points to begin thinking about working with a particular group of people or acting upon a certain issue. A critically informed practice embraces complexity and self-reflexivity. Placed together, this scaffolding 
process between numerous polarities provides an invitation to imagine how belonging and transnational settlement provides helpful anchors and ethical insight when thinking about the possibilities of professional practice and understandings of refugees. These broadened horizons provide the foundation to engage with people's stories, the recognition of the multiple ways that they belong and the acknowledgment of transnational settlement possibilities.

\section{Notes}

1 This section on social justice is partly informed by the following publication in the British Journal of Social Work:

Irizarry, C., Marlowe, J. M., Hallahan, L. \& Bull, M. (2015) Restoring connections: Social workers' practice wisdom towards achieving social justice. The British Journal of Social Work, 46(7): 1855-71.

2 There could be a criticism of placing Fraser's political theory of recognition and Margalit's decent society in a sequential fashion. Margalit, in many respects, espouses the writings of Axel Honneth. Honneth takes a more monistic approach to recognition theory, which creates a number of incompatibilities with Fraser's perspectival dualism of recognition and redistribution. Margalit's emphasis on humiliation and the harm to a person's self-respect fits well with Honneth's writings on disrespect in recognition theory. Thus, I have taken more of an extractive approach to Margalit's writings to present professional practice in decent and civilized realms. Honneth's work has not been incorporated as extensively due to a critique that it has a tendency to focus too strongly on the psychologization of misrecognition, thereby placing too much emphasis on what it means to experience misrecognition rather than what it might mean for the misrecognizers to commit it (see associated works by Zygmunt Bauman, Patchen Markell and Lois McNay. Fraser engages misrecognition from the standpoint of status insubordination rather than harm to personal identity and provides a better fit to engage professional practice and how intersects with the everyday and the extraordinary from micro- to macro-based levels.

3 I refer to 'interpersonal' situations when working solely with the client system, whether it is individual, group or community-based. And broader realms refers to work that addresses the expression of private pains from a particular client system to more structural considerations of policy, institutional power and the wider social consciousness.

4 I relate this idea of horizons to Benhabib's (2002) work where she writes about identity and culture as dynamic processes that recede every time a person begins to approach it.

\section{References}

Beck, U. (1992) Risk society: Towards a new modernity. New Delhi: Sage.

Benhabib, S. (2002) The claims of culture. Princeton, NJ: Princeton University Press.

Bogen, R. \& Marlowe, J. (2015) Asylum discourse in New Zealand: Moral panic and a culture of indifference. Australian Social Work, 1-12. doi:10.1080/03124 07X.2015.1076869

Dominelli, L. (2007) Revitalising communities in a globalising world. Burlington, VT: Ashgate.

Esping-Anderson, G. (1990) The three worlds of welfare capitalism. Cambridge: Polity Press. Fraser, N. (2000) Rethinking recognition. New Left Review, 3: 107-20.

Fraser, N. (2001) Recognition without ethics? Theory Culture Society, 18(2-3): 21-42. doi:10.1177/02632760122051760 
Gale, P. (2004) The refugee crisis and fear: Populist politics and media discourse. Journal of Sociology, 40(4): 321-40. doi:10.1177/1440783304048378

Haebich, A. (2007) A twilight of knowing: The Australian public and the Bringing Them Home report. Fitzroy, VIC: Secretariat of National Aboriginal and Islander Child Care.

Hage, G. (2003) Against paranoid nationalism: Searching for hope in a shrinking society. Annandale, NSW: Pluto Press Australia.

Honig, B. (1993) Political theory and the displacement of politics. Ithaca, NY: Cornell University Press.

Irizarry, C., Marlowe, J. M., Hallahan, L. \& Bull, M. (2015) Restoring connections: Social workers' practice wisdom towards achieving social justice. The British Journal of Social Work, 46(7): 1855-71. doi:10.1093/bjsw/bcv129

Kirmayer, L. (2007) Failures of imagination: The refugee's predicament. In L. Kirmayer, R. Lemelson \& M. Barad (eds) Understanding trauma: Integrating biological, clinical, and cultural perspectives (pp. 363-80). New York: Cambridge University Press.

Margalit, A. (1996) The decent society (N. Goldblum, trans.) Cambridge, MA: Harvard University Press.

Margalit, A. (1997) Decent equality and freedom: A postscript. Social Research, 64(1): 147-61.

Margalit, A. (2001) Privacy in the decent society. Social Research, 68(1): 255-69.

Mills, C. (1971) The sociological imagination. London: Harmondsworth, Penguin.

Papastergiadis, N. (2000) The turbulence of migration: Globalizaton, deterritorialization and hybridity. Cambridge: Polity Press.

Pedersen, A., Watt, S. \& Hansen, S. (2006) The role of false beliefs in the community's and the federal government's attitudes toward Australian asylum seekers. Australian Journal of Social Issues, 41(1): 105-23.

Schwartz, W. (1969) Private troubles and public issues: One social work job or two. In P. Weinberger (ed.) Perspectives on social welfare: An introductory anthology. New York: Macmillan.

Surwaski, N., Pedersen, A. \& Briskman, L. (2008) Resisting refugee policy: Stress and coping of refugee advocates. Australian Community Psychologist, 20(2): 16-29.

Thoreau, H. D. (1904) Walden. London: George Routledge \& Sons.

Turton, D. (2003) Conceptualising forced migration. Oxford: Queen Elizabeth House, International Development Centre, University of Oxford.

Yuval-Davis, N. (2011) The politics of belonging: Intersectional contestations. London: Sage. 


\section{Index}

\author{
Abbott, T. 44 \\ acceptability, human rights: role in \\ challenging perceptions and practice \\ with refugees 149-50 \\ accessibility, human rights: role in \\ challenging perceptions and practice \\ with refugees 148-9 \\ adaptability, human rights: role in \\ challenging perceptions and practice \\ with refugees $150-51$ \\ adaptive resilience 105 \\ al-Assad, B. 84
}

Aldrich, D.P. 105, 107

alternative stories $134-5,143$

Amin, A. 38

Amnesty International 14

Andrews, K. 77, 78

Antonsich, M. 40

Arendt, H. 4

Armero mud slide (1985) 100-101

Aroche, J. 69

attachments, emotional: as aspect of trauma 66-7; relevance for refugee sense of belonging and intersectionality 44-6; role in framework for understanding refugee sense of belonging 136-7; significance for disaster recovery and DRR 116-17; significance for sense of belonging 82-3; situation after Canterbury region earthquakes 109

Australia: as target country for transnationalization 10; asylum seeker policies 19, 20, 40; case study of response to South Sudan migrant and refugee trauma 72-9; externalization of borders 7; impact of ethics and political values on approach to refugees 47 , 48 ; impact on refugees of Australia's approach to integration $54,68,83$; protection and rights for refugee resettlement 15-16; refugee settlement per capita 14; resettlement of Syrian war refugees 87 ; role of recognition theory in lives of refugees in 52

availability, human rights: role in challenging perceptions and practice with refugees 146-8

Basch, L. 10

Bascom, J. 39

belonging, sense of: and intersectionality 39-49; case study of as expression of migrant and refugee trauma 76-7; case study of emergence and destabilization of 109-15; framework for understanding refugee 135-42, 144-5; impact of disaster recovery on 102-8; impact of everyday and extraordinary events 134; impact of trauma on migrant and refugee 65-7; influence of transnational settlement and trauma 79-87; politics of 49-56; significance for disaster recovery and DRR 115-18; significance of politics for 77-9, 83-4; see also identifications, personal; lives, transnational; migrants and migration, forced; refugees; repatriation, voluntary; transnationalism

Benhabib, S. 45-6, 165

Berger, P. 36

Betts, A. 3

Bhabha, H. 5, 45, 47, 73

Bhopal gas leak (1984) 101

Billig, M. 38, 84

bonding capital: significance for disaster recovery 106-7 
borders, national: Australia's externalization of 7 ; relevance in context of refugee crises 19-21

Bourdieu, P. 21, 33-4, 35, 69, 79, 133, 154

BP Deep Water Horizon explosion (2010) 101

Bradshaw, S. 97

bridging capital: significance for disaster recovery $106-7$

Brin, S. 88

Brooks, D. 121

Bryceson, D. 55

Business Review Weekly 54

Callaghan, J. 140

Cameron, D. 17

Canada: role of recognition theory in lives of refugees in 52; refugee settlement per capita 14; as target country for transnationalization 10; protection and rights for refugee resettlement 16 ; resettlement of Syrian war refugees 87, 97

Canterbury region earthquakes: case study of refugee settlement following 108-15; significance of ethical and political values post-disaster 117-18; significance of identifications and emotional attachments post-disaster 116-17

capacity, personal: significance for disaster recovery 104-6

capital: significance of bonding, bridging and social capital for disaster recovery $106-8$

Carney, S. 104

Carruthers, A. 41-2

Cartagena Declaration (1984) 4

Carter-Black, J. 139

case management: framework for understanding and informing refugee settlement 130-45

case studies: conceptualising and responding to migrant and refugee trauma 71-9; refugee settlement after Canterbury region earthquakes $108-15$

Center for Excellence in Disaster Management and Humanitarian Assistance (2015) 8

Centre for Research on the Epidemiology of Disaster (CERD) 99

Chernobyl nuclear meltdown 101

Christchurch (New Zealand): case study of refugee settlement following earthquakes 108-15; significance of ethical and political values post-disaster $117-18$; significance of identifications and emotional attachments post-disaster 116-17

Cienfuegos, A. 4-5, 66

Clifford, J. 137

Coello, M. 69

Coker, E.M. 74

Collins, F.L. 12

community demographics: interaction with sense of belonging after Canterbury earthquakes 113-15

Convention Relating to Status of Refugees (UN) 3-4

counselling: framework for understanding and informing refugee settlement $130-45$

countries, of resettlement: protection and rights for refugee resettlement 13-18

crises, human-induced 101-2

crises, refugee: and refugee resettlement 18-19; national borders, diaspora and 'nation' in context of 19-21; response of New Zealand 19; response of UK 18; response of USA 19

Crowley, J. 50

curiosity, critical: role in challenging practice with refugees $151-4$

de Jong, K. 69, 70

Delueze, G. 44

demographics, community: interaction with sense of belonging after Canterbury earthquakes 113-15

Denmark: protection and rights for refugee resettlement 17-18; refugee settlement per capita 14; transmationalization of refugees living in 118

Desai, A. 119

D'Halliun, E. 68

Diagnostic and Statistical Manual for Mental Disorder (DSM) 67-8

diaspora: relevance in context of refugee crises 19-21; see also disasters; migrants and migration, forced; refugees; transnationalism; see also countries involved e.g. South Sudan digital unification: role in facilitating transnational lives 12

disaster risk reduction (DRR): case study of following Canterbury region earthquakes 108-15; definition and characteristics 102; transnational implications of disaster riskcapes 118-21; see also recovery, disaster 
disasters: case study of Canterbury region earthquake 108-15; definitions, characteristics and contexts 96-7, 99-102; impact of recovery from on sense of belonging 102-8; refugee characteristics and identification in situations of 97-9; significance of personal capacity and resilience for recovery from 104-6; significance of personal vulnerability for recovery from 103-4; significance of social capital for recovery from 106-8; social context of recovery from 115-18; see also outcomes e.g. displacement; migrants and migration, forced; refugees; resettlement and settlement, migrant and refugee; trauma, migrant and refugee; see also specific and type e.g. Armero mud slide; Canterbury region earthquakes; droughts; earthquakes; explosion disasters; Exxon Valdez oil spill; Fertile Crescent drought; gas leak disasters; Hurricane Andrew; Hurricane Katrina; mud slides; nuclear meltdown disasters; oil spill disasters; Three Mile Island nuclear meltdown; tsunamis displacement: impact within South Sudan 71-9; see also belonging, sense of; resettlement and settlement, migrant and refugee

Doka, K. 143

dominant stories: role in aiding understanding of refugee settlement 134-5, 143

Dominelli, L. 163

droughts 102

Drozdek, B. 37

Dublin Convention (EU, 1990) 18

earthquakes: case study of refugee settlement following Canterbury region 108-15; significance of ethical and political values post-disaster 117-18; significance of identifications and emotional attachments post-disaster 116-17

Edkins, J. 49

Edwards, F.L. 97

Einstein, A. 88

Ekblad, S. 68, 85

emotions, attachments made through see attachments, emotional

Epston, D. 134

Esnard, A.M- 118, 119
Esping-Anderson, G. 163

ethics: relevance for refugee sense of belonging and intersectionality 46-9; role as aspect of trauma 67; role in aiding understanding of refugee settlement and belonging 137; significance for disaster recovery and DRR 117-18; significance for sense of belonging 83-4; situation after Canterbury region earthquakes 109 ethnicity: relevance for sense of belonging and intersectionality 43-4

European Border and Coastguard (EBCG) 20

European Refugee Fund (UK) 16-17

events, extraordinary and everyday: evaluation of 37-9; framework for conceptual analysis of 130-45; impact on migrant understanding, responses and sense of belonging 34-9; see also types e.g. droughts; earthquakes; explosion disasters; gas leak disasters; mud slides; nuclear meltdown disasters; oil spill disasters; tsunamis

explosion disasters 101

Exxon Valdez oil spill (1989) 101

Faist, T. 21

families, transnational 10-12

Farage, N. 18

Fassin, D. 65, 68

Fazel, M. 69

Fertile Crescent drought (2007-2010) 102

Finland: refugee settlement per capita 14

Foucault, P. 134

frameworks, human rights: role in challenging perceptions and practice with refugees $145-54$

frameworks, practice: for understanding and informing refugee settlement 130-45; see also name e.g. Sendai Framework for Disaster Risk

Fraser, N. 50-51, 52-3, 55, 83, 162-3, 168

Friere, P. 151

Fukushima Daiichi nuclear meltdown 101

Furedi, F. 66, 153

Furlong, M. 153

Gaillard, J.C. 103-4, 121

gas leak disasters 101

Gateway Protection Programme (GPP, UK) 16

Geertz, C. 135 
gender: interaction with sense of belonging after Canterbury earthquakes 113-15

Germany: resettlement of Syrian war refugees 86; significance and acceptance of asylum seekers 14, 23

Gifford, S.M. 41

Gillespie, D. 104

Grandi, F. 84

Haebich, A. 163

Hall, S. 48

Harrell-Bond, B. 37

hazards: definition and characteristics 100-102; see also disasters; see also specific e.g. droughts; earthquakes; mud slides; tsunamis

health services: framework for understanding and informing refugee settlement 130-45

Herman, J. 65

High Commissioner for Refugees (UNHCR) 4, 6-7, 8-9, 36, 72, 84, 120, 121-2

Hollander, A.-C. 69

Honig, B. 165

Honneth, A. 51

Horvath, J.A. 139

human rights: frameworks of 145-54

Humpage, L. 149

identifications, personal: as aspect of trauma 66-7; refugee characteristics in situations of 97-9; relevance for refugee sense of belonging and intersectionality 44-6; role in understanding refugee sense of belonging 136-7; significance for disaster recovery and DRR 116-17; situation after Canterbury region earthquakes 109

identities: significance for sense of belonging $82-3$

Ignatieff, M. 140

Indian Ocean tsunami (2004) 100, 104

Ingleby, D. 51, 66

Integrated Strategy for Disaster Reduction (UN) (UNISDR) 102, 103, 105, 120

integration, local: characteristics as solution to global forced migration 8

interaction, transnational: role in facilitating transnational lives 11-12; role of networked society in facilitating 11

International Federation of the Red Crescent (IFRC) 97, 99-100, 101, 118, 122
International Monetary Fund 54

International Organization for Migration (IOM) 7

International Rescue Committee (IRC) 47

internet: role in facilitating transnational lives 11-12

intersectionality: and sense of belonging 39-49

invitation and welcome: significance in context of resettlement 13-14

Iser, M. 54

Johnson, P. $80-81$

Jok, J.M. 72

Kelley, C.P. 102

Khawaja, N. 153

Kirmayer, L. 66, 71, 164

Kleinman, A. 71

Klinenburg, E. 104

Kundera, M. 88

Kunz, E.F. 99

Kurdi, A. 3, 135

labels and labelling: impact on trauma of migrants and refugees 69-71

Legrain, P. 54

Lévi-Strass, C. 88

Levitt, P. 10, 11, 21

Levy, P. 5

Lie, B. 70

lives, transnational: role of digital technologies in facilitating 11-12; role of internet and transnational interaction 11-12; role of networked society in facilitating 11; ocations, social see social locations

'Lost boys' (South Sudan) 72

Luckman, T. 36

Mabeka, M. 88

Malkki, L. 51, 68

management, case: framework for understanding and informing refugee settlement 130-45

Mandate Refugee Scheme (MRS, UK) 16

Margalit, A. 5, 161-2, 163, 164, 168

Markell, P. 83, 86

Marlowe, J. 149

McCall, L. 43

McFarlane, A. 71

Merkel, A. 10, 86 
migrants and migration, forced: characteristics and responses to trends in 6-9; characteristics of situation in South Sudan 71-2; impact of extraordinary and everyday events $34-9$; observations and recommendations for resettlement of 160-70; see also crises, refugee; identifications, personal; lives, transnational; refugees; resettlement and settlement, migrant and refugee; see also factors driving e.g. disasters; see also factors impacting e.g. attachments, emotional; belonging, sense of; ethics; repatriation, voluntary; social locations; trauma, migrant and refugee; values, political and ethical

Migration Act (New Zealand, 1958) 19

Miller, K. 70, 71

Mills, C. 141

misrecognition: role in politics of belonging 53-6; see also recognition Missing Migrants Project (IOM) 7, 14 mobility: role in facilitating transnational lives 12

Mollica, R. 70

Monelli, C. 4-5, 66

mud slides 100-101

Murji, K. 38

narratives: role in aiding understanding of refugee settlement 134-5, 143

'nation,' the: relevance in context of refugee crises 19-21

Neal, S. 38

networks, societal: role in facilitating transnational lives 11

New Zealand: as target country for transnationalization 10 ; impact of ethics and political values on approach to refugees 47,48 ; protection and rights for refugee resettlement 17 ; refugee settlement per capita 14 ; resettlement of Syrian war refugees 87 ; response to refugee crisis 19 ; role of recognition theory in lives of refugees in 52; see also Canterbury Region earthquakes

Norway: protection and rights for refugee resettlement 17-18; refugee settlement per capita 14

nuclear meltdown disasters 101

oil spill disasters 101

Osman, M. 116
Papastergiadis, N. 165

Parsons, T. 68

participation: significance in context of resettlement 13-14

Pedersen, A. 164

Pew Research Center 15

Pham, M. 87

Pham, T. 87

'place belongingness' (Antonsich) 40

politics: of sense of belonging 49-56; role as aspect of trauma 67 ; role in aiding understanding of refugee settlement and belonging 137; role in informing understandings of practice and refugees 140-41; significance for sense of belonging 77-9, 83-4; see also values, political

post-traumatic stress disorder see trauma, migrant and refugee

practice, professional: framework for understanding and informing refugee settlement 130-45; see also name e.g. Sendai Framework for Disaster Risk

presence: significance in context of resettlement 13-14

Private Sponsorship of Refugees Programme (PSR, Canada) 16

PSTD see trauma, migrant and refugee

psychology: framework for understanding and informing refugee settlement 130-45

Pupavac, V. 48, 68, 153

Putnam, R. 106

Rechtman, R. 65

recognition: role of theories of for politics of belonging 50-53; see also misrecognition

recovery, disaster: case study of

Canterbury region earthquake $108-15$;

definitions and characteristics 102-3; significance of personal capacity and resilience 104-6; significance of personal vulnerability 103-4; significance of social contexts and locations 115-18; significance of social, bonding and bridging capital 106-8; transnational implications 118-21; see also disasters; resettlement and settlement, migrant and refugee

Red Market (Carney) 104

reduction, risk see disaster risk reduction Refugee Convention (UN, 1951) 3, 4, 8, $16,17,19,98$ 
Refugee Processing Center 15

Refugee Protocol (1967) 3, 4, 8, 15, 16, 17,19

refugees: definitions and context 3-5; impact of extraordinary and everyday events 34-9; observations and recommendations for resettlement of 160-70; relevance of transnationalism in context of refugees 19-21; see also crises, refugee; identifications, personal; lives, transnational; migrants and migration, forced; resettlement and settlement, migrant and refugee; see also factors driving e.g. disasters; see also factors impacting e.g. attachments, emotional; belonging, sense of; ethics; repatriation, voluntary; social locations; trauma, migrant and refugee; values, political and ethical

repatriation, voluntary: characteristics as solution to global forced migration 7-8

resettlement and settlement, migrant and refugee: as solution to global forced migration 8-9; case study of following Canterbury region earthquakes 108-15; definition and characteristics 6; framework for understanding and informing refugee settlement 130-45; impact within South Sudan 71-9; observations and recommendations for 160-70; role of human rights frameworks in challenging perceptions and practice 145-54; strengths and weaknesses of transnational approach to 9-21; transnational settlement, trauma and sense of belonging 79-87; see also countries, of resettlement; transnationalism; see also factors affected e.g. attachments, emotional; belonging, sense of

resilience, personal: significance for disaster recovery 104-6

rights: refugee resettlement in Australia 15-16; refugee resettlement in Canada 16; refugee resettlement in New Zealand 17; refugee resettlement in Scandinavia 17-18; refugee resettlement in UK 16-17; refugee resettlement in USA 15

rights, human: frameworks of 145-54

risks, reduction of see disaster risk reduction

Robinson, V. 38
Rosińska, Z. 74-5

Ryan, D. 71

Rytter, M. 118

Sapat, A. 118, 119

scaffolding perspectives: role in understanding professional practice with refugees 138-42, 143-4

Scandinavia: protection and rights for refugee resettlement 17-18; see also countries e.g. Denmark; Norway; Sweden

Schiller, N.G. 10, 21

Sendai Framework for Disaster Risk (2015-2030) 119-21

settlement, of migrants and refugees see resettlement and settlement, migrant and refugee

'sick role' (Parsons) 68

Silove, D. 68, 69, 85, 153

Smith, A.D. 20

social capital: significance for disaster recovery 106-8

social locations: relevance for sense of belonging and intersectionality 43-4, 45 ; role in framework for understanding refugee sense of belonging 135-6; significance for disaster recovery and DRR 115-16; significance for sense of belonging 81-2; situation after Canterbury region earthquakes 109

social work: framework for understanding and informing refugee settlement $130-45$

society, networked: role in facilitating transnational lives 11

South Sudan: case study of responses to migrant and refugee trauma $72-9$; characteristics of migrant and refugee situation in 71-2

Special Humanitarian Programme (SHP, Australia) 16

status, refugee: definitions and context 3-5

Sternberg, R.J. 139

Stoll, K. 80-81

story telling: role in aiding understanding of refugee settlement 134-5, 143

superdiversity (Vertovec) 39

Surwaski, N. 162

Sweden: mental ill health among refugees in 69; protection and rights for refugee resettlement 17-18; refugee settlement per capita 14; role of recognition theory in lives of refugees in 52 
Syria: global resettlement response for war refugees from 84-7; globalization of refugee trends from 6; integration of refugees from into Australia 16; integration of refugees from into Canada and USA 15, 16; integration of refugees from into Sweden 18; integration of refugees from into UK 17; movement of refugees from into Turkey 47; power of media images in shaping responses to refugees in 3

Tan, N.T. 105

Taylor, C. 51

technologies, digital: role in facilitating transnational lives 11-12; see also 'ethno-portals'

'terrain of truth' (Fassin) 68

'testimonio' (Cienfuegos) 66-7

Theorem, T. 46

theory (recognition theory) recognition: role of theories of for politics of belonging 50-53; see also misrecognition

Thoreau, J. 169

Three Mile Island nuclear meltdown 101

Tierney, K. 101, 102, 105, 106, 107, 121, 122

Tomasevski, K. 146

'transmigration' 10

transnational families $10-12$

transnationalism: definition and characteristics 9-10; impact on disaster riskcapes and DRR 118-21; interaction with sense of belonging after Canterbury earthquakes 113-15; relevance in context of refugees 19-21; role in informing understandings of practice with refugees 138-42; see also interaction, transnational; migrants and migration, forced

trauma, migrant and refugee: case study of South Sudanese 72-9; definitions, contexts and impact on 'belonging' 65-7; impact of labels and labelling 69-71; influence of transnational settlement on 79-87; medicalization of 67-9

Trauma and Recovery (Herman) 65 trauma-focused psychiatric epidemiology (TFPE) (Miller) 70-71

Trudeau, J. 16

Trump, D. 15, 19, 47, 86, 149 tsunamis 101,104

Turnbull, M. 19

Turton D. 55, 165-6

UK Independence Party (UKIP) 18

UN Convention Relating to the Status of Refugees (1951) 3, 4, 8, 16, 17, 19, 98

UN High Commissioner for Refugees (UNHCR) 4, 6-7, 8-9, 36, 72, 84, 120, 121-2

unification, digital: role in facilitating transnational lives 12

United Kingdom: as target country for transnationalization 10; protection and rights for refugee resettlement 16-17; referendum on link with EU 15, 18, 54, 86-7; refugee settlement per capita 14 ; response to refugee crisis 18

United States of America: as target country for transnationalization 10 ; attitudes to asylum seekers 40; impact of ethics and political values on approach to refugees 47; impact of ethics and political values on approach to refugees 48; impact on refugees of USA commitment to integration 68; protection and rights for refugee resettlement 14, 15-16; refugee settlement per capita 14; responses to crises and resettlement of refugees in 9, 19, 85-6, 87, 98; role of recognition theory in lives of refugees in 52

values, political and ethical: relevance for refugee sense of belonging and intersectionality 46-9; role in aiding understanding of refugee settlement and belonging 137; significance for disaster recovery and DRR 117-18; situation after Canterbury region earthquakes 109; see also politics

Van Hear, N. 20-21, 80

Vertovec, S. 39

Vulnerable Persons Relocations Scheme (UK) 17

Vuorela, U. 55

Vygotsky, L. 130

Walden (Thoreau) 169

welcome and invitation: significance in context of resettlement 13-14

Wessells, M.G. 153

Westoby, P. 83

White, M. 134 
Wiesel, E. 88

Wilding, R. 41

Wilson, J. 37

Windle, J. 78

Women's Refugee Commission 104

World Bank 11
Yuen, F. 105

Yuval-Davis, N. 39-40, 42-3, 44, 45, 49, $50,55,66,78,81,135,166-7$

Zakour, M. 104

Zetter, R. 53, 69, 80, 140 